\title{
IUCN
}

\section{Governance for ecosystem-based adaptation}

Alejandro Iza

Editor

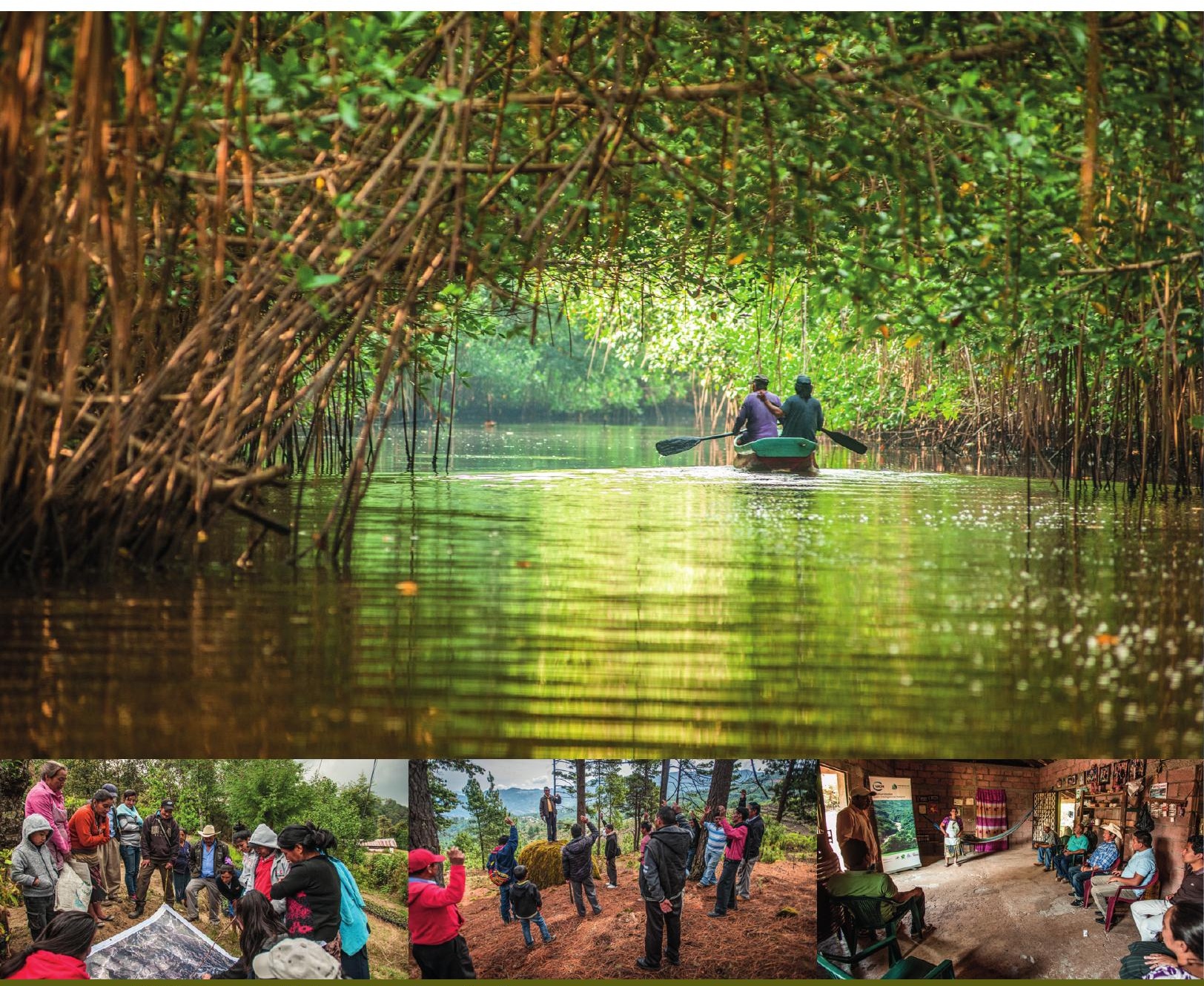

IUCN Environmental Policy and Law Paper No. 89 
Governance for ecosystem-based adaptation 



\section{Governance for ecosystem-based adaptation}

Alejandro Iza

Editor 
The designation of geographical entities in this book, and the presentation of the material, do not imply the expression of any opinion whatsoever on the part of IUCN or other participating organisations concerning the legal status of any country, territory, or area, or of its authorities, or concerning the delimitation of its frontiers or boundaries.

The views expressed in this publication do not necessarily reflect those of IUCN or other participating organisations.

IUCN is pleased to acknowledge the support of its Framework Partners who provide core funding: Ministry of Foreign Affairs of Denmark; Ministry for Foreign Affairs of Finland; Government of France and the French Development Agency (AFD); the Ministry of Environment, Republic of Korea; the Norwegian Agency for Development Cooperation (Norad); the Swedish International Development Cooperation Agency (Sida); the Swiss Agency for Development and Cooperation (SDC) and the United States Department of State.

IUCN and the other participating organisations claim no responsibility for errors or omissions that may occur in the translation into English of this document whose original version is Spanish. In the case of discrepancies, please refer to the original edition. Title of the original edition: Gobernanza para la adaptación basada en ecosistemas (2019). UICN Serie de Política y Derecho Ambiental, No. 89. Published by: IUCN, Gland, Switzerland. DOI: https://doi.org/10.2305/IUCN.CH.2019.EPLP.89.es

This publication has been made possible in part by funding from the International Climate Initiative (IKI). The German Federal Ministry for the Environment, Nature Conservation and Nuclear Safety (BMU) supports this initiative based on a resolution adopted by the German Parliament.

Published by:

IUCN, Gland, Switzerland in collaboration with the IUCN Environmental Law Centre (ELC), Bonn, Germany, and the Regional Office for Mexico, Central America and the Caribbean (ORMACC)

Copyright: (C) 2019 IUCN, International Union for Conservation of Nature and Natural Resources

(c) 2021 IUCN, International Union for Conservation of Nature and Natural Resources, for the English translation

Reproduction of this publication for educational or other noncommercial purposes is authorised without prior written permission from the copyright holder provided the source is fully acknowledged. Reproduction of this publication for resale or other commercial purposes is prohibited without prior written permission of the copyright holder.

Citation: Iza, A. (ed) (2021). Governance for ecosystem-based adaptation. IUCN

ISBN: $\quad$ 978-2-8317-2136-1 (PDF) Environmental Policy and Law Paper, No. 89. Bonn, Germany: IUCN.

978-2-8317-2174-3 (print)

DOI: https://doi.org/10.2305/IUCN.CH.2019.EPLP.89.en

Cover photos: (C) Paul Aragón

Design by: layout \& more, Bonn, Germany

Translated by: Leslie Simmons

Printed by: Druckerei Eberwein, Bonn, Germany

Available from: IUCN, International Union for Conservation of Nature www.iucn.org/resources/publication

\section{Environmental Law Centre (ELC)}

53175 Bonn, Germany

Tel: ++ 492282692231

elcsecretariat@iucn.org

www.iucn.org/law
Regional Office for Mexico, Central America and the Caribbean (ORMACC)

San Jose, Costa Rica

Tel: ++ 50622838449

Fax: ++ 50622838472

ormacc@iucn.org

www.iucn.org/ormacc

The text of this book is printed on DigiFinesse Premium Silk, FSC Mix Credit, 100 gsm. 


\section{Contents}

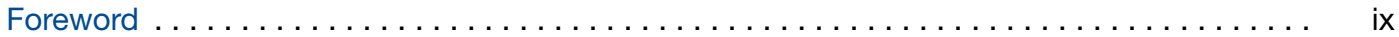

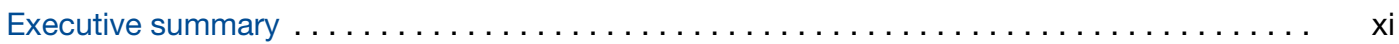

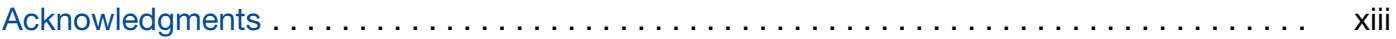

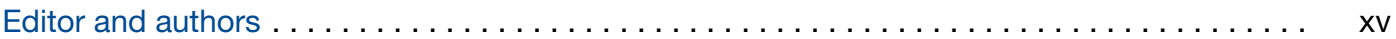

Abbreviations and acronyms $\ldots \ldots \ldots \ldots \ldots \ldots \ldots \ldots \ldots \ldots \ldots \ldots \ldots \ldots \ldots \ldots \ldots \ldots \ldots \ldots, \quad x v i i$

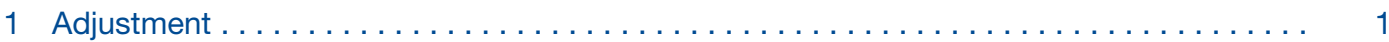

1.1 Introduction: reprising biodiversity and ecosystem services as essential theme for

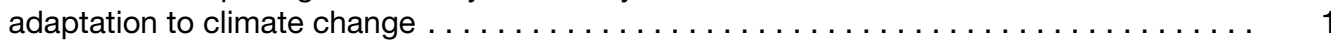

1.1.1 The context .......................................... 1

1.1.2 Ecosystem-based adaptation (EbA) in the current context............... 3

1.2 Good governance: an innovative value proposition for the sustainability of adaptation measures...................................... 4

1.3 The linkage necessary between governance and EbA: a future vision

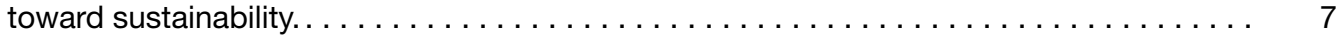

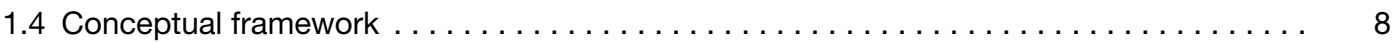

1.5 Contributions of EbA governance to international agreements $\ldots \ldots \ldots \ldots \ldots \ldots \ldots . \ldots \ldots$

1.5.1 Convention on Biological Diversity (CBD) $\ldots \ldots \ldots \ldots \ldots \ldots \ldots \ldots \ldots \ldots \ldots \ldots \ldots \ldots \ldots$

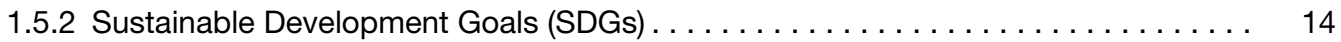

1.5.3 Paris Agreement and Nationally Determined Contributions (NDC) . . . . . . . 16

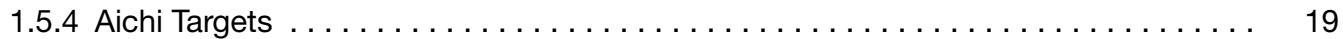

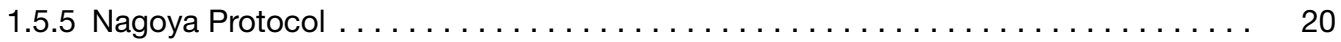

1.5.6 Sendai Framework for Disaster Risk Reduction $2015-2030 \ldots \ldots \ldots \ldots \ldots \ldots .21$

1.6 Challenges and opportunities for EbA governance..................... 22

2 Capacities 25

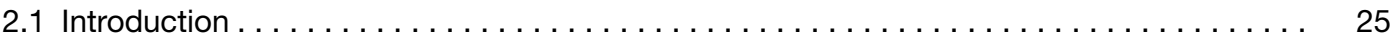

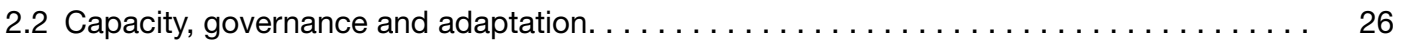

2.3 Actors, skills and capacities for EbA governance..................... 27

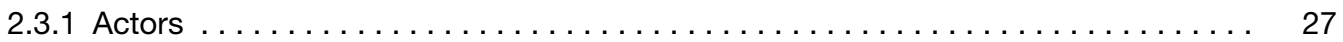

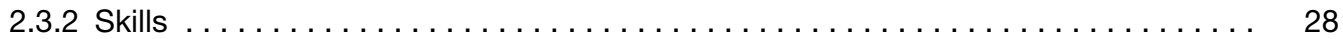

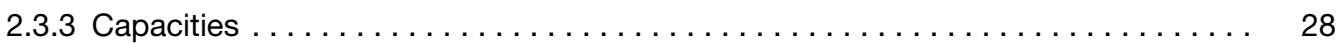

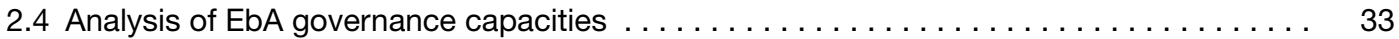

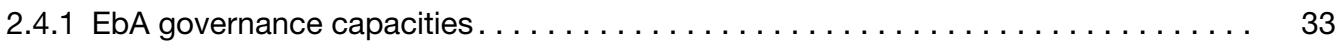

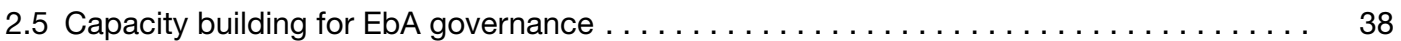

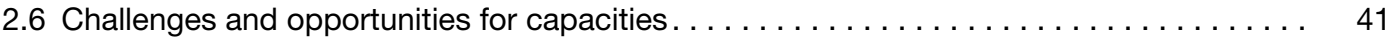


3 Evidence

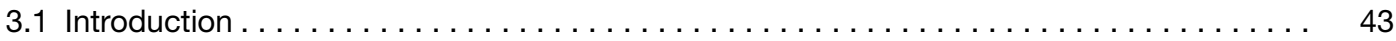

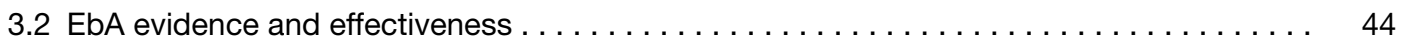

3.3 More common types of evidence and how it is generated $\ldots \ldots \ldots \ldots \ldots \ldots \ldots \ldots$

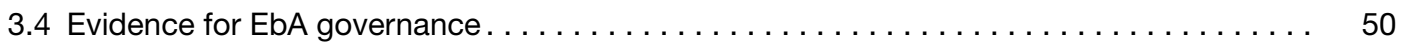

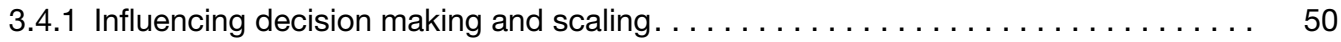

3.4.2 Favourable environment for the formulation of EbA policies

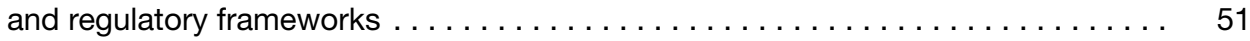

3.4.3 Information transfer, knowledge and communication for EbA governance . . . . . 52

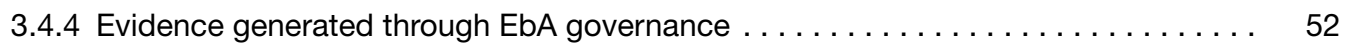

3.4.5 Monitoring and evaluation of EbA governance $\ldots \ldots \ldots \ldots \ldots \ldots \ldots \ldots \ldots \ldots$

3.5 Challenges and opportunities for the functionality of EbA governance $\ldots \ldots \ldots \ldots \ldots \ldots$

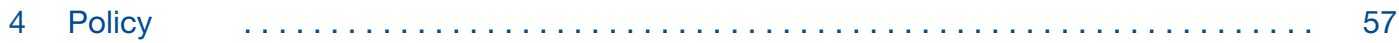

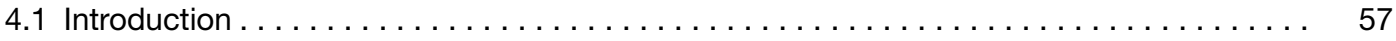

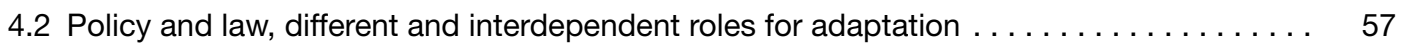

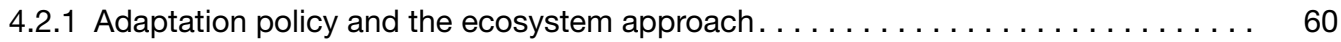

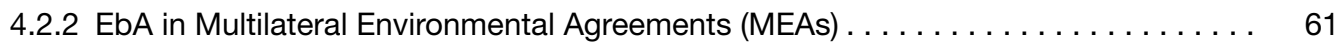

$4.2 .3 \mathrm{EbA}$ in national policies . . . . . . . . . . . . 63

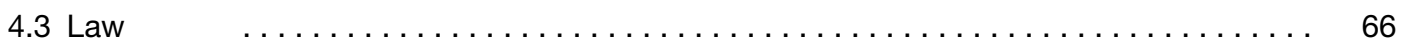

4.3.1 The law and adaptation to climate change $\ldots \ldots \ldots \ldots \ldots \ldots \ldots \ldots \ldots \ldots \ldots \ldots \ldots$

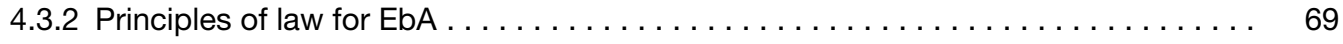

4.3.3 Integration of EbA in legal environmental, sectoral and natural

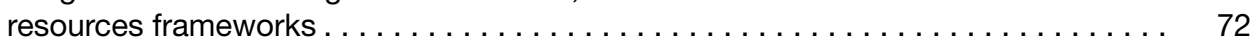

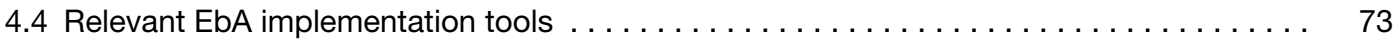

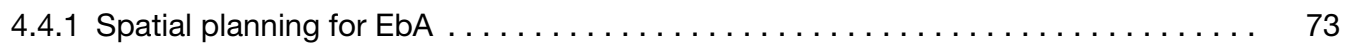

4.4.2 Strategic environmental assessment and environmental impact assessment . . . . 74

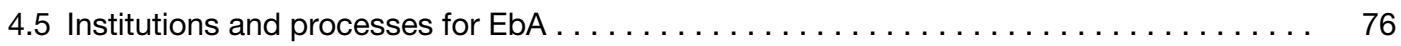

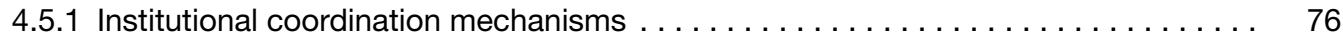

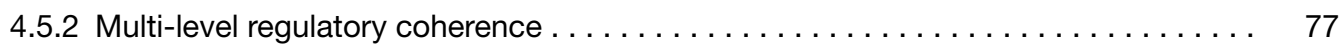

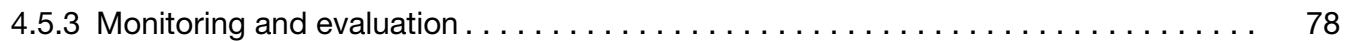

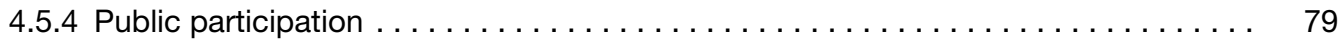

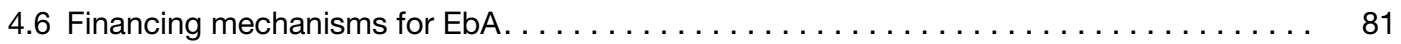

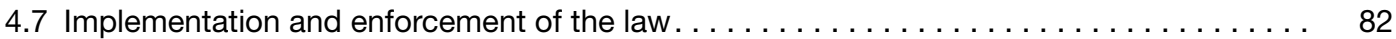

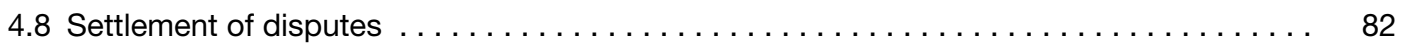

4.9 Policy challenges and opportunities $\ldots \ldots \ldots \ldots \ldots \ldots \ldots \ldots \ldots \ldots \ldots \ldots \ldots \ldots \ldots$

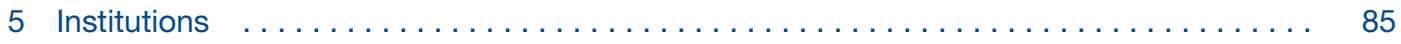

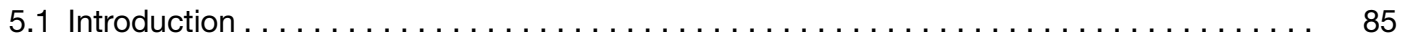

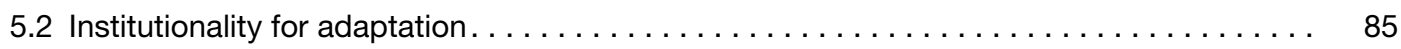

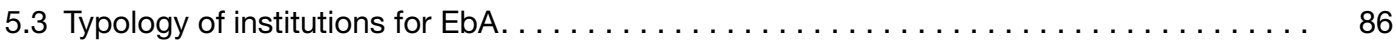

5.4 Advances and challenges in the institutions $\ldots \ldots \ldots \ldots \ldots \ldots \ldots \ldots \ldots \ldots \ldots \ldots$ 


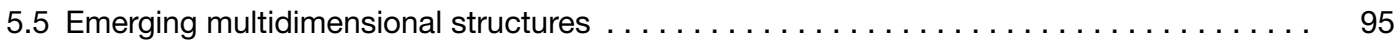

5.5.1 Consejo Consultivo de Cambio Climático del Estado de Chiapas . . . . . . . . . . 96

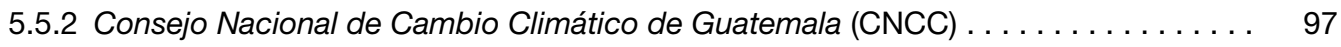

5.5.3 Comité Técnico Interinstitucional de Cambio Climático de Honduras (CTICC). . . . . 98

5.5.4 Consejo Consultivo Ciudadano de Cambio Climático (5C) de Costa Rica . . . . . . . 100

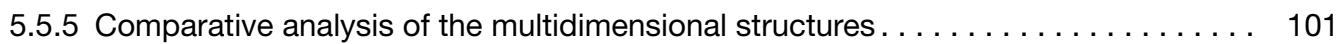

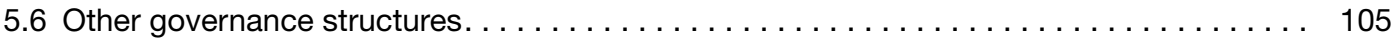

5.6.1 Comisión Binacional de la Cuenca del Río Sixaola (CBCRS) . . . . . . . . . . . . 105

5.6.2 Coordinadora Departamental de Recursos Naturales y Ambiente de

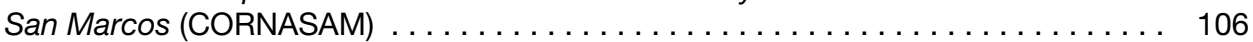

$5.7 \mathrm{EbA}$ implementation: fundamental characteristics of the institutions $\ldots \ldots \ldots \ldots \ldots \ldots$

5.7 .1 Flexible. . . . . . . . . . . . . . . . . . . . . . . . . . . . . . . 108

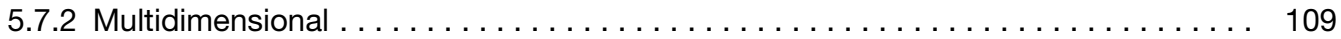

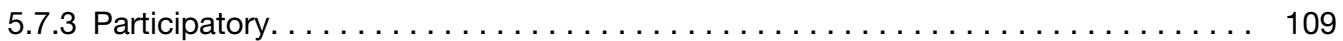

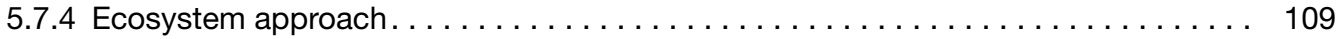

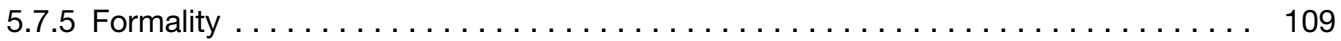

5.8 Challenges and opportunities for EbA institutions $\ldots \ldots \ldots \ldots \ldots \ldots \ldots \ldots \ldots \ldots$

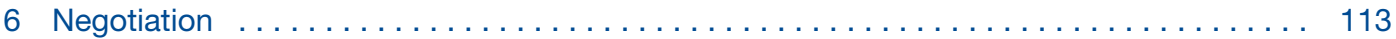

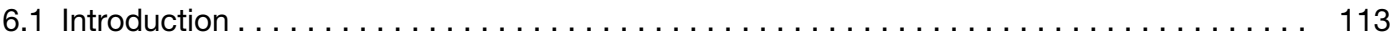

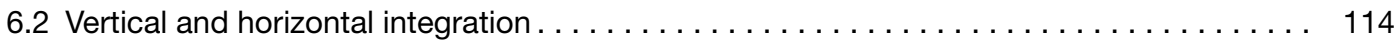

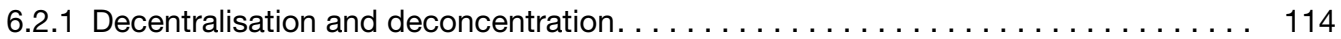

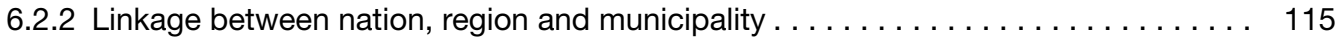

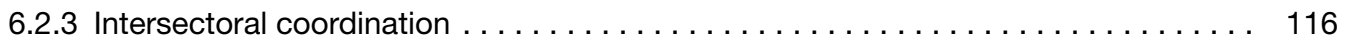

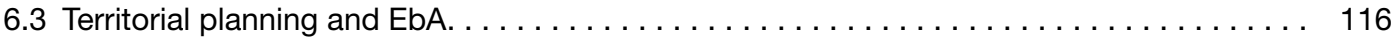

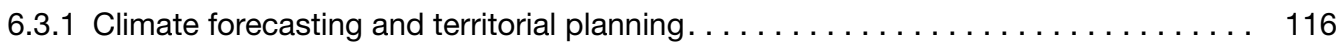

6.3.2 Incorporating EbA in territorial planning instruments $\ldots \ldots \ldots \ldots \ldots \ldots \ldots \ldots$

6.4 Negotiation: warp or weft? $\ldots \ldots \ldots \ldots \ldots \ldots \ldots \ldots \ldots \ldots \ldots \ldots \ldots \ldots \ldots \ldots \ldots \ldots 118$

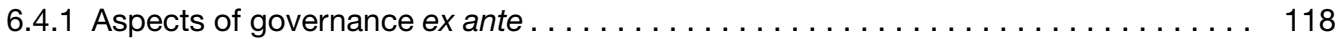

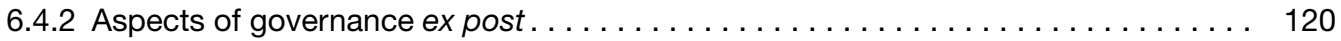

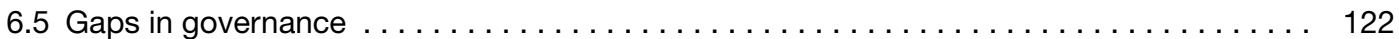

6.5.1 Limitations on citizen participation $\ldots \ldots \ldots \ldots \ldots \ldots \ldots \ldots \ldots \ldots \ldots \ldots \ldots \ldots \ldots \ldots$

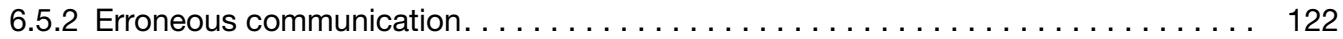

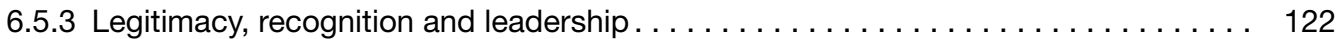

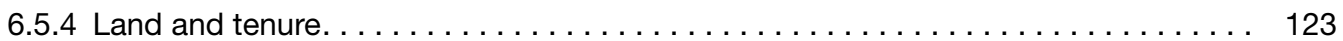

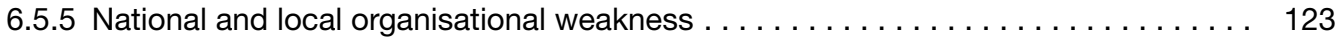

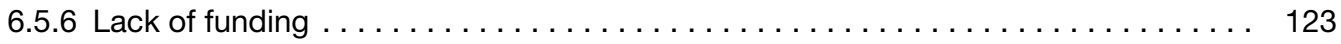

6.6 Challenges and opportunities for negotiation $\ldots \ldots \ldots \ldots \ldots \ldots \ldots \ldots \ldots \ldots \ldots \ldots \ldots \ldots$

Conclusions and recommendations: calibrating $\ldots \ldots \ldots \ldots \ldots \ldots \ldots \ldots \ldots \ldots \ldots \ldots$

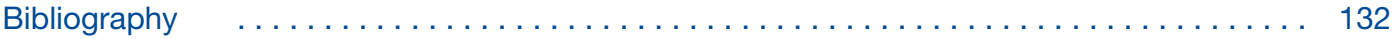





\section{Foreword}

In recent decades the planet has undergone transformations associated with the effects of climate change, confronting societies and individuals with important challenges to reduce their risk and vulnerability. Meso America is no exception, as the region depends to a great extent on ecosystem services that are increasingly threatened.

One of the main causes for loss of biodiversity, a fundamental pillar of these ecosystem services, is, precisely, climate change. The Global Assessment Report on Biodiversity and Ecosystem Services of the Intergovernmental Science-Policy Platform on Biodiversity and Ecosystem Services (IPBES), published in May 2019, determined that the essential variety of planetary life forms continues in decline. Of eight million species, one million will be extinguished in a matter of decades. As IPBES Chair Robert Watson put it: "We are eroding the very foundations of our economies, livelihoods, food security, health and quality of life worldwide."

This situation has incited individuals in different sectors of society to raise their voice. For example, young people around the world organize 'Fridays for Future' to demand profound and swift changes allowing immediate policy transformations. In this context, there is a responsibility to adopt urgent measures offering multiple benefits for both sustainable use of nature and for societies and people.

Of the different approaches available, ecosystem-based adaptation (EbA) encourages nature to be considered as response to the impacts of climate change. Under this approach, conservation, restoration and sustainable management can be implemented to lessen effects on people and biodiversity. At the same time, EbA offers alternatives for the mitigation and capture of greenhouse gases, food security and water security.

To reach its objectives, EbA must be anchored in science- and experience-based policies orienting and coordinating adaptation efforts to achieve national and global commitments and objectives. Sound governance requires all sectors and government levels to coordinate and participate in implementing the conservation measures appropriate to each society's climate risks, as well as participatory and transparent processes involving actions for adjustment to the climate and conservation of ecosystems.

Based on experience in Meso America, this book reflects upon the many aspects and dimensions of EbA governance, with recommendations to spur the changes in policies, laws and institutions necessary for its effective and sustainable implementation over time.

\author{
Dr. Alejandro Iza \\ Director \\ IUCN Environmental Law Centre \\ Head \\ Environmental Law Programme
}

\author{
Viviana Sánchez \\ Acting Regional Director \\ IUCN Regional Office for Mexico, \\ Central America and the Caribbean
}





\section{Executive summary}

Climate change is now a reality that undermines human well-being and the ecological integrity of ecosystems, their services, their availability and their use by human populations. Conventional solutions (of an engineering nature) must cease to be isolated and reactive, and instead be combined with solutions that are nature-based and include biodiversity and ecosystem services. In this sense, adaptation to climate change is vital so that ecosystems as well as human populations can adjust, transcend and even improve their health and living conditions.

Along with defining the measures needed to achieve ecosystem-based adaptation (EbA), solid governance components are imperative to make it effective. Such governance must be flexible, participatory, multidimensional and include ecosystem-based approaches (maintain ecosystem structure and function to guarantee human well-being). The aim of this book is to reflect upon and assess enabling and indispensable conditions for EbA governance and scaling, particularly in the Meso American region, with recommendations for implementation in this region and others with similar characteristics. To that end, the book has been divided into six chapters on the conditions considered most important for EbA, specific measures and especially, reflections about governance to make it effective, functional, replicable and sustainable over time.

Chapter 1, Adjustment, sets the stage for EbA governance and its synchronisation with important related concepts such as: biodiversity, adaptive capacity, natural infrastructure, resilience, naturebased solutions, vulnerability and others. The chapter also contains specific information about global governance instruments for climate change adaptation, conservation and sustainable use of biodiversity and ecosystem services. Essentially, this chapter lays the conceptual foundations critical for understanding the rest of the book, including questions or raising them, and spurring reflection throughout the text.

The objective of Chapter 2, Capacity, is to show what capacities would be necessary for the design, implementation and evaluation of EbA governance as part of a more comprehensive adaptation strategy aligned with country development plans. This chapter outlines the multiple differentiated capacities, depending on the players, that are necessary for this to be effective. It also reflects upon mechanisms needed to strengthen those capacities so they can persist over time and enable EbA actions to be sustainable.

Chapter 3, Evidence, aims to establish proof of EbA functionality over time as tool to reduce vulnerability and enhance resilience. In particular, it analyses the generation and use of technical and scientific evidence to demonstrate the effectiveness of adaptation to climate change, and to inform the development and implementation of effective governance structures.

Chapter 4, Policy, considers the role of policy and normative frameworks in implementing coherent climate change adaptation strategy across the different sectors and government levels affected. With an eye to demonstrating their importance for governance, the chapter also explores procedural environmental rights and identifies opportunities that are required to integrate $\mathrm{EbA}$ in national policies and laws. 
Chapter 5, Institutions, analyses those needed to implement an EbA strategy and measures at different levels (from local to transboundary). This chapter weighs, as an essential component of EbA governance, the necessary arrangements tailored to national and sub-national situations, focussing on those of a formal nature. Particular attention is given to the cases of Guatemala, Honduras, Costa Rica and the State of Chiapas, Mexico.

Chapter 6, Negotiation, explores and encourages comprehensive reflection about the processes required to harmonise the different interests at play in EbA governance for Meso America, specifically. It assesses necessary conditions to address the challenges arising from climate uncertainty and the vital importance of pursuing consensus and cooperation so that action is immediate and effective.

Each chapter closes with reflections on the main challenges of designing, implementing and improving EbA governance and its different aspects. Readers are invited to raise more questions with the aim of enriching their own experiences, and in this way continue seeking solutions to the multiple challenges and dilemmas of climate change and adaptation to it.

The intent of this book is to offer recommendations based on real-life experiences, projects and case studies, for better-designed and better-implemented EbA governance at different levels. It also provides practical ideas for scaling in the Meso American region, with the idea that these can be applied in other contexts with similar environmental, social and economic conditions.

While each of these aspects is relevant and specifically addressed in the different chapters, it should be underscored that this book proposes a participatory EbA governance, meaning that it requires: solid capacities, knowledge and information; clear policies tailored to ecological, social and economic dynamics; and robust, inclusive and including institutions with legitimacy, representativeness and ownership by all players. It must be realistic, in that it is reliable, valid and useful, and functional, meaning that objectives and results are clear and attainable. Finally, participatory EbA governance must be relevant: appropriate for the context, with all stakeholders having a sense of ownership.

For the purposes of this book, Meso America includes the countries of Mexico, Guatemala, Belize, Honduras, El Salvador, Nicaragua, Costa Rica and Panama. It is based on the experiences of the IUCN project, Transforming evidence into change: A holistic approach to EbA governance (Project AVE), which was implemented in Mexico, Guatemala, Honduras, El Salvador, Costa Rica and Panama. 


\section{Acknowledgments}

This publication is the joint effort of experts in several areas, including ecosystem management, adaptation to change, governance and water rights, and the result of a process of reflection about experiences gathered over the course of almost ten years in six transboundary basins in Meso America.

Our gratitude first of all to those who were part of the initiative culminating in this publication: all the communities, individuals, leaders and authorities who accompanied us in the search for solutions to climate change and supported us with their efforts toward strengthening the necessary structures for it.

Special recognition to Rosalía Ibarra Sarlat, Associate researcher "C" at Instituto de Investigaciones Jurídicas, Universidad Nacional Autónoma de México; and to Angela Andrade of the IUCN Commission on Ecosystem Management (CEM) and Conservation International-Colombia, for their input, ideas and contributions in reviewing the manuscript of this work.

In addition, we wish to thank Lorena Martínez Hernández, former Legal Officer at the IUCN Environmental Law Centre, for coordinating all phases of the publication; Sarina van der Ploeg, IUCN Publications Officer, for her support and guidance in the editing and publication process; Anni Lukács, Senior Information Officer in charge of editorial correction and design supervision; Ann DeVoy, Project Administrator, who coordinated numerous tasks of the project resulting in the preparation of this book; and Sandra Dalfiume and Juan Carlos Barrientos García, interns at the Environmental Law Centre, for their assistance in the final revision of the text.

Finally, our deepest appreciation to the International Climate Initiative (IKI) of the German Federal Ministry for the Environment, Nature Conservation and Nuclear Safety (BMU) for its contribution to the project Transforming evidence into change: A holistic approach to governance for ecosystembased adaptation, and to this book, which is the outcome of its implementation. 



\section{Editor and authors}

\section{Editor:}

Dr. Alejandro Iza

Director

IUCN Environmental Law Centre

\section{Authors:}

Rocío Córdoba-Muñoz

Independent Natural Resources Professional

IUCN Ecosystem Management Commission

Pascal Girot

Professor

Escuela de Geografía

Universidad de Costa Rica

Mauricio Luna Rodríguez

Regional Advisor for Climate Governance

Deutsche Gesellschaft für Internationale Zusammenarbeit (GIZ)

EUROCLIMA+ Programme

Melissa Marín Cabrera

Programme Officer

Asociación Costa Rica por Siempre

Lorena Martínez Hernández

Legal Officer (former)

IUCN Environmental Law Centre

Marta Pérez de Madrid Utrilla

Project Officer (former)

IUCN Regional Office for Mexico, Central America and the Caribbean 



\section{Abbreviations and acronyms}

$4 \mathrm{C}$

$5 \mathrm{C}$

A y $A$

ACOFOP

ADESCO

AECID

AGAAI

AMHON

ANAM

ANVCC

ASADAS

ASOREMA

AVE

BRIDGE

C3

CBCRS

CBD

$\mathrm{CC}$

$\mathrm{CCCl}$

CDB

Consejo Científico de Cambio Climático (Costa Rica) (Scientific Council on Climate Change)

Consejo Consultivo Ciudadano de Cambio Climático (Costa Rica) (Citizen Consultative Council on Climate Change)

Instituto Costarricense de Acueductos y Alcantarillados (Costa Rican Water and Sewers Institute)

Asociación de Comunidades Forestales del Petén (Guatemala) (Petén Association of Forest Communities)

Asociación de Desarrollo Comunitario (ADESCO) (Community Development Association)

Agencia Española de Cooperación Internacional al Desarrollo (Spanish Agency for International Development Cooperation)

Asociación Guatemalteca de Alcaldes y Autoridades Indígenas (Guatemalan Association of Mayors and Indigenous Authorities)

Asociación de Municipios de Honduras (Association of Municipalities of Honduras)

Asociación Nacional de Municipalidades (Guatemala) (National Association of Municipalities)

Atlas Nacional de Vulnerabilidad ante el Cambio Climático de México (National Atlas of Vulnerability to Climate Change in Mexico)

Asociaciones Administradoras de Sistemas de Acueductos y Alcantarillados Comunales (Costa Rica) (Community Water Boards)

Asociación Nacional de Organizaciones No Gubernamentales de Recursos Naturales y Medio Ambiente (National Association of Nongovernmental Natural Resource and Environment Organisations)

"Transforming Evidence into Change: A Holistic Approach to EbA Governance" project

"Building River Dialogue and Governance" project

Consejo de Cambio Climático (Mexico ) (Climate Change Council)

Comisión Binacional de la Cuenca del Río Sixaola (Costa Rica-Panama) (Binational Commission for the Sixaola River Basin)

Convention on Biological Diversity

Climate change

Comités de Coordinación Cantonales Inter-institucionales (Costa Rica) (Interinstitutional County Coordination Committees)

Convention on Biological Diversity (abbreviation in Spanish) 
CENIGA

CEPAL

CES

$\mathrm{CICC}$

CICC

CLIMA+

CME

CNCC

CNE

COCODES

COHEP

CONRED

COPECO

CORAC

CORNASAM

CP

CTICC

CTICC

DCC

DNCC

DNCC

EbA

ECADERT

Centro Nacional de Información Geoambiental (Costa Rica) (National Geoenvironmental Centre)

Comisión Económica para América Latina y el Caribe

Consejo de Educación Superior (Honduras) (Higher Education Council)

Comisión Intersecretarial de Cambio Climático (Mexico) (Intersectoral Climate Change Commission)

Comité Interinstitucional de Cambio Climático (Honduras) (Interinstitutional Climate Change Committee)

Secretaría Presidencial de Cambio Climático Clima Más (Honduras) (President's Climate Change Secretariat)

Comités Municipales de Emergencia (Costa Rica) (Municipal Emergency Committees)

Consejo Nacional de Cambio Climático (Guatemala) (National Climate Change Council)

Comisión Nacional de Prevención de Riesgos y Atención de Emergencias (Costa Rica) (National Commission on Risk Prevention and Emergency Response)

Consejos Comunitarios de Desarrollo (Guatemala) (Community Development Councils)

Consejo Hondureño de la Empresa Privada (Honduran Private Enterprise Council)

Coordinadora Nacional para la Reducción de Desastres (Guatemala) (National Coordination for Disaster Reduction)

Comité Permanente de Contingencia (Honduras) (Permanent Contingency Committee)

Consejos Regionales de Áreas de Conservación (Costa Rica) (Regional Conservation Area Councils)

Coordinadora Departamental de Recursos Naturales y Ambiente de San Marcos (Guatemala) (San Marcos Departmental Coordination for Natural Resources and Environment)

Conference of Parties to Multilateral Environmental Agreements

Comité Técnico Interinstitucional de Cambio Climático (Honduras) (Interministerial Technical Committee on Climate Change)

Comité Técnico Interministerial de Cambio Climático (Costa Rica) (Interinstitutional Technical Committee on Climate)

Dirección de Cambio Climático (Costa Rica) (Department of Climate Change)

Dirección Nacional de Cambio Climático (Guatemala) (National Department of Climate Change)

Dirección Nacional de Cambio Climático (Honduras) (National Department of Climate Change)

Ecosystem-based Adaptation

Estrategia Centroamericana de Desarrollo Rural Territorial (Central American Rural Territorial Development Strategy) 


\begin{tabular}{|c|c|}
\hline ECLAC & Economic Commission for Latin America and the Caribbean \\
\hline Eco-DRR & Ecosystem-based Disaster Risk Reduction \\
\hline EIA & Environmental Impact Assessment \\
\hline ELC & IUCN Environmental Law Centre \\
\hline ENEE & Empresa Nacional de Energía Eléctrica (Honduras) (National Electric Company) \\
\hline ENOS & El Niño-Oscilación del Sur \\
\hline EPANB & $\begin{array}{l}\text { Estrategias y Planes de Acción Nacionales para la Biodiversidad (National } \\
\text { Biodiversity Strategies and Action Plans) }\end{array}$ \\
\hline FEBA & Friends of Ecosystem-based Adaptation \\
\hline FPIC & Free, prior and informed consent \\
\hline GmbH-GIZ & Deutsche Gesellschaft für Internationale Zusammenarbeit GmbH-GIZ \\
\hline ICE & $\begin{array}{l}\text { Instituto Costarricense de Electricidad (Costa Rica) (Costa Rican Electricity } \\
\text { Institute) }\end{array}$ \\
\hline ICF & $\begin{array}{l}\text { Instituto Nacional de Conservación Forestal, Áreas Protegidas y Vida Silvestre } \\
\text { (Honduras) (National Institute of Forest Conservation, Protected Areas and } \\
\text { Wildlife) }\end{array}$ \\
\hline ICT & Instituto Costarricense de Turismo (Costa Rica) (Costa Rican Tourism Institute) \\
\hline ICWL & Improving Coastal Watershed and Livelihoods Project \\
\hline IHT & Instituto Hondureño de Turismo (Honduran Tourism Institute) \\
\hline IIED & International Institute for Environment and Development \\
\hline IKI & Internationale Klimaschutzinitiative (International Climate Initiative) \\
\hline ILO & International Labour Organization \\
\hline IMN & Instituto Meteorológico Nacional (Costa Rica) (National Meteorological Institute) \\
\hline INAB & Instituto Nacional de Bosques (Guatemala) (National Forest Institute) \\
\hline INCOPESCA & $\begin{array}{l}\text { Instituto Costarricense de Pesca y Acuicultura (Costa Rican Fishery and } \\
\text { Aquaculture Institute) }\end{array}$ \\
\hline INDER & Instituto de Desarrollo Rural (Costa Rica) (Rural Development Institute) \\
\hline INEC & $\begin{array}{l}\text { Instituto Nacional de Estadística y Censos (Costa Rica) (National Statistics and } \\
\text { Censuses Institute) }\end{array}$ \\
\hline INECC & $\begin{array}{l}\text { Instituto Nacional de Ecología y Cambio Climático de México (National Ecology } \\
\text { and Climate Change Institute of Mexico) }\end{array}$ \\
\hline INVU & $\begin{array}{l}\text { Instituto Nacional de Vivienda y Urbanismo (Costa Rica) (National Housing and } \\
\text { Urbanism Institute) }\end{array}$ \\
\hline IPCC & Intergovernmental Panel on Climate Change \\
\hline IUCN & International Union for Conservation of Nature \\
\hline LCC & $\begin{array}{l}\text { Ley de Cambio Climático del Estado de Chiapas (Mexico) (Climate Change Act } \\
\text { of the State of Chiapas) }\end{array}$ \\
\hline LGEEPA & $\begin{array}{l}\text { Ley General del Equilibrio Ecológico y la Protección al Ambiente (México) } \\
\text { (Ecological Balance and Environmental Protection Act) }\end{array}$ \\
\hline$\& E$ & Monitoring and evaluation \\
\hline
\end{tabular}


MAG

MAGA

MARN

MEA

MINAE

MIVAH

MOPT

NCG

NDC

NGOs

OCDE

OECD

OIT

ONCCDS

PEDTT

PES

PINFOR

PINPEP

PNA

PNA

PNACC

PROFEPA

RECOPE

REDD

SDGs

SEA
Ministerio de Agricultura y Ganadería (Costa Rica) (Ministry of Agriculture and Livestock)

Ministerio de Agricultura, Ganadería y Alimentación (Guatemala) (Ministry of Agriculture, Livestock abd Food)

Ministerio de Ambiente y Recursos Naturales (Guatemala) (Ministry of Environment and Natural Resources)

Multilateral Environmental Agreements

Ministerio de Ambiente y Energía (Costa Rica) (Ministry of Environment and Energy)

Ministerio de Vivienda y Asentamientos Humanos (Costa Rica) (Ministry of Housing and Human Settlements)

Ministerio de Obras Públicas y Transportes (Costa Rica) (Ministry of Public Works and Transportation)

Programa de Gestión Comunitaria de Cuencas en el Río Goascorán, Honduras. "Nuestra cuenca Goascorán" (Community Management of the Goascorán River Basin)

Nationally Determined Constributions

Nongovernmental organisations

Organización para la Cooperación y el Desarrollo Económico (OECD)

Organisation for Economic Co-operation and Development

Organización Internacional de Trabajo

Observatorio Nacional de Cambio Climático y Desarrollo Sostenible (National Climate Change and Sustainable Development Observatory)

Plan Estratégico de Desarrollo Territorial Transfronterizo (Cuenca Río Sixaola, Panama-Costa Rica) (Strategic Transboundary Territorial Development Plan)

Payment for Environmental or Ecosystem Services

Programa Nacional de Incentivos Forestales (Guatemala) (National Forest Incentives Programme)

Programa de Incentivos Forestales para Poseedores de Pequeñas Extensiones de Tierra de Vocación Forestal o Agroforestal (Guatemala) (Forest Incentives Programme for Smallholders of Land with Forest or Agroforesty Vocation) Plan Nacional de Adaptación (National Adaptation Plan)

Protected natural areas

Política Nacional de Adaptación al Cambio Climático (National Climate Change Adaptation Plan)

Procuraduría Federal de Protección al Ambiente (Mexico) (Federal Attorney's Office for Environmental Protection)

Refinadora Costarricense de Petróleo S.A. (Costa Rican Oil Refinery)

Reducing emissions from deforestation and forest degradation

United Nations Sustainable Development Goals

Strategic Environmental Assessment 


\section{SEGEPLAN}

SEMARNAT

SENARA

SEPLASA

SERNA

SICA

SINACC

SINAMECC

SNICC

UNESCO

UNFCCC

WCMC

WEF

WWAP
Secretaría de Planificación y Programación de la Presidencia (Guatemala) (Presidential Secretariat of Planning and Programming)

Secretaría de Medio Ambiente y Recursos Naturales (Mexico) (Secretariat of Environment and Natural Resources)

Servicio Nacional de Aguas Subterráneas, Riego y Avenamiento (Costa Rica) (National Groundwater, Irrigation and Drainage Service)

Secretaría de Planificación del Sector Ambiental (Costa Rica) (Secretariat of Environmental Sector Planning)

Secretaría de Energía, Recursos Naturales, Ambiente y Minas (Honduras, currently called MiAmbiente+) (Secretariat of Energy, Natural Resources, Environment and Mines - MiAmbiente+)

Sistema de Integración Centroamericana (Central American Integration Systgem)

Sistema Nacional de Cambio Climático (Mexico) (National Climate Change System)

Sistema Nacional de Métrica para el Cambio Climático (Costa Rica) (National System of Climate Change Metrics)

Sistema Nacional de Información sobre Cambio Climático (Guatemala) (National Climate Change Information System)

United Nations Educational, Scientific and Cultural Organization

UN Framework Convention on Climate Change

United Nations World Conservation Monitoring Centre

World Economic Forum

World Water Assessment Programme (UNESCO) 



\title{
1 Adjustment
}

\author{
Rocío Córdoba-Muñoz
}

\subsection{Introduction: reprising biodiversity and ecosystem services as essential theme for adaptation to climate change}

\subsubsection{The context}

The negative effects of climate change and climate variability on humans and their livelihoods, mainly due to increased greenhouse gases in the atmosphere, are imminent and amply demonstrated (Mann et al., 2017). Climate change also heightens the frequency, intensity and gravity of extreme weather events, representing a palpable threat in the form of floods and droughts, for example. Approximately $30 \%$ of the world's population lives in areas exposed to the impacts of these extreme phenomena (WWAP, 2018). The integrity of ecosystems also suffers from climate onslaughts, reducing their capacities to provide essential services for livelihoods. Typical examples include the degradation of coasts and associated populations due to sea level rise; shortened rainy seasons in places like the Meso American Dry Corridor with less water available for human consumption and food production; and coral bleaching as ocean temperature rises, exacerbated by sedimentation and pollution from unsustainable human activities upstream and in coastal zones (Mumby et al., 2014).

It has nonetheless taken some 20 years for different key development actors and some decision makers to recognise the potential of biodiversity and ecosystem services for reducing these climate effects (Costanza, 2017; Chong, 2014). In the environmental arena, there is a growing understanding of the importance of ecosystem services in reducing vulnerability to climate change, but there is still much to be done for these services to be incorporated effectively, efficiently and responsibly in the development strategies and plans of Meso American countries.

Because of this gap in understanding (between the environmental sector and development decision makers), the response to this pressing and visible process of change is a rush to find solutions that reduce the vulnerability of populations and their livelihoods, especially to lessen the consequences of extreme events. These 'solutions' are generally limited to grey infrastructure. Usually such actions are not sustainable over the long run and concentrate on a single sector of populations to the detriment of others (CBD, 2018), not to mention they often favour certain, more economically powerful, productive sectors that generally exercise a direct influence on decision making in the countries. The consequences of these decisions are reflected in the heightened vulnerability of poorer populations and the deterioration of biodiversity and ecosystem services crucial for life on the planet (Tickner et al., 2017). Despite the growing availability of information about processes occurring in ecosystems and associated resources, their capacities to provide services and hence co-benefits for human populations continue to decline alarmingly. It was determined (Evaluación de los Ecosistemas del Milenio, 2005) that at least $60 \%$ of ecosystem services were degraded in 2005.

Indeed, the ecosystem approach (CBD, 2000), which includes socio-economic as well as ecological dimensions (Guerrero et al., 2006) for sustainable ecosystem management, was incorporated in the environmental field by the CBD in 2000 and in several global, climate change-related instruments years later (CBD, 2009a - definition of EbA adopted; CBD, 2010 - Aichi Targets; UNDP, 2015 Sustainable Development Goals, and in the Paris Agreement - UNFCCC, 2015, among others). 
Previously, biodiversity and ecosystems and their intrinsic relation to human survival remained tangential (or non-existent) in development plans and legally-binding, local, national and global frameworks and instruments.

Currently that situation has improved substantially. For example, $67 \%$ of Nationally Determined Contributions (NDCs) include adaptation actions involving ecosystems (IIED \& IUCN, 2016; CohenShacham et al., 2016). These actions are related to those existing for decades in the realm of natural resources implemented to preserve and maintain ecosystems for human well-being, such as:

- Compensation and payment for ecosystem/environmental goods and services (PES) (Abell et al., 2017), regimes in which users of natural resources (especially water) compensate or pay those who protect forests or springs,

- Natural resource conservation, which covers a wide range of actions to maintain ecosystem services and safeguard biodiversity in the long term,

- Promotion of agroecology, to produce food through sustainable farming practices that do not use chemicals,

- Comprehensive water management, aimed at integrating water, soil and natural resource management in general to maximize long-term social good. Water is one of the key resources in the Meso American region that is affected by climate change and extreme events (droughts or floods).

- Community management of protected areas in which the community actively participates together with the State to protect natural resources. Protected areas are important repositories of biodiversity resources and ecosystem conservation whose benefits eventually reach human beings (MacKinnon et al., 2011).

- Protection of water sources, basin management and landscape management that include an important component of coordination and governance among stakeholders located in different parts of a watershed, for example. Basin and landscape management recognises the extension of ecosystems, their interactions and hence the difficulties of more broadly managing the resources found in these spaces.

- Protection and recovery of natural infrastructure, such as coral reefs, mangroves, coasts and forests as buffers from natural threats, erosion and floods (Chong, 2014), as well as reforestation of recharge zones and slopes, contributing to the recovery of soil, the preservation of water quality and quantity and the reduction of erosion and threat of landslides,

- Re-establishment of traditional and non-traditional agroforestry systems, recognising the populations' traditional knowledge, culture and customs, and

- Restoration and rehabilitation of ecosystems to improve vital services such as availability of good quality water, food, fisheries and genetic resources.

It should be mentioned that over the course of the 20 plus years the ecosystem approach has been promoted, these actions have been 'recovering from the past' and are being improved through structured and systematic contextualisation to address climate change impacts and taking environmental and social risks into account. For example, agroecological and agroforestry actions are being strengthened through the use of more climate-resistant species ('climate-smart agriculture') (IIED and IUCN, 2016; Cohen-Shacham et al., 2016). It can be said that, in general, decision makers are increasingly taking biodiversity and its ecosystems into consideration for inclusion in more 
comprehensive adaptation strategies, as well as in developing strategies and plans. Nevertheless, given the scenarios of uncertainty posed by climate change, there is still much remaining for a full understanding of the relation between social systems, natural ecosystems and the interaction between them.

\subsubsection{Ecosystem-based adaptation (EbA) in the current context}

As is known, EbA can be classified in different ways: as an approach, an initiative, a combination of both or a series of strategies and plans. It includes actions intimately connected with the conservation, maintenance and restoration of biodiversity and its ecosystem services as means to improve the climate change adaptation options of human beings.

During COP 10 (Decision X/33) of the Convention on Biological Diversity (CBD, 2009) the following definition of EbA was formulated and adopted: "The use of biodiversity and ecosystem services as part of an overall strategy to help people to adapt to the adverse effects of climate change."

For practical purposes, in this book EbA is understood to be the array of strategies, policies and practices aimed at protecting and restoring ecosystem services to reduce society's vulnerability to climate change.

The proposal of this definition is not meant to ignore all the conceptual elements predicated for EbA according to the CBD, FEBA and IUCN ${ }^{1}$ (CBD, 2018). However, it has more practical ends and underscores the inalienable relation existing between activities to conserve ecosystems and their services for humankind, natural resource governance (contemplating equity and social justice) and climate change adaptation. Governance and $\mathrm{EbA}$ are inseparable; together they create the right conditions enabling climate change strategies, policies and practice to be sustainable.

Countless publications have demonstrated the dependence of people and their communities, especially those with the greatest vulnerability (social, cultural and economic), on natural capital or goods. There is no doubt that without healthy ecosystems, the continued existence of human beings is in danger (Rubio-Scarano, 2017). EbA generates important co-benefits as the long-term, positive outcome of applying such measures. These include, inter alia, carbon fixing, conservation of biodiversity and ecosystem services, increased pollination (fostering sustainable agriculture), improved air quality and local regulation of climate (Cohen-Shacham et al., 2016; Potschin et al., 2014).

EbA is a natural solution that emphasises the value of ecosystem services and human beings, and seeks more comprehensive options to improve the long-term resilience of both (people and ecosystems) in current and future scenarios. It is an alternative costing less than grey infrastructure solutions (conventional) that fail to contemplate permanence, sustainability and potentially adverse effects on people and ecosystems (UNEP-DHI Partnership/IUCN/TNC, 2014). However, scientific research should be expanded beyond some specific, isolated examples and show the extent to which $\mathrm{EbA}$, through green infrastructure, can at least partly replace conventional infrastructure - in other words, a combination of natural and engineering solutions (Bai, 2018). 
It is vital as well not to lose sight that if $\mathrm{EbA}$ is to be incorporated in local and national climate change adaptation strategies, it must also be linked with comprehensive improvement of sustainable livelihoods. These comprise the capacities, assets and activities indispensable to maintain or improve human living conditions without undermining the natural resource base (DFID, 1999). An intrinsic part of EbA is therefore accounting for the current and potential impacts of adaptation measures on the different kinds of livelihood 'capital' or 'assets': human, natural, social, physical and financial (Reid et al., 2017).

According to Friends of Ecosystem-based Adaptation (FEBA) (2017) based on the essential principles for $\mathrm{EbA}^{2}$ (Andrade et al., 2011), EbA must incorporate the following quality criteria:

1. reduces social and environmental vulnerabilities,

2. generates societal benefits in the context of climate change adaptation,

3. restores, maintains and improves ecosystem health,

4. is upheld by policies at multiple levels, and

5. supports equitable governance and enhances capacities to adapt.

This book focusses mainly on criteria 4 and 5 , related to EbA governance, with the understanding that it is indispensable to ensure that actions will be sustainable over the long term with all stakeholders' participation.

\subsection{Good governance: an innovative value proposition for the sustainability of adaptation measures}

In simplified form, the term 'governance' refers to the relation between governments and citizens. Governance has been gaining ground in natural resource management during recent years and has become a fundamental pillar in maintaining human well-being. There are a great many definitions, but they all include stakeholder objectives, decision making and actions to achieve those objectives (Cosens, 2017; Adger et al., 2018).

For the purposes of this publication, governance is defined as the means by which society defines goals and priorities and moves toward global, national or local decision making (Burhenne-Guilmin \& Scanlon, 2004).

Governance has four essential elements or components (Iza \& Stein (eds.), 2009):

- Political: the frame of reference and guiding principles for government administration of public affairs

- Legal: includes laws, decrees, municipal ordinances and customary laws (non-formal norms and behaviours that are accepted by the community and which persist over time)

2 Essential principles for EbA: 1. Promotes the resilience of both ecosystems and societies. 2. Promotes multi-sectoral approaches. 3. Operates at multiple geographic scales. 4. Integrates flexible management structures allowing adaptive management. 5. Minimises compensations and maximises benefits with development and conservation goals to avoid unintended negative social and environmental impacts. 6. Based on best science and local knowledge available and promotes the generation and spread of knowledge. 7. Deals with resilient ecosystems and the use of nature-based solutions at the service of people, especially those most vulnerable. 8 . Is participatory, transparent, responsible and culturally appropriate, and actively addresses equity and gender aspects. 
- Institutional: the establishment, consolidation and supervision of effective institutions with clear functions

- Processes: the array of actions required to implement policies and laws. They must guarantee public participation mechanisms in which organised civil society forms an integral part of decision making on matters that directly or indirectly affect them, and through which stakeholders express their interests, exercise their rights, meet their obligations and resolve their differences.

The policy and legal components of governance will be examined in detail in chapter 4 (Policy) and the institutional component in chapter 5 (Institutions).

Moreover, good governance refers to efficient and effective enforcement of the legal and institutional framework, with the participation of the different stakeholders and under a series of essential principles (UICN, 2016). For there to be good governance (or effective governance), another series of characteristics must all be kept in mind:

- Transparency - openness in decision making,

- Access to information - precise, effective and open communication,

- Access to justice - equitable mechanisms for accountability and protection of rights,

- Public participation - genuine intervention in decision making,

- Coherence - a consistent approach,

- Subsidiarity - decisions are adopted at the grassroots level (local) or whichever is appropriate,

- Respect for human rights - in close relation with good environmental governance,

- Accountability - about economic, social and environmental results,

- Rule of law - impartial, transparent and consistent enforcement of legal norms at all levels, and

- Promotion of gender equality and women's empowerment - as integrating element of the principles of good governance and a theme mainstreamed in all of IUCN's work.

Hence, governance is a participatory, inclusive and equitable process with responsibilities and rights. Good or effective governance is characterised by all stakeholders' ownership of problems and possible solutions, from local to national and regional (from communities at the level of microbasin, for example, to the regulatory agencies of a transboundary basin).

For good governance to be achieved, it is crucial that suitable capacities exist in the different decisionmaking contexts and levels. Chapter 2 (Capacity) takes an in-depth look at training and capacity building so that players will be able to exercise their rights, influence political bodies (political power over decision making) over private actors (economic power) and take differentiated responsibilities together, recognising the rights and obligations of individuals as well as public and private organisations, levels of government, provincial units, agencies, public enterprises, foundations, etc. At the same time, there must be solid and timely technical, scientific, social and economic information to make well-reasoned decisions. Academia and research centres are therefore a fundamental part of civil society actors (and also the private sector in some cases) that must be taken into account when making sound decisions. Under this same scheme of knowledge management, traditional knowledge must be suitably weighed as basis for building EbA governance.

As mentioned in the preceding section, there is an inherent relation between EbA and adaptation governance, which (for the purposes of this book) not only includes the aforementioned components 
or elements but also to "promote the legal institutional frameworks and public participation processes necessary for improving societal resilience to existing and potential climate change impacts" (Sanchez \& Roberts, 2014).

Hence, EbA governance will be understood as the norms, institutions and processes determining the way power is exercised and responsibilities are distributed, and how and when decisions are made and implemented to conserve, restore and sustainably manage biodiversity and ecosystem services as part of the general strategy for adjusting to actual or forecasted climate and its effects.

EbA governance also entails searching for effective and socially just responses to resolve a series of complex processes that involve a multiplicity of players, power relations and interests of diverse sectors with respect to economic development (generally not sustainable) (Sieber et al., 2018). Achieving good governance in this context therefore poses several inherent challenges: functional and flexible legal and institutional frames articulating economic development and ecosystem maintenance with respect for the value of human beings, democracy and social equity (Colloff et al., 2017). These are all requisites enabling the world's people to live together freely and peacefully.

Good EbA governance also entails the promotion of dynamic decision-making systems capable of responding opportunely to the implicit uncertainty of both climate variability and climate change. The lack of certainty about what the impacts of climate change will be provides solid justification for forging EbA governance. The components of the law itself aim at stabilising structures to provide security for such harmonious co-existence in States, regardless of their territorial size. This stability could actually constitute a barrier for adaptation (Cosens et al., 2017). Current EbA dynamics call for mechanisms that foster such stability (under stable government schemes), combined with tools to permit changes in policy, legal and institutional frames as the situation transforms in each context (Colloff, et al., 2017).

Hence, EbA governance must be flexible (envisages mechanisms for adapting legal and institutional frames); multidimensional (encourages multisectoral coordination, for example agriculture, water, biodiversity and industry at multiple levels such as community, local, regional, national and international, combining horizontal and vertical integration); and participatory (from the stance of social justice, informed public participation permits greater equity in decisions that affect the groups most vulnerable to climate change, such as women, children, young people, the elderly and ethnic and indigenous minorities). It must also be ecosystemic, with some of the most urgent measures being political, legal and institutional mechanisms to increase ecosystem resilience to climate and non-climate impacts (Martínez \& Luna, 2018).

Although significant strides have been made in EbA governance frames and arrangements, grey infrastructure solutions prevail in current instruments. For example, at this time direct investments in nature-based solutions comprise less than $1 \%$ of the total compared to those involving conventional infrastructure (WWAP, 2018). The scale and scope of legal instruments generally do not contemplate long-range processes of ecosystem change and transformation, the relation between them or their impacts on climate change and people's livelihoods (Creed \& van Noordwijk, 2018). Thus, maintaining biodiversity and ecosystem services (supply, regulation, cultural and support) as part of solutions toward reducing the negative impacts of climate change have not yet permeated country policies and regulatory frames in any clear, effective and structured way. Notwithstanding, significant efforts exist in Meso America and other regions with developing nations to incorporate EbA governance arrangements that combine diverse formal and non-formal institutions in emerging entities at national level. This topic will be addressed in Chapter 5 (Institutions). On the other hand, it is by 
enhancing EbA capacities and governance exercised by different key stakeholders that decision makers can be influenced, all the way from the local level (development organisations, water boards, microbasin councils, groups for local management of protected areas, for example) to national and transborder levels. Chapter 2 (Capacity) explores in detail which of those capacities are required in EbA governance at different levels and in different stakeholder groups.

Good EbA governance must also foster the development of a common language and understanding of key concepts among all actors (Cosens et al., 2017). Legal and institutional mechanisms should not be perceived as thorny and unattainable. Capacity strengthening for all players must include EbA governance processes and the exercise of rights and obligations, including the dynamics of policy and decision influencing. It is crucial that ethics, equity and social justice be guaranteed. Human and institutional capacities for EbA governance affect and determine the establishment and achievement of public policies and strategies (UNSTT, 2012)

\subsection{The linkage necessary between governance and EbA: a future vision toward sustainability}

The concepts of EbA and governance have been discussed in the previous sections. But why must the two be linked? Efforts to maintain the integrity of ecosystems and tie their services to society's wellbeing necessarily call for governance structures that are stable and yet have adequate adaptation capacities to address climate variations and global economic development trends.

This document includes some examples of ecosystem-based measures for climate change adaptation, framed within the criteria necessary for reducing societal and ecosystem vulnerability. These actions can only be carried out through effective coordination among different stakeholders and legal and institutional arrangements to uphold them in the long run.

EbA arrangements at different levels will be sustainable insofar as they are supported by a binding legal and institutional framework. In this sense, any action for nature conservation must necessarily be accompanied by effective and efficient institutional arrangements (OCDE, 2015; OECD, 2018). The State must concern itself with forging a favourable policy, legal and economic environment for adaptation and disaster risk reduction (CBD, 2018). Notwithstanding, civil society and other stakeholders are the ones who, in organised and concerted form, can enforce policy and legal instruments. To make this happen, those actors need negotiation and lobbying capacities, and must also understand, appropriate and exercise their rights and obligations. Interactions between human values, knowledge and regulations must form an integral part of decision making.

Given that EbA governance is admittedly recent and not well studied, Meso American countries cannot be expected to have consolidated EbA governance structures bringing together all sectors and interests, both vertically and horizontally. This is part of a long-range process. However, it is vitally important to have adequate knowledge of existing legislation, regulations and procedures in the sphere of environmental and ecosystem conservation, climate change and also economic development. Identifying entry points in existing policies and legal frames is essential to propose and execute adaptation actions that are safe (avoid maladaptation) and sustainable in the long term.

Here it is ultimately a matter of breaking paradigms and being aware that societal challenges related to ecosystem services (inter alia, water security, food security, health, and livelihoods in general) also require dynamic legal frames. Stakeholders' capacities must therefore allow them to devise and promote legal reforms necessary to close the gaps and couple development, society's values 
and ecosystem health with just and balanced climate change adaptation. This means that laws and regulations need to be modified with an eye to sustainability (despite the time and effort required). This is valid at all levels, from local (promoting specific municipal ordinances, for example) to national, transnational and global.

\subsection{Conceptual framework}

This section presents a series of fundamental notions used in the book with the aim of contextualising the issues to be addressed. These notions and concepts can be found in numerous publications that in turn quote 'official' definitions in international agreements such as the Convention on Biological Diversity (CBD, 1992; CBD, 2009b), UNFCCC (1992) or glossaries of the Intergovernmental Panel on Climate Change (IPCC, 2007; 2014). For the theme of this publication, specifically, the frame of reference is the CBD document Voluntary Guidelines for the design and effective implementation of ecosystem-based approaches to climate change adaptation and disaster risk reduction (CBD, 2018) as one of the more recent official documents.

It is not the task of this publication to compare the different definitions of a single concept, but rather to try and simplify them so they can be easily understood by a broad group of readers. An exhaustive explanation of governance and EbA governance has already been made, so these concepts are not included below. Other relevant notions will be presented in chapters 2 to 6 .

\section{Adaptation:}

A process that can be interpreted from the standpoints of either society or natural resources. Both deal with adjustment to current or expected climate (in the short, medium and long term) and its effects, in order to moderate potential harm or deterioration (of living conditions or ecosystem functions, respectively) these conditions can cause. According to IPCC (2014), it also includes taking advantage of beneficial opportunities those climate changes can provide.

\section{Adaptation capacity (adaptive capacity):}

The combination of strengths, attributes and resources (human, institutional, infrastructure and others) possessed by a person, community, society or organisation making it possible to take actions that can reduce adverse impacts of climate change and 'recover' from them (Reid et al., 2017). This capacity includes the resources and legal authority necessary to respond to the change as reflection of a governance system that adjusts to uncertainty. It also includes the capacity of participation in which the people affected have the rights, obligations and resources to play a role in decision making. In this sense, this capacity of participation reduces stakeholders' risk of being marginalised or not taken into account in governance processes concerning climate change (Cosens et al., 2017). Adaptive capacity is another of the three fundamental components of the vulnerability equation: sensitivity, exposure and adaptation capacities (see definition of vulnerability), inasmuch as capacity is the component that can be directly improved through diverse mechanisms and tools (Chapter 2). 


\section{Appropriation:}

Process through which stakeholders assimilate and internalise, as being of self-interest, actions taken around human (social) and environmental wellbeing. Themes, actions and projects become an integral part of people's lives without the need for incentives or outside influence from other people to continue with their execution. Appropriation allows organised groups to own these shared interests and push decision makers to carry out their actions efficiently and effectively.

\section{Benefits (co-benefits):}

Direct or indirect goods, products or services generated for people or ecosystems by applying EbA measures. These can have an ecological, social, cultural and monetary value. For example, reforestation can generate intangible benefits such as improving air quality, conserving water quality, positively affecting local climate and encouraging the pollination of species important for food security.

\section{Biodiversity:}

The variability among living organisms from all sources, including terrestrial, marine and other aquatic ecosystems and the ecological complexes of which they form part. This includes diversity within species, between species and of ecosystems (variability of genes, species and ecosystems). Some parameters to measure how biodiverse an ecosystem is, for example, relate to the number and abundance of species within a specific geological space.

\section{Climate change:}

A change in the state of the climate that can be identified (e.g., by using statistical tests) through changes in the mean and/or the variability of its properties, and which persists for an extended period, typically decades or longer. Climate change may be due to natural internal processes or external forcings, or to persistent anthropogenic changes in the composition of the atmosphere or in land use. For the purposes of this book, this term also includes climate variability. It involves modifications of the average state and other statistical characteristics, as well as extreme events at all temporal scales and at more extensive spatial scales than those of weather events. Sea level rise primarily affecting the coastal zones of Meso America is a direct effect of climate change, while droughts or the concentration of rainfall in fewer days in certain areas are effects of climate variability

\section{EbA measures:}

Options and actions based on the maintenance and restoration of ecosystems that in turn improve quality of life for human populations and their capacity to adapt to climate change.

\section{Ecosystem:}

The collection of communities of plants, animals and micro-organisms and their non-living environment that interact within a specific geographical unit. It is a functional system that possesses physical parts (structure) and dynamic processes of material and energy transformation (function). Natural resources and biodiversity form part of the ecosystem, as do human beings since they interact with the goods and services ecosystems provide. These systems have been classified in 
different ways, most commonly as terrestrial ecosystems (such as forests), aquatic (wetlands, for example) and marine (for example, coral reefs).

\section{Ecosystem functions:}

All of the processes in which material and energy are transformed (energy flow within ecosystems). These are the physical, chemical and biological processes that occur through both living beings and in their interaction with the surroundings (habitat). Examples include all of the nutrient cycles, biomass production, photosynthesis and pollination, which make up ecosystem services and benefit human beings (Creed \& van Noordwijk, 2018).

\section{Ecosystem health (ecological integrity):}

Refers to the good condition of an ecosystem in terms of structure and the functions it carries out (analogous to human health, for example). In other contexts the term is used to denote the ecological integrity of ecosystems wherein both the structure (species and habitats) and function (transformation of matter and energy) are found in natural ranges of variation and can sustain and recover from disturbances due to natural dynamics or human interventions (Williams et al., 2012).

\section{Ecosystem restoration:}

Processes implemented to restore the resources, species, community structures, productivity and services provided by ecosystems that have been degraded, damaged or destroyed. This makes it possible to increase their resilience to changes and preserve their biodiversity (Creed \& van Noordwijk, 2018).

\section{Ecosystem services:}

The benefits people obtain from nature. They derive from the inherent characteristics of ecosystems (see definition of ecosystem), from both their structure and functions. Some of these benefits are tangible resources such as those obtained from fishing, logging and water (supply). Others are not as tangible but exist if ecosystems are in good condition, such as pollination, erosion control, flood regulation, climate regulation and absorption of carbon (regulatory services). Ecosystems also have spiritual, cultural and aesthetic values (cultural services). All these services would be impossible without those necessary for their production and maintenance (support services) such as soil formation, maintenance of the nutrient cycle, oxygen production, habitat and biodiversity, among others (Layke, 2009).

\section{Empowerment:}

The process by which local communities and other disadvantaged social groups acquire power and independence, as well as the ability to make oneself known and heard to achieve proposed changes. It means acquiring security (confidence) in themselves (capacities), legitimacy and recognition from other players to be heard and influence political decision-making structures.

\section{Green infrastructure:}

While closely related to natural infrastructure, this term refers to improved structure and functioning so that ecosystems can provide their services. The term is generally used in relation to processes 
primarily in urban areas; green infrastructure is commonly combined with grey infrastructure (CohenShacham et al., 2016).

\section{Grey infrastructure:}

Constructions or works carried out mainly in urban zones to channel water (dikes, walls), provide drinking water and sanitation services (delivery networks, treatment plants), hold soil (retaining walls) and others, using traditional artificial materials. These types of works are generally detrimental to ecosystems and their services as they fail to take costs or geographical location into consideration.

\section{Human well-being:}

The way of living of people or social groups, including elements necessary for life. It refers to the array of elements required to live adequately (with quality) and in peace. The dimensions of human well-being (Evaluación de los Ecosistemas del Milenio, 2005) encompass basic material needs for a good life, health, good social relations, security, and freedom of choice and action. It also comprises livelihood assets or capital (human, natural, social/cultural, physical and financial) and is closely related to participation capacity and identity for decision making.

\section{Low-regrets adaptation options:}

Actions that could potentially deliver net socio-economic benefits to local communities and ecosystems whatever the extent of future climate change. They maximise positive aspects and minimise the negative aspects of nature-based solutions. Many of the conventional options in ecosystem conservation, such as restoration of certain wetlands, are socially and environmentally beneficial, with or without impacts from climate change.

\section{Maladaptation:}

Actions designed for climate change adaptation that, owing to a number of factors, instead increase ecosystem and societal vulnerability to climate-related risks. Generally, maladaptation relates to development policies and measures that deliver short-term gains but over a longer period turn out to be harmful. It also includes actions favouring certain sectors of the population in detriment to others, as well as measures applied in some parts of ecosystems that are harmful to resources and services in others.

\section{Natural capital:}

The stock of natural resources in ecosystems that, combined with other capital or assets for sustainable livelihoods, produces ecosystem services (Costanza, 2017). These resources include the earth's crust, minerals, energy reserves, soils, water, air, atmosphere, climate and all living organisms (Creed \& van Noordwijk, 2018). They do not require human activities to exist, unlike other capital (physical or built, human, financial, social or cultural).

\section{Natural infrastructure:}

An approach that seeks to restore ecosystem structure, function and composition in order to maintain the services they provide. Natural infrastructure is an important part of EbA (Cohen-Shacham et al., 2016). 


\section{Nature-based solutions (natural solutions):}

Actions to protect, sustainably manage and restore natural or modified ecosystems to address societal challenges effectively and adaptively while simultaneously providing benefits for human beings and biodiversity (Cohen-Shacham et al., 2016). It is a new concept in science and conservation that emphasises work with ecosystems, their resources and their services instead of traditional engineering solutions for climate change adaptation. These solutions must be adjusted to the different local contexts, take traditional, local and scientific knowledge into account and include the active participation of all actors. They must also be an integral part in the design of policies, legislation and institutionality from local to national and transboundary level so that they can be implemented transparently and effectively.

\section{Negotiation:}

Process of harmonising different interests in agreements or arrangements concerning a certain matter (Iza \& Stein (eds.), 2009).

\section{Political advocacy:}

The conscious and directed action of a social group in order to change a given situation. It is predicated on a setting with multiple actors, projects, interests and perspectives as opposed to some unilateral action. Political advocacy should include addressing power relations and conflicts that can be resolved through negotiation, consensus building and agreements, but can also sometimes lead to confrontations (IUCN, 2006). Capacities to influence or impact on power and decision-making groups are an important ingredient of negotiations, and to promote changes in policy, legal and institutional frames making them functional with respect to climate change.

\section{Resilience:}

The ability of a system and its component parts to anticipate, absorb, accommodate or recover from the negative effects of climate change while ensuring the preservation of its basic structures and function, capacity to organise and the capacity to adapt to stress and change (IPCC, 2007). A distinction is usually made between ecosystem resilience, referring to its tolerance to the impacts of external factors without suffering irreversible changes (Reid et al., 2017), and human resilience. The latter is the ability to buffer impacts or cope with changes. It requires resistance, or capacity to absorb the impact, recovery or time required to return to the state of things prior to the impact, and learning in order to better anticipate potential future changes. Increasing people's resilience depends on their livelihoods, adaptation capacity and good governance based on solid institutions and clear, inclusive legal frames.

\section{Social systems:}

Similarly to ecosystems, this refers to the assemblage of people or groups of people who interact with particular and specific functions and characteristics. The main elements of a social system are values, norms, customs, uses and agreements. The aim of a social system is to pursue and improve livelihoods through networks and connections, participation in formal groups and relations of trust and exchange (DFID, 1999). Linkage and interaction between social systems and ecosystems is vital for good EbA governance. 


\section{Strategic territorial planning:}

In general terms, spatial or land use planning beyond traditional urban/rural planning, accounting for impacts and influences of other sectoral policies, geographical spaces and the use of terrestrial and/or marine resources, as well as other change factors such as climate change and disaster risks. Its aim is to plan for future development needs and opportunities in particular geographical jurisdictions taking into consideration policies relevant to the area and its people, and for more equitable distribution of economic development (Lausche, 2011).

\section{Territorial planning:}

Systematic analysis of physical, social and economic factors to select the options most apt to increase productivity, be sustainable and meet society's needs. The aim is to plan appropriate uses of a given geographical space without deteriorating natural resources. Such a plan inevitably requires the participation of all actors and solid institutionality capable of balancing development, conservation and the well-being of human populations.

\section{Vulnerability:}

The propensity or predisposition of an ecosystem, person or group of people to be adversely affected (IPCC, 2014). Vulnerability to climate change depends on multiple factors, so must be assessed in each particular case. Three specific components are defined, in general. The first is exposure, involving variations in climate (temperature, rainfall, seasons with extreme events or hurricanes), and usually refers to geographic locations (for example, people who live near watercourses are more exposed to floods). The second is sensitivity, or the degree to which a system is affected by external stimulae (SINAC, 2013; IPCC, 2007). This depends on the particular characteristics of each system. For example, a change in temperature or rainfall can affect a dry forest differently than a tropical wet forest. On the other hand, people with few resources are more sensitive to these variations. The third component is adaptive capacity (see definition). The degree of exposure to climate changes in the Meso American region is very difficult to modify. The same occurs with the sensitivity of certain ecosystems (such as coral reefs with respect to higher water temperature) and communities (native people in their territories). For these reasons, it is increasingly important to work toward improving the adaptive capacities of people and communities to lower their exposure and sensitivity. This includes improving the capacities of government institutions to cope with the current and future EbA governance challenges of climate scenarios.

\subsection{Contributions of EbA governance to international agreements}

UN agreements and treaties are a vital part of international law based on common values that help ensure peace and cooperation among countries through a series of principles.

In general terms, there are different types of international-level agreements, which may or may not be binding. They include conventions, treaties, pacts, charters, codes of conduct, memorandums of understanding and exchanges of notes, for example (Aguilar \& Iza, 2011), or may be constituted through international custom. Binding international treaties provide States the opportunity to agree on joint agendas and commitments that must be achieved within a given period to improve quality of life for human beings. For this, States need to have in place governance arrangements capable of 
incorporating mandates emanating from those agreements and turning them into policies, legal and institutional frames to ensure efficient, effective and timely compliance.

This section examines five such agreements related to climate change and ecosystem conservation: the Convention on Biological Diversity, the Sustainable Development Goals (SDGs), the Paris Agreement and Nationally Determined Contributions (NDCs), the Aichi Targets, the Nagoya Protocol and the Sendai Framework of Action for disaster risk reduction.

\subsubsection{Convention on Biological Diversity (CBD)}

The Convention defines biological diversity as the "variability among living organisms from all sources including, inter alia, terrestrial, marine and other aquatic ecosystems and the ecological complexes of which they are part; this includes diversity within species, between species and of ecosystems". (CBD, 1992).

The CBD is the first global instrument that refers to all aspects of biological diversity (components): genetic resources, species and ecosystems. Its main objectives relate to the conservation of biological diversity, sustainable use of its components and fair and equitable sharing of the benefits deriving from use of genetic resources. As already mentioned in this chapter, the definition of EbA was adopted in one of the Conferences of Parties to the CBD (COP 10, Decision X/33). EbA is directly related to this convention and its objectives, especially those concerning conservation and sustainable use of ecosystems. Numerous EbA-related instruments and protocols have emanated from the convention. One of the most recent in the context of climate change and disaster risk reduction (COP 14) also links EbA with ecosystem-based disaster risk reduction (CBD, 2018).

An instrument currently being discussed in the CBD is the Post-2020 Global Biodiversity Framework (CDB, 2019) resulting from a 2018 decision adopted at COP14 to carry out an exhaustive, participatory process for the preparation of a global biological diversity framework after the year 2020 (CDB, 2018a). Among other matters, the cited documents mention specific, measurable, ambitious and attainable goals with timescales based on science and knowledge. It was proposed that the Aichi Targets be used as foundation and improvement of this framework. In general, an exhaustive review of the CBD was also proposed, explicitly incorporating target groups, gender perspective, civil society, youth, the private sector and the role of sub-national governments, cities and other local authorities.

\subsubsection{Sustainable Development Goals (SDGs)}

The UN defines sustainable development as "development that meets the needs of the present without compromising the ability of future generations to meet their own needs".

Although this has been a subject of interest for several decades, in September 2015, 189 Member States of the United Nations approved a new vision toward economic, social and environmental sustainability through what is known as Agenda 2030, with 17 development goals and 169 targets (UN, 2016).

As indicated in previous sections, EbA seeks to maintain the integrity of ecosystems and the services they provide, which is achieved through conservation and restoration (among other means), while also reducing people's vulnerability. The SDGs clearly define the challenges facing both societies and ecosystems; moreover, because it combines environmental, economic and social themes, EbA relates to practically all of the SDGs and many of the targets. On the other hand, many of the SDGs are upheld by the services ecosystems provide humanity (and which EbA seeks to maintain), which 
makes it important to understand the dynamics of these systems for decisions about sustainable development (Wood et al., 2018).

Table 1.1 offers an approximation of the linkage between each of the SDG and EbA components and principles, and the governance required for implementation. This is not meant to be a thorough and exhaustive review; the intent is rather to reflect on the links between EbA governance and the SDGs. It should be noted, however, that the SDGs are set out separately (Creed \& van Noordwijk, 2018) so the interaction between them is not easy to see, which constitutes a limitation for this analysis.

\section{Table 1.1 Linkage between EbA governance and the SDGs and their targets}

\begin{tabular}{|c|c|c|}
\hline SDGs & Targets & Contribution of different EbA initiatives and their governance \\
\hline 1. End poverty & 1 & $\begin{array}{l}\text { - Adaptation measures that help people improve their sustainable } \\
\text { livelihoods } \\
\text { - Enhanced resilience and reduced vulnerability of the poor to } \\
\text { extreme events } \\
\text { - Generation of employment as part of co-benefits }\end{array}$ \\
\hline 2. Zero hunger & 3,4 and 5 & $\begin{array}{l}\text { - Improved capacities of adaptation to climate change and extre- } \\
\text { me weather events for food security } \\
\text { respecting the availability of genetic resources and traditional } \\
\text { knowledge } \\
\text { - Diversification of agriculture and food supply through agrofores- } \\
\text { try practices and agroecological activities }\end{array}$ \\
\hline $\begin{array}{l}\text { 3. Health and well- } \\
\text { being }\end{array}$ & 9 and $3 d$ & $\begin{array}{l}\text { - EbA governance directly and indirectly affects the health and } \\
\text { well-being of human populations } \\
\text { - Increased capacities of populations at risk of disasters to cope } \\
\text { with extreme climate events }\end{array}$ \\
\hline 4. Quality education & 7 & $\begin{array}{l}\text { - Strengthening of capacities for learning and application of new } \\
\text { knowledge about EbA and sustainable development }\end{array}$ \\
\hline 5. Gender equality & 5 & $\begin{array}{l}\text { Promotion of full, egalitarian and effective participation of all sta- } \\
\text { keholders } \\
\text { - Women with equal opportunities for leadership at all decisi- } \\
\text { on-making levels }\end{array}$ \\
\hline $\begin{array}{l}\text { 6. Clean water and } \\
\text { sanitation }\end{array}$ & 5 and 6 & $\begin{array}{l}\text { - Maintenance of ecosystems, their goods and services including } \\
\text { water, and their equitable and sustainable distribution in the fra- } \\
\text { me of climate change } \\
\text { - Inseparably related to goals } 13,14 \text { and } 15 \text { (climate change, terre- } \\
\text { strial and aquatic ecosystems) }\end{array}$ \\
\hline $\begin{array}{l}\text { 7. Affordable and clean } \\
\text { energy }\end{array}$ & 2 & $\begin{array}{l}\text { - Maintenance of healthy ecosystems and with human populations } \\
\text { capable of managing them adequately }\end{array}$ \\
\hline $\begin{array}{l}\text { 8. Decent work and } \\
\text { economic growth }\end{array}$ & 4 & $\begin{array}{l}\text { - Restoration and sustainable management of ecosystems } \\
\text { - Linkage between restoration and sustainable livelihoods } \\
\text { - Economic growth without environmental degradation }\end{array}$ \\
\hline $\begin{array}{l}\text { 9. Industry, innovation } \\
\text { and infrastructure }\end{array}$ & 1 & $\begin{array}{l}\text { - Promotion of sustainable infrastructure in the long term: green } \\
\text { infrastructure and nature-based solutions } \\
\text { - Combination of natural and traditional solutions }\end{array}$ \\
\hline
\end{tabular}




\begin{tabular}{|c|c|c|}
\hline SDGs & Targets & Contribution of different EbA initiatives and their governance \\
\hline 10. Reduced inequalities & 2 & $\begin{array}{l}\text { - Application of principles for good EbA governance (social, eco- } \\
\text { nomic and political inclusion of all people, especially those most } \\
\text { vulnerable) }\end{array}$ \\
\hline $\begin{array}{l}\text { 11. Sustainable cities } \\
\text { and communities }\end{array}$ & 4 and $11 a$ & $\begin{array}{l}\text { - Improvement of environmental planning in a scenario of climate } \\
\text { uncertainty }\end{array}$ \\
\hline $\begin{array}{l}\text { 12. Responsible } \\
\text { production and } \\
\text { consumption }\end{array}$ & 2 and 8 & $\begin{array}{l}\text { - Strengthening of knowledge about sustainable development, na- } \\
\text { tural resource management, wise use of ecosystem goods and } \\
\text { services and efficient resource use }\end{array}$ \\
\hline 13. Climate action & 1,2 and 3 & $\begin{array}{l}\text { - Improvement of governance for climate change } \\
\text { - Inclusion of EbA measures in national policies, strategies and } \\
\text { plans }\end{array}$ \\
\hline 14. Life below water & All & $\begin{array}{l}\text { - Implementation of EbA governance concerning coastal and ma- } \\
\text { rine resources } \\
\text { - Conservation and sustainable use of ecosystems }\end{array}$ \\
\hline 15. Life on land & All & $\begin{array}{l}\text { - Implementation of EbA governance concerning coastal and ma- } \\
\text { rine resources } \\
\text { - Conservation and sustainable use of ecosystems and their } \\
\text { services }\end{array}$ \\
\hline $\begin{array}{l}\text { 16. Peace, justice and } \\
\text { strong institutions }\end{array}$ & $\begin{array}{l}3,6,7 \\
16 b\end{array}$ & $\begin{array}{l}\text { - Application of EbA principles such as equal access and justice } \\
\text { - for all } \\
\text { - Implementation of EbA governance } \\
\text { - Strengthening of institutional capacities } \\
\text { - Participation and inclusion of the interests of all actors } \\
\text { - Horizontal and vertical coordination between institutions, organi- } \\
\text { sations and stakeholders }\end{array}$ \\
\hline $\begin{array}{l}\text { 17. Partnerships for the } \\
\text { goals }\end{array}$ & 14 & $\begin{array}{l}\text { - Establishment of strategic relations between different actors to } \\
\text { improve the effectiveness and efficiency of adaptation actions } \\
\text { - Improvement of coherence between environmental policy and } \\
\text { adaptation to climate change }\end{array}$ \\
\hline
\end{tabular}

\subsubsection{Paris Agreement and Nationally Determined Contributions (NDC)}

The Paris Agreement refers to the commitments assumed by signatories to the UN Framework Convention on Climate Change (UNFCCC) at its 20th session in Paris, in 2015. This accord represents a milestone in negotiations among countries to reduce the negative effects of climate change. It not only addresses the reduction of greenhouse gases but also themes related to adaptation, which several countries also indicated as priority in their work plans. The agreement seeks to "...strengthen the global response to the threat of climate change, in the context of sustainable development and efforts to eradicate poverty". To this end, it proposes: a) Holding the increase in the global average temperature well below $2^{\circ} \mathrm{C}$ above pre-industrial levels...; b) Increasing the ability to adapt to the adverse effects of climate change and foster climate resilience and low greenhouse gas emissions development, in a manner that does not threaten food production...; and c) making finance flows consistent with a pathway towards low greenhouse gas emissions and climate-resilient development (UNFCCC, 2015).

One of the accord's most notable characteristics is that climate change adaptation is included as crucial theme for State parties. Moreover, as part of adaptation in Article 7, the Paris Agreement establishes that: 
Parties hereby establish the global goal on adaptation of enhancing adaptive capacity, strengthening resilience and reducing vulnerability to climate change with a view to contributing to sustainable development and ensuring an adequate adaptation response in the context of the temperature referred to in Article 2.

In this context, EbA governance has an important role to play in the agreement, which stresses the importance of "ensuring the integrity of all ecosystems, including oceans, and the protection of biodiversity ...". It likewise recognises the need for joint actions to improve understanding, adaptation measures and support to enhance the resilience of communities, livelihoods and ecosystems (Article 8.4) (UNFCCC, 2015).

Intended nationally determined contributions (INDCs), commitments to reduce greenhouse gases and implement climate change adaptation actions, were prepared by each country according to their own situations. These are also called 'climate action plans.'

The Paris Agreement includes a change in the legal status of these concrete action plans, transforming the INDCs into concrete action plans called Nationally Determined Contributions (NDCs). ${ }^{3}$

All eight Meso American countries have ratified the Paris Agreement, and the following paragraphs analyse EbA governance as contribution to achieve their NDCs. This is not intended to be an exhaustive study, but simply to show how EbA contributes currently and potentially to the actions proposed by these countries towards achieving the Paris Agreement. Chapter 5 (Institutions) will give some examples of the countries' work in relation to their NDCs.

\section{Mexico}

The theme of adaptation is divided into actions for three specific components: the Social Sector, EbA and Infrastructure and Production Systems. There are goals and actions explicitly dealing with EbA so its contributions are clear. One of Mexico's most important commitments is to achieve zero deforestation by 2030. However, EbA governance could contribute to the Social Sector component, specifically in relation to food security, capacity building and social participation; reduction of vulnerability by applying land-use planning tools and integrated water resource management, along with assurance that adaptation policies address capacity and social participation.

Regarding the Production Systems component, EbA governance could also contribute in influencing to incorporate adaptation criteria in public investment projects and integrating climate criteria in agricultural and livestock programmes, for example (Gobierno de México, 2015).

\section{Guatemala}

While Guatemala's NDCs do not explicitly include EbA, marine and coastal ecosystems, forests and forest resources, water resources, agriculture, livestock and food security are all priority themes for country adaptation.

EbA governance can support the implementation of climate change agendas and especially biodiversity and climate change strategy, and in strengthening policies on integrated coastal zones management. With respect to climate mitigation, forests are one of the main resources to protect and manage sustainably. EbA could contribute significantly in one of the most important instruments 
for protecting these ecosystems, the Estrategia de Restauración de Paisaje Forestal (Gobierno de Guatemala, 2015).

\section{Belize}

The country's first NDC focusses on themes related to mitigation. However, improvement of key protected areas is included among these measures, with a commitment to rehabilitate critical conservation areas through local community participation and sustainable community use of ecosystems and their services (Government of Belize, 2015). These themes are important components of $\mathrm{EbA}$.

\section{El Salvador}

Contrary to Belize, El Salvador's NDC explicitly emphasises that adaptation "es de la mayor trascendencia y prioridad para el país" but stresses actions that generate socio-economic cobenefits and adaptation-based mitigation. This approach permeates ecosystem and landscape restoration programmes and other forest-related initiatives. One of the most important adaptation programmes in El Salvador is called Paisajes Sostenibles y Resilientes al Cambio Climático, involving the rehabilitation of forested areas, the establishment of biological corridors, resilient agroforestry systems and reforestation activities in critical zones (including recharge zones). In addition, the country pledges to promote framework legislation and institutional arrangements orienting development toward climate change adaptation (Gobierno de El Salvador, 2015). While not expressly mentioned, the contribution of EbA governance is therefore important to achieve the NDCs.

\section{Honduras}

Adaptation to climate change is considered a priority to reduce vulnerability, promoting natural and production systems as well as the protection, conservation and restoration of marine, coastal and terrestrial ecosystems and their biodiversity. According to its NDCs, adaptation measures focus on water resources, risk management, agriculture, soil and food security, forests and biodiversity, coastal and marine systems, human health and infrastructure, mainly to generate hydroelectric energy (Gobierno de la Republica de Honduras, 2015). EbA can contribute to the scope of actions related to water, ecosystems and food, primarily.

\section{Nicaragua}

In several sections of the document the focus is on climate change mitigation, without taking adaptation into consideration, and is divided into two sectors: energy, and land use and change in land use. While EbA is not mentioned explicitly, many of the actions proposed for the latter sector clearly refer to actions prioritising climate change adaptation that can also form part of EbA measures. This is the case of agroecological production; more effective protection of biosphere reserves and other protected areas; restoration, conservation and wise use of wetlands; and promotion of reforestation, as well as programmes for resilient management and restoration of priority ecosystems and their services with landscape approach (Gobierno de Nicaragua, 2018). Watershed management and restoration, biodiversity protection and conservation, and restoration of forests in recharge zones are other areas considered. EbA governance will be of utmost importance in participatory preparation of the national adaptation plan, one of the priorities expressed in the document. 


\section{Costa Rica}

EbA is explicitly included in the country NDCs, which emphasise increasing forest cover throughout national territory, promoting synergies between adaptation practices and reducing emission from avoided deforestation through the consolidation of payment for environmental services (PES) and forest certification as mechanisms to achieve sustainable management and production of water sources. Other key actions include promoting and consolidating the national system of biological corridors and the national system of protected wilderness areas, while the Plan Nacional de Adaptación al Cambio Climático centres on the following components: agriculture and livestock, biodiversity, water resources, coastal zones and disaster risk reduction (Gobierno de Costa Rica, 2015). An important issue not necessarily included in the direct EbA actions of this NDC is capacity building for adaptation, one of the most important aspects of EbA governance.

\section{Panama}

Its NDCs concentrate on mitigation, specifically in two sectors: Energy, and Land Use, Land-Use Change and Silviculture, with measures that could eventually be linked and improved through EbA. In the latter sector, the emphasis is on forest ecosystems, their protection, restoration and sustainable management. With respect to mitigation, the focus is on creating biological corridors, protecting water sources and incorporating agricultural systems as part of reforestation and ecosystem restoration (Gobierno de la República de Panamá, 2015).

\subsubsection{Aichi Targets}

In 2010, signatories to the Convention on Biological Diversity (CBD) adopted the Strategic Plan for Biological Diversity 2011-2020, a framework for actions over the decade so that all countries and stakeholders safeguard biological diversity and its benefits to people.

The plan has 20 goals called the Aichi Targets, grouped in five strategic objectives. National biodiversity strategies and action plans reflect how a country intends to achieve the CBD objectives. The mission of the Strategic Plan is to:

Take effective and urgent action to halt the loss of biodiversity in order to ensure that by 2020 ecosystems are resilient and continue to provide essential services, thereby securing the planet's variety of life, and contributing to human well-being, and poverty eradication. To ensure this, pressures on biodiversity are reduced, ecosystems are restored, biological resources are sustainably used and benefits arising out of utilization of genetic resources are shared in a fair and equitable manner; adequate financial resources are provided, capacities are enhanced, biodiversity issues and values mainstreamed, appropriate policies are effectively implemented, and decision-making is based on sound science and the precautionary approach. (CBD, 2010).

EbA actions are implicit in many of the Aichi Targets. The theme of climate change adaptation is explicit only in Targets 10, 11 and 15 (mitigation); nonetheless, they all relate directly or indirectly to biodiversity, and therefore ecosystems.

An attempt to assess the contribution of EbA governance to the objectives of the Strategic Plan is shown in Table 1.2. Since the plan's original timeframe finalises after 2020, it would be interesting to revise these targets in light of climate change adaptation challenges. 


\section{Table 1.2 Linkage between EbA governance and the Aichi Targets}

\begin{tabular}{|c|c|c|}
\hline Strategic objectives & $\begin{array}{l}\text { Targets } \\
\text { with } \\
\text { direct } \\
\text { relation }\end{array}$ & Contribution of different initiatives of EbA and its governance \\
\hline $\begin{array}{l}\text { A. Address the } \\
\text { underlying causes } \\
\text { of biodiversity loss } \\
\text { by incorporating } \\
\text { biodiversity in all } \\
\text { spheres of government } \\
\text { and society }\end{array}$ & 1 & $\begin{array}{l}\text { - Emphasis on the value of biodiversity as part of natural capital } \\
\text { - Reduction of vulnerability } \\
\text { - Incorporation of biodiversity conservation and political advocacy }\end{array}$ \\
\hline $\begin{array}{l}\text { B. Reduce direct } \\
\text { pressures on } \\
\text { biodiversity and } \\
\text { promote sustainable use }\end{array}$ & $5,7,10$ & $\begin{array}{l}\text { - Restoration of degraded ecosystems } \\
\text { - Implementation of ecosystem-based approaches for climate } \\
\text { change adaptation } \\
\text { - Reduction of impacts on vulnerable ecosystems } \\
\text { - Influencing of decision making to reduce threats to biodiversity } \\
\text { integrity }\end{array}$ \\
\hline $\begin{array}{l}\text { C. Improve the } \\
\text { status of biodiversity } \\
\text { by safeguarding } \\
\text { ecosystems, species } \\
\text { and genetic diversity }\end{array}$ & 11 & $\begin{array}{l}\text { Effective application of conservation measures for ecosystem } \\
\text { services in protected areas }\end{array}$ \\
\hline $\begin{array}{l}\text { D. Enhance the benefits } \\
\text { to all from biodiversity } \\
\text { and ecosystem services }\end{array}$ & $14,15,16$ & $\begin{array}{l}\text { - Fair and equitable sharing of benefits to human populations } \\
\text { - Maintenance and restoration of the integrity of ecosystem } \\
\text { services (and ecosystem biodiversity) }\end{array}$ \\
\hline $\begin{array}{l}\text { E. Enhance } \\
\text { implementation through } \\
\text { participatory planning, } \\
\text { knowledge management } \\
\text { and capacity building }\end{array}$ & $17,18,19$ & $\begin{array}{l}\text { - Implementation of policy and legal instruments } \\
\text { - Participation of all stakeholders } \\
\text { - Knowledge management (including traditional and scientific) } \\
\text { - Strengthening of adaptation capacities }\end{array}$ \\
\hline
\end{tabular}

\subsubsection{Nagoya Protocol}

The third objective of the Convention on Biological Diversity concerns equitable access to genetic resources (which are part of biodiversity and therefore also of ecosystems' natural capital), and specifically states:

... the fair and equitable sharing of the benefits arising from the utilization of genetic resources, including by appropriate access to genetic resources and by appropriate transfer of relevant technologies, taking into account all rights over those resources and to technologies, and by appropriate funding. (CBD, 1992).

To give greater thrust to this objective, an international regimen was negotiated to promote and safeguard such fair and equitable sharing of benefits, resulting in the 2010 adoption of the Nagoya Protocol on Access to Genetic Resources and the Fair and Equitable Sharing of Benefits Arising from their Utilization to the Convention on Biological Diversity (Nagoya Protocol). The objective of this protocol is: 
... the fair and equitable sharing of the benefits arising from the utilization of genetic resources, including by appropriate access to genetic resources and by appropriate transfer of relevant technologies, taking into account all rights over these resources and to technologies, and by appropriate initiation, thereby contributing to the conservation of biological diversity and the sustainable use of its components. (CBD, 2011).

What makes the Nagoya Protocol so important? A fundamental component of EbA governance is the fair and equitable sharing of benefits and respect for stakeholders' rights over ecosystem resources (i.e. genetic resources as part of ecosystems), and thus the provisions of the Nagoya Protocol are taken into account in all EbA policies, laws and practices carried out at different levels and with different stakeholders.

\subsubsection{Sendai Framework for Disaster Risk Reduction 2015-2030}

Disaster risk is increasing due to the negative impacts of climate change, and in Meso America these are closely related to hydrometeorological events. While EbA helps reduce the vulnerability of populations and ecosystems to climate change, it can also contribute indirectly to disaster risk reduction, strengthening natural infrastructure (ecosystem integrity) and populations' capacities to cope with these events. Another nature-based solution specifically applicable to disaster is Ecosystem-based Disaster Risk Reduction (Eco-DRR), which also makes use of ecosystem services to help people lower disaster risk (CBD, 2018). The two types of nature-based solutions are closely related and contribute directly or indirectly to disaster risk reduction.

The Sendai Framework for Disaster Risk Reduction 2015-2030 was adopted at the third UN World Conference on Disaster Risk Reduction held in Sendai, Japan, on 18 March 2015. The aim of the Sendai Framework is "the substantial reduction of disaster risk and losses in lives, livelihoods and health and in the economic, physical, social, cultural and environmental assets of persons, businesses, communities and countries." The Framework considers it vital to "plan for and reduce disaster risk in order to more effectively protect persons, communities and countries, their livelihoods, health, cultural heritage, socioeconomic assets and ecosystems, and thus strengthen their resilience" (UNISDR 2015).

Concerning this point, it is crucial to emphasise that the CBD is now clearly linked with the Sendai Framework through its "Voluntary Guidelines for the design and effective implementation of ecosystem-based approaches to climate change adaptation and disaster risk reduction" (CBD, 2018). The CBD, UNFCCC and UN Office for Disaster Risk Reduction (UNDRR) collaborated in the joint preparation of these documents, which identify lessons learnt as gaps and challenges for EbA implementation and disaster risk reduction.

Table 1.3 summarises the contribution of EbA governance to the priorities of the Sendai Framework for Disaster Risk Reduction. 


\section{Table 1.3 Linkage between EbA governance and the Sendai Framework}

\begin{tabular}{|c|c|}
\hline Priorities & $\begin{array}{c}\text { Contribution of different EbA initiatives and } \\
\text { their governance }\end{array}$ \\
\hline 1. Understand disaster risk & $\begin{array}{l}\text { - Generation of information about zones vulnerab- } \\
\text { le to risk and the potential of their ecosystems to } \\
\text { reduce it } \\
\text { - Strengthening of community management and } \\
\text { adaptation capacities }\end{array}$ \\
\hline $\begin{array}{l}\text { 2. Strengthen governance of disaster risk to manage } \\
\text { that risk }\end{array}$ & $\begin{array}{l}\text { Strengthening of governance for EbA in different } \\
\text { geographical contexts and levels, from local to } \\
\text { transboundary }\end{array}$ \\
\hline 3. Invest in disaster risk reduction for resilience & $\begin{array}{l}\text { - Maintenance and improvement of ecosystem } \\
\text { functions } \\
\text { - Strengthening of ecosystem and community } \\
\text { resilience } \\
\text { - Linkage between sustainable livelihoods, vulne- } \\
\text { rability and ecosystem services in broader risk } \\
\text { reduction strategies } \\
\text { - Incorporation of disaster risk reduction measures } \\
\text { in EbA measures }\end{array}$ \\
\hline $\begin{array}{l}\text { 4. Increase preparedness for cases of disaster to } \\
\text { respond effectively and 'build back better' in } \\
\text { recovery, rehabilitation and reconstruction }\end{array}$ & $\begin{array}{l}\text { - Fostering of preventive approaches and capacity } \\
\text { strengthening }\end{array}$ \\
\hline
\end{tabular}

\subsection{Challenges and opportunities for EbA governance}

This chapter has analysed concepts about EbA and governance for adaptation to climate change, and other notions intimately related to these two. Indeed, for EbA to be sustainable over time functional governance structures are necessary from the standpoint of policies, legal frames and processes. Adaptation to climate change is itself a complex issue calling for a range of disciplines and actors to cope with the accompanying uncertainties. While not exclusively an environmental matter, it requires urgent actions to ensure that ecosystems continue providing indispensable goods and services for human survival.

The time horizon of processes is not always taken into proper consideration. Yes, EbA measures are urgent, but their effects cannot be framed within a two- or three-year period. Planning must be aligned with the inherent processes of nature, biodiversity and ecosystem functionality, where one could more realistically speak of decades, not years. Training and capacity building in adaptation for stakeholders and institutions alike are long-term processes and require continuity to be effective. How can planning be done with a long-range vision while also responding to the urgency imposed by the negative impacts of climate change? How is that impact measured, and what type of monitoring and evaluation systems are needed? EbA processes and initiatives are still quite young, and more experience and capacities are necessary to demonstrate their positive effects.

Hence, there is a need for knowledge management that is coherent, continuous, innovative, that contemplates traditional knowledge and is scientifically backed to demonstrate that EbA works. In other words, it is necessary to create the evidence that is so urgently needed to show diverse actors, mainly those in charge of decisions and the players with economic power who generally 
influence those decisions at a political level. It is imperative to have facts and figures that can justify and convince decision makers and the private sector that nature-based solutions, particularly EbA, will eventually provide greater economic benefits in the long run. Ecosystem valuation is crucial to be able to make this case. New metrics are needed that go beyond income and economic power, given that there are other components of human well-being (UNEP, 2011).

EbA governance faces the same challenges as natural resource governance, but with the added factor of climate uncertainty. There are still several gaps (especially in terms of legal and institutional coordination instruments) that must be resolved so that government arrangements for adaptation are functional and sustainable over time. Regulatory frameworks require time to become consolidated and enable the conditions necessary for implementing EbA measures. There is a need for clear and decisive policies, plans and guidelines that are at least 'neutral' (do no harm) when related to naturebased solutions or natural solutions, so that these may be implemented (WWAP, 2018). Ideally, all the necessary elements would be included in planning, execution, monitoring and improvement of EbA measures in a context of good governance for climate change. However, it is vital to go ahead building this under the conditions available while identifying strategic partners and human and financial resources from different sources to take advantage of favourable conditions for scaling, respecting and supporting the poorest sectors.

Funding for EbA governance is an additional challenge. Nevertheless, options must be sought for mobilising funds from national budget lines (for which a legal, solid and clear framework is needed), as well as from the private sector and businesses that depend on ecosystem services for their economic activities.

While there are international financing sources for climate change adaptation actions, processes to access these resources are generally cumbersome, take a great deal of time and require well-consolidated and well-defined institutional capacities. These conditions are not the norm in 'developing' countries, so such international financing sources are still hard to reach for many countries of Mesoamerica and other developing regions. 



\section{Capacities*}

\section{Marta Pérez de Madrid Utrilla}

\section{$2.1 \quad$ Introduction}

Adaptation to climate change poses an unprecedented challenge for society and its governance arrangements. The next decades will witness other global changes (inter alia, loss of biodiversity, decline of food and water security and rising populations in cities), coupled with the uncertainty associated with climate change. As with ecosystems and society itself, governance arrangements must adapt. Adjustments will have to be made at all levels, from local to national, global and transboundary, and at each level governance capacities will be required to face these changes.

Top-down governance arrangements, or those emanating from the highest levels down to communities, do not normally respond at the scale and complexity of socio-environmental systems and speed of climate change (Cumming, 2006), while adaptation processes are specific to local contexts. This will necessitate direct linkage and coordination with local players and their context, a process not always facilitated through centralised governance arrangements. Furthermore, the consequences of climate change transcend the scale of States, as in the case of shared ecosystems such as transboundary basins, offering ample opportunities to promote $\mathrm{EbA}$ and its governance to the benefit of the States and communities in border areas.

Changes will be necessary in all State spheres, at multiple levels and by all societal actors, since governance will require complex adjustments and new arrangements of an institutional nature (IPCC, 2014). Indeed, institutions and their own adaptation capacity will play a vital role in empowering society so that adaptation can be carried out effectively (Gupta et al., 2010)

For all the above, one thing is certain: not all countries have the same capacity to make such adjustments. The UNFCCC Paris Agreement recognises that developing countries have less capacity to implement adaptation measures and take actions to cope with climate change. To facilitate the attainment of these measures by those countries, the Convention establishes a framework that follows up on capacity building and promotes collaboration among States for this purpose.

This raises several questions, such as:

a) What should be understood by capacity?

b) What capacities will be needed by society and its institutions to promote EbA?

c) Who - individuals or institutions - requires such capacity/capacities?

d) What capacities are needed in EbA governance?

Apart from these questions, certain closely related concepts must be clarified, such as 'adaptive capacity' or 'capacity for adaptation,' 'EbA governance' and 'EbA governance capacity.'

Following the logic sequence of the questions posed above, this chapter aims to describe and analyse capacities of EbA governance, in other words, the specific capacities necessary to govern adaptation processes utilising ecosystems and biodiversity.

\footnotetext{
* This chapter contains substantial contributions from Rocío Córdoba Muñoz and Alejandro Iza.
} 
Through a deductive analysis of IUCN's work experience in Meso America, the intent is to identify existing (or non-existing) capacities that influence governance and support the implementation of EbA.

\subsection{Capacity, governance and adaptation}

The concept of the adaptive capacity of communities, institutions and countries has been analysed in depth in recent years, while adaptive governance has been the subject of vast investigation during the past decade. It is therefore relevant to examine these two concepts and their interrelation so that the capacities necessary for EbA governance can be identified and analysed.

Adaptive capacity can be understood as the

...combinación de fortalezas, atributos y recursos (humanos, institucionales y de infraestructura entre otros) que posee una persona, comunidad, sociedad u organisación que los faculta para realizar acciones que puedan reducer los impactos adversos del cambio climático y 'recuperarse' de ellos (...combination of strengths, attributes and resources [human, institutional and infrastructure, among others] possessed by a person, community, society or organisation enabling them to take actions that can reduce the adverse impacts of climate change and 'recover' from them) (Reid et al., 2017).

This capacity includes the resources and legal authority necessary to respond to climate change as reflection of a governance system that adjusts to uncertainty. It also includes capacity of participation, wherein the people affected have the right, obligation and resources to play a role in decision making.

The ability to adapt to climate change effects is not static; it can be improved (or worsened) if the elements that influence it are changed or conditioned. These elements are, among others, economic resources, information, technology, infrastructure, institutions or individual abilities (Smit \& Pilifosova, 2001).

Capacity is predicated on multiple levels, from individual to transboundary. Interaction between the different components of the State-society relation must also be taken into account to define that capacity, in the sense that the greater the capacity of the State and its institutions, the greater the adaptive capacity of civil society (Gupta et al., 2010) or private sector, as long as the State utilises its capacities to empower society and provide the necessary spaces to learn and resolve some of the main problems arising from climate change. In turn, a society with greater capacities pushes State institutions to adapt more quickly.

EbA governance recognises that there are multiple players and interactions between the State, civil society and private sector, and that decisions usually require interaction between different scales and levels, possibly extending beyond State borders given that ecosystems do not respect political borders.

EbA governance signifies promoting policies, laws, institutions and processes that facilitate adaptation and decision making in a context of uncertainty. This requires learning and coordination among multiple actors and levels so that sustainable conservation practices and ecosystem restoration may be implemented and scaled to enhance the resilience of both human beings and the ecosystems, themselves. Transforming governance with this new vision is vital, not only to implement nature-based solutions for climate change, but also to achieve the Sustainable Development Goals of Agenda 2030 (Martínez \& Luna, 2019). 
Hence, suitable governance arrangements are required if EbA is to be effective and scaled up.

In relation to societal actors, EbA governance capacity enables the development and implementation of policies, laws, institutions and processes, such as the facilitation of decision making at different scales to promote sustainable use of biodiversity and ecosystem services as a means to address climate change.

Honduras's Plan Nacional de Adaptación offers an example of such capacities. In developing this national adaptation plan, the environmental ministry (MiAmbiente) included EbA as one of the main components. Operationalising that inclusion first required training at national level, the organisation of participation spaces and consensus building, as well as demonstration experiences. MiAmbiente has collective and individual leadership capacities to advise on the plan's design and preparation, carry out a participatory process linking actors, mobilise funds and ultimately, promote the necessary governance adjustments for the plan's implementation as a mechanism of interinstitutional coordination.

\subsection{Actors, skills and capacities for EbA governance}

\subsubsection{Actors}

EbA entails complex processes of adjustment in the multiple sectors and spheres where different players interact. Societal actors connected with natural resource management and use, agriculture, health, cities, businesses and the economy as a whole will need to adapt to, promote and internalise the necessary governance adjustments. This includes women and men, youth and adults, farmers and fishers, engineers and builders, merchants, businesspeople, corporations and others. As for the public sector, this comprises all State powers, executive, legislative and judicial alike, that must design, decide and incorporate participatory, ecosystemic and more flexible governance models, where appropriate.

From a more global perspective, both developed nations and, more urgently, developing countries need to have and adapt the necessary capacities to improve governance as a means of driving EbA. This should not be interpreted as meaning that only the most vulnerable groups require adaptation capacities, albeit greater efforts are required in the more vulnerable countries and populations. Notwithstanding, it is important to underscore that unless EbA governance capacities are developed across the entire multiplicity of players involved, effective EbA implementation is compromised.

The development of Costa Rica's Plan Nacional de Cambio Climático, adopted in 2018, serves as illustration. To define the priorities of that instrument, the government drove a multisectoral and multi-tiered process that included the formation of sector panels (with governmental representation), as well as the creation of an advisory drafting committee with representation of experts from the academic sector, NGOs and the government. Multiple actors were convened from the environmental, agricultural, tourism and infrastructure sectors. The policy draft was submitted for consultation to elicit observations from civil society using social networks as well as workshops organised for this purpose. Given Costa Rica's experience in nature-based solutions, the policy included an EbA component. 


\subsubsection{Skills}

As individuals, people need to have the skills needed to conduct suitable transformation and governance processes for promoting EbA.

The skills necessary for the fourth industrial revolution, as described by the World Economic Forum (WEF, 2016), are also valid for adaptation processes. According to the report, these skills are: resolution of complex problems, critical thinking, creativity, management of people, coordination, emotional intelligence, judgment and decision making, service orientation, negotiation and cognitive flexibility.

IUCN's experience in climate change adaptation in Meso America indicates that coordination, negotiation, critical thinking and resolution of complex problems are indispensable skills to forge effective governance arrangements for adaptation.

In the Paz River basin, in El Salvador, women have demonstrated leadership, coordination and negotiation skills allowing them to be an effective part of the Garita Palmera mangrove surveillance committee and carry out restoration activities that involve neighbours and local NGOs, as well as working with the media to shed light on local problems (Pérez de Madrid, 2019). This was accomplished through participation in a capacity-building programme on climate change, communication and leadership in which women strengthened their technical knowledge, increased their self-esteem and identified their own leadership for action (Narvaez Marulanda, 2018). The next step in this ongoing process is scaling up the experiences through entities such as the microbasin committee, with broader participation of actors. The goal is co-management of the Manglar Garita Palmera protected area together with the Salvadoran environmental ministry.

\subsubsection{Capacities}

Capacities for adaptation to climate change can be classified as follows:

- social capacity

- political/legal capacity

- institutional capacity

- technological capacity, including knowledge management

- financial capacity

- innovation capacity

- scaling capacity

Because EbA is so new, innovation is not included, but the capacity to innovate should also be weighed.

Each capacity as it relates to EbA is described below.

1. Social capacity: Social capacity starts with the intra-community ties established among members of a community and encompassing families, friends, social groups or associations. At a higher level it refers to the degree of interaction among public entities, associations and other organised ways of coming together around certain interests. Examples are farming cooperatives, water boards, professional associations, women's associations, cultural associations, trade unions, 
business associations and political parties. To implement EbA measures effectively local, national and sectoral interests must be articulated.

In Chiapas, Mexico, for example, communities have the ejido structure, which groups communal owners of land and promotes a space of dialogue for the conservation of forests. In Guatemala and El Salvador, Consejos Comunitarios de Desarrollo (COCODES) (community development councils) and Asociaciones de Desarrollo Comunitario (ADESCOs) (community development associations) permit dialogue, consensus, prioritising adaptation measures and linkage between sub-national and national institutions.

2. Political/legal capacity: The purpose of climate change adaptation policy is to plan the climate adjustment process based on available information about the climate threats and risks that society and ecosystems face. Ideally, adaptation policy should be concretised in a framework instrument that establishes overall directives for all sectors in the short, medium and long term. Implemented through strategies, this instrument can translate into actions, criteria and indicators. A policy can be finetuned in different sectors with their own adaptation strategies, and together with an adaptation policy proper, contributes to the implementation of concrete actions to protect and restore ecosystems, reduce vulnerability and enhance social resilience. For its part, a law must define the institutions responsible for coordinating adaptation in its multiple dimensions, distribute competencies among different sectors and government levels and provide mechanisms to manage and resolve conflicts between different administrative boundaries or when different institutions have overlapping competencies. Ultimately, the function of law is to provide a stable, clear and mandatory policy framework and institutionalise the arrangements necessary for EbA.

The object of Peru's Ley Marco sobre Cambio Climático (Ley No. 30754), announced in 2018, is, inter alia, to establish principles, approaches and general provisions to coordinate, design, execute and publicise public policies for comprehensive, participatory and transparent management of climate change adaptation measures reducing vulnerability. The principle of climate governance, included in the law, is aimed at forging processes and public policies on adaptation (and mitigation) with the effective participation of all public and private actors in decision making, conflict management and consensus building, based on clearly defined responsibilities, goals and objectives defined at all levels of government. This law creates an institutional framework for comprehensive management of climate change and the instruments required for it, as well as adaptation and mitigation measures. It also contains provisions on transparency, access to information and citizen participation, education, science and technology, innovation and financing, integrating EbA as part of that management.

The Peruvian environmental ministry explained that this framework law was necessary, among other things, to:

- Reinforce the national authority in regard to climate policy, for which it establishes, guides, directs, facilitates, monitors and promotes climate change action;

- Encourage all country entities at national, regional and local level to define, prioritise and report concrete adaptation and mitigation actions;

- Drive the inclusion of adaptation and mitigation actions in management instruments, development planning and sector investment;

- Contribute to the execution of the Estrategia Nacional ante el Cambio Climático, Nationally Determined Contributions, management of sector and territorial planning instruments and water resources investments; and 
- Create a permanent, high-level, multisector commission in the frame of current regulations, which will update the Nationally Determined Contributions ${ }^{1}$

3. Institutional capacity: In the context of uncertainty deriving from climate change, institutions need to evolve and become more flexible, where appropriate, to address the changes and needs of multiple actors in society and their interrelations. Such institutions are those that: 1) have the capacity to encourage the involvement of different perspectives, players and solutions; 2) can enable social actors to learn from their institutions and continuously improve them; 3) allow and motivate social actors to adjust their behaviour; 4) establish the conditions necessary to facilitate leaderships; 5) can mobilise resources to implement adaptation measures and 6) support effective governance.

In the example of the Honduran national adaptation plan cited in the previous section, MiAmbiente formed an interinstitutional adaptation committee whose function is to ensure interinstitutional coordination for the plan, its financial sustainability, political will and technical and logistical resources, as well as formal monitoring of advances. This committee represents an opportunity for dialogue, learning and participation in the plan's implementation.

4. Technological capacity: Technology is increasingly important for EbA governance in that it allows, inter alia, the systematisation of information, thus facilitating timely communication and societal participation. To the extent that EbA seeks to implement measures for the conservation, restoration and sustainable management of ecosystems, a State institution or other entity such as basin authority must make use of technology and knowledge management to adopt and agree on decisions, and inform society about improving the implementation of EbA measures.

In 2018, Costa Rica launched its Sistema Nacional de Métrica para el Cambio Climático (SINAMECC) (national system of climate change metrics), a mechanism that makes use of information technologies to comply with the measurement, reporting and verification requirements of the Enhanced Transparency Framework for Action and Support of the UNFCCC and Paris Agreement. Working together, the Dirección de Cambio Climático under the Ministerio de Ambiente y Energía (MINAE) in coordination with the Instituto Nacional de Estadística y Censos (INEC), Instituto Meteorológico Nacional (IMN) and Centro Nacional de Información Geoambiental, (CENIGA) generate open-access information through software that facilitates decision making based on data and reporting at both national and international level ${ }^{2}$.

5. Financial capacity: The capacity of institutions or other bodies to channel and invest resources for implementing EbA. Such capacity should contemplate specific lines of credit at local, regional or State level; transparent financial management of local and national institutions; and mechanisms and instruments for proper and equitable distribution of those funds.

In Costa Rica, Mexico and Guatemala, conservation actions also prioritised as adaptation measures have been possible thanks to payment for environmental services administered by different State institutions.

In the ejidos (a system of communal land tenure) of La Azteca and Alpujarras in the Cahoacán river basin, farmers often need to carry out soil conservation actions to prevent erosion caused by the intense rains occurring in this region of southern Mexico. The machinery needed for these tasks is costly and frequently inaccessible to these rural communities, so conservation practices (such as 
trenches, infiltration ditches and tree planting) are performed manually. To successfully carry out these actions, it was necessary to intensify local empowerment, coordinate among different entities, raise awareness with local communities and prioritise certain actions based on an assessment of community vulnerability. Financing was obtained through State funds from the Comisión Nacional Forestal in three programmes: payment for environmental services, comprehensive restoration of high-priority zones and environmental compensation for land-use changes in forest areas (Arrevillaga \& López, 2019). The process itself and its multiple results are the outcome of mobilising social, institutional and financial capacity facilitated by public entities.

6. Innovation capacity: Innovation makes it possible to identify solutions for new problems or new solutions for pre-existing problems. Solutions for climate change problems must be more efficient, participatory, long range, and contemplate climate variability and climate scenarios. In the business world, innovation is predicated on the design of new services, products or processes in the context of climate change. For example, corporations need to adapt their operations (production, storage and distribution) in adjusting to changing climate conditions that affect the availability of resources such as water (Newborne \& Dalton, 2016). However, innovation should not be limited to the private sphere, since the public sector can help countries identify means for improving their position in terms of vulnerability by moving from a short-term outlook to a long-range vision. According to the OECD, to facilitate innovation countries must promote the development of a knowledge economy and implementation of research, development and innovation policies, as well as channel private sector investment.

In Meso America, where agriculture is predominant, innovation in production methods (such as regenerative agriculture, soil conservation, agrosilvopastoral systems, sustainable subsistence farming or landscape restoration) offer great potential for EbA. Honduras, El Salvador, Guatemala and Costa Rica have assessed landscape restoration opportunities through a process led by Mesas Nacionales de Restoración, an interinstitutional space of consensus between the private sector and producers, that analyses how to scale up more sustainable agricultural and livestock production models.

7. Scaling capacity: The capacities needed to promote the multiplication of EbA measures between and within different levels (vertical and horizontal). Some of the most important elements to improve scaling capacity include the following:

1. demonstration sites,

2. governance enabling stakeholder ownership,

3. systematisation of experiences, monitoring and evaluation of results and lessons learnt,

4. participatory methodologies to replicate actions,

5. spaces for learning and strengthening capacities,

6. organisation of events to share and reflect on those experiences,

7. communication and publicising of the outcomes of experiences,

8. policies and laws that recognise, establish and promote EbA and

9. financing.

Figure 2.1 illustrates the exponential effect of different elements of scaling capacity through learning or demonstration sites that could be a starting point for building scaling capacity. It is at these sites where the groundwork can be laid to design and implement EbA measures and generate evidence. 
Local actors appropriate adaptation measures and reflect or incorporate them in management instruments and mechanisms. These actors' empowerment occurs in a context where they have access to information and technical advice to implement EbA actions, and can also make decisions based on that information. Learning spaces make it possible to share experiences with other communities that have similar livelihoods and suffer the impacts of climate change in a comparatively similar way. These exchanges have a positive influence and motivate actors to implement measures even when they may distrust them. Communicating results through EbA-generated evidence, as well as monitoring and evaluating those results, is vital to make them known more widely, including to those in charge of decisions. Governance structures can be consolidated through policies and laws establishing the rules of the game for all players and sectors involved.

Finally, it should be stressed that financing is indispensable to ensure actions are implemented and scaled and guarantee that the most vulnerable communities and sites have the resources necessary to access the benefits derived from EbA.

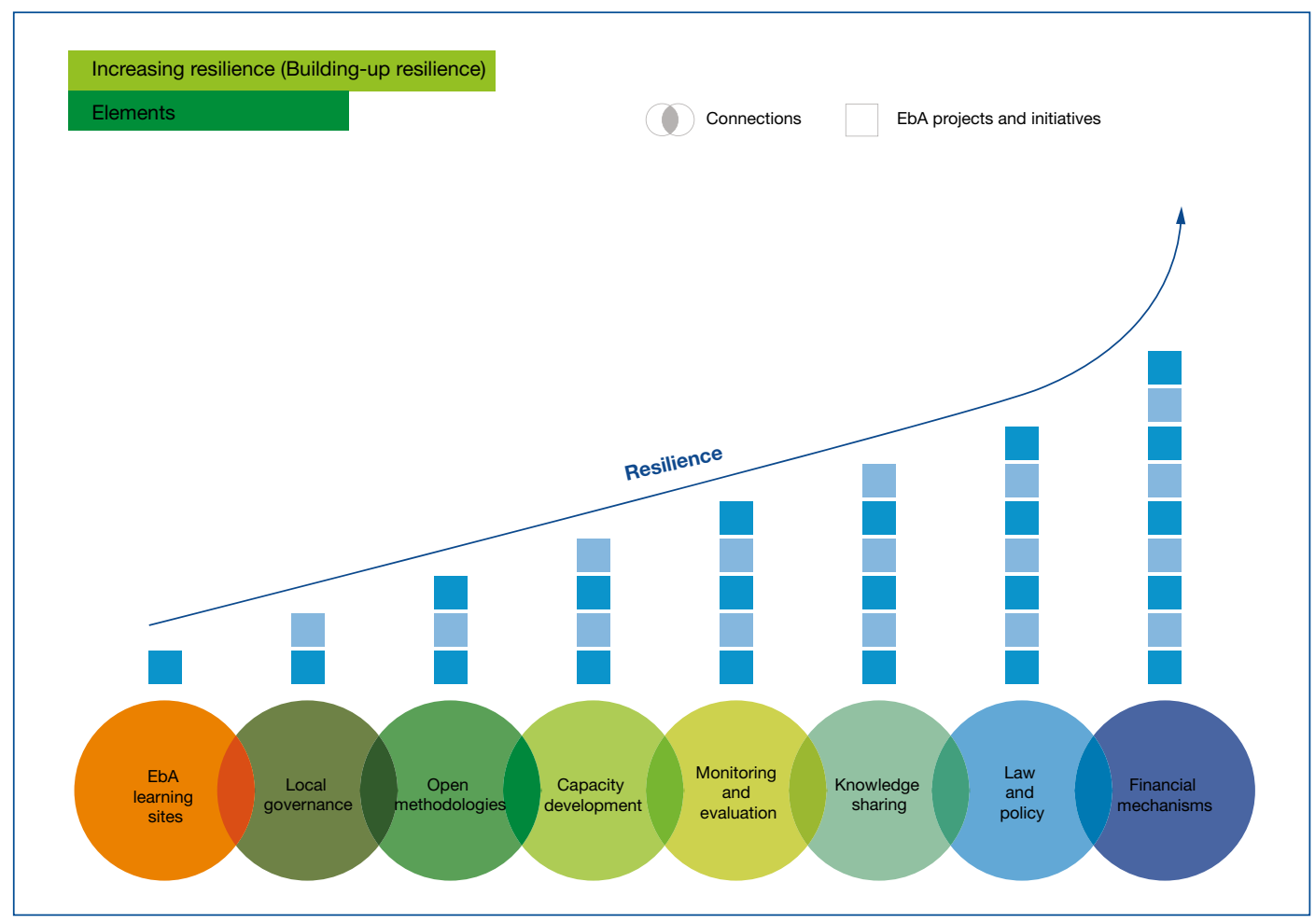

Figure 2.1 Elements of the EbA scaling process

In the department of San Marcos, Guatemala, several communities have worked with organisations like IUCN to improve the environment. The many efforts promoted include strengthening organisational capacities through structures such as basin councils, microbasin committees and others necessary to conserve forest where rivers and springs arise (Pérez de Madrid \& Navarro, 2019). One of those microbasin committees, in Esquichá (municipality of Tacaná), brought together 18 communities in initiatives to improve water, forest and soil management. Thanks to the results and benefits derived 
through the committee's work, added to its influencing capacity, in 2016 the Ministerio de Ambiente y Recursos Naturales (MARN) recognised the water user committees and established a climate change adaptation project in the Guatemalan highlands (Proyecto Fortalecimiento de la Resiliencia de los Medios de Vida ante el Cambio Climático en las Cuencas Altas del Altiplano de Guatemala). This project set up a fund to finance adaptation measures, administering public funding from several sources (Instituto Nacional de Bosques, Ministerio de Agricultura y Ganadería y Alimentación, Instituto de Sismología, Vulcanología e Hidrología and MARN).

\subsection{Analysis of EbA governance capacities}

\subsubsection{EbA governance capacities}

Effective EbA governance requires stakeholder capacity building at multiple levels, namely local, subnational, national and transboundary. These capacities or their strengthening must be differentiated according to the level and context in which they are required.

Table 2.1 identifies the essential elements of EbA governance capacities, distinguishing between stakeholder groups and levels. 


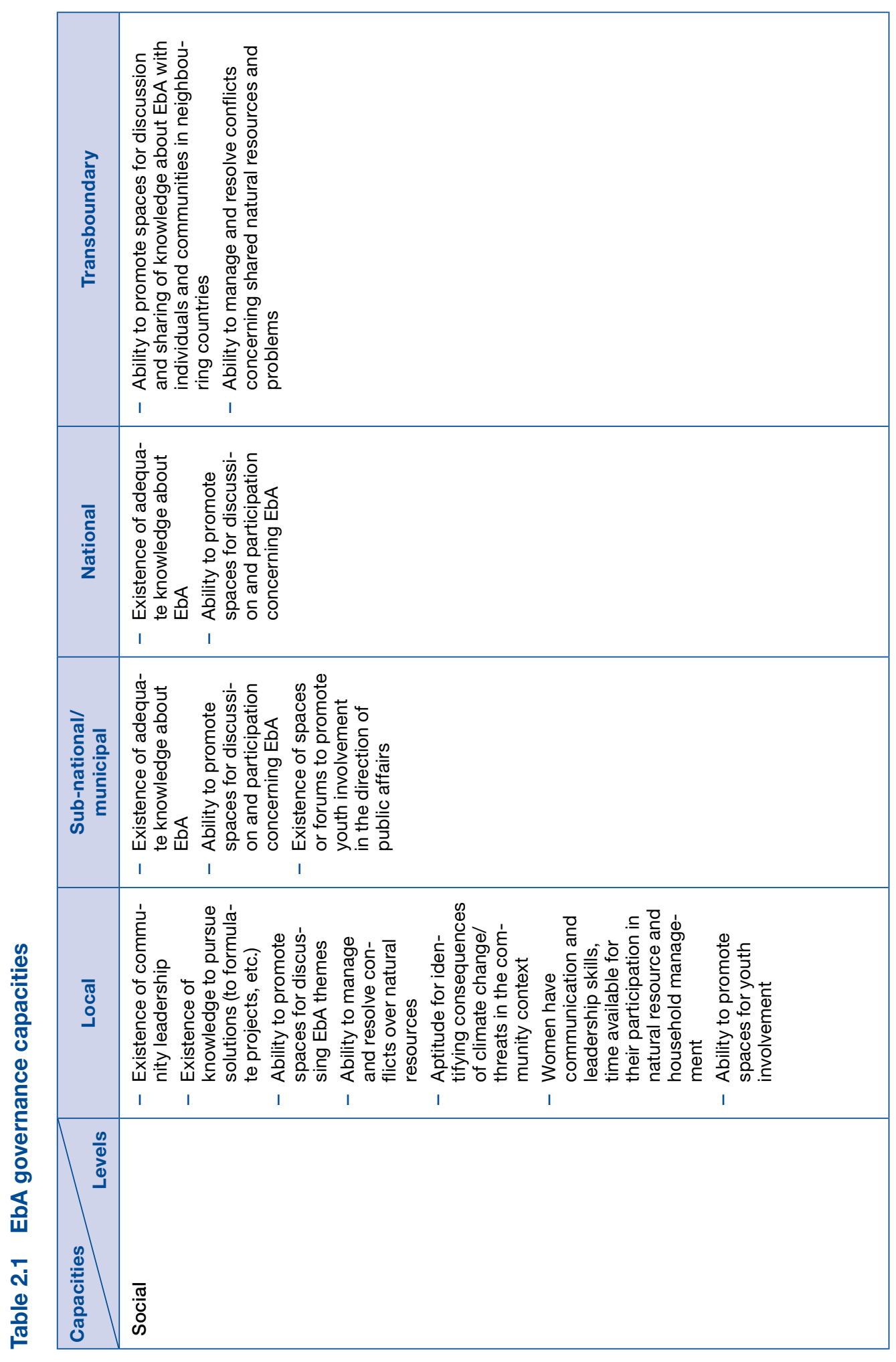




\begin{tabular}{|c|c|c|}
\hline 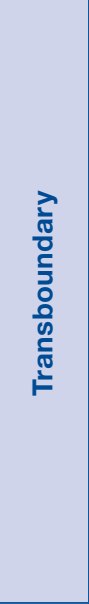 & 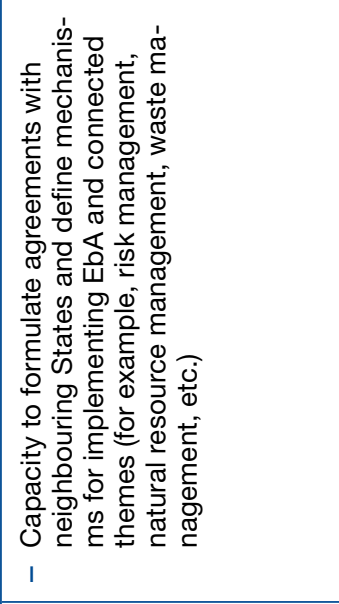 & 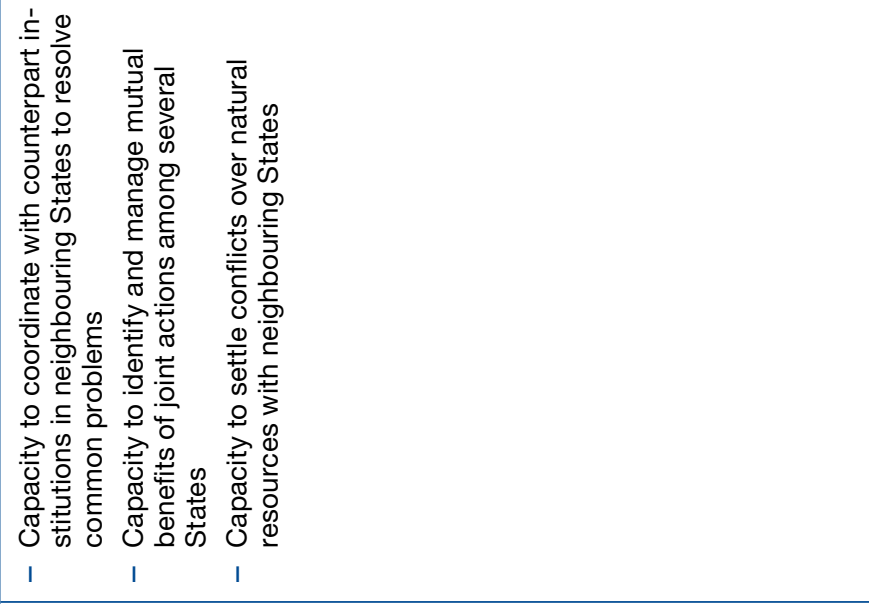 \\
\hline $\begin{array}{l}\overline{\widetilde{J}} \\
\stackrel{0}{0} \\
\overline{\mathbb{T}}\end{array}$ & 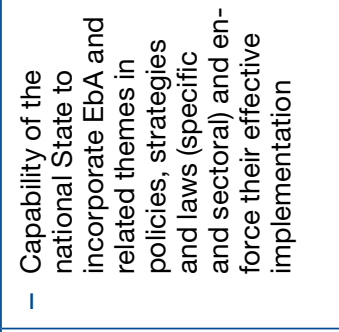 & 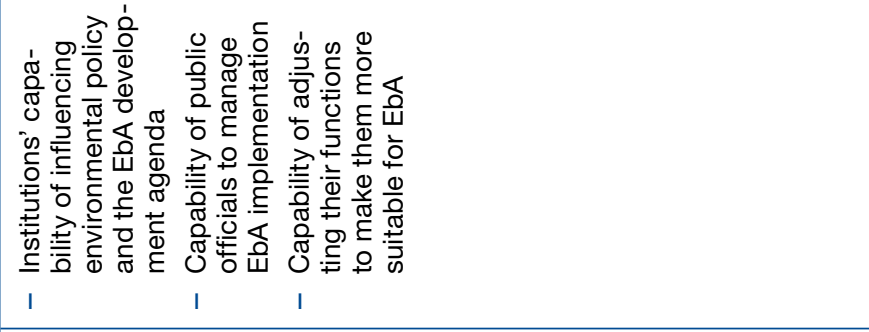 \\
\hline 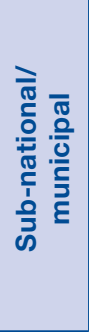 & 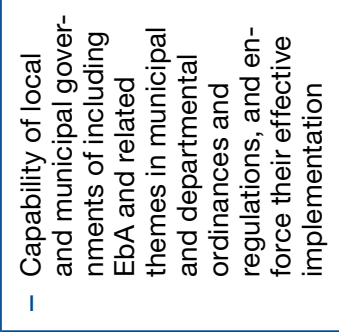 & 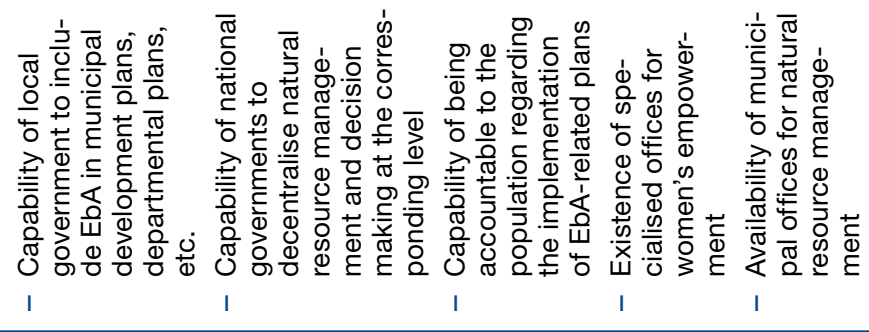 \\
\hline 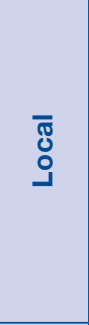 & 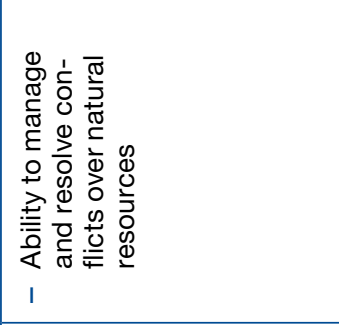 & 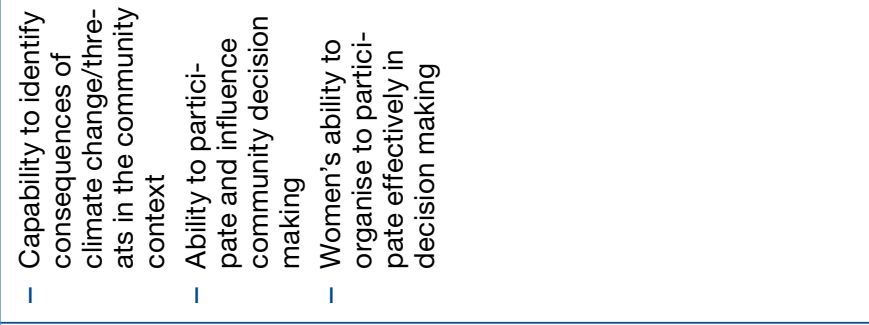 \\
\hline 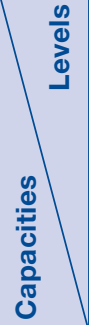 & 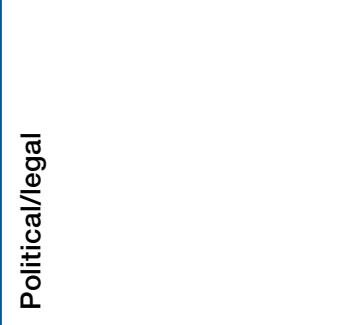 & 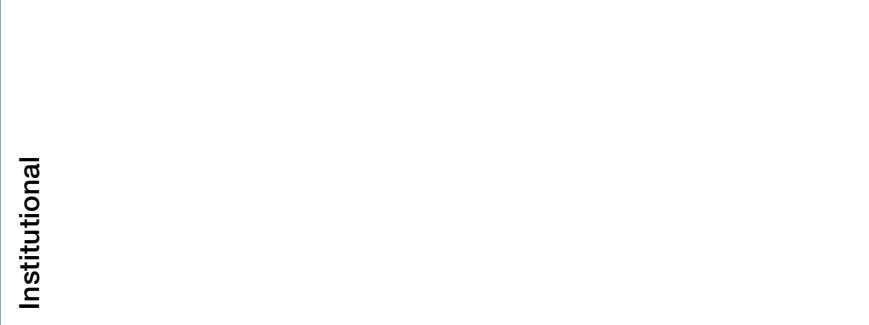 \\
\hline
\end{tabular}




\begin{tabular}{|c|c|c|c|}
\hline 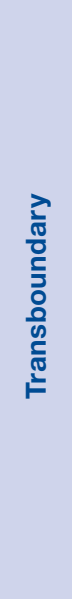 & 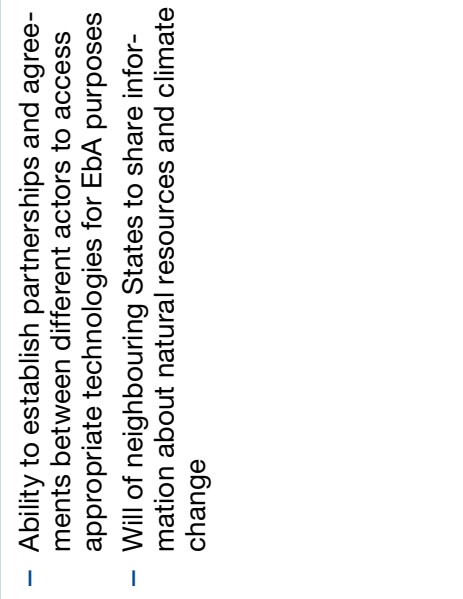 & 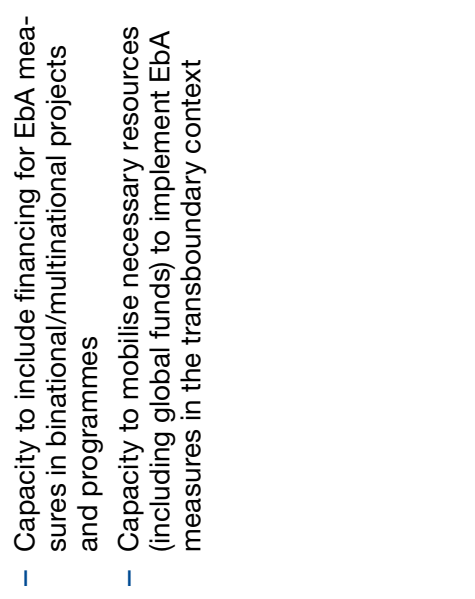 & 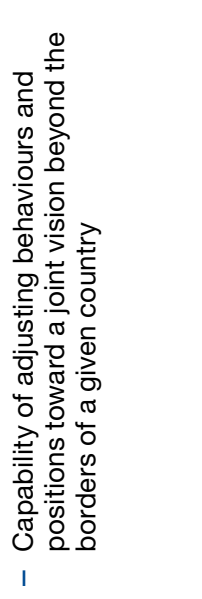 \\
\hline 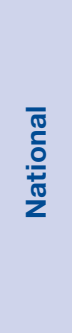 & 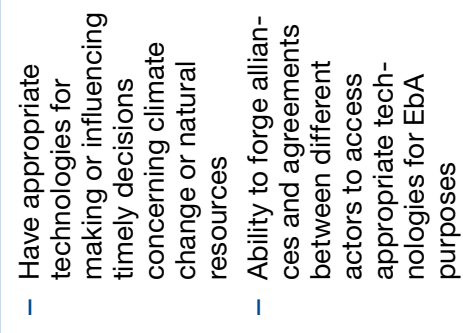 & 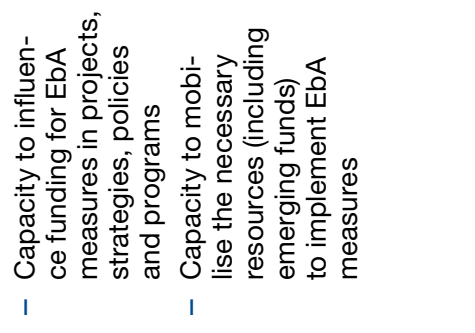 & 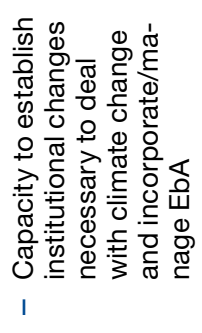 \\
\hline 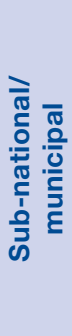 & 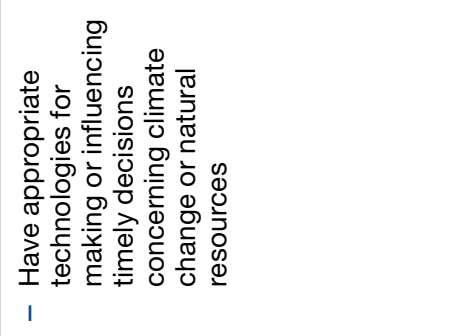 & 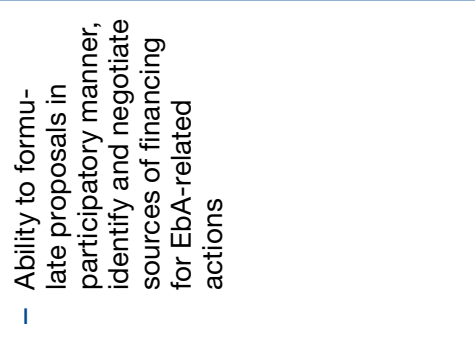 & 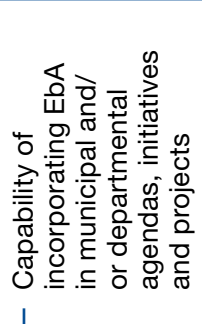 \\
\hline $\begin{array}{l}\overline{\mathbb{J}} \\
\text { O }\end{array}$ & 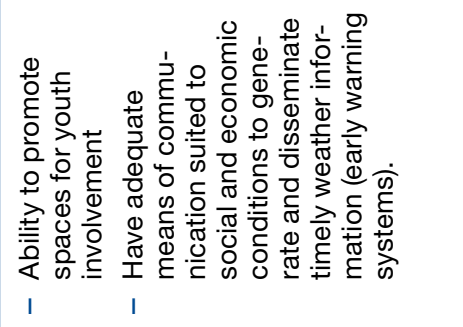 & 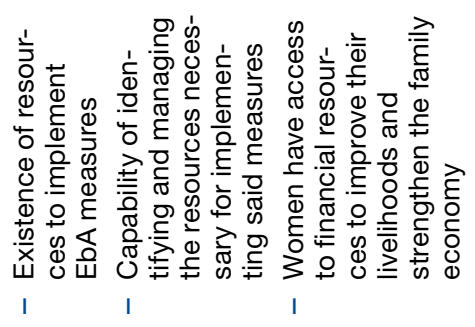 & 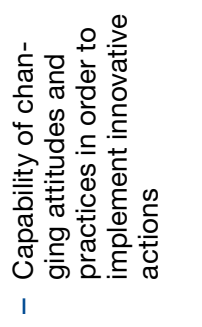 \\
\hline | & 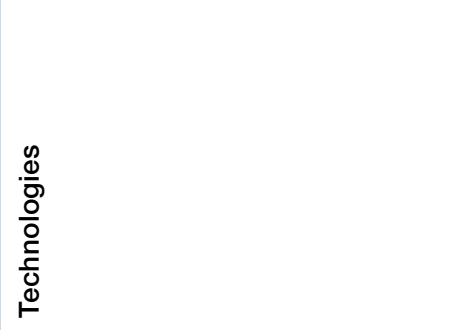 & 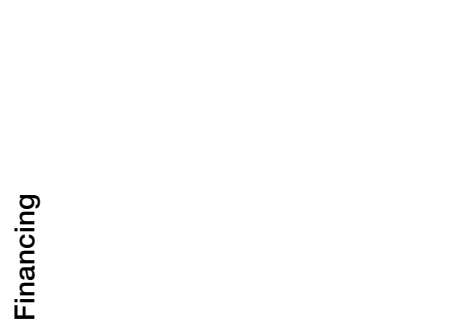 & 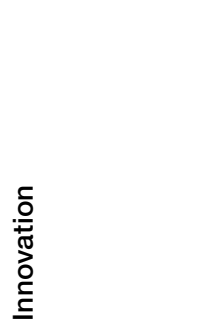 \\
\hline
\end{tabular}




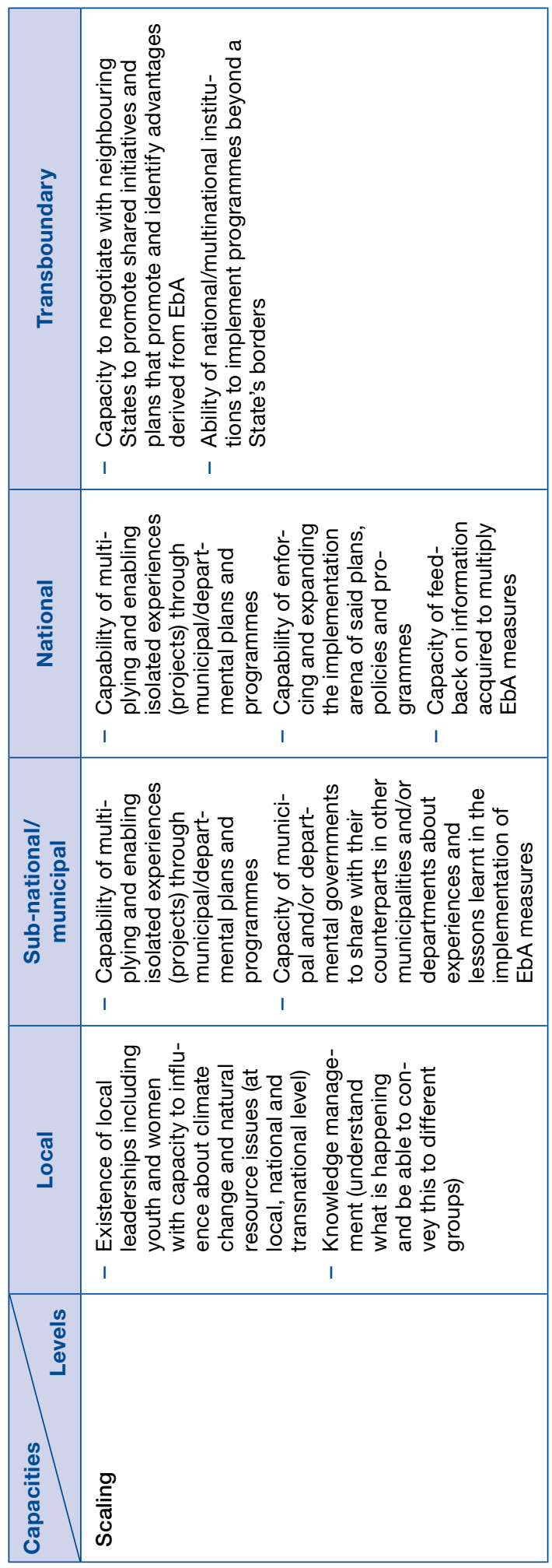

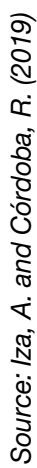




\subsection{Capacity building for EbA governance}

For the purposes of this book, if EbA is the array of strategies, policies and practices aimed at the protection and restoration of ecosystem services to reduce societal vulnerability to climate change, then EbA governance is the collection of norms, institutions and processes necessary for the protection and restoration of ecosystem services to reduce societal vulnerability to climate change.

To explain capacity building, different target groups must be examined to discern and differentiate the capacities each requires. The following are considered for the purposes of this book:

Social: Individuals, communities in general (including indigenous peoples and rural communities), nongovernmental organisations in a broad sense, associations (community, water boards, etc.), academia, research institutions and the media.

Corporate: Producers (at different scales, including agriculture, livestock, mining, fishing and aquaculture), industry (at different scales), financial institutions and the insurance sector, commerce (at different scales), tourism, transportation and infrastructure (for example, highways, ports, dams, housing, etc.).

Political/institutional: The State, meaning its executive, legislative and judicial branches, but also the different administrative bodies ranging from commonwealths and municipalities to departments, counties, provinces and federal, depending on the administrative structure of the States.

With target groups now defined, capacity building for governance in relation to these groups can be explained according to the four basic components of governance: policy, law, institutions and processes. 


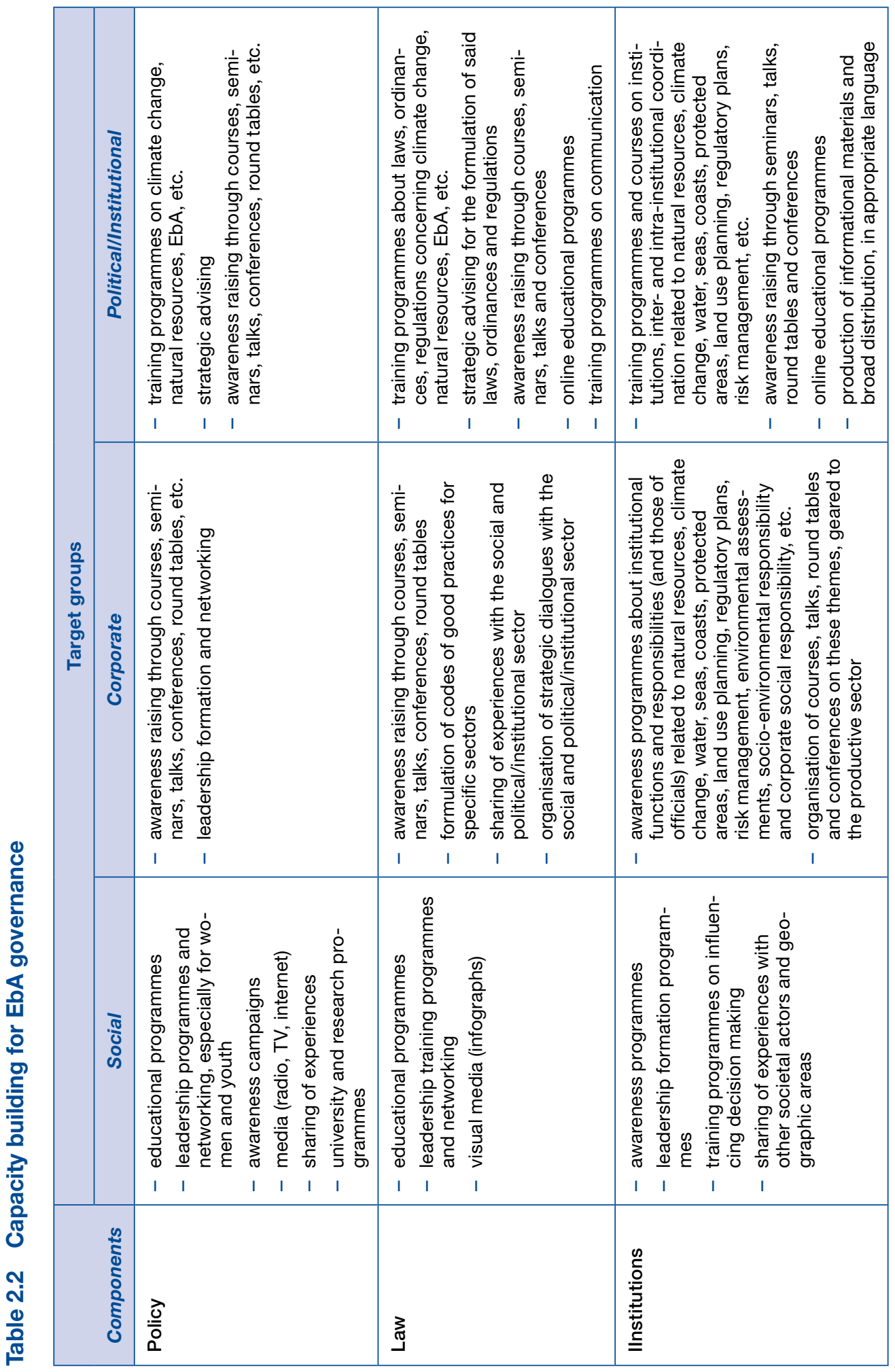




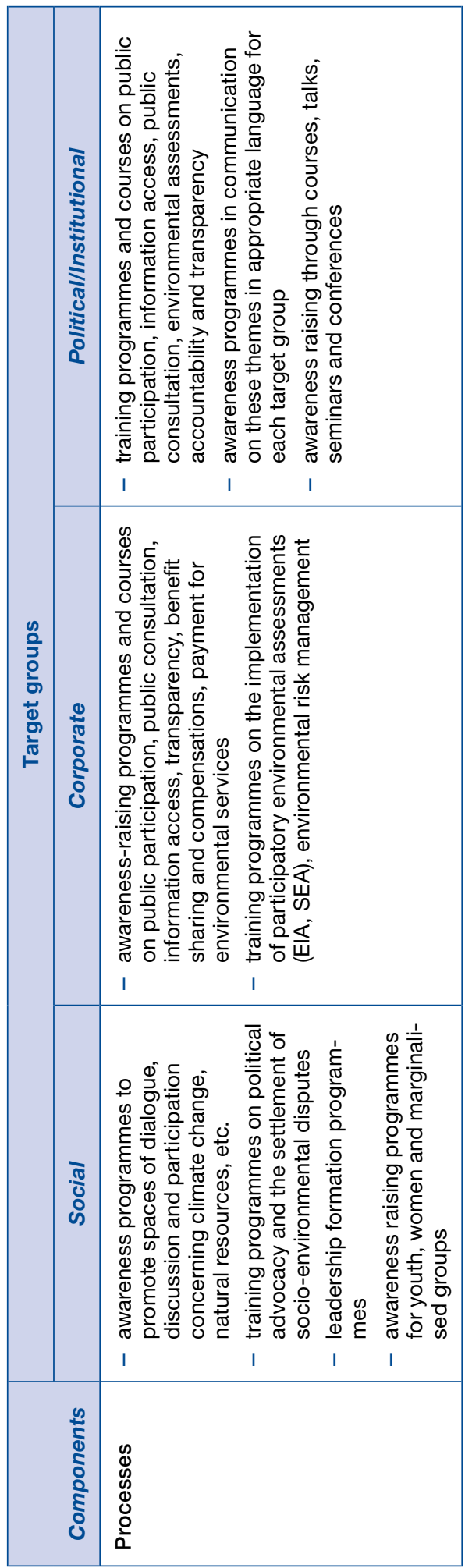

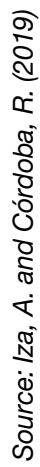


It should be emphasised that capacity building for EbA governance must be adapted to the contexts of each country, region and locality since needs are different. The table above nonetheless offers an overall panorama of the main mechanisms necessary to build the indicated capacities applicable to all countries. It must be stressed that the capacities described in tables 2.1 and 2.2 should be viewed in holistic and integral form, not compartmentalised as isolated components.

\subsection{Challenges and opportunities for capacities}

There is an imbalance of capacities between developed and developing nations. In the latter, such imbalances also exist between national and local entities, as well as between those who are more versus less vulnerable to climate change. The greater the vulnerability of ecosystems and society, the lower the capacity. It should be the other way around: to reverse vulnerability, greater adaptation capacities are needed.

In itself, EbA and the many capacities required to manage it effectively pose a challenge given all that is involved, from climate change and its effects to risk management, conservation and maintenance of ecosystems' health, improvement of sustainable livelihoods and land use planning.

Many of the problems around EbA governance capacities derive from this multiplicity of issues to be addressed, in other words, the multidimensionality of the capacities necessary since EbA spans from social capacity to innovation.

As mentioned previously, climate change requires a permanent process of adjustment and readjustment, with the subsequent consequences for training and consolidation of specific capacities in governing climate change.

Another significant challenge is access to timely and sound information for decision making on EbA-related themes and therefore their inclusion in training programmes at all levels. As well, States allocate only limited resources to training, academic and research programmes, and in the case of developing countries, depend to a great extent on international cooperation.

In their NDCs, several countries have explicitly committed to implementing ecosystem management actions and are now compelled to develop policies, laws and institutional structures for climate change adaptation. This includes building and consolidating the capacities necessary for its implementation. The UNFCCC itself has recognised the importance of this theme.

Global or international funds such as the Green Climate Fund (GCF) and Adaptation Fund in the frame of UNFCCC offer a favourable vehicle for mobilising resources that can be used for concrete EbA actions, as well as for training and strengthening multiple actors. 



\section{Evidence}

\section{Rocío Córdoba-Muñoz and Melissa Marín Cabrera}

\subsection{Introduction}

There is a wide variety of proof that climate change and climate variability are worsening the degradation of ecosystems and quality of life for human communities. Despite the uncertainty of different climate scenarios, it has been scientifically demonstrated that global climate trends have generated adverse consequences for ecosystems and human beings for several decades.

The objective of this chapter is not to discuss these changes, but rather to clarify the necessary elements for showing how climate change adaptation applying the ecosystem approach represents a better option compared to other types of actions. To demonstrate that this is a sounder alternative, there must be a series of compelling validations that $\mathrm{EbA}$ functions over time and offers advantages over other adaptation initiatives. At the same time, EbA governance must be shown to contain enough elements to demonstrate that its implementation can ensure ecosystem services are maintained and people have a better quality of life.

According to the dictionary definition (Diccionario de la Real Academia Española (2018)), evidence is the "certeza clara y manifiesta de la que no se puede dudar" (clear and evident certainty that cannot be doubted). From the standpoint of law, evidence is "prueba determinante en un proceso o lo que permite mostrar la verdad de un hecho" (definitive proof in a process or what makes it possible to show the truth of a fact). Evidence constitutes reliable information and knowledge that could be utilised to support the development, the implementation and even the evaluation of policies and other legal instruments of effective governance (Collins et al., 2015).

Evidence produced through the implementation of $\mathrm{EbA}$ measures ${ }^{1}$ is a useful instrument to demonstrate that these actions positively impact on both ecosystem health and the production of social, economic and cultural co-benefits for human beings. While it seems simple, ideally the generation of evidence requires monitoring and evaluation systems, as well as systematic and continuous collection and analysis of information and data (Marín \& Navarro, 2019).

The generation of evidence must ideally be supported by scientific data, research and the knowledge of indigenous peoples and local communities (CBD, 2018); on the other hand, it must come from reliable sources of information and knowledge with qualitative and quantitative data so that it can be used to influence decision making (Chong, 2014). However, data showing the positive effects of natural resource conservation on human well-being tend to be scarce and come from numerous, highly diverse sources, many of which are not accessible to decision makers or other stakeholders (McKinnon et al., 2016). Evidence can be produced through the use of solid scientific information, but also from other types of information originating from processes in which many societal actors participate.

Evidence of EbA effectiveness in connection with its respective governance arrangements is only just taking its first steps (Reid et al., 2018; Sieber et al., 2018). As such, at this time developing countries cannot be expected to have sufficient, clear mechanisms to assess the ecological, social

1 EbA measures refer to options and actions based on improving ecosystems and the quality of life for human populations, which that can be implemented to improve adaptation to climate change. 
and economic feasibility of EbA and hence build a solid argument demonstrating that nature-based solutions are more effective than those commonly used to address the effects of climate change.

In general terms, currently there is no consolidated system showing that EbA measures are undeniably effective and demonstrating the respective cause-effect relation in a context of climate forecasts with great uncertainty (UNDP-INEC, 2017). Other sources of information and knowledge must therefore be identified to show changes and improvements in ecosystem services and people's quality of life (or at least relevant trends in this sense) derived from EbA.

\subsection{EbA evidence and effectiveness}

Evidence is proof verifying the effectiveness of EbA measures. According to Seddon et al., (2016) effective EbA refers to measures or actions that have restored, maintained or increased ecosystem capacity to provide services. These services enhance human well-being, adaptation capacity or resilience and reduce vulnerability. Such measures and actions help ecosystems resist the impacts of climate change and other pressures and range from actions on the ground (such as agroforestry systems, wind breaks or soil conservation works, protection of springs and replanting riparian forests) to those strengthening social capital (such as improvement of coordination systems or local capacities, and awareness campaigns).

According to Reid, et al. $(2017,2018)^{2}$, EbA effectiveness must be demonstrated by generating evidence that can be simply and clearly communicated to different audiences. For this, they have developed a guide setting out a process based on a questionnaire to determine the effectiveness of $\mathrm{EbA}$. Their instrument has four main questions, each subdivided into more detailed questions about the following

1. Effectiveness for human societies: This refers primarily to adaptive capacity, participation, social justice, benefit sharing, co-benefits for communities and reduction of vulnerability.

2. Effectiveness for ecosystems: These questions focus on restored or increased ecosystem services for communities, and the ecosystem's resilience to the impacts of climate change.

3. Financial and economic effectiveness: Focusses on cost-efficiency and long-term economic viability compared to other types of more conventional adaptation investments that exist.

4. Political and institutional aspects: Social, institutional and political factors for effective EbA implementation over the long run.

A recent and innovative initiative, this questionnaire is a joint effort of the International Institute for Environment and development (IIED), the UN Environmental Programme, the World Conservation Monitoring Centre (UNEP-WCMC) and IUCN to guide professionals in planning and executing EbA measures. While this series of questions can provide qualitative and in some cases quantitative information as to how effective $\mathrm{EbA}$ is compared to other adaptation alternatives, quantifying the success of EbA is admittedly no simple task since ecosystems are inherently dynamic and a statistical baseline is lacking to measure changes (Doswald et al., 2014).

Ecological and social processes move at their own pace, which generally take longer than changes in government administrations at the different levels. This is why it so important to consider the economic,

2 The complete publication about questions to evaluate effectiveness can be found at: http://pubs.iied. org/17606SIIED 
environmental and social benefits connected with $\mathrm{EbA}$, and principally with EbA governance, as a means of convincing decision makers responsible for environmental and development policy of the benefits.

The comparative advantage of EbA over the usual engineering-based solutions ('business as usual') must be demonstrated through compelling evidence and ownership by social actors to circumvent the short-term solutions that tend to be prioritised in developing countries (Calliari et al., 2019; Albert et al., 2019). Hence, it is imperative to relate stakeholders and actors with ecosystem services, their threats and their vulnerabilities, along with systematic mapping of their potential interests in the long run (Raum, 2018).

In terms of policies, institutions and societal participation, the effectiveness of EbA actions requires cooperation and communication among multiple sectors and geographic scales as absolute requisites for good governance and their scaling (see Chapters 4 and 5), yet another challenge in obtaining any type of evidence.

\subsection{More common types of evidence and how it is generated}

The generation of evidence about EbA should be established from the early stage of planning adaptation actions within a limited geographical space and time scale defined according to the dynamics of ecosystems and human societies (Raymond et al., 2017). Proper planning must therefore include clear objectives and a hypothesis about what is intended to be shown and improved. It is important to have an exhaustive baseline on the aspects to be managed (such as area of degraded ecosystems, existence or absence of crops more resistant to climate variations, people's capacity to improve their agroecological practices, poverty level, the food and water security of communities associated with the ecosystems, stakeholder groups, power relations among actors, presence or absence of governance structures, or level of state governability). It also needs to be constructed collectively by all involved, along with defining selection criteria on a set of indicators that provide information about the changes to be affected.

Nevertheless, studies of EbA projects and initiatives underscore the dearth of initial baselines built on scientifically collected and analysed data and long-range processes and the implementation of thorough monitoring and evaluation systems (Raymond et al., 2017; Hills, 2015; McKinnon et al., 2016; Marín et al., 2019). Because of this limitation other sources of information and knowledge must be sought, and while they may not be the result of rigorous scientific research, they can offer elements demonstrating that EbA works in practice.

Table 3.1 classifies evidence according to a typology ranging from scientific to other processes (secondary sources) showing trends of value for analysing the outcomes of EbA actions. It also includes examples of the different types of evidence. 


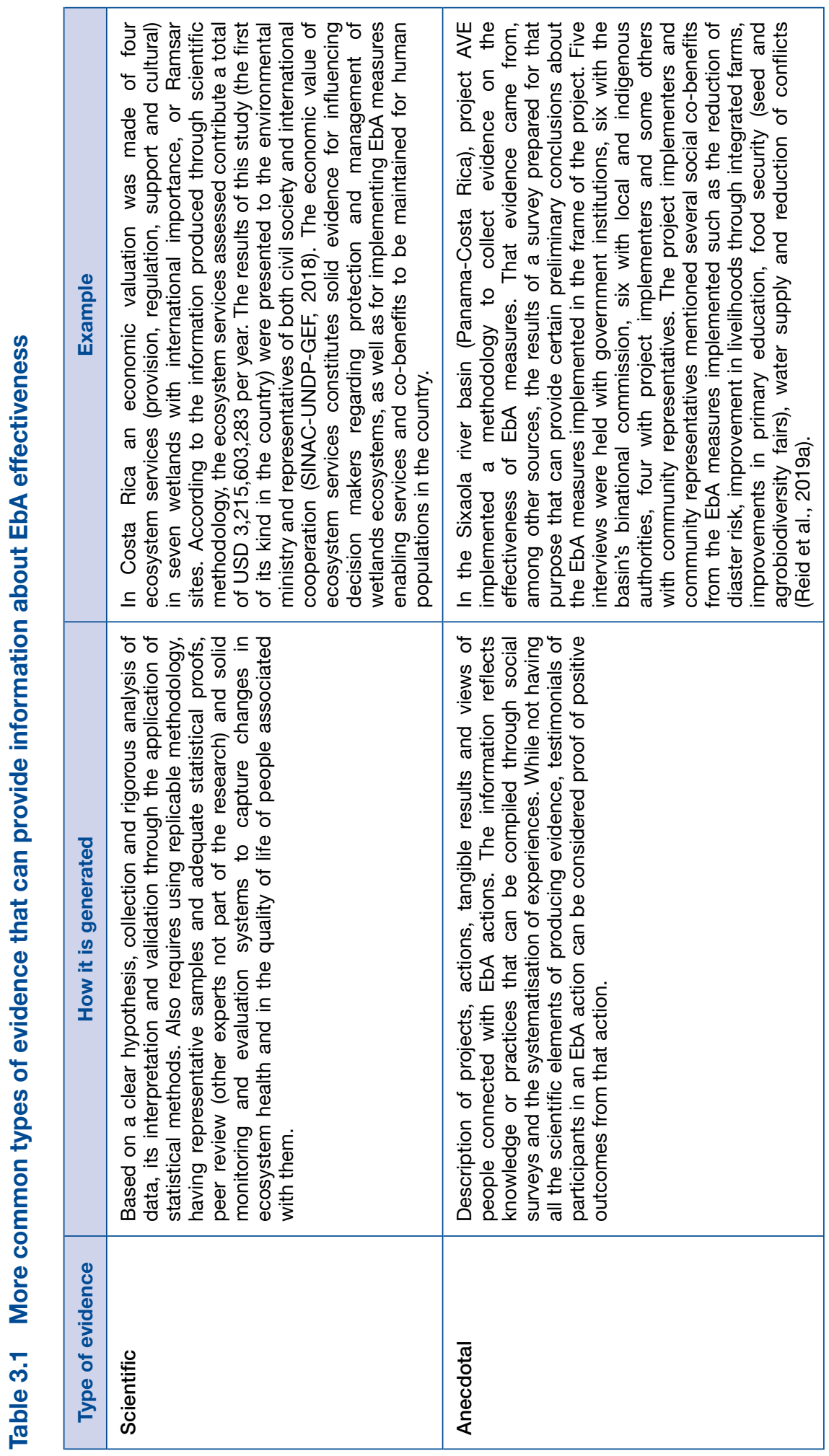


믐응

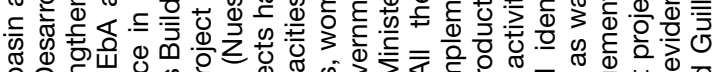

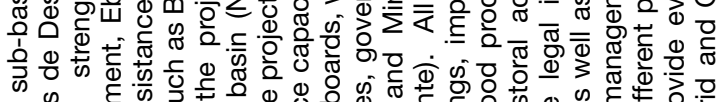

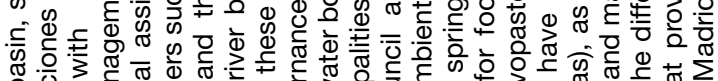

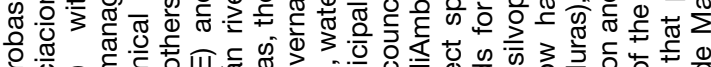

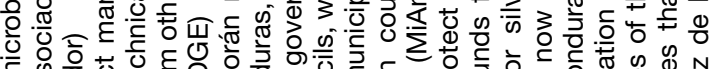

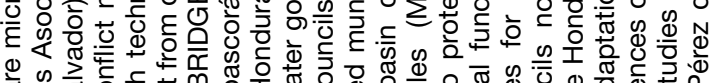
๙

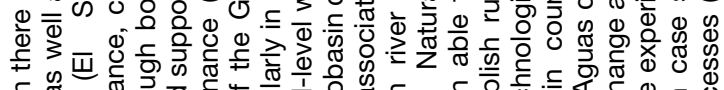

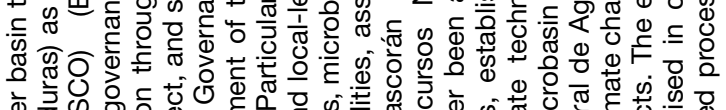

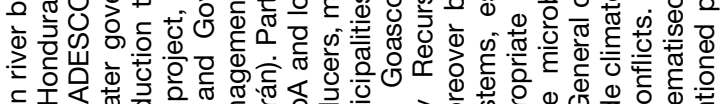

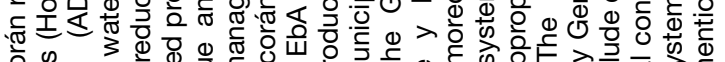

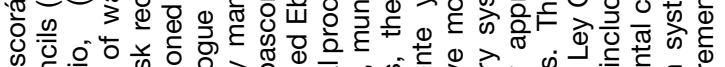

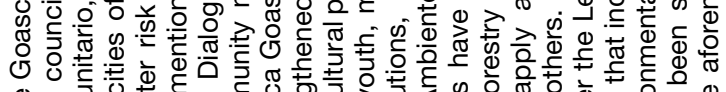

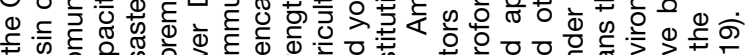

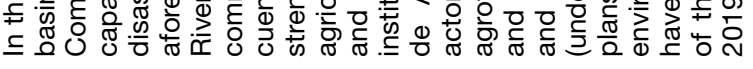

ڤ

O

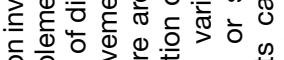

을 을 을

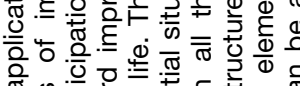

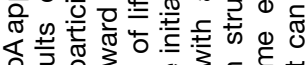

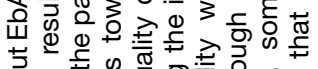

亏

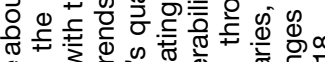

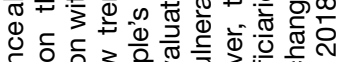

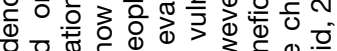

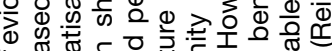

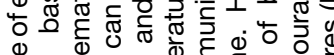

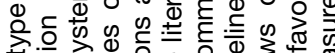

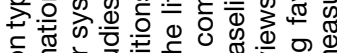

ᄃ

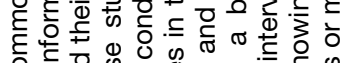

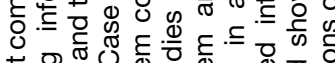

药

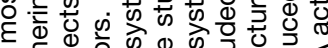

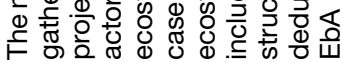




\begin{tabular}{|c|c|c|}
\hline & 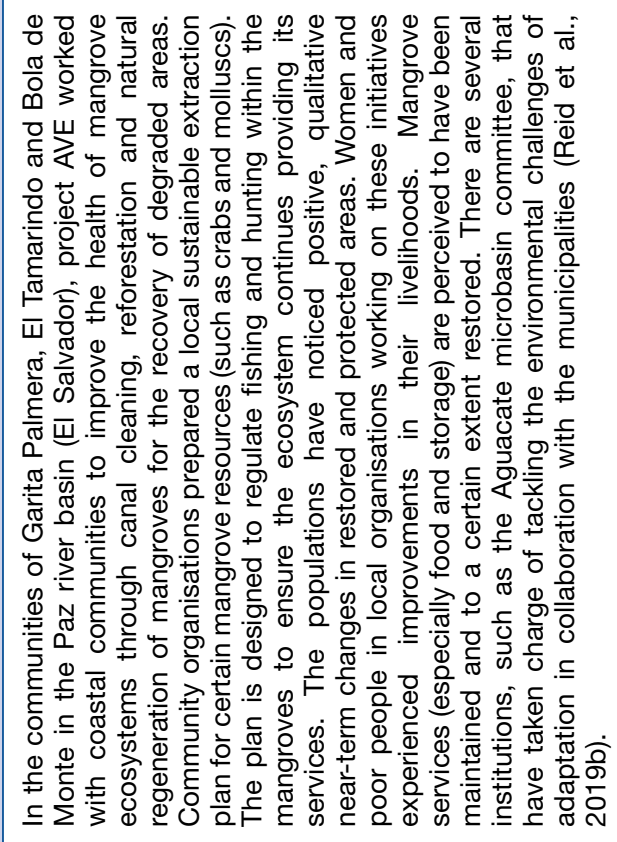 & 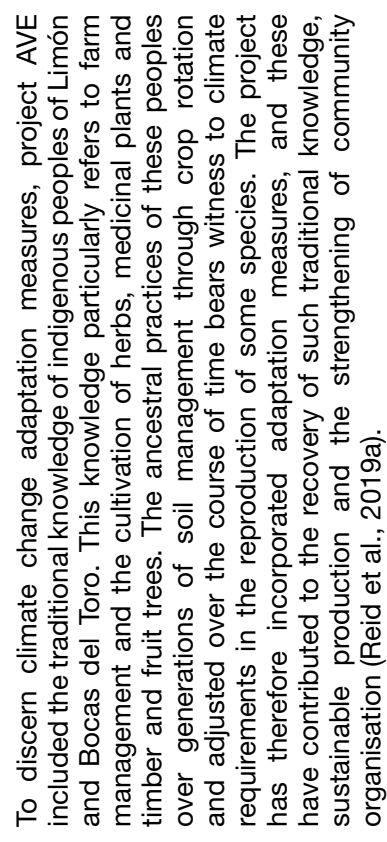 \\
\hline & 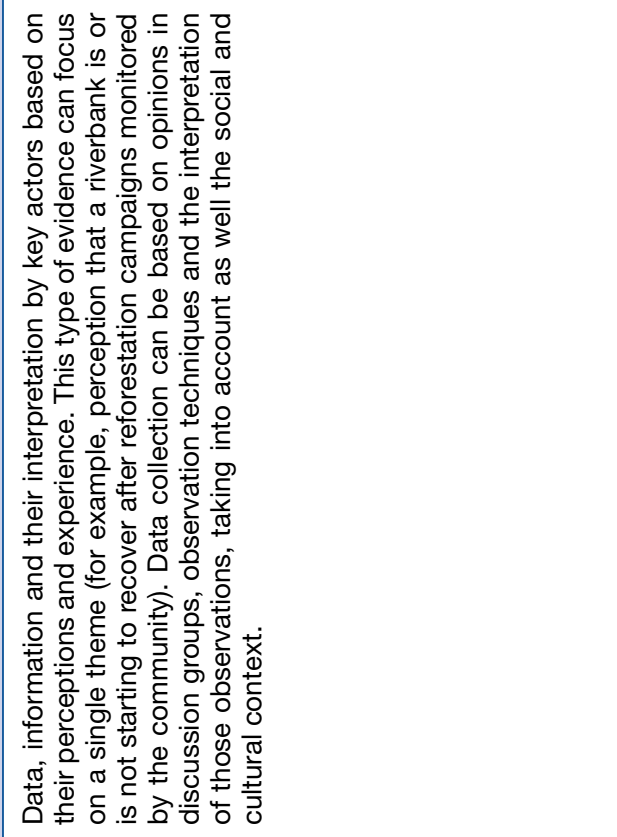 & 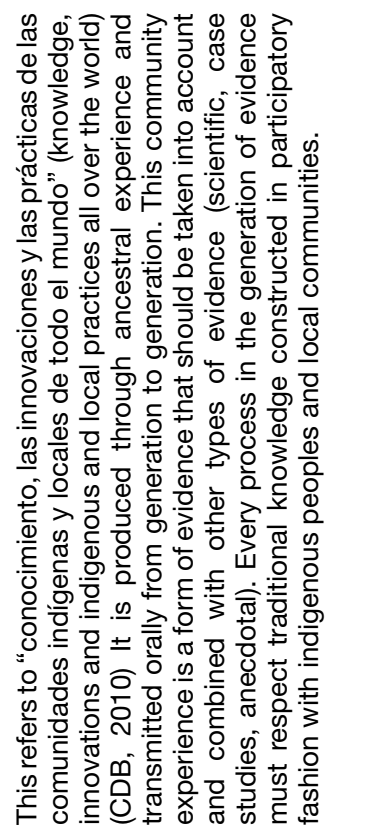 \\
\hline 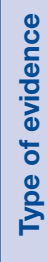 & 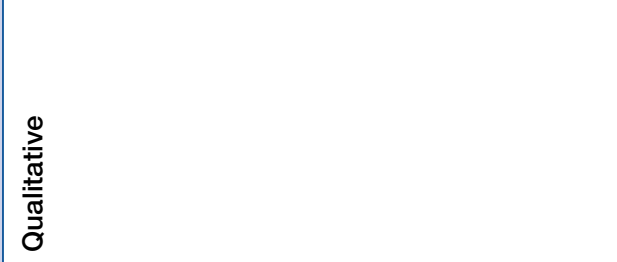 & 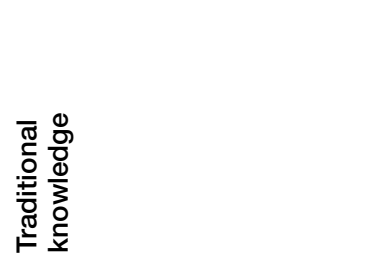 \\
\hline
\end{tabular}




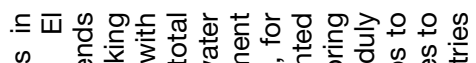

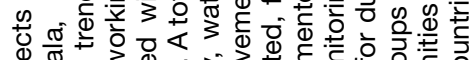

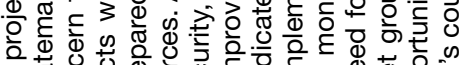

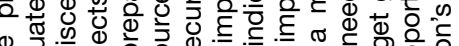

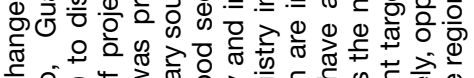

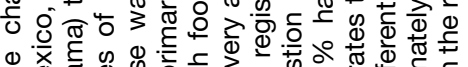

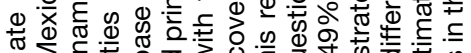

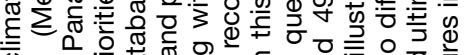

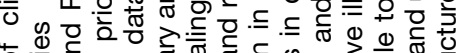

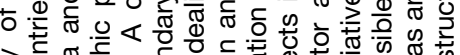
>

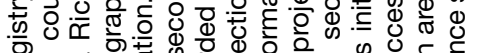
ब.

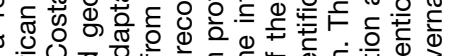

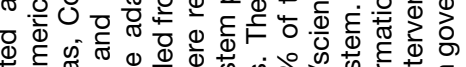

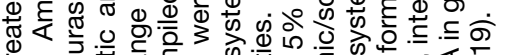

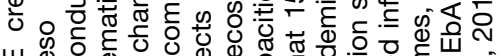

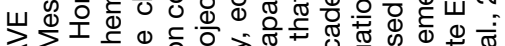

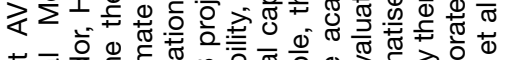

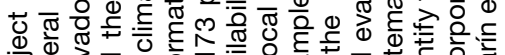

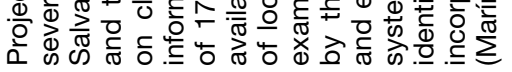

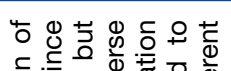

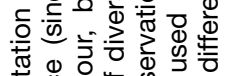

要出

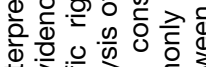

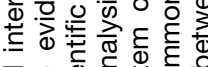

응.

त :

छ

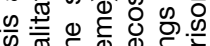

क्ष

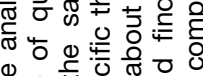

ه

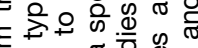

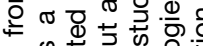

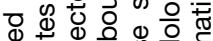

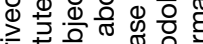

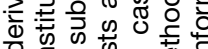

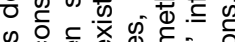

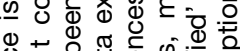

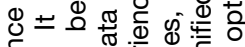

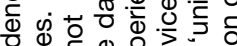

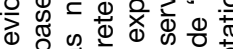

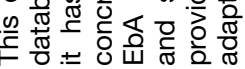

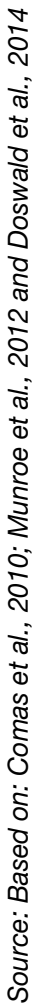


The unification of all these types of evidence (and others that may exist) and their generation (in keeping with the capacities and resources available in each case) constitutes what could be defined as comprehensive evidence (Raymond et al., 2017).

Comprehensive evidence is 'transdisciplinary,' constituting a coherent and logical composite of knowledge in different sectors (scientific, decision makers and civil society representatives) for proposing solutions to an issue of collective concern, based on research and on the practical application of knowledge (Dendoncker et al., 2018).

What is known as 'participatory action research' is one of the proposals for integrating different actors in the generation of evidence. It is a method that combines 'knowing' and 'acting,' and includes the population whose situation is being addressed. It aims to better understand the situation, facilitate a critical awareness about the situation and promote a population's empowerment and transformative action geared to better planning. Nevertheless, one of the concerns of those who plan adaptation and those responsible for formulating related policy and management decisions is the lack of quantitative studies and investigations on cost-effectiveness that include EbA measures compared to other adaptation activities, such as hard infrastructure options (Doswald et al., 2014).

Ideally, any EbA measure should be designed and planned in a participatory manner to answer questions related to their effectiveness objectively (see previous section), as well as clearly identify a problem, its causes and effects. The aim is to be able to generate evidence identifying which outcomes can be attributed to the implementation of that measure and to what degree. Moreover, given that governance is one of the essential components of EbA, there must be clarity about the existing legal and institutional framework as well as about all the stakeholders and their capacity to scale up results. This way the potential of EbA governance, its gaps and strengthening needs can be discerned.

\subsection{Evidence for EbA governance}

\subsubsection{Influencing decision making and scaling}

The use of evidence for EbA must be an effective vehicle to influence decision making about adaptation to climate change. For this, it is important that the experiences and results of EbA actions persuasively reflect (argument) the economic, environmental and social benefits for both ecosystems and populations involved in the work (Calliari et al., 2019). Over the years, concern about knowing how to preserve the health of ecosystems and what services they provide to humans has changed from being a communication and awareness-raising tool to one of advocacy for reflection and decisions on the environment and local, national, regional and global development (Chong, 2014).

Evidence makes it possible to analyse objectively the effectiveness and cost-benefit of the implemented adaptation measures, and to assess the opportunities afforded by different models for reducing climate vulnerabilities, as well as their reach and results as overwhelming 'proof' of the co-benefits (Raymond, 2017). In terms of governance, these arguments constitute the instrument that gives meaning to decision making about climate change, while also contributing to civil society, State and private sector awareness of the need to adopt practices and policies, through social networking (Montaña, 2015; Vignola et al., 2019). Evidence makes it possible to show the effectiveness and efficiency (cost-effectiveness ratio) of the cooperation and networking mechanisms themselves among different sectors. It can also provide indications of institutional or local capacity to scale 
up and transform society's climate change-related requirements into community agreements, regulations (formal or informal), public policies and laws.

The generation of evidence is aimed at obtaining impartial and objective information. Its use, however, depends on the capacity of governance structures and mechanisms to draw it into the different social, political and economic contexts, as well as concretising it in agreements that give legal sustainability to adaptation actions. Governance and evidence are thus closely linked, in the understanding that EbA governance requires evidence as a tool for negotiation. In turn, the generation of evidence would not have the desired effects if governance structures did not exist or were inefficient in producing the expected social change.

In addition to producing information and a stock of knowledge about ecosystem services, the generation of evidence aims to establish, feed and enrich a reliable database of actors, decision makers and their adaptation capacities within effective governance arrangements and a specific geographic and time scale. All EbA projects or initiatives must necessarily include an analysis of the challenges its implementation and sustainability represent for stakeholder groups (Nalau \& Bekens, 2018). In this context, knowledge management ${ }^{3}$ must be part of $\mathrm{EbA}$ actions from the moment of their planning.

For this evidence to serve in scaling up EbA in States' strategic decision making about development, it is imperative to raise awareness and train those responsible for this decision making so they commit to planning with a long-range vision (Calliari et al., 2019). This forms part of the adaptation capacities that must be contemplated to ensure effective EbA governance (see Chapter 2, Capacities).

\subsubsection{Favourable environment for the formulation of EbA policies and regulatory frameworks}

The lack of structured information about EbA effectiveness is one of the most important gaps in the formulation of policies and regulatory frames (OECD, 2018). Furthermore, the weakness of State institutions, especially in developing countries, imposes an important constraint on having a solid legal foundation that helps guarantee good governance. Evidence from EbA experiences and measures in practice (case studies, scientific investigations, etc.) can provide the necessary elements to build tools for ensuring the sustainability of those actions (see Chapters 4 and 5).

As can be seen throughout this chapter, the generation of evidence should not only be aimed at seeking long-term EbA effectiveness in ecosystems and co-benefits, but also in the solidity of the institutions, stakeholder participation and conditions permitting citizen participation.

Evidence about EbA is also needed to encourage decision makers' interest in facilitating participatory formulation of policies and laws that guarantee the continuity and improvement of EbA actions. Once again, this depends on stakeholders' negotiation and influencing capacities to convince policy makers about the comparative advantages of EbA. Policies must be socially acceptable for the diverse stakeholder actors and sectors, including the corporate sector, which demands precise and scientific information (evidence) demonstrating the economic and social advantages of EbA in relation to other alternatives (Cvitanovic et al., 2016). organising, filtering and presenting information in order to improve people's understanding in a particular area of interest. 
The more scientific information and evidence (quantitative) there is about the costs and social and economic distribution of benefits from EbA measures, the greater the opportunity to influence the formulation of long-term policies and regulatory frames (Munroe, 2012). This is why capacity building is essential to generate, analyse and convey evidence to different groups and levels: local, national, regional and international. Adaptation policies, strategies and plans in developing countries are based on different types of evidence (Vignola, et. al., 2019). Even in developed countries, the foundation of evidence is only just being built and requires more time to be consolidated (UNDP-INECC, 2017).

\subsubsection{Information transfer, knowledge and communication for EbA governance}

Effective communication (that achieved through a clear and understandable message) aimed at specific target audiences should be considered a tool to improve EbA and hence its governance, in that this can generate awareness, sensitivity, persuasion and motivation. Communication structured on evidence fosters attitudinal changes, social interaction, exchange of opinion, feedback processes and modifications of human behaviour (Encalada, 2005). Communication requires proper planning since chaotic action in this area can lead to confusion or delays in encouraging the creation of capacities or send the wrong message to those in charge of formulating EbA policies and laws.

For communication of evidence to be objective, it must reflect the situation derived from data analysis and information, not the aspirations of those who communicate. While analysis of the information generated through evidence should ideally be participatory, the process must be led by a person or institution with expertise to prevent improper use or possibly poor interpretations of that information.

When planning communication about evidence on $\mathrm{EbA}$, a series of points should be weighed:

1. The characteristics of the audience (stakeholder groups involved), the ways in which they exchange information and the local contexts that affect climate change;

2. The capacity of those who communicate the information to convey the message correctly based on local adaptation needs and State commitments in relation to policy and legal and institutional frameworks;

3. The 'language' used to express the content. For this, it is important to consider that language in this area is complex and integrates multiple concepts; a single word can have several meanings and thus generate different interpretations. It is essential to adapt the language to facilitate comprehension by its recipients.

4. Stakeholders' access to information

Finally, capacities required to effectively communicate evidence include the promotion of effective communication skills, motivation and leadership so that others commit to EbA governance. Evidence-based decisions require a two-way exchange of knowledge: between beneficiaries/users and scientists on one hand, and on the other, between beneficiaries/users and decision makers.

\subsubsection{Evidence generated through EbA governance}

Evidence showing the efficacy of EbA policies, strategies, laws and regulation must be generated, analysed and communicated. In other words, evidence of EbA effectiveness must exist in order to foster its good governance, and at the same time, to ensure that EbA actions continue.

The sustainability of nature-based solutions, including EbA, requires two-way feedback. EbA governance arrangements (multidisciplinary, participatory, ecosystemic and flexible) should provide 
information to projects and initiatives, and vice versa. Those responsible for the formulation and application of policies, laws and regulations improving favourable conditions for $\mathrm{EbA}$ have the obligation to inform stakeholders about the results of such policies. Likewise, it is necessary to monitor and evaluate transparency, institutional capacity, supervision and compliance with the law to give citizens feedback and in a participatory manner, forge necessary changes to specific legal frames.

In the last analysis, institutional and human capacities for good governance determine whether strategies and public policies are effective (UNSTT, 2012). These subjects are examined in greater detail in Chapter 4 of this book.

Figure 3.1 illustrates this two-way dynamic between generating evidence on EbA to influence its governance, and the evidence of EbA effectiveness necessary for its sustainability.

As mentioned, EbA measures must be planned in participatory form, and ideally baselines exist on the vulnerability of beneficiary populations and ecosystems associated with them. Analysis of these data and interpretation of results over time are essential to generate evidence and lessons learnt for EbA effectiveness over the course of time, including understanding on the part of stakeholder groups about ecological processes. EbA governance furthermore requires creating tools tailored to the different social, political, economic and environmental contexts, along with clear objectives and innovative and flexible governance arrangements satisfying the needs of populations and ecosystems. By implementing these tools, the effectiveness of EbA governance can be measured while also providing feedback and improving the implementation of adaptation measures.

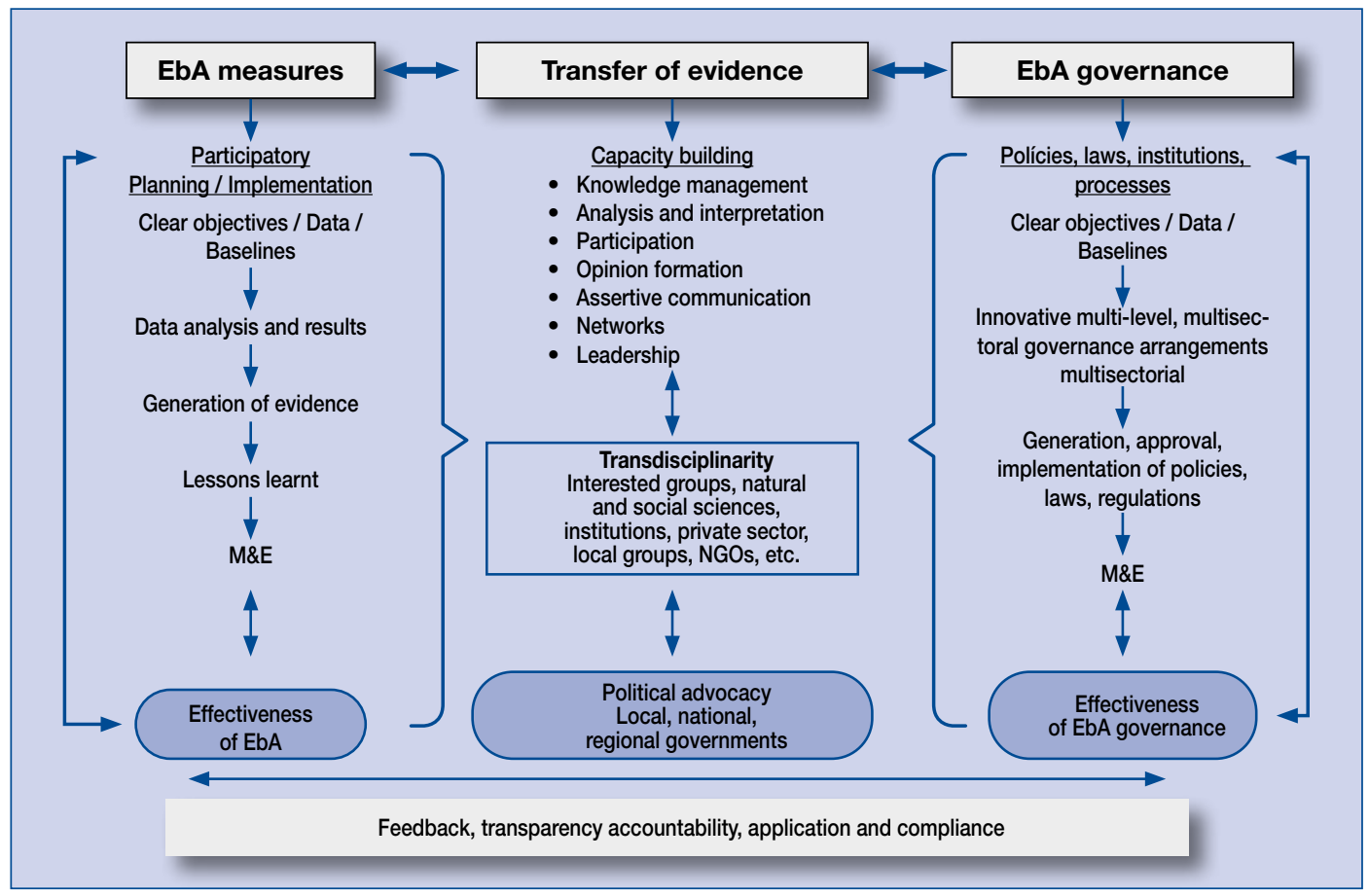

Figure 3.1 Linkage between evidence generated from EbA and evidence of effective EbA governance 
The feedback between evidence generated by EbA and evidence generated by EbA governance holds vital importance for communication and information transfer (knowledge) to uphold innovative and efficient arrangements for EbA governance. Decision makers and those responsible for formulating policies, laws and other instruments must also answer to stakeholder groups, providing information about the application and enforcement of legal frameworks, and thereby continue to enrich EbA implementation. In these dynamics, monitoring and evaluation are an instrument to be taken into account.

\subsubsection{Monitoring and evaluation of EbA governance}

The effects of EbA actions become apparent primarily in the medium or long term. Depending on the complexity of the cost-benefit to be demonstrated, sometimes the anticipated results cannot be seen clearly or are embedded within other changes. The generation of evidence must therefore include continuous monitoring and evaluation systems to measure the progress of an EbA measure and governance through conscientious, explicit and wise use of valid available data.

Monitoring refers to outputs, the advances achieved during the implementation of an action, and identifies corrective measures, while evaluation focusses on describing the process, the how and why results and medium- and long-term impacts were obtained, and providing with it a foundation for learning.

In actions with cumulative effects (such as those of $\mathrm{EbA}$ and biodiversity conservation, which can be considered more as processes than one-off projects), evaluation is key to measure impacts in the long run. However, the reality shows that financial entities and implementers of EbA measures alike tend to prioritise monitoring only. This diminishes possibilities for enriching other initiatives and longrange planning based on accurate information.

In terms of EbA governance, States must not only monitor changing ecosystem conditions but also the implementation and enforcement of related laws and norms. This calls for quality standards based on accepted methods of scientific measurement, data processing and analysis (Iza \& Stein (eds.), 2009).

Selecting indicators ${ }^{4}$ that provide qualitative and quantitative data to generate evidence about the functionality of EbA are part of an effective monitoring and evaluation system.

In the specific case of EbA governance, indicators should be established when measures are first launched so that opportunities can be identified to formulate policies, laws and regulations on EbA.

Such indicators need to be established with stakeholder participation and be relevant for political, legal, institutional and process aspects in each specific instance, while also providing rigorous evidence on the capacity, functionality and performance of these elements over time (Bennett \& Satterfield, 2018).

An indicator can be defined as "una expresión cualitativa o cuantitativa observable que permite describir características, comportamientos o fenómenos de la realidad a través de la evolución de una variable o el establecimiento de una relación entre variables, la que comparada con periodos anteriores o bien frente a una meta o compromiso, permite evaluar el desempeño y su evolución en el tiempo" (an observable qualitative or quantitative expression making it possible to describe characteristics, behaviours or phenomena of the situation through the evolution of a variable or the establishment of a relation between variables, which compared to previous periods or against a goal or commitment, allow evaluating performance and its evolution over time) (DANE, 2013). 
Given the inherent complexity of ecosystems, their services and related social dynamics, demonstrating the viability of EbA and its governance is enormously challenging compared to more conventional and customary solutions. The recommendation is therefore to monitor, for example, a single ecosystem service, not all of them at once. Experience shows that in most EbA projects, monitoring and evaluation is put off until the end and provides very little truly useful information for decision making (Raymond et al., 2017). Nevertheless, it is advantageous to select, in a participatory manner, at least one activity that exemplifies tangible benefits in quality of life to obtain the commitment, ownership and empowerment of local actors. Ultimately, they are the ones who, on the basis of their experience, will influence policy making, laws and other types of regulations.

It should be emphasised that at national level, monitoring systems for climate change adaptation policies are complex, take time and are only just beginning to be formulated so there are no results yet showing advances in the achievement of these instruments (UNDP-INEC, 2017). Furthermore, most indicators included in the majority of these systems concern social and economic development issues as well as ecosystem services. This is what makes it necessary to define ways of linking these with the application and enforcement of EbA-related policies, laws and processes, and thereby have monitoring and evaluation that is integrated, coherent and holistic.

Finally, it is important to note that the costs of establishing and implementing monitoring and evaluation systems for EbA represent a significant investment of resources, inasmuch as they include training for different actors associated with implementation (Iza \& Stein (eds.), 2009).

\subsection{Challenges and opportunities for the functionality of EbA governance}

Currently the greatest challenge regarding practical evidence that helps build EbA governance lies in generating rigorous scientific and technical information (on ecosystem services, social and political capital and co-benefits for populations) to feed into effective and efficient governance systems.

Quantitative estimations are still very scarce in the literature, especially in developing countries where data on physical impacts and economic valuation of those impacts are difficult to obtain. Most case studies lack a scientific evaluation with reliable and solid evidence indicating how effective EbA approaches are (Munroe et al., 2012).

The difficulties of generating data and knowledge are normally associated with limited financial resources and adaptation capacities, particularly of local populations who are generally the ones that most depend on ecosystem services (Mehvar et al., 2018). In addition, the benefits of ecosystem conservation, restoration and sustainable management for adaptation become apparent in approximately ten years. Even though methodologies are being developed to monitor and evaluate such benefits, rigorous scientific information will only be available in the medium term, resulting in the lack of suitable participatory planning and poor or non-existent baselines on the aspects to be improved through EbA measures (ecosystem services, sustainable livelihoods, political and institutional systems).

Without ecosystem benefits that can also be economic, clearly people will not commit to EbA or feel motivated to improve their organisational options and seek governance arrangements allowing them to continue adapting to climate change and ultimately, improve their quality of life. Therein lies another great challenge related to long-range changes in ecosystems and society that interact in a complex way within the context of the inherent uncertainty of climate scenarios. 
Unless evidence provides inputs showing economic and social benefits, decision makers and policy makers will not be able to improve EbA governance. Well-informed players with a good understanding of evidence can formulate solid arguments for improving governance structures and the mechanisms necessary to implement them.

Traditional or local knowledge about ecosystem functioning and nature's interaction with society must always be properly weighed and incorporated in planning and implementing EbA measures and governance (WWAP/ ONU-AGUA, 2018). Generally indigenous peoples and local communities are the ones with a historically long-range panorama of ecosystem changes and behaviours, one that contributes to generating different types of evidence.

The systematisation and dissemination of case studies on EbA wherein lessons learnt and challenges are clearly shown offer a good opportunity to influence policy agendas on climate change (Nalau \& Becken, 2018).

EbA capacities are essential to analyse evidence and turn it into policies and regulatory frameworks. Stakeholder groups need the ability to perceive and systematise trends toward changes in vulnerability and resilience, as well as tools to monitor those trends over time.

Insofar as states are influenced to develop national plans and policies on climate change adaptation in keeping with their global commitments, opportunity exists to incorporate $\mathrm{EbA}$ and consequently improve policy and legal instruments for its implementation and sustainability. This requires evidence derived from projects of all types (concrete EbA governance actions) permitting logical and wellconsidered design of monitoring, indicators and evaluation systems to meet international commitments (such as the Paris Agreement, for example).

Few developing countries have these systems, and the ones that exist are still somewhat ambitious and complex. Formulating these systems with the participation of all stakeholders has taken time, so as yet there is no tangible evidence demonstrating the effectiveness of climate change adaptation policies (UNDP-INECC, 2017).

However, financing sources to establish the much-cited monitoring and evaluation systems have increased, especially for developing nations, which should make good use of these circumstances to strengthen adaptation measures and consequently their effective governance. 


\section{Policy}

\section{Lorena Martínez Hernández}

\subsection{Introduction}

Governance is the means by which society defines its goals and priorities and advances toward decisions at global, national or local level. It includes: a) policies, b) legal frameworks, c) institutions and d) processes and mechanisms for stakeholders to express their interests, exercise their rights, meet their obligations and resolve their differences (Burhenne-Guilmin \& Scanlon (eds.), 2004). Governance includes institutions and both formal and informal processes through which citizens and communities organise and make decisions (Martin, Boer \& Slobodian (eds.), 2016). It should be stressed that governance is more than government, since it recognises specific roles for civil society and the private sector (CBD, 2018).

The intent of this chapter is to reflect upon the role of policy and regulatory frameworks to implement climate change adaptation strategy that coherently integrates nature-based solutions among diverse sectors, government levels and administrative or political limits in the territory. It also describes procedural environmental rights and their importance in EbA governance. Institutions are not addressed in this chapter, as this is the specific focus of another chapter of the book.

The emphasis here is on the role of policies and norms for integrating EbA in a national adaptation strategy, opportunities to incorporate this approach in diverse policies and laws and finally, main areas for reform and some recommendations.

\subsection{Policy and law, different and interdependent roles for adaptation}

Policy and law are easily differentiated, in theory at least. Policy sets out visions, strategies, plans and an array of directives on how government must address a public matter. Its role is to guide legislative creation or reform to achieve a social objective. It also promotes the coordination of actions and activities of other government bodies relevant to that end. Unlike law, policy is not binding and does not create enforceable rights; it is instead dynamic and flexible (Iza \& Stein (eds.), 2009).

Policy is vital for the formulation or reform of legal frameworks because it gives experts, researchers and the general public opportunity to participate in formulating guidelines as the foundation for what new legislation should include (Iza \& Stein (eds.), 2009).

Policy needs law ${ }^{2}$ to:

- Create institutions: Establish government bodies to administer public affairs;;

- Distribute competencies and authorities: Determine who has the power to take decisions, who has the authority to implement them and who is responsible if decisions are not implemented; and

- Define processes: Determine how decisions are made, how those decisions are implemented and how decision makers must be accountable for their acts.

2 Understood as the set of norms in a legal system. 
Law also creates rights and obligations and establishes mechanisms for settling disputes between actors. It provides stability and security to systems for the administration of public affairs. Governance benefits from a functional legal framework that provides concrete, mandatory directives (Greiber \& Schiele, 2011).

Adaptation to climate change is the process of adjusting to current or anticipated climate conditions (in the short, medium and long term) and their effects in order to reduce the potential damage or deterioration (in living conditions or ecosystems, respectively) these conditions can cause. According to IPCC (2014) it also includes making use of beneficial opportunities these climate changes may provide.

Adaptation can be spontaneous or planned. The first is an unconscious response to climate stimuli, which responds to changes in ecological systems, human systems or markets (Verschuuren, 2013a). The second is a proactive response, an attempt to anticipate the impacts of climate change, and seeks to prevent maladaptation (Verschuuren, 2013a).

Adaptation policies and laws aim to direct or institutionalise the iterative process of society and ecosystems to adjust to the climate in a proactive and informed manner. Their purpose is to generate inclusive decisions and implement actions at the different administrative levels and in sectors for intentional and integrated management of climate change impacts.

From the standpoint of policy, adaptation is complex because planning cannot be done with a 'sectoral' or specific instrument. It is crosscutting and must necessarily cover all sectors affected by climate change, signifying additional challenges of multisectoral coherence and coordination. Another complex component is that vulnerability to climate change depends on many specific factors in a given context, and to be effective an adaptation policy needs inputs from knowledge about local conditions and the capacity to respond to changes (Flatt, 2012). Likewise, adaptation demands close coordination of diverse affected sectors and at different government levels, from local to national and international (Verschuuren, 2013), along with new mechanisms to engage sectors of society historically marginalised from decision making.

Ideally, adaptation policy should be expressed in a framework instrument establishing general directives for diverse sectors and government levels in the short, medium and long run. Additionally, a series of policy instruments, such as climate change strategies and special programmes, further delineate implementation strategy (road map) and concrete actions to be carried out in each sector.

Adaptation policy must also pursue coherence between adaptation policies and concrete actions from local to global levels. For this, it must define spaces of participation and communication channels in decision-making processes and identify implementation mechanisms or instruments. 


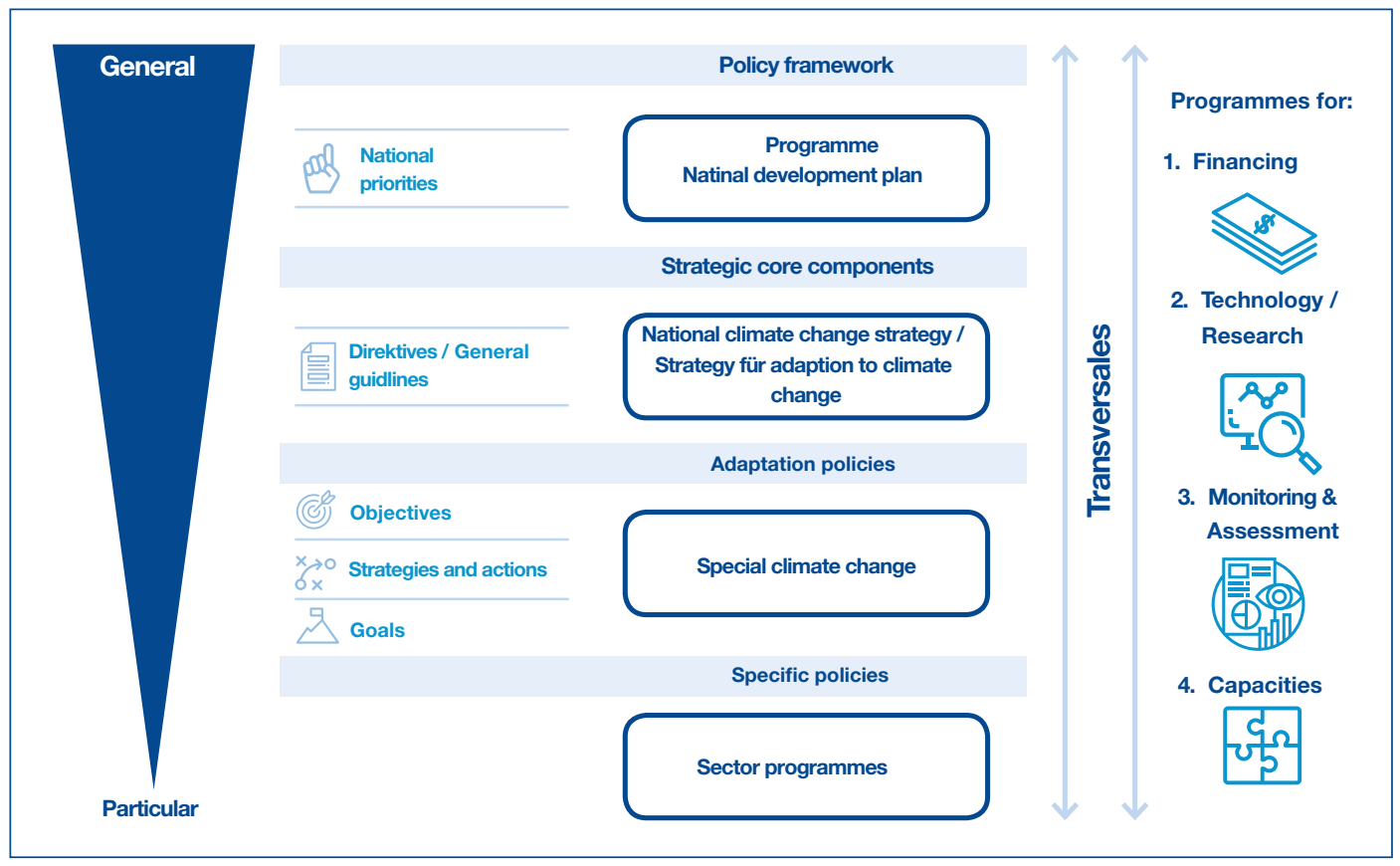

Figure 4.1 Mainstreaming adaptation in sectoral legal regulation

Source: Adapted from Ascencio, 2019, p.104

In addition, adaptation policy should establish methodologies and measurable, verifiable and reportable indicators for short- and long-term monitoring and evaluation to manage uncertainty about the moment, intensity and place that climate change will impact human and natural systems. Criteria and indicators should serve to evaluate not only progress in implementing the policy framework but also, and above all, the effectiveness of the adaptation (OECD, 2015; Vallejo, 2017). This includes reducing vulnerability, improving the resilience and adaptative capacities of people, ecosystems, sectors and institutions. While the importance of indicators and criteria to measure adaptation progress is widely recognised, there are no measurement systems that integrate all of these elements, nor the suitability and efficacy of the adaptation (UNFCCC, 2018).

For its part, law must create institutions responsible for coordinating the adaptation process, distributing competencies among institutions governing the diverse sectors and among levels of government. Additionally, it needs to establish arrangements or mechanisms for reaching agreements and settling differences when the administrative competencies or demarcations of those institutions enter into conflict or have overlapping jurisdictions. Ultimately, the law institutionalises and gives clarity, stability and legal certainty to the coordination process for climate change adaptation.

In addition, law must establish the rights and obligations of individuals and legal persons, public and private, in relation to climate change adaptation so that more sectors of society can be involved. Probably the rights easiest to identify in this area are access to information, public participation in decision making and access to justice in environmental matters, commonly known as procedural environmental rights. Likewise, emphasis should be on the right of indigenous peoples to free, prior and informed consent (FPIC) over their territory and the natural resources in it, as well as women's 
rights to participate in decisions. There are other less evident but equally important rights involved in adaptation, such as property rights, patent rights and insurance derivatives, among others (Greiber, 2010).

The law also establishes mechanisms and procedures ensuring the implementation of adaptation policies $^{3}$ indicating the competent authorities to oversee compliance and determine penalties.

Finally, law also has the function of preventing disputes between rights and interests and designing conflict resolution mechanisms, both judicial and extra judicial. It establishes the precepts or formulae a judge applies in weighing conflicting rights and interests.

\subsubsection{Adaptation policy and the ecosystem approach}

Human beings are completely dependent on ecosystems and their services (Millenium Ecosystem Assessment, 2005; UNEP, 2019; IPBES, 2019), so human intervention to reduce vulnerability and enhance resilience to the effects of climate change must be a pillar of adaptation policy (Preamble, Paris Agreement, 2015).

Human intervention for ecosystem adjustment to climate change has been summed up as "actions for the conservation, restoration and sustainable management of ecosystems and their services" (CBD, 2009), presumably for the purpose of facilitating understanding and translation into concrete actions by diverse actors with diverse technical capacities. However, one of the common limitations of this strategy is that such actions are considered an environmental matter, rather than a concern that should permeate development planning in general, the work of all State entities and the regulation and action of all actors of society.

Integrating the ecosystem approach in adaptation strategy is actually broader than promoting conservation and/or restoration in the respective policies and laws. It is about aligning economic, productive and social processes with nature's cycles and an ecosystem's carrying capacity, while also taking into account additional pressures on that ecosystem from climate change.

On one hand, this means reducing ecosystem vulnerability associated with human activities (for example, the different forms of pollution, over-exploitation of natural resources, deforestation, urbanisation, production and consumption models, etc.) and on the other, increasing its resilience through parallel conservation and restoration actions. In this sense, there are examples of countries starting to identify and valuate the environmental services of their terrestrial ecosystems at national level (TEEB-Russia, 2018), and identifying environmental services in the different economic and productive sectors (for example, the ECOVALOR project in Cuba). From here, integrating EbA could be possible if the vulnerability of ecosystems and their services were also assessed and conservation and restoration actions were designed according to the ecosystem's carrying capacities for the purpose of increasing their resilience ${ }^{4}$ (see CLIMA- Guide to strengthening governance for mainstreaming and scaling up Ecosystem-based Adaptation). for example, Nationally Determined Contributions (NDCs), climate change policies, plans and strategies and National Adaptation Plans. 
While science and policy are being developed to tackle the challenge of sustainably managing ecosystems in the context of climate change, action can be taken right now by making use of a wide range of regulatory tools in environmental law, such as environmental impact assessments (EIA), territorial development plans, urban development plans, protected areas, environmental certification, fishing quotas, and many others. Integration of EbA involves aligning these instruments with information obtained from climate change vulnerability assessments and the implementation of measures necessary for ecosystem conservation and restoration consonant with human and climate pressures.

In sum, adaptation governance integrating the ecosystem approach still has a long way to go to facilitate the attainment of national and global adaptation objectives and local adaptation needs. One of the first concrete actions identified here is the inclusion of conservation and restoration measures in framework and sectoral policies and law, on one hand, and on the other, the integration of vulnerability assessments and flexibility mechanisms in environmental, social and economic laws (Ruhl, 2010; Yazykova \& Bruch, 2018).

\subsubsection{EbA in Multilateral Environmental Agreements (MEAs)}

Scientists first reported climate change effects on ecosystems and biodiversity in global assessments, such as the first report of the Intergovernmental Panel on Climate Change (IPCC) in 1990. The Conference of Parties (COP) of the Multilateral Environmental Agreements (MEA) therefore asked their respective expert groups to analyse climate change effects on the ecosystems or species they protect.

Over the last decade, the EbA approach has been integrated gradually in multilateral environmental treaties, mainly through recommendations of their permanent bodies and decisions by COPs of the MEAs. The COPs recommend that State Parties to those treaties incorporate EbA as a key piece of their adaptation strategies and incorporate it in their relevant environment and sector policies. These recommendations are general to give States room to develop internal policies based on their own vulnerabilities, conditions, circumstances and contexts (Paris Agreement, art. 7.5).

Recognising that ecosystems and climate change are transnational by nature, COPs promote international cooperation for the adaptation of ecosystems and people. Given the transversality of adaptation, COPs have asked their secretariats to cooperate with counterparts of other environmental treaties in issuing coordinated recommendations to the Parties and helping them achieve their international commitments.

The following table provides details on global treatment of EbA, in order of relevance. 
Table 4.1 Treatment of EbA

\begin{tabular}{|c|c|c|}
\hline Subject & Treaty & Recommendations related to EbA \\
\hline \multirow[t]{2}{*}{$\begin{array}{l}\text { Climate } \\
\text { change }\end{array}$} & $\begin{array}{l}\text { UN Framework } \\
\text { Convention on } \\
\text { Climate Change } \\
\text { (UNFCCC) }\end{array}$ & $\begin{array}{l}\text { Stabilise concentrations of greenhouse gases at a level that } \\
\text { impedes dangerous anthropogenic interference for a period of time } \\
\text { that allows ecosystems to adapt to climate change. } \\
\text { Cancún agreements: Adaptation actions should take vulnerable } \\
\text { ecosystems into consideration with a view to integrating adaptation } \\
\text { in relevant social, environmental and economic policies and actions } \\
\text { (UNFCCC, 2013). }\end{array}$ \\
\hline & Paris Agreement & $\begin{array}{l}\text { Recognises the importance of protecting ecosystem and biodiversity } \\
\text { integrity for both mitigation and adaptation of climate change } \\
\text { (Preamble). } \\
\text { The principles for adaptation take ecosystems into account and } \\
\text { call for integrating adaptation in relevant environmental policies } \\
\text { and actions and enhancing the resilience of ecosystems through } \\
\text { sustainable management of natural resources. (art. 7). }\end{array}$ \\
\hline \multirow[t]{2}{*}{ Biodiversity } & $\begin{array}{l}\text { Convention } \\
\text { on Biological } \\
\text { Diversity }\end{array}$ & $\begin{array}{l}\text { Integrate considerations of biological diversity in all pertinent national } \\
\text { policies, programmes and plans in response to climate change, and } \\
\text { quickly develop tools to implement activities for the conservation } \\
\text { of that diversity contributing to adaptation to climate change (CBD, } \\
\text { 2006; CBD 2014). } \\
15 \text { Aichi Targets establish a specific commitment to restore at least } \\
15 \% \text { of degraded land, contributing to adaptation. } \\
\text { Make use of the Voluntary guidelines for the design and effective } \\
\text { implementation of ecosystem-based approaches to climate change } \\
\text { adaptation and disaster risk reduction (CBD, 2018) }\end{array}$ \\
\hline & $\begin{array}{l}\text { Convention on } \\
\text { Conservation of } \\
\text { Migratory Species } \\
\text { of Wild Animals }\end{array}$ & $\begin{array}{l}\text { Incorporate actions for migratory species' adaptation in the Strategic } \\
\text { Plan for Migratory Species (CMS, 2017) and in national climate } \\
\text { change plans, prioritising National Biodiversity Strategies and Action } \\
\text { Plans (NBSAPs) (CMS, 2017b). }\end{array}$ \\
\hline $\begin{array}{l}\text { Ecosystems/ } \\
\text { Natural } \\
\text { resources }\end{array}$ & $\begin{array}{l}\text { Convention on } \\
\text { Wetlands of } \\
\text { International } \\
\text { Importance } \\
\text { especially as } \\
\text { Waterfowl Habitat }\end{array}$ & $\begin{array}{l}\text { Administer wetlands to enhance their resistance to climate change, } \\
\text { promoting the protection and re-establishment of wetlands and } \\
\text { watersheds (Ramsar, 2002). } \\
\text { Promote the restoration of rivers, lakes, aquifers and their wetlands as } \\
\text { an important aspect of climate change policies, and also encourage } \\
\text { the Parties to promote coordinated integration in the development } \\
\text { and implementation of their national policies on water, agriculture, } \\
\text { energy, poverty reduction and health to ensure that sector objectives } \\
\text { mutually support one another to cope with the negative effects } \\
\text { of climate change, as well as ensuring that policy objectives are } \\
\text { coherent with the need to protect the health of wetland ecosystems } \\
\text { (Ramsar, 2008). } \\
\text { Goal } 12 \text { of the Fourth Strategic Ramsar Plan 2016-2024. Restore } \\
\text { degraded wetlands giving priority to those important for adaptation } \\
\text { to climate change. (Ramsar Convention, 2015). } \\
\text { Integrate wetlands-based risk management and EbA in plans and } \\
\text { policies at all levels of government, including the integration of } \\
\text { vulnerability assessments, poverty reduction strategies and plans } \\
\text { and natural resource management sectors, as well as in multisectoral } \\
\text { plans and policies (Ramsar Convention, 2015b). }\end{array}$ \\
\hline
\end{tabular}




\begin{tabular}{|c|c|c|}
\hline Subject & Treaty & Recommendations related to EbA \\
\hline \multirow[t]{4}{*}{$\begin{array}{l}\text { Ecosystems/ } \\
\text { Natural } \\
\text { resources }\end{array}$} & $\begin{array}{l}\text { United Nations } \\
\text { Convention } \\
\text { to Combat } \\
\text { Desertification in }\end{array}$ & $\begin{array}{l}\text { Work Programme of the Science-Policy Interface for the biennium } \\
2018-2019 \text { must issue a report on the potential of soil interventions } \\
\text { to mitigate the effects of drought in order to improve the resilience of } \\
\text { people and ecosystems (UNCCD, 2017a). }\end{array}$ \\
\hline & $\begin{array}{l}\text { Those Countries } \\
\text { Experiencing } \\
\text { Serious } \\
\text { Drought and/or } \\
\text { Desertification, } \\
\text { Particularly in } \\
\text { Africa }\end{array}$ & $\begin{array}{l}\text { Land Degradation Neutrality objectives are considered a tool to } \\
\text { enhance the resilience of communities and ecosystems (UNCCD, } \\
\text { 2017b). }\end{array}$ \\
\hline & $\begin{array}{l}\text { Convention on } \\
\text { the Protection } \\
\text { and Use of } \\
\text { Transboundary }\end{array}$ & $\begin{array}{l}\text { Implement the Guide on Water and Adaptation to Climate Change } \\
\text { (UNECE). UNECE manages a programme of pilot projects and a } \\
\text { platform for sharing experiences in adaptation and water resource } \\
\text { management in a transboundary context. }\end{array}$ \\
\hline & $\begin{array}{l}\text { Watercourses } \\
\text { and International } \\
\text { Lakes }\end{array}$ & $\begin{array}{l}\text { A guide for management of water-related disasters in a transboundary } \\
\text { context is being prepared (UNECE, 2018). }\end{array}$ \\
\hline
\end{tabular}

Also relevant are: the Sustainable Development Goals (SDG 13 in relation to SDGs 1, 2, 3, 6, 14 and 15) ${ }^{5}$; the Sendai Framework for Disaster Risk Reduction (Priorities 2 and 3) 6 ; the New Urban Agenda of Habitat III (Commitments to transformation furthering paragraph 80); and the Bonn Challenge to restore 150 million hectares of degraded and deforested landscapes by 2020 and 350 million hectares by 2030. The latter has generated diverse countries' growing interest in adopting forest landscape restoration thanks to its benefits for improving adaptation to climate change (IUCN, 2017).

In practice, the need to adapt to climate change has been encouraging transnational cooperation driven by local communities that share a same ecosystem (Sanchez \& Roberts, 2014). In Meso America there are several examples of this at the basin and sub-basin level. One is the upper subbasin of the Sumpul River shared by Honduras and El Salvador where in 2017, communities formed the Comité Binacional de la Cuenca del Río Sumpul, a binational committee with the representation of diverse interests on both sides of the border to manage water resources and implement EbA measures toward improving water quantity and quality and reducing risks of landslides and flooding. The recently installed committee now has a strategic action plan that includes EbA measures. This 'micro' cooperation is important not just for the communities sharing the ecosystem, but also for the States and global governance. For the States because it could serve as example and boost broader cooperation between neighbours in management of shared ecosystems, and for global governance because all together, these cases could contribute to achieving global goals. (IUCN, 2019).

\subsubsection{EbA in national policies}

The international order recommends that States integrate EbA in domestic policies related to development, climate change adaptation, biodiversity, ecosystem or natural resource management, disaster risk management and civil protection, urban development and/or territorial planning. for a visual representation of EbA contribution to the SDGs. 
EbA integration in national, regional or local policies can follow a grassroots approach, meaning pilot projects or natural resource governance projects at community level. Through diverse strategies they anchor EbA actions in concrete sectoral policies (bottom-up approach) or from national entities to the bases (top-down approach).

Until now, the most common approach has been bottom-up, consisting of local planning and implementation of EbA projects helping to generate evidence of EbA benefits. Windows of opportunity have also been identified for including ecosystem aspects in adaptation objectives, strategies and policies at different government levels. In them, an assessment is made of national policies and plans addressing adaptation, environment and land use, among other issues, in search of opportunities to promote EbA. The aim is for EbA actions to gradually and eventually form part of relevant regional, national and global policies (a policy described as "mainstreaming EbA and Eco-DRR" in the CBD, 2018).

In part, the prominence of this approach is because the complexity of the interdependence between social and ecological systems, along with the uncertainties of climate change, defy simple, linear solutions that can be replicated successfully in all contexts (Vasseur, 2017). Another reason could be that EbA has had to demonstrate its cost efficiency and effectiveness to be able to compete with other adaptation measures such as types of grey infrastructure. In any case, the diversity of solutions and innovation associated with sharing experiences is a fundamental element in response to climate change. Such innovation should not only be promoted; the experiences of EbA projects should also be carefully systematised to inform or shape higher-content policies.

The top-down approach begins with an assessment of national climate risks and vulnerabilities to identify the main ecosystems and economic and social sectors affected by climate change. It is important that this assessment discern key ecosystem services and stakeholder groups, understand the relation between these services and diverse actors and sectors at national and sub-national level, and identify key social processes within governing institutions (Andrade et al., 2012).

Based on the vulnerability assessment, the policy framework can include ecosystem conservation and restoration as one of its guidelines, making reference to 'ecosystem approach,' 'ecosystem management and conservation' or similar language. The guidelines are accompanied by more concrete lines of action that can include the formulation of regional or local adaptation plans with an ecosystem approach. Regional and local plans should be at temporal and spatial scales appropriate to the dynamics of ecosystems and their services, guaranteeing their functionality and the main actors and sectors benefitting from those services (Andrade et al., 2012).

The approaches described are complementary. Bottom-up should offer relevant information for national policies, the participatory design of adaptation actions and the involvement of diverse sectors of society in the adaptation process. The top-down approach must coordinate the actions of the different social sectors and align them to achieve national adaptation objectives. It should also help identify vulnerability factors in relation to humans and nature in local contexts, for example, through atlases of national vulnerability making it easier for local actors to design local plans with EbA actions. Above all, the top-down approach should channel financial resources and implement training programmes for local players (public and private) on applying EbA (Austin et al., 2019). The role of local players is to coordinate, ensure the coherence of the different responses to create synergies and prevent maladaptation. In short, integrating EbA in policy should be a two-way exercise. 


\section{Example: Política Nacional de Adaptación al Cambio Climático de Costa Rica (PNACC)}

Costa Rica's national climate change adaptation policy (PNACC for its name in Spanish) is part of an array of strategic planning instruments in the frame of formulating its national adaptation plan. The policy was set out as a governing framework that will orient country adaptation actions. It is also a concrete step towards achieving the commitment of formulating a national adaptation plan, assumed in the frame of its Nationally Determined Contributions (NDCs) within the Paris Agreement.

The policy has six core components, each with its own action plan, policy objective and guidelines. Some of the core components are strategic and others are substantive.

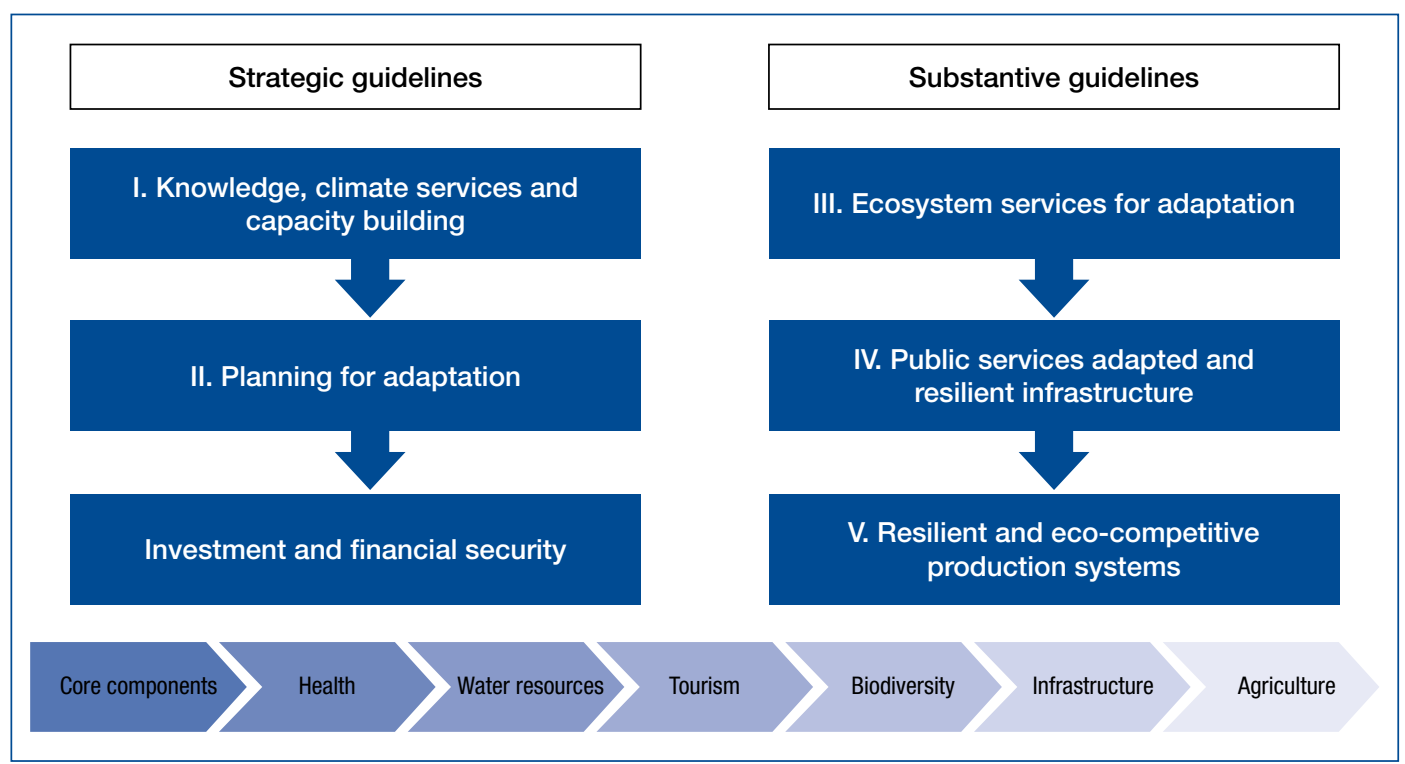

Figure 4.2 Instrumental and substantive guidelines of policy and the core components of the national adaptation plan

Source: Author, adapted from PNACC (2018), Costa Rica, p. 60

All of these components and guidelines develop the necessary elements for a favourable environment for EbA governance, such as inter alia, creation and strengthening of capacities; generation, collection and dissemination of information; and evidence concerning climate change and environmental services. In relation to $\mathrm{EbA}$, core component two is specifically noteworthy as it recognises that enhancing the resilience of human and natural systems starts with land, marine and coastal planning. It also recognises that territorial planning must be based on adaptation to climate change. Municipal and community planning instruments are strongly emphasised.

It is also important to integrate EbA in sector plans, along with training for environmental institutions to implement policy and to promote conservation and restoration of terrestrial, marine and coastal ecosystems that provide environmental services boosting adaptation.

It is worth recalling that public participation is required for policy legitimacy and quality. Participation spaces and mechanisms must be created from the earliest stage possible, in other words, during the early stage of preparing a vulnerability assessment. 
One of the greatest challenges to implementing an adaptation framework policy for the formulation of regional and local plans incorporating EbA measures is uncertainty about the way climate change will impact ecosystems, and the complexity involved in understanding socio-ecological systems. Information is often unavailable at local scales, and when it does exist, climate scenario models are inadequate for understanding how climate variability will impact on socio-ecological systems. In this context, it is important that national governments develop instruments facilitating decisions and adaptation planning at local scales.

\section{Example: Atlas Nacional de Vulnerabilidad al Cambio Climático de México}

The Instituto Nacional de Ecología y Cambio Climático (INECC) created the Atlas Nacional de Vulnerabilidad ante el Cambio Climático (ANVCC) to develop, consolidate and modernise instruments necessary for reducing vulnerability to climate change.

A tool for influencing decision making and public policy, the atlas helps identify adaptation actions reducing vulnerability to climate change, and is also a guide to achieving the Nationally Determined Contributions (NDCs) at three levels of government. Its objective is to establish a structured and systematic collection of maps showing territorial vulnerability to climate change and orient the implementation of strategies within an adaptation process. The scope of the atlas is national, and maximum resolution of the information is at municipal level. ${ }^{8}$

\subsection{Law}

Policy must identify the diverse laws or norms enabling it to be implemented or which must be modified to align with the social objectives established in an adaptation policy. Indeed, one of the overall objectives of many national adaptation plans is the explicit inclusion of climate change adaptation in sector regulations (Boer \& Clarke, 2012; Plan Nacional de Adaptación al Cambio Climático del Reino de España).

This integration should be mainstreamed in all sources of law, inter alia, international treaties, national constitutions, laws, regulations, judicial decisions, general principles of law, administrative instruments and minutes, agreements, standards, uses and customs, and mandatory traditional practices (Martin, Boer \& Slobodian (eds.), 2016).

In addition to laws on climate change (when they exist) and those related to environment and sectors, laws about public administration and other related indirect norms or those with impacts on ecosystems and their services are relevant. Examples include fiscal and finance laws, which can create incentives or deterring effects on management of ecosystems and their services, and development planning. Other examples include data collection, the foundation for developing ecosystem governance instruments and particularly laws on land ownership rights, which can affect access to ecosystem services; and laws on public participation (Greiber \& Schiele, 2011). 


\begin{tabular}{|c|c|c|}
\hline Subject & & Examples of regulations \\
\hline & $\begin{array}{l}\text { Laws and } \\
\text { programmes on } \\
\text { planning and } \\
\text { climate change }\end{array}$ & $\begin{array}{l}\text { - } \text { Constitution } \\
\text { - Nationally Determined Contributions (NDCs) } \\
\text { - National Biodiversity Strategy and Action Plan } \\
\text { - National planning of plans/strategies } \\
\text { - Climate change/adaptation plans and strategies } \\
\text { - Laws on planning } \\
\text { - Laws on environmental or natural resource protection } \\
\text { - Laws on climate change } \\
\text { - Sectoral plans and strategies }\end{array}$ \\
\hline & $\begin{array}{l}\text { Laws and } \\
\text { programmes on } \\
\text { disaster risk } \\
\text { management }\end{array}$ & $\begin{array}{l}\text { - Law on human settlements } \\
\text { - Humanitarian laws } \\
\text { - Law on land use planning and urban development } \\
\text { - Civil protection laws }\end{array}$ \\
\hline & $\begin{array}{l}\text { Laws and } \\
\text { programmes on } \\
\text { environment, natural } \\
\text { resources and biodiversity }\end{array}$ & $\begin{array}{l}\text { - Agrarian laws } \\
\text { - Water laws } \\
\text { - Biodiversity laws } \\
\text { - Biosafety laws } \\
\text { - Forest development laws } \\
\text { - Rural development laws } \\
\text { - Fishery and aquaculture laws } \\
\text { - Laws on environmental responsibility } \\
\text { - Laws on environmental sustainability } \\
\text { - Wildlife laws } \\
\text { - Laws on air quality and atmospheric protection } \\
\text { - Environmental framework laws } \\
\text { - Law on land conservation and restoration } \\
\text { - Law on comprehensive and sustainable coastal/forest management }\end{array}$ \\
\hline & $\begin{array}{l}\text { Laws and } \\
\text { programmes } \\
\text { influencing the } \\
\text { institutional framework }\end{array}$ & - Laws on public administration \\
\hline tir & $\begin{array}{l}\text { Laws and } \\
\text { programmes that } \\
\text { influence financing }\end{array}$ & $\begin{array}{l}\text { - Laws on private sector financing (for example, banks, } \\
\text { brokerage firms, insurers, guarantors, financial leasing } \\
\text { companies, multiple purpose financing firms) } \\
\text { - Laws on public finances (laws on tax revenues/ fiscal year; } \\
\text { expenditures budget/ fiscal year; tax code; tax laws; } \\
\text { government funds; laws on public debt) } \\
\text { - Laws on insurance institutions, funds and trusts } \\
\text { - Laws on insurance contract }\end{array}$ \\
\hline & $\begin{array}{l}\text { Laws and } \\
\text { programmes } \\
\text { influencing } \\
\text { accountability and } \\
\text { reporting }\end{array}$ & $\begin{array}{l}\text { - Laws on government accounting } \\
\text { - Laws on oversight and accountability } \\
\text { - Laws on revenues } \\
\text { - Law on federal budget and treasury responsibility } \\
\text { - Laws on responsibilities of public servants } \\
\text { - Laws on transparency and access to public information }\end{array}$ \\
\hline מ7 & $\begin{array}{l}\text { Crosscutting laws } \\
\text { and programmes }\end{array}$ & $\begin{array}{l}\text { - Civil codes } \\
\text { - Criminal codes } \\
\text { - Laws on the rights of indigenous peoples } \\
\text { - Laws on gender equality } \\
\text { - Laws on environmental responsibility }\end{array}$ \\
\hline
\end{tabular}

Figure 4.3 Identification of EbA-related regulations 


\subsubsection{The law and adaptation to climate change}

Over the past decade a trend has been observed toward specific laws on climate change, ${ }^{9}$ since as the former Executive Secretary of the UNFCCC said, "Nothing is going to be agreed internationally until enough is legislated domestically" (Figueres, 2013). Climate change laws are considered to support as well as facilitate the implementation of the Paris Agreement (Nachmany \& Setzer, 2018).

On occasion law is also viewed as a barrier for climate change adaptation because of the uncertainty deriving from the ever changing, unpredictable and non-linear effects of climate change on ecosystems and their services. Hence, an adaptation law should not be conservationist in the sense of preserving the current status quo; it must inherently be dynamic and adaptable (Craig, 2010).

While it may seem contradictory, law must also have a fundamental role in eliminating barriers to adaptive management by establishing conditions to integrate sectors that until now have operated in an isolated manner, and ensure that planning processes are participatory. Law must also guarantee that the substantive objectives of regulatory mechanisms remain flexible and supported by relevant climate change information. Finally, law must also establish rules on the creation of adaptation capacities (Cosens et al., 2017).

Climate change can alter ecosystem characteristics, so laws regulating them should have instruments for adjusting to ecological transformations, rather than attempting to freeze the composition of an ecosystem in the same state it was when regulated. The new paradigm for environmental and natural resource laws should be to enhance the resilience and adaptive capacity of humans, species, society and ecosystems (Craig, 2010). This is precisely what EbA seeks to do.

Craig offers five general recommendations so laws can foster ecosystems' adaptive capacity:

1. Promote and channel funds to research and monitor climate change impacts at all scales and in all sectors. The object is to have more information and knowledge about climate change effects on specific ecosystems. That information provides important guidance to avoid implementing overly simplistic adaptation measures that compromise future adaptive capacities. Likewise, having robust and timely information can help overcome political or social impediments or barriers to implementing adaptation measures.

2. Eliminate or reduce non-climate stress on ecosystems and promote their resilience. This refers to the immediate adoption of measures that will reduce adverse impacts of human activities on ecosystems, improve environmental and human health and contribute to sustainability. Measures that can be mentioned:

a. Raise environmental standards to reduce pollution, soil degradation, habitat destruction and biodiversity loss; promote scientific innovation and increase the contribution of public economic resources for these ends;

b. Reassess quotas on natural resource use to make them sustainable;

c. Eliminate subsidies that incentivise erroneous adaptation measures (maladaptation) and create incentives to increase adaptive capacity; and

d. Protect and expand open spaces and connectivity between ecosystems, allowing dynamics among species and within ecosystems to find their own adaptation responses to climate change. 
3. Plan for the long term with greater coordination between sectors, governments and interests. Laws on climate change adaptation must include mechanisms permitting and promoting planning for adaptation and its implementation in a variety of time and spatial scales simultaneously. The following sub-principles can facilitate the incorporation of multidimensional aspects:

a. Incorporate climate change in planning instruments at all levels of government;

b. Weigh a gamut of possible long-range, future climate scenarios during the planning process;

c. Increase regulatory coordination between diverse sectoral laws;

d. Improve regulatory coordination among government bodies; and

e. Give more weight to the ecological function of property to balance out public and private interests.

4. Promote flexibility based on the objectives of regulation and natural resource management. This includes making natural resource management flexible, incorporating adaptive management procedures. Some recommendations to make legal frameworks more flexible are, on one hand, establishing a principle to prefer no-regrets adaptation measures (such as those described in recommendation 2, a few paragraphs above) and on the other, establish solid decision-making processes for adaptation strategies that signify important resource investments.

5. Accept that some losses are inevitable. While acknowledging that some losses are inevitable, adaptation laws must prevent inaction when losses are avoidable.

What the above essentially tells us about the complexity and uncertainty associated with climate change adaptation, is that under any scenario, taking measures that will help improve the adaptive capacity of ecosystems and humans should be an imperative in adaptation-related laws.

\subsubsection{Principles of law for EbA}

Principles are basic postulations that help interpret laws and guide decision making when there are conflicts, by establishing directives and priorities, for example, when a judge must weigh between mutually exclusive interests and rights. Certain principles of environmental law are especially important to promote and implement EbA measures.

Some of the most relevant are the following.

- Precautionary principle, also known as in dubio pro natura. When there is danger of serious or irreversible damage, the lack of absolute scientific certainty should not be reason to delay taking effective measures because of the cost of impeding environmental degradation (Sands, 1995). The most distinctive characteristic of this principle is that it has to do with good government and taking action even though the risk is uncertain or there is doubt.

The complexity of ecosystem interrelations, added to the uncertainty associated with climate change, makes the precautionary principle a keystone for decisions about development plans, programmes and projects to avoid actions that result in maladaptation and increase the vulnerability of ecosystems and people to climate change.

- Principle of prevention. Under this principle, mechanisms, instruments and policies are used to avoid serious damages to the environment and people's health. Unlike the precautionary principle, it has to do with due diligence and certain risk. 
This principle promotes applying all available instruments, such as strategic environmental assessments and environmental impact assessments, to prevent and avoid damaging ecosystems and their services. Applying this principle to $\mathrm{EbA}$ is important in that it dictates the need to assess impacts from economic and productive activities, taking the climate change variable into account when designing and deciding about development plans, programmes and projects.

- Principle of proportionality. Under this principle, if there are several alternatives of reasonable action, the least environmentally damaging should be chosen (Draft International Covenant on Environment and Development).

When some type of infrastructure is being built, like a wind park, it may impact on ecosystems depending on the site and the technology used. Given several options of where to locate the park, this principle would authorise decision makers to choose the option impacting least on the ecological balance to prevent degradation of the ecosystems.

- Principle of non-regression. This states that environmental regulations and jurisprudence may not revert to previous levels of protection. The aim is to prevent regulations from being suppressed or requirements lowered because of interests contrary to public environmental interest.

This principle is of utmost relevance for EbA governance since it serves as a padlock to prevent setbacks when regulatory frameworks are being adjusted in line with new information about climate change, ecosystem health and the impact of actions implemented up to then during policy evaluation processes.

- Principle of permanent sovereignty over natural resources. Under this principle, it is understood that people and nations have the right to decide about natural resource use in the interest of their national development and the well-being of the people of the State concerned.

One aspect of this principle of relevance for EbA governance is that the use of natural resources should take people's well-being into account. This could indicate to a judge or decision maker that environmental services should be considered a central element of human well-being when deciding on the use of natural resources.

- Equitable and wise use of natural resources and biodiversity. This principle has both domestic and international dimensions. The first involves the obligation of the State and individuals to protect the nation's natural wealth to ensure its sustainable development, conservation or restoration, along with the obligation to intervene in natural resource exploitation to rationalise the economy for the purpose of improving inhabitants' quality of life, equitable sharing of opportunities, development benefits and protection of a healthy environment (Constitución Política de la Colombia, art. 8 and 334 (Amaya, 2002)). In its international dimension, the principle imposes a limit on territorial sovereignty and mandates that States take into consideration the needs and uses of environmental goods and services on the part of States when they share the same ecosystem, such as a watershed. When analysing the equitable and reasonable use of shared resources, States must also take into consideration geographical conditions, uses of the resources, the population that depends on them, current and future social and economic needs, and how climate and ecological factors may affect the resource's availability (Art. 6 of the Convention on the Law of the Non-Navigational Uses of International Watercourses). 
Both dimensions are important for $\mathrm{EbA}$, since they establish directives concerning the different factors to be considered when deciding about natural resource use and lay the foundation for international cooperation in shared management of natural resources.

- Principle of subsidiarity. The central idea of subsidiarity is that ecosystem management must be at the most direct level possible, and if that is not achievable or requires support or coordination with other governments at the same level, a higher level of government in the hierarchy should be involved. In the context of climate change, implementation directives could include:

- Localities take the initiative and have the autonomy to lead adaptation actions, without affecting other localities, states or departments (Flatt, 2012).

- States/departments intervene as coordinator when: i) an ecosystem or EbA measure requires the participation of two or more localities; ii) when a locality has not taken the initiative to implement adaptation or restoration measures for an ecosystem; or iii) at the request of the locality.

- The federal/central government intervenes as coordinator when: i) the intervened ecosystem is transboundary; ii) an ecosystem or EbA measure requires the participation of two or more states/departments; iii) the local or state government has not intervened for the adaptation; or iv) at the request of one or more states.

This principle promotes the coordinated strengthening of local initiatives to achieve global objectives, such as the SDGs and adaptation (Vasseur, 2017).

- Principle of solidarity. States should cooperate in a spirit of global solidarity to conserve, protect and re-establish ecosystem health and integrity.

The importance for EbA is that this principle involves a broad obligation of cooperation that can include all of its forms, including research, collecting climate information, financing, capacity building and others.

- Principle of transparency and accountability. The obligation of public authorities to provide citizens with information about the direction of public affairs.

This is especially important in relation to fighting corruption associated with natural resource management or the public treasury (see Chapter 6, Negotiation).

- Principle of environmental responsibility. Signifies that the person, physical or legal, that has damaged the environment has the obligation to restore it to the state in which it was found and compensate the damage caused.

In addition, private property is a basic right in most national constitutions that authorises the use, enjoyment and disposition of the good freely, with no other limitation than those established by the law itself or a contract. As fundamental right, ownership enjoys constitutional guarantees and can only be limited for reasons of public interest or social utility (such as expropriation) through court ruling and prior compensation. Some national constitutions, such as those of Germany and Colombia, place limits on ownership due to a property's importance for achieving social ends, inter alia, the health of ecosystems on which people depend for their wellbeing. While not an internationally recognised principle, it is an important example of the role of law in the protection of ecosystems, especially when public interest must be weighed against individual rights. 


\subsubsection{Integration of EbA in legal environmental, sectoral and natural resources frameworks}

\section{Terrestrial ecosystems}

Some of the main mechanisms to increase the resilience of terrestrial ecosystems include the following (Boer \& Clarke, 2012):

- Protected natural areas (PNA). These are defined as

".... a clearly defined geographical space recognized, dedicated and managed, through legal and other effective means, to achieve the long-term conservation of nature with associated ecosystem services and cultural values" (Lausche, 2011).

These areas are essential to preserve biodiversity and maintain ecosystem services in a context of climate change.

- Climate change alters ecosystem composition and makes the main challenge of this legal mechanism that of flexibilising its geographical limits (Tanner-McAllister et al., 2017). To meet this challenge, it is proposed that adaptive management be incorporated in plans for managing protected areas, along with strengthening ecological connectivity.

Example: Protected natural areas (PNAs) in the Ley de Cambio Climático del Estado de Chiapas (LCC)

The climate change law of Chiapas, Mexico, includes protected natural areas as the main instrument for climate change adaptation (Art. 29) in the federal entity, explicitly stating its importance to increase the adaptive capacity of people and ecosystems and maintain ecosystem services (Art. 30). It also mandates that components of climate change adaptation and mitigation be incorporated in the decree creating the law and in the management programmes of the protected natural areas (Art. 31).

By incorporating adaptation, this law promotes that both the decree creating it and the design of the management programme include a vulnerability assessment of the ecosystems, ensuring their services.

In addition, the law could be said to facilitate the integration of adaptive management principles in decrees and management programmes, such as continuous monitoring and evaluation and flexibility.

- Forests. Forest ecosystems play a vital role in the water cycle, harbour a great diversity of species and function as carbon sinks. To maintain that function and provisioning of ecosystem services, Boer and Clarke recommend that laws have the objective of preventing loss of forest cover through stipulations mandating forest inventories, sustainable logging plans, penalties to deter violations of forest laws, compulsory reforestation in deforested areas and the design of surety bonds for environmental rehabilitation. (Boer \& Clarke, 2012).

- Water resource management. Water laws must include effective mechanisms to protect and manage sources, including restrictions on logging in recharge areas. With respect to water quality, as will be indicated shortly, pollution controls must be expanded; laws must ensure restrictions on water use to protect ecosystems while also guaranteeing the availability of potable water for human populations (Boer \& Clarke, 2012). 


\section{Marine and coastal ecosystems}

Mangroves and other coastal ecosystems carry out significant roles in adaptation to climate change. They stabilise coastal areas and shorelines and regulate storms, protecting human settlements.

1. Coastal management. Some of the major recommendations for promoting EbA in laws regulating coasts include: protection of mangroves from unsustainable uses such as indiscriminate harvesting of associated flora and fauna, deforestation and changes in the coastline, as well as control of nutrient runoff and sediment flowing to coastal waters.

2. Fishery management. Fishery management tools should incorporate the EbA approach to prevent over-exploitation of fishery resources and to maintain the health of coastal ecosystems and the livelihoods of local communities. Laws in this sector could improve ecosystem health, for example by banning destructive fishing methods, protecting spawning areas, establishing controls on the issuance of permits where zones are under bans and protecting certain fish species, among other actions.

3. Marine protected areas. To maximise the resilience of marine ecosystems, these protected areas should have the following characteristics, among others: be extensive areas with simple configurations, represent and replicate multiple habitats and physical parameters, be dispersed over broad geographical areas to minimise risks, protect ecological characteristics fostering resilience and recovery from extreme weather events and maintain habitat connectivity and ecological processes (Boer \& Clarke, 2012).

\subsection{Relevant EbA implementation tools}

Law must provide the instruments, mechanisms, processes and responsibilities for implementing policy. EbA implementation mechanisms should include, inter alia, schemes for payment of environmental services, reforestation incentives, projects to reduce $\mathrm{CO} 2$ emissions through avoided deforestation (REDD) and the establishment of protected areas. It could be said that any conservation or restoration instrument aimed at increasing the resilience of ecosystems and people could be considered a mechanism for implementing EbA.

Main mechanisms to enhance the resilience of existing ecosystems and which EbA legal frames and mechanisms could strengthen are:

1. strategic spatial planning and

2. strategic environmental assessments and environmental impact assessments.

\subsubsection{Spatial planning for EbA}

In general terms, strategic spatial planning is an instrument for spatial ordering of territory that goes beyond traditional urban/rural planning. It also takes into account the impacts and influence of other sectoral policies, geographic spaces and the use of both terrestrial and marine natural resources, along with other factors such as climate change and disaster risk. Its objective is to plan for future development needs and opportunities in specific jurisdictions, bearing in mind policies relevant to the area with the aim of promoting more equitable distribution of economic development (Lausche, 2018; Rozas-Vásquez, et al., 2018). 
One of the primary difficulties of integrating $\mathrm{EbA}$ in comprehensive territorial planning instruments is defining the correct spatial scale of intervention to ensure ecosystem functioning. This is because provisioning of and demand for ecosystem services varies at local, regional and global levels, affecting a wide range of stakeholders. To tackle this challenge, the different government levels authorised to adopt decisions about ecosystems, economic activities, relations between rural and urban areas and political-administrative demarcations should coordinate to implement EbA measures.

Strategic spatial planning has potential for the incorporation of ecosystem services at multiple levels of governance, since it functions as a platform for coordinating different policy instruments in a strategic and articulated manner and making decisions about future changes in land, coastal and marine systems.

As process, planning is expressed through land use plans prepared according to processes and tools established by law (generally land-use law).

Once adopted, plans have legal implications by regulating activities that can be carried out in the respective area; in other words, they are regulatory instruments. There generally is a hierarchy of plans at national, regional and local level, and the law requires those lower down to maintain coherence with those higher up, thereby ensuring vertical normative coordination (Lausche et. al., 2013).

For effective integration of climate resilience in land planning, communities must be positioned at the heart of decision making about future land uses. In addition, it is important that EbA be recognised as a cost-efficient response in coping with the effects of climate change, and that the plans implemented make the best possible use of limited human and financial resources.

To integrate the EbA approach in territorial planning instruments, current and future climate change impacts on land uses and marine and coastal ecosystems must be assessed.

Territorial planning should integrate EbA measures that are coherent with the different uses of land, assuring connectivity between ecosystems and making visible ecosystem services that create relations of interdependence among rural, urban and industrial areas.

One of the challenges associated with this entire process lies in the need to use a combination of geographic information systems and other spatial information, since the necessary technologies or capacities are not always available. Another challenge relates to engaging key actors given that ultimately, land planning is above all a process of negotiation.

\subsubsection{Strategic environmental assessment and environmental impact assessment}

Strategic environmental assessment (SEA) and environmental impact assessment (EIA) are two environmental management tools that seek to prevent and control negative impacts of anthropogenic origin on the environment. In particular, the difference between them concerns their sphere of application. While EIA applies to activities, works or projects, SEA has a broader reach and reveals opportunities, risks, threats and potentialities, based on sustainability (see Table 4.2). 


\section{Table 4.2 Comparison between SEA and EIA scope}

\begin{tabular}{|l|l|l|}
\hline Object & SEA & EIA \\
\hline Parties responsible & $\begin{array}{l}\text { Applied to policies, plans and } \\
\text { programmes }\end{array}$ & Applied to activities, works and projects \\
\hline Scope & $\begin{array}{l}\text { Makes it possible to visualise macro } \\
\text { and cumulative impacts }\end{array}$ & $\begin{array}{l}\text { The holder, owner or legal representati- } \\
\text { ve of an activity, work or project }\end{array}$ \\
\hline $\begin{array}{l}\text { Moment within the } \\
\text { EbA scaling process }\end{array}$ & Planning for EbA & Implements area of influence only \\
\hline
\end{tabular}

The SEA is an instrument that supports decision making as process and is applied to decisions of a strategic nature, typically known as policies, plans and programmes. It informs planners, decision makers and the affected public about the sustainability of strategic decisions, facilitating the search for better alternatives and ensuring a democratic decision process (Lobos, 2015).

The EIA is a preventive tool to assess a project's negative and positive impacts on the environment and proposed alternatives to adjust levels of acceptability. Environmental impact is: "....any significant alteration of natural and transformed systems and their resources, caused by human actions (...) Impacts are expressed in the different activities and occur in both natural environments and those resulting from human intervention and creation" (Aguilar \& Iza, 2011).

The SEA and the EIA are similar and complementary instruments. The strategic character of the first makes it possible to consider indirect, cumulative and synergetic impacts of activities in a spatial and time frame not possible for EIA, since its focus is limited to concrete activities, works and projects (Lobos, 2015). EIA analyses impacts within a much more defined space than those that SEA is able to study.

The SEA has seven phases, according to the Economic Commission for Latin America and the Caribbean (ECLAC, 2009):

Phase 1. Establish the Strategic Environmental Framework. The aim in this phase is to define the foundations of the SEA and its specific objectives.

Phase 2. Scope. Consultations are initiated with social agents (authorities with jurisdiction over the plan and other stakeholder groups) to agree on the SEA's scope and level of detail.

Phase 3. Assessment model. A strategic diagnostic appraisal is made of the policy environment that governs planning, and an evaluation of the alternative options that will be formulated in the planning process.

Phase 4. Environmental analysis and appraisal. Description of the plan's strategic environmental dimension to the highest degree of precision desirable to establish that vision as cornerstone of the plan's evaluation. The objective is to acquire a very clear vision of the most relevant environmental dynamics and their past behaviour and understand the most important environmental challenges for the plan.

Phase 5. Environmental assessment of alternative options. This is an iterative process to weigh options at different relevant moments when formulating the plan. ECLAC examines three relevant 
moments: i) when defining the plan's operational objectives, ii) when defining strategic options and iii) when developing operational options.

Phase 6. Prevention and supervision. This phase involves a recapitulation of the SEA to generate recommendations on the plan's implementation process based on the exercise carried out. Environmental measures or direct environmental management instruments that should be incorporated in the plan are proposed, along with measures or instruments for its environmental supervision.

Phase 7. Formulation of final reports and consultation. The SEA process culminates in final report preparation and consultation. Consultations should be followed by reporting on the extent to which commentary is included in the final formulation of the plan, on results from prior phases of the evaluation process and on the final consultation process. Since participatory processes have been carried out in earlier phases, it concludes rather than begins in this phase.

Because strategic environmental assessments are key to incorporating EbA in development and sectoral policies, plans and programmes, UNEP proposes integrating ecosystem services as one more variable in what must be assessed. (UNEP, 2014). By putting a recommendation into practice it is possible to establish the context of the ecosystem; determine and evaluate priority ecosystem services; identify alternatives and assess impacts on ecosystem services; and monitor the ecosystem services. This likewise applies to environmental impact assessments.

Along with ecosystem services, the variable of climate change must also be integrated as an additional layer of information in these decision-making processes. Hence, it is important to include a study of climate impact and climate variability and design measures to manage possible environmental and climate impacts as well as adaptation measures, preferably EbA.

\subsection{Institutions and processes for EbA}

As part of its functions, law must also create institutions and define their functions, competencies and jurisdictions, as well as the processes that must be implemented to guarantee those functions are carried out. Chapter 5 offers an in-depth examination of institutions for adaptation.

\subsubsection{Institutional coordination mechanisms}

The first interinstitutional coordination mechanism for EbA that can be found in a law consists of a clear distribution of functions among the different sector institutions and government levels, along with a mandate to cooperate on specific matters.

\section{Example: Distribution of competencies in the Ley de Cambio Climático de México}

- The Federation has the power to "formular, conducir, dirigir e instrumentar acciones para la adaptación en materia de "preservación, restauración, manejo y aprovechamiento sustentables de los ecosistemas y recursos hídricos de su competencia (formulate, conduct, direct and operationalise actions for adaptation with respect to the 'preservation, restoration, management and sustainable use of ecosystems and water resources under its jurisdiction') (Art. 7).

- Federal entities have powers to "formular, conducir, dirigir e instrumentar acciones para la adaptación en materia de "preservación, restauración, manejo y aprovechamiento sustentables de los ecosistemas y recursos hídricos de su competencia" (formulate, conduct, direct and opera- 
tionalise actions for adaptation with respect to the 'preservation, restoration, management and sustainable use of ecosystems and water resources under its jurisdiction') (Art. 8).

- Municipalities have authority to formulate and operationalise adaptation policies and actions in line with national and state laws on "recursos naturales y protección al ambiente de su competencia" (natural resources and protection of the environment under its jurisdiction) (Art. 9).

Consequently, certain ecosystems have remained exclusively in Federation hands, while for some resources where there are concurrent competencies among different government levels, authorities are instructed to sign coordination agreements with the Federation, federal entities and municipalities for the implementation of adaptation measures (Art. 8, VII).

The Mexican case exemplifies how competencies and interinstitutional cooperation arrangements are distributed when jurisdictions overlap in some way.

Other institutional coordination mechanisms relate to support for or development of capacities. For example, Honduras's Ley de Cambio Climático mandates various national authorities (Instituto de Desarrollo y Conservación Forestal, Áreas Protegidas y Vida Silvestre, Secretaría de Estado en el Despacho de Agricultura y Ganadería, Secretaría de Estado en los Despachos de Recursos Naturales y Medio Ambiente and Secretaría Técnica de Planificación y Cooperación Externa) to collaborate with municipalities that must align their land use plans with national plans (Art. 24).

\subsubsection{Multi-level regulatory coherence}

There is nothing new about the need to ensure coherence at different government levels in the legal system since this is part of law theory itself. It is summarised in Kelsen's pyramid (Figure 4.4).

According to Kelsen's pyramid, the Constitution is the fundamental norm establishing content that determines the substantive validity of every norm lower in the hierarchy. In other words, every law, regulation, convention or use and custom must be adjusted to constitutional precepts. This could be summarised as 'nothing above or outside the Constitution.' Currently many country constitutions grant constitutional status to international human rights treaties that have been ratified by the State. In the area of climate change, the tendency has been to formulate general acts or framework laws that establish principles and basic stipulations. At the same time, these laws provide enough leeway for regional, local and sectoral regulations to set out greater detail based on local situations, while at all times respecting the limits of higher-level norms. 


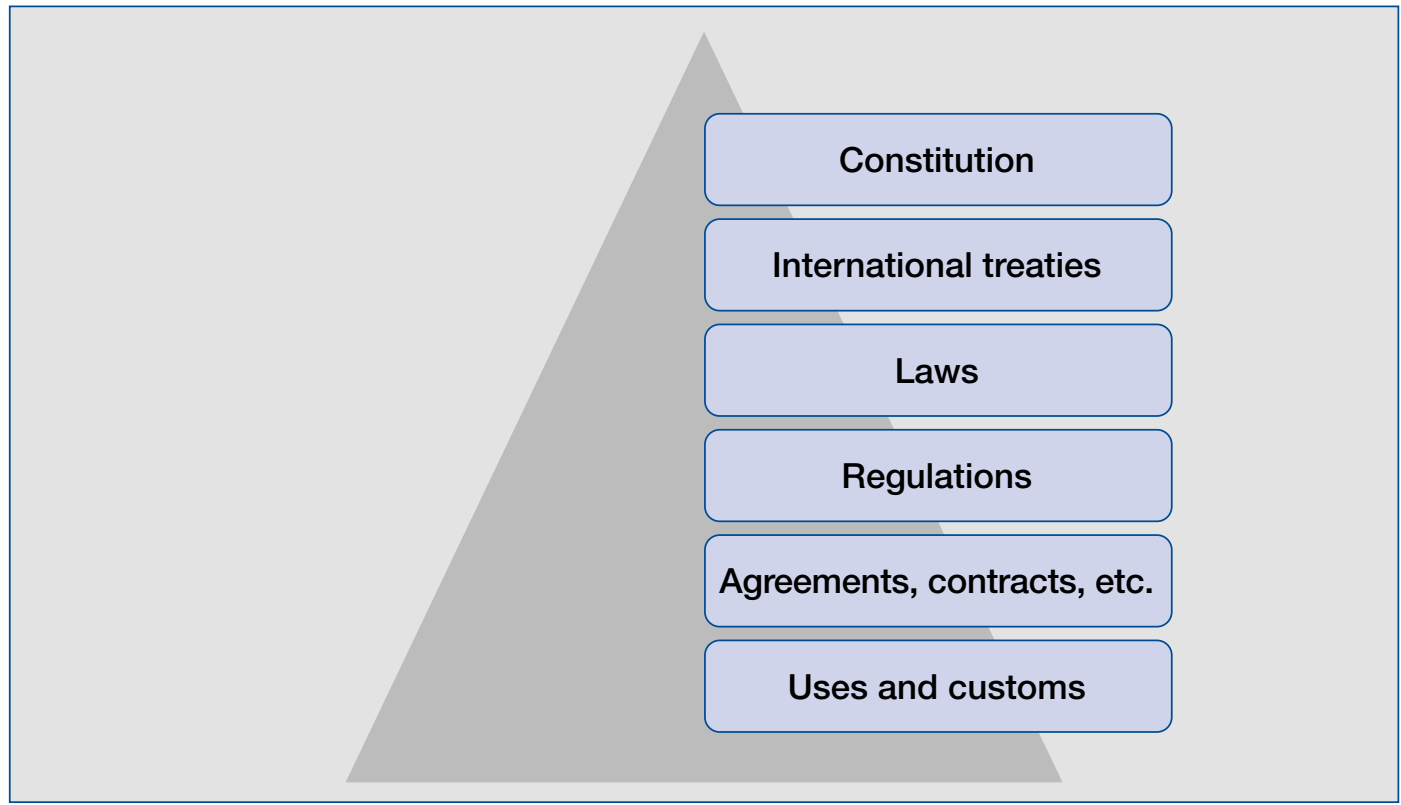

Figure 4.4 Kelsen Pyramid

Source: Adopted from Hans Kelsen

The challenge, therefore, is not achieving initial coherence between norms at different levels but maintaining that coherence in a dynamic and changing context. In this sense, adaptive management requires periodic evaluation and adjustment of laws, given the reality that government authorities in different levels and sectors do not operate at the same pace.

\subsubsection{Monitoring and evaluation}

Monitoring, evaluation and adjustment are the keystone in the new form of adopting public policies. The law must include these processes in all of the policy instruments and regulatory instruments analysed. For example, laws must also include mechanisms needed for protected area management plans and land use plans to be reviewed periodically due to climate vulnerabilities. In this manner, specific mechanisms that become mandatory have the flexibility to deal with the uncertainties associated with climate change.

Given that adaptation is specific to each territorial context, laws must prescribe evaluation processes based on scientific information and local and traditional knowledge (Boer \& Clarke, 2012).

Moreover, laws must stipulate processes for amending regulatory mechanisms, since monitoring and evaluation would lose much of their value if adjustments could not be made. These processes must find a balance between simplicity and flexibility, on one hand, and on the other, transparency and due process. The law must also clearly indicate the institutions in charge of carrying out the evaluation.

All processes for amending regulatory mechanisms should establish opportunities for the people affected to participate, following the minimum standards of international agreements for public participation in environmental matters and pertinent national legislation. 


\subsubsection{Public participation}

Public participation in environment-related matters is a basic principle of environmental law, a necessary condition of environmental policies and a human right.

The role of public participation has won prominence in international law thanks to the many benefits reported, such as those below and others. Public participation:

- Fosters environmental awareness;

- Permits identifying environmental problems and possible solutions. In the case of EbA, participation makes it possible to identify vulnerabilities to climate change and design adaptation measures;

- Promotes democracy, so that decisions are not only based on technical factors or information (technocracy);

- Facilitates reaching decisions that support distributive justice and thus recognise the interests of diverse actors, and by allowing them to participate in decision processes and defend their rights, also encourages their rights to be taken into account in accessing the benefits and sharing the costs of the decisions adopted (promotes equity);

- Allows people to take responsibility for caring for the environment and makes them agents of change; and

- Facilitates oversight of compliance with environmental legislation, so that when people file claims with the authorities or take to the courts to demand compensation for environmental damages, they become overseers of environmental legislation.

In the sphere of international law, participant rights were first recognised in Principle 10 of the 1992 Rio Declaration on Environment and Development. Since then it has entered into State constitutions as part of the right to a healthy environment, in national legislation on transparency, access to information and environment and in international environment and human rights treaties. Furthermore, international human rights courts have recognised the environmental dimension of civil and political rights.

These are now enshrined in a special way in two specific international treaties:

- The Convention on Access to Information, Public Participation in Decision-Making and Access to Justice in Environmental Matters (hereon the Aarhus Convention);

- The Regional Agreement on Access to Information, Public Participation and Justice in Environmental Matters (hereon the Escazú Agreement). ${ }^{10}$

These treaties recognise three interrelated and inalienable rights:

- the right of access to information

- the right to public participation in environmental matters

- the right of access to justice

Accessible information is considered a prerequisite for stakeholders to be able to form an opinion and participate in the direction of environmental matters. The existence of administrative or judicial

10 At the closing of this book's preparation, 16 countries had ratified the agreement, but the period for its entry into force (Article 22) was still open. 
resources is a necessary condition to ensure the right of access to information and to exercise the right to public participation in environmental matters.

The three rights signify that public authorities are required to fulfil certain common obligations:

a) Legislate to enforce access rights. Legislation must meet certain international minimum standards;

b) Strengthen capacities and educate the population and public officials about the exercise of these rights;

c) Remove barriers preventing full enjoyment of access rights (for example, public authorities must ensure the safety of environmental advocates); and

d) Establish effective recourse against violations of access rights (such as the possibility of going to court to demand compensation for rights violations).

Procedural environmental rights are enormously important to EbA effectiveness, in that they allow citizens to exercise a role as change agents. On one hand, citizens can promote the integration of EbA in plans, programmes and projects, and on the other, they can monitor enforcement of the law to defend ecosystems and consequently contribute to their own adaptation. A case recently decided in Colombia illustrates the importance of procedural environmental rights.

\section{Judgment C-035/16 of 8 February 2016 of the Tribunal Constitucional de Colombia}

This sentence annulled the provisions of two national laws (Law No. 1450 of 2011 and Law No. 1753 of 2015) because they threatened paramos, sensitive highland ecosystems. The court drew attention to the characteristics of paramos, such as their fragility, the lack of legal protection and their role in providing $70 \%$ of the country's drinking water, as well as the capacity of their soil and vegetation to capture $\mathrm{CO}_{2}$. The court emphasised that the paramos are carbon sinks and explained that these ecosystems can ultimately have greater sequestration capacity than tropical forests of the same size, so warrant special protection.

The court consequently deemed both laws (1450 and 1753) unconstitutional, especially two provisions in Law No. 1753 of 2015. One, because it authorised the Comisión de Infraestructura Intersectorial y Proyectos Estratégicos to declare certain projects of national interest, meaning exempt from local regulatory oversight. The other prohibited several activities in paramos such as agriculture, mining and oil and gas exploration, but only if project owners had obtained their environmental permits any time after 9 February 2010, and for gas and hydrocarbon after 16 June 2011.

The court declared both provisions unconstitutional because, among other things, they jeopardised the population's right to potable water and because government authorities had not met their obligation to justify decisions that would result in the degradation of sensitive areas and ecosystems with high value to society.

Other human rights treaties recognise the participation right of specific people or groups, such as indigenous peoples, women, children and people with disabilities, for example, for the same reasons described above. However, the treaties give special treatment to the right of these people to participate for the purpose of eliminating de facto obstacles they commonly face in exercising their rights.

Of utmost importance, the Indigenous and Tribal Peoples' Convention No. 169 of the International Labour Organization (ILO) and the United Nations Declaration on the Rights of Indigenous Peoples recognise the rights of indigenous peoples to free, informed and prior consent (FPIC) in decisions affecting their 
territories and the natural resources in them. FPIC has intrinsic value in the claims of indigenous peoples, as it recognises and promotes respect for their autonomy and their right to self-determination. This means it has social justice value by allowing them to determine their model of developing, using and distributing their natural resources and, in theory, to arrange equitable sharing of the benefits of those resources and biodiversity. Beyond that, indigenous peoples are recognised as having ancestral knowledge and practices harmonious with nature that are of great value in seeking climate change solutions, so their participation in decision processes enhances the quality of decisions in this area.

Currently most laws on environment and climate change include provisions for access to information and public participation in relation to climate change.

\subsection{Financing mechanisms for EbA}

From the moment EbA becomes a social objective incorporated in public plans and strategies, it must be accompanied by suitable financing mechanisms to implement the actions laid out in such plans and strategies.

Laws have a crucial role in financing EbA by directly establishing public funds for adaptation actions or creating specific markets or other economic mechanisms.

\section{Example: Public budgetary allocations for EbA actions in Guatemala}

Guatemala's framework law to regulate vulnerability reduction, mandatory adaptation to climate change effects and mitigation of greenhouse gases tasks the Consejos de Desarrollo Urbano y Rural with incorporating climate change in their development policies, plans, programmes and projects. These must be coordinated with public investment planning at sectoral, public and territorial level. In addition, the Secretaría de Planificación y Programación de la Presidencia is responsible for ensuring projects are included in the Sistema Nacional de Inversión Pública).

The law identifies priority areas for developing strategic and operational plans on vulnerability reduction and climate change adaptation as starting points for EbA practices in sector plans. Those priorities are human health; marine and coastal zones; farming, livestock raising and food security; forest resources, ecosystems and protected areas; and infrastructure. As reinforcement measure, public and private persons, physical and corporate, are responsible for adopting new practices, including those deriving from traditional and ancestral knowledge that minimises soil degradation. Further, the ministries of Agricultura, Ganadería y Alimentación (MAGA) and Ambiente y Recursos Naturales (MARN) must establish policies and programmes to prevent degradation and improve soil conservation and issue recommendations for its productive use.

Finally, the law establishes a national climate change fund, under MARN, to finance payment for natural services of carbon fixing, water production and protection, ecosystem protection, scenic beauty and others. Financing sources for this fund are diverse, and in particular include a yearlydetermined contribution in the State revenues and expenditures budget, payments to compensate for greenhouse gas emissions under the regulations MARN issues as mandated by this law; "fondos provenientes de las negociaciones de Canje por Adaptación y Mitigación al Cambio Climático" (funds deriving from climate change adaptation and mitigation debt swap negotiations) and funds from national donations or international cooperation. These funds are to be used especially for adaptation. 
The framework law also creates funds to capture and channel economic resources for EbA implementation and may create economic mechanisms for EbA, such as payment for environmental services schemes, concessions, green bonds, entry fees for parks in protected natural areas, climate insurance, etc. (Boer \& Clarke, 2012).

EbA measures must be tailored to the conditions of each particular context (climate risk, ecosystem, geographic scale of the measure and level of implementation), so no single mechanism can fund all the types of EbA actions applicable to all cases (GIZ, 2018). Hence, allowing economic mechanisms to be created based on the ecosystem, specific service and conditions of local populations seems to be the best option. For example, Mexico's Ley General de Cambio Climático leaves the choice and/ or creation of suitable mechanisms in the hands of the Federation and Federal entities to encourage the achievement of national policy objectives on climate change (Art. 91). This flexibility must nonetheless be accompanied by careful legal engineering to guarantee that whatever mechanism chosen is effective, since this depends on appropriate legal frames and clear, equitable agreements amongst the parties.

\subsection{Implementation and enforcement of the law}

Implementation and enforcement of law depends on the existence of solid and efficient institutions (Iza \& Stein (eds.), 2009), as well as inspection and surveillance, security measures and penalties. Most countries now have a body that supervises enforcement of environmental legislation, so while EbA regulation is dispersed among general environmental acts, natural resource laws and indirectly related legislation, this is not necessarily true of implementation and enforcement procedures. For example, in Mexico the Procuraduría Federal de Protección al Ambiente (PROFEPA) is responsible for ensuring compliance with the Ley General del Equilibrio Ecológico y la Protección al Ambiente (LGEEPA), and all other general and federal acts related to natural resources. PROFEPA also carries out inspections and oversight of natural or legal persons subject to emissions reporting.

This normative and institutional coherence is fundamental to optimise resources and capacities for monitoring EbA laws. The lack of proper enforcement supervision could increase pressures on ecosystems (such as more activities emitting gases or other polluting substances into the atmosphere, illegal harvesting of forest resources or illicit trade in species) and therefore threaten the capacity of those ecosystems and people to adapt to climate change.

\subsection{Settlement of disputes}

Governance goes beyond government; it also concerns any other form of organisation among members or sectors of society. Governance includes relations between public authority and community, public authority and business (private sector), business and community, financial entity and community, and many other possibilities, all of which can generate conflict.

There are countless ways disputes can arise; to name just a few examples: activities that degrade the resources on which communities depend, the implementation or interpretation of an environmental or sectoral law that has effects on ecosystem balance, land ownership or tenure; implementation or enforcement of a payment for environmental services contract; implementation or enforcement of an ecosystem co-management contract or internal distribution of benefits from an EbA financing scheme in a community. 
These conflicts are normally settled by tribunal or national judicial power in civil, administrative or criminal courts, as corresponds. But conflicts can take years and even decades to resolve, making it important to find ways of speeding up legal procedures related to ecosystem adaptation and management.

Compounding the difficulty, uncertainty about climate change can also trigger conflict. This is not only due to change in the physical conditions upon which regulatory frameworks, implementation mechanisms and contracts (and all else mentioned in this chapter) are designed and established, but also due to ever greater competition for ever dwindling resources, such as water.

Thus, along with legal channels, alternative conflict resolution measures are important since these are generally quicker and more flexible. The advantages of using these as opposed to judicial mechanisms must be weighed in each particular case.

Alternative conflict resolution brings in diverse techniques and approaches to settle differences through mutual agreement between persons (physical or legal), thereby avoiding costs, delay and the unpredictability of traditional adjudication procedures.

These processes employ neutral third parties with substantive and decision-making authority. Alternative conflict resolution entities can include courts or divisions of the judicial authority.

Main conflict resolution techniques include the following processes.

- Arbitration: Employs a private neutral third party with decision-making power and substantive authority. The parties explicitly agree to use this mechanism to end a dispute, and typically have greater control over the procedure.

- Advising with decision-making power: Employs a neutral party, public or private, with decision-making power whose authority can be binding in terms of procedure but not substance. This category includes non-binding arbitration.

- Mediation: Employs a neutral third-party communicator, public or private, who has decision-making power aimed at reaching a substantive agreement between the parties. The possibility of settling substantive matters is entirely up to the parties.

- Facilitation: A neutral, third-party communicator, public or private, is employed to reach a substantive agreement between the parties. Facilitators are the ultimate neutral parties in the universe of conflict resolution techniques and the parties negotiate directly. With this technique the neutral actor can achieve an agreement among all parties, even for procedural decisions.

\subsection{Policy challenges and opportunities}

Climate change and its effects require a new way of understanding and formulating policies and laws. The centralisation and concentration of decisions is no longer adequate, trust in a single source or type of information is insufficient, and the certainty and stability of a rigid law is, in many cases, shown to be problematic.

Holism, coordination, decentralisation, the participation of all sectors, the integration of different types of knowledge and information, and flexibility are key terms defining planned adaptation and EbA governance.

Dealing with these issues is at once a challenge and an opportunity. Climate change makes us aware of the interrelations among socio-environmental systems. It invites us to reformulate the way 
we perceive the relation between human beings and nature and in the last analysis, to redefine that relation from all aspects of social organisation and particularly from the stance of policy and legislation. 


\title{
5 Institutions
}

\author{
Mauricio Luna Rodríguez
}

\subsection{Introduction}

In general terms, institutions are the conditions established by human beings that structure their social, economic and political interactions. Throughout history, institutions have been created to reduce uncertainty in human interactions and have evolved in response to the growing needs of an increasingly interconnected world (North, 1991; O'Riordan \& Jordan, 1999). The phenomenon of climate change heightens uncertainty when making decisions, so institutions play a pivotal role in managing the challenges of global warming (Sanchez \& Roberts, 2014).

Institutions can be classified as formal and informal, and may also pertain to public, private or civil spheres (North, 1991; Wang et al., 2013). Institutions are, on one hand, the uncodified 'rules of the game' (informal) such as values and traditions dictating behaviour in a society, and on the other, they are the tangible organisations for governance (formal), such as development associations (civil sphere), businesses (private sphere) or government structures (public sphere) (O'Riordan \& Jordan, 1999; Mubaya \& Mafongoya, 2017).

In recent times and in response to climate change, a series of formal institutions has emerged bringing together players from multiple arenas. For the purposes of conceptual classification helping to identify different types of formal institutions, in this chapter those with actors from more than one sphere of governance will be called multidimensional.

Institutions are often viewed as synonymous with organisations. However, organisations are simply those institutions that have formalised their regulatory and decision-making standards (Gupta et al., 2010).

This chapter focusses on the analysis of formal institutions (multidimensional structures or organisations) identified in policies as part of the institutional system responding to climate change, with particular attention to Guatemala, Honduras, Costa Rica and the State of Chiapas, Mexico.

\subsection{Institutionality for adaptation}

The challenges that climate change adaptation poses call for a multisector and multilevel institutional approach (Vignola et al., 2009). The theme of climate change adaptation is linked with development, which has given rise to a series of institutional arrangements aimed at providing responses that are by nature multidimensional, meaning multilevel and multisectoral, to the challenges of adaptation (Chaudhury et al., 2016; Sanchez \& Roberts, 2014). Analysing and understanding the institutional dimensions of adaptation is therefore fundamental in the process of adjustment to climate change that is needed to manage and attempt to reduce uncertainty (Cuevas, 2018).

Adaptation challenges call for new, formal institutional arrangements that go beyond the 'sectoral' form in which states have organised themselves. Although there is no formula for defining the ideal institution to tackle the challenges of climate change, if the institutional dimension is neglected resources are frequently wasted (Bolman \& Deal, 2013). Paying more attention to institutions is consequently of utmost importance for the effective implementation of adaptation actions (Chaudhury et al., 2016). 
The intent of this chapter is, on one hand, to analyse the formal institutions that are part of national policies on adaptation to climate change and on the other, to examine the multidimensional institutions now emerging in response to climate change in Meso America. The latter will be accomplished through a description and analysis of formal institutionality for adaptation in the public policies of Mexico, Guatemala, Honduras and Costa Rica, policies that incorporate diverse sectors, actors and government levels.

\subsection{Typology of institutions for EbA}

The literature on climate change acknowledges that public, private and civil sector participation is vitally important in adaptation governance (Fröhlich \& Knieling, 2012; Mubaya \& Mafongoya, 2017; Sanchez \& Roberts, 2014; Wang et al., 2013). The need for a multilevel approach, from local to international, is also stressed (Girard et al., 2015; Sanchez \& Roberts, 2014). The following table outlines proposed typology of formal institutions (multilevel and multisector) for adaptation, emphasising a multidimensional approach.

\section{Table 5.1 Typology of institutions for adaptation}

\begin{tabular}{|c|c|c|c|c|}
\hline \multirow{2}{*}{ LEVEL } & \multicolumn{4}{|c|}{ SECTOR } \\
\hline & Public & Private & Civil & Multidimensional \\
\hline Global & $\begin{array}{l}\text { Global institutions } \\
\text { comprised of } \\
\text { States }\end{array}$ & $\begin{array}{l}\text { Private global } \\
\text { institutions }\end{array}$ & $\begin{array}{l}\text { Civil society } \\
\text { institutions }\end{array}$ & \multirow{5}{*}{$\begin{array}{l}\text { Structures that } \\
\text { simultaneously } \\
\text { integrate } \\
\text { organisations in } \\
\text { more than one } \\
\text { sector and/or } \\
\text { more than one } \\
\text { level (adaptation } \\
\text { governance) }\end{array}$} \\
\hline Regional & $\begin{array}{l}\text { Regional } \\
\text { institutions } \\
\text { comprised of } \\
\text { States }\end{array}$ & $\begin{array}{l}\text { Private regional } \\
\text { institutions }\end{array}$ & $\begin{array}{l}\text { Regional civil } \\
\text { society institutions }\end{array}$ & \\
\hline National & $\begin{array}{l}\text { State institutions } \\
\text { governing the } \\
\text { climate agenda at } \\
\text { national level }\end{array}$ & $\begin{array}{l}\text { Private national } \\
\text { institutions }\end{array}$ & $\begin{array}{l}\text { National civil } \\
\text { society institutions }\end{array}$ & \\
\hline Sub-national & $\begin{array}{l}\text { State sub-national } \\
\text { and municipal } \\
\text { institutions }\end{array}$ & $\begin{array}{l}\text { Private sub- } \\
\text { national } \\
\text { institutions }\end{array}$ & $\begin{array}{l}\text { Sub-national civil } \\
\text { society institutions }\end{array}$ & \\
\hline Local & - & $\begin{array}{l}\text { Private local } \\
\text { institutions }\end{array}$ & $\begin{array}{l}\text { Local civil society } \\
\text { institutions }\end{array}$ & \\
\hline
\end{tabular}

Source: Author, based on Chaudhury et al. 2016; Fröhlich \& Knieling, 2012; Iza \& Stein (eds.), 2009; Mubaya \& Mafongoya 2017

The analysis of institutionality for adaptation in this chapter focusses on national and sub-national entities in the previously mentioned countries, including examples of transboundary institutions dealing with shared basins. Because of the recent rise of multidimensional structures addressing climate change, special attention will be on this emergent type of structure.

\section{Mexico}

This country has the Sistema Nacional de Cambio Climático (SINACC) established through the Ley General de Cambio Climático (articles 38-57). Its main objective is to "fungir como un mecanismo 
permanente de concurrencia, comunicación, colaboración, coordinación y concertación sobre la política nacional de cambio climático" (serve as a permanent mechanism for concurrence, communication, collaboration, coordination and consultation regarding national climate change policy) (Congreso de la Unión de los Estados Unidos Mexicanos, 2012, Art. 38, I).

SINACC is comprised of the Comisión Intersecretarial de Cambio Climático; Consejo de Cambio Climático; Instituto Nacional de Ecología y Cambio Climático; governments of the federated states; representatives of the Asociaciones de Autoridades Municipales and representatives of the Congreso de la Unión (Congreso de la Unión de los Estados Unidos Mexicanos, 2012), as illustrated in Figure 5.1.

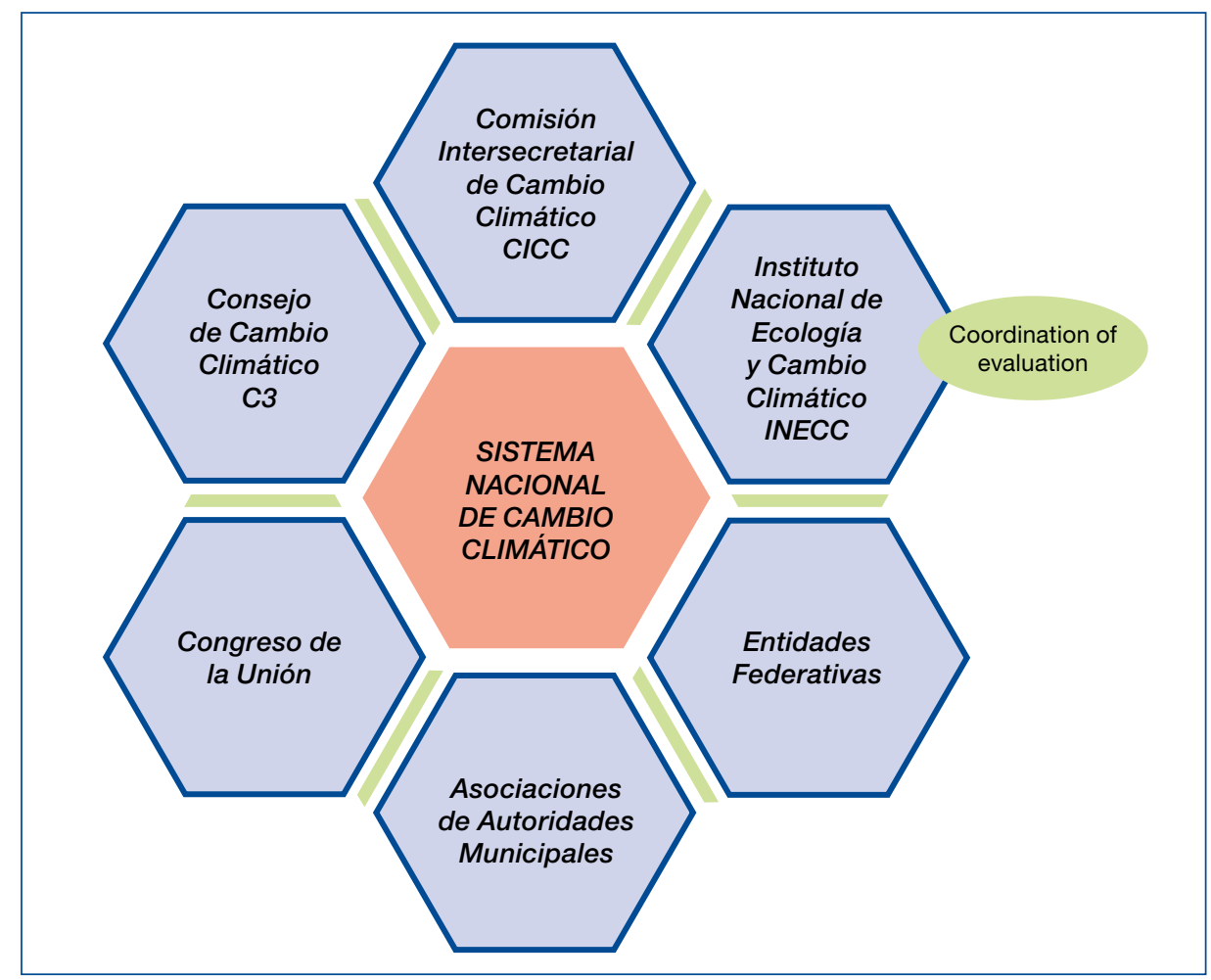

Figure 5.1 Institutional framework of the Sistema Nacional de Cambio Climático de México

Source: SEMARNAT, 2018

One of the strengths of Mexico's system is that it is protected in the nation's climate change framework legislation, which provides solid legal underpinnings in a region where countries commonly lack public policies that transcend electoral cycles and changes in government (Delamaza et al., 2017). It also coherently integrates existing institutionality (for example, in the Congress and federated entities) with institutional arrangements newly created for further multisector and multilevel coherence. Institutions making up the national climate change system are described below. 


\section{Comisión Intersecretarial de Cambio Climático (CICC) (Intersectoral Climate Change Commission)}

This is a permanent, national-level public body led by the President of Mexico, who may delegate that function to the head of the Secretaría de Gobernación or head of the Secretaría de Medio Ambiente y Recursos Naturales. It is multisectoral since it integrates the heads of 14 secretariats: Medio Ambiente y Recursos Naturales; Agricultura, Ganadería; Desarrollo Rural, Pesca y Alimentación; Pesca y Alimentación; Salud; Comunicaciones y Transportes; Economía; Turismo; Desarrollo Social; Gobernación, Marina; Energía; Educación Pública; Hacienda y Crédito Público; Relaciones Exteriores; and Desarrollo Agrario, Territorial y Urbano (Congreso de la Unión de los Estados Unidos Mexicanos, 2012).

\section{Consejo de Cambio Climático (C3) (Climate Change Council)}

C3 is the permanent, multidimensional consultation body of the CICC. Its members represent civil society, academia and the private sector and have recognised expertise and experience in climate change. Its major functions are to: 1) advise CICC and recommend the implementation of studies, policies and actions and set goals aimed at adaption to the adverse effects of climate change and 2) promote informed and responsible societal participation through public consultations (Congreso de la Unión de los Estados Unidos Mexicanos, 2012).

\section{Instituto Nacional de Ecología y Cambio Climático (INECC) (National Institute of Ecology and Climate Change)}

Established through article 13 of the Ley General de Cambio Climático, INECC is a public federal institution and the Mexican State investigation entity focussed on conducting studies and carrying out science and technology projects with academic research institutions (public or private, national or foreign) on climate change, environmental protection and conservation and restoration of ecological balance (Congreso de la Unión de los Estados Unidos Mexicanos, 2012).

\section{Congreso de la Unión (State parliament)}

Mexico has a bicameral parliamentary system, one for senators and the other for deputies, together comprising the Congreso de la Unión. Both chambers have commissions responsible for promoting or modifying laws for climate change mitigation and adaptation. In the senatorial chamber this work is tasked to the special commission on climate change together with the environment and natural resources commission, and in the deputies chamber to the climate change and environmental commissions (SEMARNAT, 2018).

\section{Federal and municipal entities}

Officially called the United Mexican States, Mexico is made up of a national federal government, the governments of the 32 federated states and 2457 municipal governments. These entities have powers and responsibilities related to climate change, summarised as follows (SEMARNAT, 2018).

Federated states:

- formulate, conduct and evaluate state climate change policy and implement adaptation and mitigation actions;

- prepare and integrate information on categories of emission sources under their jurisdiction for incorporation in the Inventario Nacional de Emisiones in collaboration with INECC;

- develop and administer state funds; 
- promote scientific and technological research, development, transfer and development of technologies;

- develop projects to reduce greenhouse gas emissions;

- publish and update the state atlas of disaster risk; and

- design and promote the establishment and implementation of incentives.

Municipalities:

- conduct and evaluate municipal policy on climate change;

- develop policies and actions to address climate change and operationalise mitigation and adaptation actions;

- generate and integrate information on categories of emission sources originating in their territory, for incorporation in the Inventario Nacional de Emisiones in collaboration with INECC;

- foster scientific and technological investigation, development and technology transfer;

- develop projects for reducing greenhouse gas emissions;

- conduct education and awareness campaigns; and

- participate in the design and implementation of incentives.

\section{Asociaciones de Autoridades Municipales (Associations of Municipal Authorities)}

The country's associations of municipal authorities have a representative for each legally recognised association of municipal governments (Congreso de la Unión de los Estados Unidos Mexicanos, 2012).

\section{Guatemala}

Guatemala has a general climate change law that establishes a series of institutional arrangements as new institutionality in this area, representing important strides toward multidimensional linkage among sectors, ministries and levels of government.

Main formal institutions addressing climate change are described below.

\section{Ministerio de Ambiente y Recursos Naturales (MARN) (Ministry of Environment and Natural Resources)}

MARN is the national public institution that governs climate change matters. Among its many tasks as lead authority, under Article 12 of the Guatemalan climate change framework law it is in charge of linkage with the Ministerio de Agricultura, Ganadería y Alimentación (MAGA) and Secretaría de Planificación y Programación de la Presidencia (SEGEPLAN) to promote collaboration with the municipalities in adjusting their land use plans (Congreso de la República de Guatemala, 2013). Article 12 also mandates multidimensional linkage with different ministries and levels of government.

\section{Dirección Nacional de Cambio Climático (DNCC) (National Climate Change Department)}

As part of MARN, this department is responsible for designing and implementing local, sub-national and national plans, programmes, projects and strategies in accordance with the climate change framework law. The DNCC is formed of technical work groups that follow up on the core components of climate change adaptation and mitigation (MARN, 2018). It is also in charge of linkage among different levels and actors in the country. 


\section{Consejo Nacional de Cambio Climático (National Council on Climate Change)}

Passage of Guatemala's framework law on climate change gave rise to this formal, multidimensional governance body comprising representatives of the public and private sectors and civil society and presided by MARN (Congreso de la República de Guatemala, 2013). This entity will be examined more closely in the next section on multidimensional governance structures addressing climate change.

Secretaria de Planificación y Programación de la Presidencia (SEGEPLAN) (Planning and Programming Secretariat of the President's Office)

This body plays an articulating role in the interlocking mechanism of climate change governance established through the framework law (Congreso de la República de Guatemala, 2013). Its primary function is to facilitate DNCC operations presided over by MARN, as indicated above (Art. 8). It is also tasked with integrating climate change in the Consejos de Desarrollo Urbano y Rural and in the coordination of public investment planning and programming processes (Art. 10). Finally, SEGEPLAN together with the Consejo Nacional are charged with formulating the Plan Nacional de Acción de Cambio Climático (Art. 11).

\section{Sistema Nacional de Información sobre Cambio Climático (SNICC) (National Climate Change Information System)}

This system was established through Article 9 of the climate change framework law and is attached to MARN (Congreso de la República de Guatemala, 2013). This legislation stipulates that all public and private entities will provide all information directly related to climate change that the ministry may request (Art. 9). The aim is to guarantee access to public information for decision making.

\section{Honduras}

Compared to the countries above, the institutionality established in this nation's climate change framework law, passed by its congress in 2014, is far more limited in scope. The institutional framework to confront climate change is complex in that there are a series of executive decrees giving rise to structures that complement the institutions established by law.

Secretaría de Energía, Recursos Naturales, Ambiente y Minas (SERNA) (Secretariat of Energy, Natural Resources, Environment and Mines)

As stipulated in Article 3 of the Ley de Cambio Climático, SERNA 1 is the governing entity in this area, as established in the Ley de Cambio Climático. As stated in the law's Article 3, its responsibilities include the "gestion, creación y el establecimiento de medidas de prevención, adaptación y mitigación dirigidas a contrarrestar las amenazas" (management, creation and establishment of prevention, adaptation and mitigation measures aimed at countering threats) (Congreso Nacional de Honduras, 2014). As in the aforementioned countries, this means climate change solutions continue to be viewed as a primarily environmental problem.

\section{Dirección Nacional de Cambio Climático (DNCC) (National Department of Climate Change)}

Part of SERNA, the Honduran department of climate change was created through Executive Decree PCM-022-2010. It leads the implementation of climate change actions, such as the UNFCC National Communications, Nationally Determined Contributions and assessments of country technological

1 Currently called MiAmbiente+, through Decreto Ejecutivo Número PCM-009-2018, published in La Gaceta, Diario Oficial de la República de Honduras, 23 March 2018. 
needs to address climate change (SERNA, 2018b). Major actions include the formulation and implementation of pertinent public policy, such as the Plan Nacional de Adaptación formalised in 2018.

\section{Comité Interinstitucional de Cambio Climático (CICC) (Interinstitutional Climate Change Committee)}

The creation of this body was stipulated in Article 8 of the Ley de Cambio Climático (Congreso Nacional de Honduras, 2014). According to this law, it is a permanent, consultative, deliberative and advisory body for policy making, monitoring and social control (Art. 10).

$\mathrm{CICC}$ is a multidimensional institution with 14 representatives.

\section{Table 5.2 Members of the Comité Interinstitucional de Cambio Climático de Honduras}

1. President of the Republic, who presides and can delegate this function

2. Secretaría de Recursos Naturales y Ambiente (SERNA)

3. Secretaría de Finanzas

4. Instituto Nacional de Conservación Forestal, Áreas Protegidas y Vida Silvestre (ICF)

5. Instituto Hondureño de Turismo (IHT)

6. Empresa Nacional de Energía Eléctrica (ENEE)

7. Comisión de Medio Ambiente y Cambio Climático del Congreso Nacional
8. Consejo Hondureño de la Empresa Privada (COHEP)

9. Asociación de Municipios de Honduras (AMHON)

10. Consejo de Educación Superior (CES)

11. Fundación de Iniciativas de Cambio Climático de Honduras

12. Consejo Nacional de Desarrollo Sostenible

13. Comité Permanente de Contingencia (COPECO)

14. Members of climate-related organised civil society that the Committee deems should be convened

\section{Comité Técnico Interinstitucional de Cambio Climático (CTICC) (Interinstitutional Technical Committee on Climate Change)}

Created through the Ley de Cambio Climático de Honduras (Congreso Nacional de Honduras, 2014), this multidimensional body provides advising and support to DNCC and CICC in cases warranting broad participation (Art. 13). It is comprised of at least 16 representatives of the public and private sectors and civil society, which makes it the country's broadest consultative platform for climate change. The next section on emerging multidimensional structures in the region provides more details about this entity.

\section{Secretaría de la Presidencia CLIMA+ (Secretariat of the Presidency)}

One of the main objectives of CLIMA+ as established through Executive Decree PCM 017-2016, is to harmonise the country's climate agenda. This office coordinates national policy called the Plan Maestro Agua, Bosque y Suelos (Gobierno de la Republica de Honduras, 2017).

The nation's climate agenda calls for DNCC and CLIMA+ to coordinate joint activities between their respective programmes (SERNA, 2018a). As a newly created office, in practice actual linkage of CLIMA+ with the rest of the institutional climate change system has yet to be defined. 


\section{Observatorio Nacional de Cambio Climático y Desarrollo Sostenible (ONCCDS) (National Climate Change and Sustainable Development Observatory)}

The aim of this SERNA initiative is to facilitate climate monitoring and manage information about environmental variables for better decision making addressing the challenges of climate change. Its main tasks are to:

- interpret climate change indicators and their relation to sustainable development,

- promote applied research through its connection with the Mesa de Monitoreo Biológico,

- maintain state databases on natural resources,

- produce technical publications,

- support public and private institutions to manage knowledge about climate change and sustainable development, and

- develop an educational programme on climate change for sustainable development (ONCCDS, s.a.).

\section{Costa Rica}

This country has no framework law establishing a systematic relation among State institutions addressing climate change. To the contrary, Costa Rica has chosen to make a series of adjustments in its institutional structure, taking advantage of existing environmental legislation, recent executive decrees and public policies such as the Plan Nacional de Adaptación (2018). This policy outlines the institutional framework for adaptation in the following way.

\section{Consejo Nacional Ambiental (National Environmental Council)}

The Consejo Nacional Ambiental was created through Art. 77 of the Ley Orgánica del Ambiente (Asamblea Legislativa de Costa Rica, 1995). The council is composed of: 1) the President of the Republic or the minister of the presidential office in representation of the President, as the council's head, along with the ministers of: 2) Planificación Nacional y Política Económica; 3) Ambiente y Energía; 4) Salud; 5) Agricultura y Ganadería; 6) Educación Pública; and 7) Ciencia, Tecnología y Telecomunicaciones (Art 79).

Executive Decree 38536-PLAN designates the environmental and energy ministry as lead authority of the Environment, Energy, Seas and Territorial Planning sector, which is articulated through the Secretaría de Planificación del Sector Ambiental (SEPLASA). 


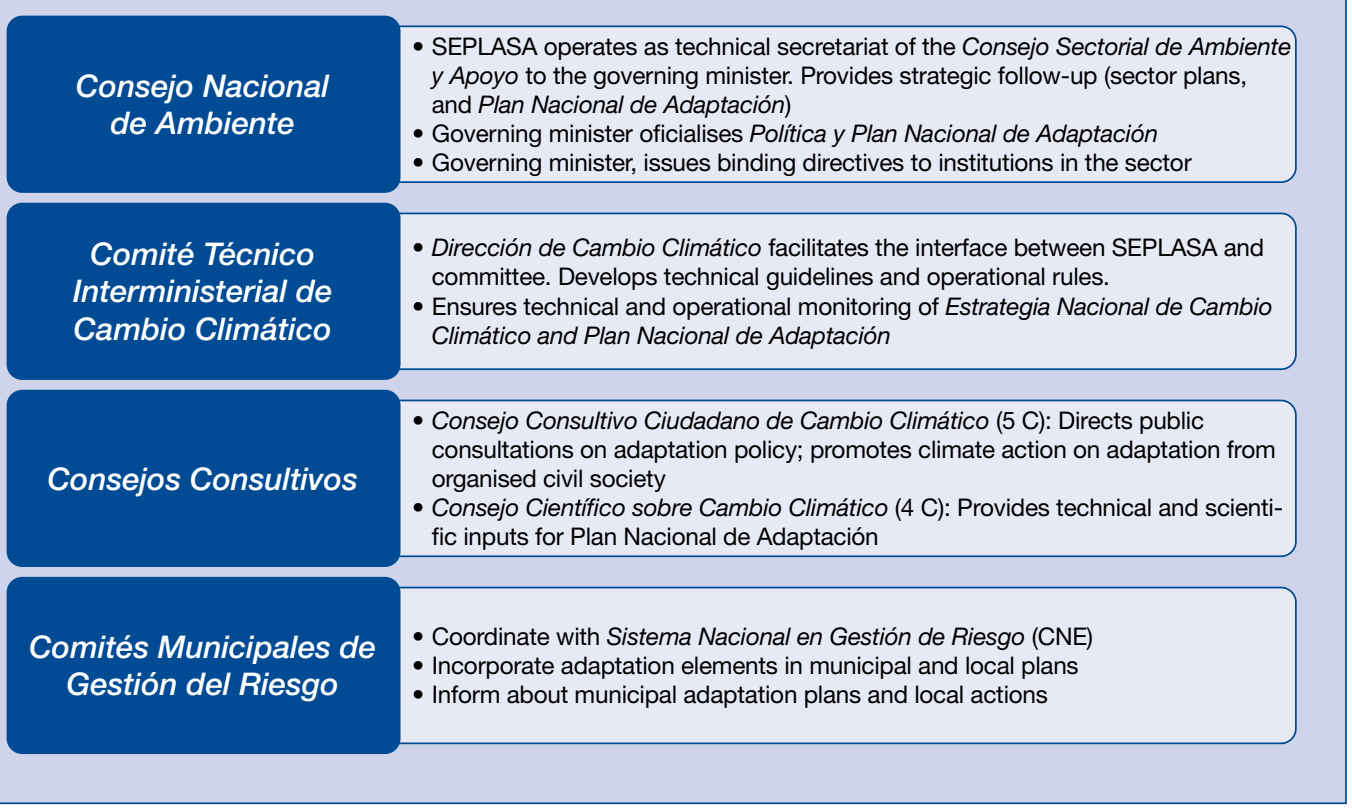

\section{Figure 5.2 Institutional climate change framework in Costa Rica}

Source: MINAE, 2018

SEPLASA is governed through the Consejo Sectorial de Ambiente, a multi-sector entity comprising a wide range of institutions: Ministerio de Ambiente y Energía (MINAE); Ministerio de Vivienda y Asentamientos Humanos (MIVAH); Ministerio de Agricultura y Ganadería (MAG); Ministerio de Obras Públicas y Transportes (MOPT); Instituto Costarricense de Turismo (ICT); Instituto Costarricense de Electricidad (ICE); Instituto Costarricense de Acueductos y Alcantarillados (AyA); Instituto Nacional de Vivienda y Urbanismo (INVU); Instituto de Desarrollo Rural (INDER); Instituto Costarricense de Pesca y Acuicultura (INCOPESCA); Refinadora Costarricense de Petróleo S.A. (RECOPE); Comisión Nacional de Prevención de Riesgos y Atención de Emergencias (CNE); Servicio Nacional de Guardacostas de la Fuerza Pública del Ministerio de Seguridad Pública; and Servicio Nacional de Aguas Subterráneas, Riego y Avenamiento, (SENARA) (Gobierno de la República de Costa Rica, 2014).

\section{Comité Técnico Interministerial de Cambio Climático (CTICC) (Interministerial Technical Committee on Climate Change)}

Established through Executive Decree No.36823-MINAET, CTICC is an advisory and support body to the environmental ministry (MINAE) to follow up on climate change policy. It is composed of the representative and alternate of the following institutions: 1) MINAE (represented by Dirección de Cambio Climático serving as coordinator and technical secretariat); 2) MOPT; 3) MAG; 4) MICT; 5) Ministerio de Hacienda and 6) Ministerio de Planificación Nacional y Política Económica.

\section{Dirección de Cambio Climático (DCC) (Department of Climate Change)}

This unit was created through Executive Decree 35669 as part of MINAE (Gobierno de la República de Costa Rica, 2011). Even though it is under the environmental ministry, its objective is to 
coordinate, administer and formulate public policy on climate change, promoting the integration of an interinstitutional agenda (DCC, 2018).

\section{Consejos Consultivos de Cambio Climático (Advisory Councils on Climate Change)}

The Government of Costa Rica has set up two advisory councils as part of its commitments in relation to the country's Nationally Determined Contributions (NDCs).

The Consejo Científico de Cambio Climático (4C) (Advisory Council on Climate Change) created through Executive Decree 40615-MINAE is tasked with strengthening climate change information and related scientific capacity, better integrating isolated efforts. This is an independent advisory body comprised of eight national or foreign scholars, researchers and experts (with gender parity criteria) designated by MINAE. Informally, it has been considered the "Costa Rican IPCC."

The Consejo Consultivo Ciudadano de Cambio Climático (5C) (Citizen Advisory Council on Climate Change) was established through Executive Decree 40616-MINAE for the purpose of independent deliberation on the design, application and evaluation of climate change policies proposed and implemented by the government through its different institutions (Art. 3). The council consists of 21 representatives of legally registered social, sectoral and production organisations representing civil society and the producer sector. The next section looks more closely at this multidimensional structure.

\section{Comités Municipales de Emergencia (CME) (Municipal Emergency Committees)}

Created through Executive Decree No. 34361-MP (Gobierno de la República Costa Rica, 2007) these committees are made up of the municipal mayor (who coordinates the entity), deputy mayors, the head of the technical unit of the Unidad Técnica de Gestion Vial, the head of the Departamento de Ingeniería u Obras and any member authorised by the Consejo Municipal (Apartado c.ii). According to regulations on the organisation and operation of the regional, municipal and community emergency committees (CNE, 2009), articulation of these entities occurs through the participation of representatives of organisations, directors or chiefs of public institutions, nongovernmental organisations and private businesses active in the county (Chapter 2).

\subsection{Advances and challenges in the institutions}

As described previously, the Mexican federation has three levels of government: federal, state and municipal, although some authors believe the ejido form of community organisation has elements making it a fourth level (see, for example, Lozano Moheno, 2012). Given their smaller size, the other countries examined above have less complex territorial governance structures, primarily national and municipal. While there may be provincial (Costa Rica) or departmental divisions (Guatemala and Honduras), for all practical purposes these have limited or non-existent decision-making influence, as in the case of Costa Rica, for example (González Jacobo, 2008).

All of the countries have made efforts to set up national structures of public character as well as establishing multidimensional structures of different kinds: Mexico's Consejo de Cambio Climático, Guatemala's Consejo Nacional de Cambio Climático, Honduras's Comité Interinstitucional de Cambio Climático and Costa Rica's Consejo Consultivo Ciudadano de Cambio Climático.

Mexico stands out for its interlocking institutions at multiple levels and enshrined in the framework legislation, together comprising its national climate change system (SINACC). While Guatemala and Honduras have made great efforts to propose a new institutionality through framework legislation, 
they do not have a well-articulated institutional climate system.

Costa Rica's case is quite different; while there is no general climate change legislation it has strived for greater institutional articulation through the use of executive decrees. A challenge for this country is to give national climate institutionality greater legal security by updating its regulatory framework, for example, through a framework law. Passage of such legislation would shield the efforts made thus far from potential abrupt changes in the executive power, as has occurred in other countries.

In Meso America as a whole, environmental ministries or secretariats have been made responsible for the theme of climate change. As a result, the climate agenda in this region has remained within the confines of environment, despite calls from academia that climate change be addressed as a development problem (Parry, 2009) and as such, led by development or planning ministries.

Finally, as has been mentioned, one of the most striking similarities among the institutional arrangements analysed here is the creation of multidimensional structures. These are described in greater detail in the next section.

\subsection{Emerging multidimensional structures}

From the standpoint of governance, one response to confront climate change has been the formation of new institutional arrangements (Fröhlich \& Knieling, 2013).

As countries move from the formulation of public policies to their implementation, novel governance structures arise (Chaudhury et al., 2016). Recognising that the challenges of climate change are greater than the capacity and legitimacy of individual organisations, these structures employ a multisectoral and multilevel approach (Girard et. al., 2015).

From here on, these emerging structures composed of diverse and independent organisations will be classified as 'multidimensional'. Table 5.3 presents selected multidimensional structures and the variables that will be examined in this section.

Table 5.3 Multidimensional governance structures for climate change and variables of analysis

\begin{tabular}{|l|l|}
\hline \multicolumn{1}{|c|}{ Multidimensional structures } & \multicolumn{1}{c|}{ Variables for analysis } \\
\hline a. Consejo Consultivo de Cambio Climático del & 1. Legal status \\
Estado de Chiapas & 2. Participants and roles \\
b. Consejo Nacional de Cambio Climático de & 3. Functions \\
Guatemala & 4. Financing \\
c. Comité Técnico Interinstitucional de Cambio & 5. Internal processes and decision making \\
Climático de Hondura & 6. Results \\
d. Consejo Consultivo Ciudadano de Cambio & \\
\hline
\end{tabular}

In a passage worth underscoring from their analysis of new institutional arrangements for adaptation to climate change, Chaudhury et al. (2016) state that:

Estas estructuras tienen muchos de los elementos que caracterizan a las organizaciones formales, como objetivos, reglas, sistemas de reporte, procedimientos de monitoreo $y$ evaluación para alinear todas sus actividades. Aun así, dependen de actores autónomos (normalmente otras organizaciones) para poder implementar sus propias iniciativas 
mientras que cada una tiene su propio alcance organizacional, agenda, mediciones de éxito, lenguaje, $y$ abordaje. (These structures have many of the characteristic elements of formal organisations, such as objectives, rules, reporting systems and monitoring and evaluation systems to align all of their activities. Even so, they depend on autonomous actors [normally other organisations] to be able to implement their own initiatives while each has its own organisational scope, agenda, success measures, language and approach.) (p. 244).

\subsubsection{Consejo Consultivo de Cambio Climático del Estado de Chiapas}

This structure was created through the Ley para la Adaptación y la Mitigación ante el Cambio Climático en el Estado de Chiapas, which states in its Art. 67:

Se crea el Consejo Consultivo de Cambio Climático del Estado de Chiapas, que es el órgano permanente de consulta de la Comisión ${ }^{2}$, se constituirá con un mínimo de quince integrantes provenientes de los sectores social, privado y académico, con reconocidos méritos y experiencia en cambio climático, que serán designados por el Presidente de la Comisión, a propuesta de sus integrantes, y conforme a lo que al efecto se establezca en el Reglamento Interno del Consejo, debiendo garantizarse el equilibrio entre los sectores e intereses respectivos. (The Consejo Consultivo de Cambio Climático del Estado de Chiapas, which is the permanent advisory body of the Commission, is created, to be constituted of at least fifteen members from social, private and academic sectors, having recognised merits and experience in climate change, who will be designated by the Chair of the Commission, as proposed by its members, and as established in the Council's Internal Regulations, requiring that a balance be maintained among the respective sectors and interests.)

In 2018, this advisory council was composed of 12 members from civil society, four from the academic sector and none from the private sector.

By law the council must be headed by a chair and secretary chosen by the majority of the members, who will hold their post for a period of three years and may be re-elected for an additional period (Art. 68). Notably, members exercise their post in a personal capacity, "con independencia de la institución, empresa u organización de la que formen parte o en la cual presten sus servicios" (independently of the institution, company or organisation of which they form part or for which they provide their services) (Art. 69).

The Council has the following functions:

I. Asesorar a la Comisión en los asuntos de su competencia. (Advise the Commission on matters within its competence.)

II. Recomendar a la Comisión realizar estudios y adoptar políticas, acciones y metas tendientes a enfrentar los efectos adversos del Cambio Climático. (Recommend to the Commission conducting studies and adopting policies, actions and goals toward addressing the adverse effects of climate change.)

III. Promover la participación social, informada y responsable, a través de las consultas públicas que determine en coordinación con la Comisión. (Promote informed and responsible societal participation through public consultations as determined in coordination with the Commission.) 
IV. Dar seguimiento a las políticas, acciones y metas previstas en la presente Ley, evaluaciones del Programa Estatal de Cambio Climático, la Estrategia Estatal de REDD+; así como formular propuestas en materia de Cambio Climático a la Comisión, la Secretaría y la Subsecretaría. (Follow up on the policies, actions and goals envisaged in this law, evaluations of the State Climate Change Programme, State REDD+ Strategy; as well as formulating climate change proposals to the Commission, Secretariat and Under Secretariat.)

V. Integrar Grupos de Trabajo especializados que coadyuven con las atribuciones de la Comisión $y$ las funciones del Consejo. (Form specialised work groups supporting the authorities of the Commission and the functions of the Council.)

VI. Integrar, publicar y presentar a la Comisión, a través de su Presidente, el informe anual de sus actividades, a más tardar en el mes de febrero de cada año. (Integrate, publish and present to the Commission, through its Chair, the annual report on its activities, no later than February of each year.)

VII. Las demás que se establezcan en el Reglamento Interno o las que le otorgue la Comisión. (All other functions established in the Internal Regulations or those granted by the Commission.)

Unfortunately, the legislation creating the council makes no mention of how it is to be funded. With respect to internal regulations, these are agreed by its members (approval of internal regulations has been a cumbersome negotiation process for the different parties to reach agreement). Among results thus far, the council has been able to strengthen a State-level space of deliberation by climate change experts. It is also a platform to present experiences, which can then be conveyed to the Comisión de Coordinación Intersectorial de Cambio Climático for consideration in public policy formulation.

\subsubsection{Consejo Nacional de Cambio Climático de Guatemala (CNCC)}

This structure was created through the Ley Marco para Regular la Reducción de la Vulnerabilidad, la Adaptación Obligatoria ante los Efectos del Cambio Climático y la Mitigación de Gases de Efecto Invernadero (Congreso de la República de Guatemala, 2013). It is headed by the President of the Republic of Guatemala and formed of the following actors representing three different sectors (Art. 8) (see Table 5.4).

\section{Table 5.4 Representation in the Consejo Nacional de Cambio Climático}

\begin{tabular}{|c|c|c|}
\hline Public & Private & Civil \\
\hline 1. President of the Republic & $\begin{array}{l}\text { 1. A representative of the } \\
\text { Comité de Asociaciones } \\
\text { Comerciales, Industriales y } \\
\text { Financieras }\end{array}$ & $\begin{array}{l}\text { 1. A representative of } \\
\text { indigenous organisations }\end{array}$ \\
\hline $\begin{array}{l}\text { 2. Ministro de Ambiente y } \\
\text { Recursos Naturales }\end{array}$ & $\begin{array}{l}\text { 2. A representative of the } \\
\text { Cámera de Industria }\end{array}$ & $\begin{array}{l}\text { 2. A representative of } \\
\text { campesino organisations }\end{array}$ \\
\hline $\begin{array}{l}\text { 3. Ministro de Agricultura, } \\
\text { Ganadería y Alimentación }\end{array}$ & $\begin{array}{l}\text { 3. A representative of the } \\
\text { Cámera del Agro }\end{array}$ & $\begin{array}{l}\text { 3. A representative of } \\
\text { indigenous authorities } \\
\text { (AGAAI) }\end{array}$ \\
\hline
\end{tabular}




\begin{tabular}{|c|c|c|}
\hline Public & Private & Civil \\
\hline 4. Ministro de Energía y Minas & $\begin{array}{l}\text { 4. A representative of the } \\
\text { country's private universities }\end{array}$ & $\begin{array}{l}\text { 4. A representative of the } \\
\text { Asociación Nacional de } \\
\text { Organizaciones Aociación } \\
\text { de Organizaciones No } \\
\text { Gubernamentales de } \\
\text { Recursos Naturales y Medio } \\
\text { Ambiente, (ASOREMA) } \\
\text { endorsed by Mesa Nacional } \\
\text { de Cambio Climático }\end{array}$ \\
\hline $\begin{array}{l}\text { 5. Ministro de Comunicaciones, } \\
\text { Infraestructura y Vivienda }\end{array}$ & & \\
\hline $\begin{array}{l}\text { 6xecutive Secretariat of } \\
\text { Coordinadora Nacional para } \\
\text { la Reducción de Desastres } \\
\text { (CONRED) }\end{array}$ & & \\
\hline $\begin{array}{l}\text { 7. A representative of the } \\
\text { Asociación Nacional de } \\
\text { Municipalidades (ANAM) }\end{array}$ & & \\
\hline $\begin{array}{l}\text { 8. A representative of } \\
\text { Universidad de San Carlos } \\
\text { de Guatemala }\end{array}$ & & \\
\hline
\end{tabular}

According to the law, the National Council's functions are:

... la regulación, la supervisión de la implementación de acciones y resolución de conflictos, para darseguimiento a la puesta en ejecución de las acciones derivadas de esta ley, incluyendo la política nacional de cambio climático, el fondo de cambio climático, las estrategias y los planes y programas de acción en mitigación (reducción de emisiones) y la adaptación a los impactos del cambio climático. (regulation, supervision of the implementation of actions and settlement of disputes, in order to monitor the execution of actions deriving from this law, including national climate change policy, the climate change fund, strategies and plans and programmes of action on mitigation (emissions reductions) and adaptation to the impacts of climate change) (Art. 8).

The legislation does not give any other indication about the functions of the Consejo Nacional or how it is to be funded. In practice, the council's internal processes have been complex due to the many different positions converging on this platform. Its main achievement to date is approval of the Plan de Acción Nacional de Cambio Climático.

\subsubsection{Comité Técnico Interinstitucional de Cambio Climático de Honduras (CTICC)}

This body was established through the Ley de Cambio Climático (Congreso Nacional de Honduras, 2014). According to that law the committee was created: "como un órgano permanente de apoyo $y$ consulta a la Dirección de Cambio Climático y al Comité Interinstitucional de Cambio Climático en aquellos casos en que amerite un amplio análisis y participación" (as a permanent body of support and consultation for the Department of Climate Change and Interinstitutional Committee on Climate Change in those cases warranting extensive analysis and participation) (Art. 13).

The law does not establish that committee recommendations are binding, nor does it mention financing. 
Article 13 stipulates that CTICC must be composed of the following organisations:

\section{Table 5.5 Representatives of the Comité Técnico Interinstitucional de Cambio Climático de Honduras}

\begin{tabular}{|c|c|c|}
\hline Public & Private & Civil \\
\hline $\begin{array}{l}\text { 1. Secretaría de Estado en } \\
\text { el Despacho de Recursos } \\
\text { Naturales y Ambiente } \\
\text { (coordination through } \\
\text { Dirección de Cambio } \\
\text { Climático) }\end{array}$ & $\begin{array}{l}\text { 1. Consejo Hondureño de la } \\
\text { Empresa Privada (COHEP) }\end{array}$ & $\begin{array}{l}\text { 1. Fundación de Iniciativas } \\
\text { de Cambio Climático de } \\
\text { Honduras }\end{array}$ \\
\hline $\begin{array}{l}\text { 2. Secretaría de Estado en el } \\
\text { Despacho de Educación }\end{array}$ & & $\begin{array}{l}\text { 2. Members of pertinent } \\
\text { organised civil society the } \\
\text { Committee deems can be } \\
\text { convened }\end{array}$ \\
\hline $\begin{array}{l}\text { 3. Secretaría de Estado en el } \\
\text { Despacho de Finanzas }\end{array}$ & & \\
\hline $\begin{array}{l}\text { 4. Secretaría de Estado en } \\
\text { el Despacho de Obras } \\
\text { Públicas, Transporte y } \\
\text { Vivienda }\end{array}$ & & \\
\hline $\begin{array}{l}\text { 5. Secretaría de Estado en el } \\
\text { Despacho de Agricultura y } \\
\text { Ganadería }\end{array}$ & & \\
\hline $\begin{array}{l}\text { 6. Secretaría de Estado en el } \\
\text { Despacho de Defensa }\end{array}$ & & \\
\hline $7 \quad \begin{array}{l}\text { Secretaría Técnica } \\
\text { de Planificación y de } \\
\text { Cooperación Externa }\end{array}$ & & \\
\hline $\begin{array}{l}\text { 8. Instituto Nacional de } \\
\text { Conservación Forestal Áreas } \\
\text { Protegidas y Vida Silvestre } \\
\text { (ICF) }\end{array}$ & & \\
\hline $\begin{array}{l}\text { 9. Instituto Hondureño de } \\
\text { Turismo }(\mathrm{IHT})\end{array}$ & & \\
\hline $\begin{array}{l}\text { 10. Empresa Nacional de Energía } \\
\text { Eléctrica (ENEE) }\end{array}$ & & \\
\hline $\begin{array}{l}\text { 11. Comisión de Medio } \\
\text { Ambiente y Cambio } \\
\text { Climático del Congreso } \\
\text { Nacional }\end{array}$ & & \\
\hline $\begin{array}{l}\text { 12. Asociación de Municipios de } \\
\text { Honduras (AMHON) }\end{array}$ & & \\
\hline $\begin{array}{l}\text { 13. Consejo de Educación } \\
\text { Superior (CES) }\end{array}$ & & \\
\hline $\begin{array}{l}\text { 14. Comité Permanente de } \\
\text { Contingencia (COPECO) }\end{array}$ & & \\
\hline
\end{tabular}


The CTICC has been convened a limited number of times since its formation, and only to give its approval to national-level public policies on climate change. Internal processes have been cordial despite the diverse representation. Results to date include input for public policy such as the Plan Nacional de Adaptación. One of its main constraints is the lack of resources to convene members periodically since this structure does not have its own funding.

\subsubsection{Consejo Consultivo Ciudadano de Cambio Climático (5C) de Costa Rica}

This governance structure (known as " $5 \mathrm{C}$ ") was originally proposed in Costa Rica's Intended Nationally Determined Contribution (INDCs) to the UNFCCC Conference of Parties (COP21), and then became part of the Nationally Determined Contributions (NDCs) once the Paris Agreement was ratified in 2016. In 2017, the Costa Rican Government upheld 5C through Executive Decree 40616MINAE.

This citizen advisory and monitoring platform is comprised of social, sectoral and producer organisations (associations, foundations, cooperatives, chambers), which must be legally registered, have existed at least three years, have an interest in climate action and be capable of contributing at national level. This council also includes the environmental minister (or designated representative) and director of the Dirección de Cambio Climático, who has the right to vote but not veto and cannot sit on the steering committee (Art. 4).

Article 6 of the executive decree stipulates that $5 \mathrm{C}$ will have 21 full members in total, named for a two-year period and representing a wide range of sectors, as Table 5.6 shows.

\section{Table 5.6 Representatives of the Consejo Consultivo Ciudadano de Cambio Climático (5C)}

\begin{tabular}{|ll|ll|}
\hline \multicolumn{2}{|c|}{ Sector representatives of 5C } \\
\hline \multicolumn{1}{|c|}{ Civil sector (12) } & \multicolumn{1}{c|}{ Private sector (9) } \\
\hline 1. & $\begin{array}{l}\text { Community (ASADAS }{ }^{3} \text { and development } \\
\text { associations) (three representatives) }\end{array}$ & 1. & $\begin{array}{l}\text { Agriculture-forestry-fishery (three } \\
\text { representatives) }\end{array}$ \\
2. & Biodiversity-Ecosystem (three representatives) & 2. & $\begin{array}{l}\text { Industrial-commercial (three representatives) } \\
\text { 3. }\end{array}$ \\
$\begin{array}{l}\text { Indigenous-women's-labour organisations } \\
\text { (three representatives) }\end{array}$ & 3. $\begin{array}{l}\text { Infrastructure-transportation (three } \\
\text { representatives) }\end{array}$ \\
4. $\begin{array}{l}\text { Urban mobility and sustainability (three } \\
\text { representatives) }\end{array}$ & & \\
\hline
\end{tabular}

The decree also mandated that the proportion of men and women could not differ by more than one (Ley No. 8901 y voto 004630-2014 de la Sala Constitucional). Furthermore, the different sectors are urged to include young people under the age of 35 years among their representatives in $5 \mathrm{C}$ (Art. 6) The full group chooses a steering committee comprised of chair, vice chair and secretary (Art. 7 and 8).

$5 \mathrm{C}$ is a platform of deliberation, consultation, awareness, coordination, and oversight, and relates to Sustainable Development Goal 13 "Climate Action." Specifically, it is tasked with the following (Article 3): 
1. Deliberar de forma independiente acerca del diseño, aplicación y evaluación de las políticas de cambio climático que proponga y opere el gobierno, por medio de sus diferentes instituciones. (Deliberate in an independent manner regarding the design, application and evaluation of climate change policies that the government proposes and applies through its different institutions.)

2. Responder las consultas que presente el MINAE u otras instancias públicas sobre el diseño, aplicación y evaluación de sus políticas, programas y métricas climáticas. (Respond to consultations requested by MINAE or other public entities concerning the design, application and evaluation of their climate policies, programmes and metrics.)

3. Generar las actividades que se consideren necesarias para aumentar el nivel de información y sensibilización de la ciudadanía en relación al Cambio Climático. (Generate activities deemed necessary to raise the level of information and citizen awareness in relation to climate change.)

4. Mejorar los niveles de coordinación y comunicación entre la administración pública y la ciudadanía. (Improve levels of communication and coordination between public administration and the citizenry.)

5. Servir de espacio de auditoría ciudadana a cargo de analizar, discutir y apoyar la implementa ción de la Contribución Prevista y Determinada a Nivel Nacional presentada por Costa Rica ante la Conferencia de las Partes 21 celebrada en París en diciembre 2015. (Serve as a citizen auditing space in charge of analysing, discussing and supporting the implementation of Intended Nationally Determined Contributions presented by Costa Rica to the $21^{\text {st }}$ Conference of Parties held in Paris in December 2015.)

6. Interactuar con las instancias de gobernanza establecidas para los Objetivos de Desarrollo Sostenible de las Naciones Unidas (Decreto No. 40203-PLAN-MINAE), generando insumos sobre los avances en el cumplimiento del Objetivo 13 (sobre el combate al cambio climático y sus efectos), de los Objetivos de Desarrollo Sostenible en el marco de la Agenda 2030, brindándoles una retroalimentación para las instituciones correspondientes. (Interact with governance entities established for the United Nations Sustainable Development Goals [Decree No. 40203-PLAN-MINAE], generating inputs regarding progress toward the achievement of Objective 13 of the Sustainable Development Goals (on fighting climate change and its effects) in the frame of Agenda 2030, providing feedback for the corresponding institutions.)

The decree creating $5 \mathrm{C}$ makes no reference to its functioning, although representatives from the different sectors clearly participate on a volunteer ad honorem basis (Art. 5).

$5 \mathrm{C}$ is an emerging platform formed only recently. The formulation of its internal regulations gives some idea of the complex negotiations that take place in a multidimensional structure.

\subsubsection{Comparative analysis of the multidimensional structures}

Although there is no ideal composition of multidimensional structures (Chaudhury et al., 2016) an analysis of emerging institutionality offers some significant lessons. In the paragraphs that follow, the structures described in this chapter are compared based on the variables previously cited (see Table 5.3): 1) legal status; 2) participants; 3) functions; 4) financing; 5) internal processes and 6) results and challenges. 


\section{Legal status}

Most of the structures arise from parliamentary legislation. Three are stipulated in framework laws on climate change (Chiapas, Guatemala and Honduras) and one was created through an executive decree (Costa Rica) as the main distinction. Unlike the others, which are upheld in laws passed by the various legislatures, Costa Rica's $5 \mathrm{C}$ could be eliminated by presidential decree.

\section{Participants and responsibilities}

Although the structures share general similarities in terms of members, important details differentiate one from another. All four multidimensional structures bring in civil society and private sector actors, but two (Honduras and Guatemala) also include full participation of the public sector. Furthermore, all four vary significantly with respect to representation by sector and how representatives are chosen (see Table 5.7).

To illustrate, members of Mexico's Consejo Consultivo de Cambio Climático de Chiapas act in personal capacity (autonomously) while in the other structures they represent the formal institutions to which they belong. Chiapas incorporates representatives of the 'academic sector' along with civil and private sectors and must ensure a balance among the respective sectors and interests; in practice, this heightens the participation of academia. Notwithstanding, as indicated previously currently there is no representation of the private sector, contrary to the spirit legislators aspired to inculcate in the structure's composition.

\section{Functions}

The main function common to all four governance structures analysed is that they act as advisory bodies and monitor public policies. Three state that function explicitly, while Guatemala's structure speaks of regulation, supervision of the implementation of actions, and conflict resolution, as summarised in Table 5.9. However, thus far consultations of these bodies have been of a formal nature to approve policies already established;, for example, adjustments to the Plan Nacional de Cambio Climático were requested of Guatemala's Consejo Nacional de Cambio Climático, as mentioned earlier.

\section{Financing}

None of the instruments giving rise to these structures mention how they are to be funded. This is at once one of the greatest omissions and greatest challenges they share in tackling climate change. Clearly, not having their own economic resources hampers their actions and must be remedied in the near term if they are to be sustainable.

\section{Internal processes}

The multidimensional climate change structures face several hurdles with respect to their internal processes. Main challenges identified by the members who were consulted lie in the multiple interests of the actors involved. In theory these entities were conceived to reach consensus with a common objective but in reality, the representatives' interests are as dissimilar as those of society itself.

Compounding the matter, representatives bring in multiple work experiences, socio-cultural contexts and academic disciplines. This should not be particularly important since the various actors are aware ahead of time that diversity is a prime characteristic of these structures. The situation is far more complex in actual practice, and the widely varying perspectives converging in these spaces mean basic tasks such as establishing internal regulations have been drawn-out and laborious. 


\section{Results}

The four structures examined have diverse ends in relation to climate change. They have enough common features to group them together in a category of formal institution with multidimensional characteristics (see Table 5.1), but each country has been making adjustments to align its organisations with existing formal institutionality and its own vision of climate change governance.

Each one consequently has differentiated objectives, depending on the purpose for which it was created. Hence, for example, there are advisory structures with a more general composition such as Costa Rica's Consejo Consultivo Ciudadano de Cambio Climático, while others have a more technical and specialised orientation, such as that of the Honduran Comité Técnico Interinstitucional.

Whatever their purpose, these governance structures are all recently created so any analysis of their results is still limited. On the other hand, they share a common denominator (and one of the greatest challenges facing this type of organisation), and that is the difficulty of bringing together a diversity of players located in different parts of the country or state, and who have other responsibilities stemming from their work agendas in different fields of action.

\section{Table 5.7 Summarized characterization of multidimensional structures}

\begin{tabular}{|c|c|c|c|c|}
\hline $\begin{array}{l}\text { Organization/ } \\
\text { Variables }\end{array}$ & $\mathrm{CCCH}$ & CN & CTICC & $5 C$ \\
\hline a. Legal status & $\begin{array}{l}\text { Ley Marco de CC } \\
\text { de Chiapas }\end{array}$ & $\begin{array}{l}\text { Ley Marco de CC } \\
\text { de Guatemala }\end{array}$ & $\begin{array}{l}\text { Ley Marco de CC } \\
\text { de Honduras }\end{array}$ & $\begin{array}{l}\text { Executive decree } \\
\text { Costa Rica }\end{array}$ \\
\hline $\begin{array}{l}\text { b. Participants } \\
\text { (sectors) }\end{array}$ & $\begin{array}{l}\text { Civil, private } \\
\text { and academic } \\
\text { (minimum } 15 \text { with } \\
\text { a balance among } \\
\text { members) }\end{array}$ & $\begin{array}{l}\text { Public (7), private } \\
\text { (4) and civil (4) }\end{array}$ & $\begin{array}{l}\text { Public (4), private } \\
\text { (1) and civil }(1+)\end{array}$ & $\begin{array}{l}\text { Private ( } 9 \text { and civil } \\
\text { (12) }\end{array}$ \\
\hline c. Functions & $\begin{array}{l}\text { "Órgano perma- } \\
\text { nente de consul- } \\
\text { ta de la Comi- } \\
\text { sión" (Permanent } \\
\text { advisory body of } \\
\text { the Commission) } \\
\text { (Article 67) }\end{array}$ & $\begin{array}{l}\text { "regulación, la } \\
\text { supervisión de } \\
\text { la implementa- } \\
\text { ción de acciones } \\
\text { y resolución de } \\
\text { conflictos" (regu- } \\
\text { lation, supervision } \\
\text { of the implemen- } \\
\text { tation of actions } \\
\text { and settlement of } \\
\text { disputes) } \\
\text { (Article 8). }\end{array}$ & $\begin{array}{l}\text { "como un órgano } \\
\text { permanente de } \\
\text { apoyo y consulta } \\
\text { a la Dirección de } \\
\text { Cambio Climático } \\
\text { y al Comité Inter- } \\
\text { institucional de } \\
\text { Cambio Climático } \\
\text { en aquellos casos } \\
\text { en que amerite } \\
\text { un amplio análisis } \\
\text { y participación" } \\
\text { (as a permanent } \\
\text { support and } \\
\text { advisory body to } \\
\text { the Department of } \\
\text { Climate Change } \\
\text { and the Inter-ins- } \\
\text { titutional Climate } \\
\text { Change Com- } \\
\text { mittee in those } \\
\text { cases warranting } \\
\text { extensive analysis } \\
\text { and participation) } \\
\text { (Article 13). }\end{array}$ & $\begin{array}{l}\text { Platform of deli- } \\
\text { beration, consul- } \\
\text { tation, awareness, } \\
\text { coordination, } \\
\text { supervision and } \\
\text { relation to SDG } \\
13 \text {, Climate Action } \\
\text { (Article 3) }\end{array}$ \\
\hline
\end{tabular}




\begin{tabular}{|l|l|l|l|l|}
\hline \multicolumn{1}{|c|}{$\begin{array}{l}\text { Organization/ } \\
\text { Variables }\end{array}$} & \multicolumn{1}{|c|}{ CCCH } & \multicolumn{1}{|c|}{ CN } & \multicolumn{1}{|c|}{ CTICC } \\
\hline d. $\quad$ Own financing & No & No & No & No \\
\hline e. $\quad \begin{array}{l}\text { Internal } \\
\text { processes }\end{array}$ & $\begin{array}{l}\text { Complex given } \\
\text { the diversity of } \\
\text { actors }\end{array}$ & $\begin{array}{l}\text { Problems meeting } \\
\text { periodically }\end{array}$ & $\begin{array}{l}\text { Problems meeting } \\
\text { periodically }\end{array}$ & $\begin{array}{l}\text { Complex due to } \\
\text { recent formali- } \\
\text { sation }\end{array}$ \\
\hline f. Results & $\begin{array}{l}\text { Reactivation of } \\
\text { the platform after } \\
\text { a period of inacti- } \\
\text { vity (2017) }\end{array}$ & $\begin{array}{l}\text { Approval of the } \\
\text { Plan de Acción } \\
\text { Nacional de } \\
\text { Cambio Climático } \\
\text { (2016) }\end{array}$ & $\begin{array}{l}\text { Approval of the } \\
\text { Plan Nacional de } \\
\text { Adaptación (2018) }\end{array}$ & $\begin{array}{l}\text { Approval of their } \\
\text { internal regula- } \\
\text { tions (2018) }\end{array}$ \\
\hline
\end{tabular}

\section{Challenges in the functioning of multidimensional structures}

One of the primary challenges lies in the very nature of multidimensional structures, which are comprised of autonomous organisations. This means that representatives have their own work agendas with often disparate visions. While such plurality of actions is one of the main reasons for creating these structures, as mentioned, in practice this diversity of voices makes internal processes complex due to the variety of outlooks converging within them.

The need to consolidate accountability mechanisms concerning public climate change policy indubitably poses another major challenge. Since these are advisory or oversight structures and governance is non-binding, the maturation of these processes will be crucial. As reiterated, what makes these advisory mechanisms innovative is their composition and oversight of public sector policies by non-State actors. This involves a transformation in the way accountability is exercised, given that representatives have more direct access to government decision makers.

At the same time, these structures do not have their own funding and other resources needed to operate. Given the diverse players representing different social arenas and geographical areas, economic, human, physical and technological resources are vital if these governance bodies are to be sustainable. Ironically, none of the public policies supporting the creation of these structures cover basic functioning. In practice, they look to specific budget lines in international cooperation, and as has been emphasised, the region is increasingly dependent on external resources to further its climate agenda.

Dialogue and negotiation capacity is yet another challenge. To illustrate, all the multidimensional platforms analysed have struggled to reach agreement about their internal functioning. Participants would appear to have difficulties achieving consensus so they can advance multisector development agendas to tackle climate change.

Notwithstanding, one of the main benefits of these structures is that they have conveyed items on the adaptation agenda (and climate action, in general) to actors not traditionally forming part of these decisions. This makes it possible to raise awareness in diverse actors about the challenges and opportunities posed by climate change, on one hand, and on the other, to gain numerous perspectives about possible solutions. As has been indicated, this is crucial, since the challenges of adapting to climate change impacts call for joint work by different social sectors and actors at multiple levels (Fröhlich \& Knieling, 2012; Girard et. al., 2015).

Finally, the formalisation of these structures is quite recent. This should not be overlooked, given that the adaptation process to which each institution is exposed is only just beginning. It should 
be emphasised that analysis of these multidimensional structures is preliminary. They need time to mature before more solid conclusions can be reached about their functioning and effectiveness.

\subsection{Other governance structures}

To further define the role of institutions in adaptation, in this section two governance structures are examined, one transnational, such as the Comisión Binacional de la Cuenca del Río Sixaola (Costa Rica-Panama) and the other local, the Coordinadora Departamental de Recursos Naturales $y$ Ambiente de San Marcos (Guatemala).

\subsubsection{Comisión Binacional de la Cuenca del Río Sixaola (CBCRS)}

This binational governance structure is located in the transboundary Sixaola river basin shared by Costa Rica and Panama. The CBCRS was established in 2009 for implementation of the integrated ecosystem management project, the Binational Sixaola Project emanating from the Costa RicaPanama Convention for Border Development. In 2012 a strategic alliance was formed between the Convention's two executive secretariats, the Sixaola Binational Project and IUCN, to help strengthen CBCRS as entity for the promotion and leadership of good governance and sustainable development in the basin once the Binational Sixaola Project finalised.

The commission is attached to the Costa Rica-Panama Convention on Border Development and its purpose is the coordination and development of actions necessary for integrated management of the binational basin, conservation of natural resources and biodiversity, promotion of sustainable production and strengthening of the binational institutional framework under the Border Convention and national legislation on basin management in both countries (Reglamento de la CBCRS, Art. 6). Currently the commission has 35 members from Costa Rica and Panama. 


\section{Table 5.8 Members of CBCRS}

\section{COSTA RICA MEMBERS}

1) Ministerio de Ambiente y Energía

2) Ministerio de Salud

3) Ministerio de Obras Públicas y Transporte

4) Ministerio de Planificación y Política Económica

5) Ministerio de Agricultura y Ganadería

6) Comisión Nacional de Prevención de Riesgos y Atención de Emergencias

7) Instituto Costarricense de Turismo

8) Dirección General de Migración y Extranjería

9) Dirección General de Aduanas

10) Municipio de Talamanca

11) Secretaria Ejecutiva del Convenio

Organised civil society, one representative of:

a) Producer associations

b) Community development organisations or associations

c) Tourism associations

Indigenous representatives from the following groups
a) $A D I T I B R I$
b) ADITICA
c) Keköldi

\section{PANAMA MEMBERS}

1) Ministerio de Ambiente

2) Ministerio de Salud

3) Ministerio de Obras Públicas

4) Ministerio de Economía y Finanzas

5) Ministerio de Desarrollo Agropecuario

6) Sistema Nacional de Protección Civil

7) Autoridad Nacional de Turismo

8) Servicio Nacional de Migración

9) Autoridad Nacional de Aduanas

10) Municipio de Changuinola

11) Municipio de Bocas del Toro

12) Secretaria Ejecutiva del Convenio

Organised civil society, one representative of:

a) Producer associations

b) Community development organisations or associations

c) Tourism associations

Indigenous representatives of the following peoples
a) Ngäbe
b) Naso
c) Bribri

Projects and programmes in the binational Sixaola river basin carried out in the frame of the Border Convention with the understanding that these representatives do not contribute to the formation of quorum.

Source: IUCN (2017)

To consolidate advances in CBCRS governance for climate change adaptation, it is important to reinforce investments in the project portfolio of its Plan Estratégico de Desarrollo Territorial Transfronterizo 2017-2021. Scaling of EbA actions requires strengthening the strategic objective of promoting agricultural diversification at binational level. Support is also needed for actions to protect and preserve the basin through transboundary ecological connectivity as measure for climate change adaptation, along with joint management of the basin's water resources (Luna \& Cruz, 2018).

\subsubsection{Coordinadora Departamental de Recursos Naturales y Ambiente de San Marcos (CORNASAM)}

CORNASAM was established in 2004 as an initiative of the international organisations IUCN and CARE International, and Guatemala's Instituto Nacional de Bosques (INAB), responding to the need to link the efforts of natural resource institutions in the department of San Marcos. Not a legally constituted body, it is a technical and policy coordination structure composed of San Marcos government and non-governmental institutions located on the border with the Mexican State of Chiapas. 
The objective of this sub-national and multidimensional structure is to facilitate cooperation and support comprehensive management of natural resources and environment through the formulation of joint proposals promoting sustainable development in the department of San Marcos. CORNASAM consists of a general assembly and board of directors, the latter comprised of a general coordinator, secretary and the coordinators of three inter-institutional basin commissions: El Naranjo, CoatánSuchiate and Cuilco. In turn, each commission has a similar structure for the microbasins within.

CORNASAM's consolidation required multi-tiered strengthening. At the local level, continued strengthening of community and municipal capacity is required to facilitate the formulation of a common adaptation strategy. A sub-national climate information centre is also needed to assist decision making and private sector involvement.

At departmental level, CORNASAM requires further strengthening to collect information on municipal development plans for inclusion in its annual operating plan. It is also important that the department budget contemplate allocations for the annual operating plan's effective implementation.

Nationally, reactivation of the Grupo de Coordinación Interinstitucional for sustainable natural resource management must be promoted as a platform of inter-sectoral and multilevel coordination. Finally, the connection between CORNASAM and the Consejo Nacional de Cambio Climático must be bolstered to facilitate scaling of adaptation actions and the EbA approach from sub-national to the national level (Martínez \& Navarro, 2019).

CORNASAM is composed of the following.

\section{Table 5.9 Members of CORNASAM}

\section{Local leaders}

- Community representatives

- Municipal representatives

- Representatives of commonwealths

Delegations from national government

- Ministerio de Ambiente y Recursos Naturales (MARN)

- Instituto Nacional de Bosques (INAB)

- Consejo Nacional de Áreas Protegidas (CONAP)

- Ministerio de Agricultura y Ganadería (MAGA)

- Secretaría de Planificación y Programación de la Presidencia (SEGEPLAN)

International organisations

- United Nations Food and Agriculture Organisation (FAO)

- United Nations Development Programme (UNDP)

NGOs and intergovernmental organisations

- Care International

- IUCN, among others 


\subsection{EbA implementation: fundamental characteristics of the institutions}

The following section describes the conditions required for institutions to facilitate EbA.

\subsubsection{Flexible}

Flexibility is vital for governance to cope with the uncertainty and complexity of climate change. Formal institutions for climate change governance must consequently be flexible enough to adapt to the challenges of global warming.

Organisations must have the flexibility to keep up with constant changes, including those resulting from global warming. Formal institutions tend to be conservative and somewhat rigid, making it very challenging for them to adapt to the impacts of climate change (Gupta et al. 2010; Sanchez \& Roberts, 2014). Some of the important questions to pose here would be: How do state institutions react to extreme hydrometeorological events, such as droughts and floods, that are worsening with climate change? How do institutions prepare for slowly evolving events such as sea level rise and its effects in the short, medium and long run?

Existing and emerging institutions must evolve to integrate flexibility in decision making. This is achieved by means of processes for incorporating better information available for decisions through adaptive management (Gupta et al. 2010). Adaptive management requires a paradigm shift transcending the seasonality of climate behaviour and incorporating elements of uncertainty, such as better information and decision-making models as they become available (Sanchez \& Roberts, 2014).

Institutional flexibility derives from recognising that climate and human systems are complex, as well as acknowledging the need for mechanisms that continually incorporate new information for decisions. In the institutional climate change systems of the countries examined, there are organisations that perform the role - to greater or lesser degree, depending on their nature and capacities - of generating scientific information for decision making in order to reduce the uncertainties associated with climate change. Some of the main ones appear in the table below.

\section{Table 5.10 Formal institutions generating scientific information for decisions about climate change}

\begin{tabular}{|l|l|l|l|l|}
\hline \multicolumn{1}{|c|}{ Country } & \multicolumn{1}{|c|}{ Mexico } & \multicolumn{1}{c|}{ Guatemala } & \multicolumn{1}{c|}{ Honduras } & \multicolumn{1}{c|}{ Costa Rica } \\
\hline Institution & INECC & SNICC & ONCCDS & 4C \\
\hline $\begin{array}{l}\text { Type of } \\
\text { institution } \\
\text { Public-National }\end{array}$ & Public-National & Public-National & Public-National & $\begin{array}{l}\text { Multidimensional- } \\
\text { National }\end{array}$ \\
\hline Legal basis & $\begin{array}{l}\text { Ley marco de } \\
\text { cambio climático }\end{array}$ & $\begin{array}{l}\text { Ley marco de } \\
\text { cambio climático }\end{array}$ & $\begin{array}{l}\text { SERNA initiative } \\
\text { (financing of } \\
\text { cooperation } \\
\text { projects) }\end{array}$ & $\begin{array}{l}\text { Decreto Ejecutivo } \\
\text { 40616-MINAE }\end{array}$ \\
\hline
\end{tabular}

These institutions have important challenges with respect to generating information for decision making. Mexico's INECC and Guatemala's SNICC are part of a national climate change system (Figure 5.1) and were created through framework legislation in the respective countries. ONCCDS in 
Honduras and $4 \mathrm{C}$ in Costa Rica were initiatives of the executive power. ONCCDS has not been very active thus far, and 4C was just ratified in 2018.

\subsubsection{Multidimensional}

Institutions in Meso America have been formed with broad participation of diverse sectors through mechanisms permitting greater horizontal coordination among government agencies. Examples of this type of platform are the Comisión Intersecretarial de Cambio Climático (CICC) in Mexico, and the Consejo Sectorial de Ambiente in Costa Rica.

Governance for climate change adaptation also promotes vertical integration. This occurs by creating institutions in which representatives of national and sub-national bodies participate (as well as authorities of various sectors) to establish dialogues for policy making and adaptation actions. Meso America has created a series of formal institutions that promote the participation of actors at multiple levels. These include Mexico's Consejo de Cambio Climático (C3); Guatemala's Consejo Nacional de Cambio Climático; Honduras's Comité Técnico Interinstitucional de Cambio Climático (CTICC) and Costa Rica's Consejo Consultivo Ciudadano de Cambio Climático (5C).

\subsubsection{Participatory}

Broad stakeholder participation is another desirable characteristic of governance institutions to tackle climate change. Recent decades have witnessed the emergence of formal institutions in response to climate change (Chaudhury et al., 2016). Meso America is no exception, as illustrated in this chapter regarding the creation of such multidimensional bodies. In the countries examined here, the participation of nongovernmental actors is noteworthy in such structures: the Consejo de Cambio Climático (C3) of Mexico; Consejo Nacional de Cambio Climático, in Guatemala; Comité Técnico Interinstitucional de Cambio Climático (CTICC) in Honduras and Consejo Consultivo Ciudadano de Cambio Climático (5C), in Costa Rica. Participatory structures facilitate incorporation of the ecosystem approach for adaptation by bringing in diverse actors' experiences with ecosystems in the territory.

\subsubsection{Ecosystem approach}

Added to the impacts of climate change, a series of cumulative effects occurs due to humans' overexploitation of natural ecosystems (Millennium Ecosystem Assessment, 2005). The anticipated impacts of higher average temperatures and subsequent climate change is joined by pressures related to excessive consumption, encouraging unfettered global expansion of the agricultural and urban frontier (Steffen et al., 2015).

As mentioned earlier, there are formal institutions in Meso America whose main goal is to incorporate science in decision making (see Table 5.10). Because they are informed by science, these structures can serve as agents for the incorporation of information to preserve the integrity of ecosystems as adaptation measure through the multiple support, provisioning, regulation and cultural services they provide (Millennium Ecosystem Assessment, 2005).

\subsubsection{Formality}

While all of the cases examined in this section are formally constituted, it should be noted that the legal backing and support upholding these structures vary. 
The most solidly legal institutional arrangements are those of Mexico, Guatemala and Honduras, respectively, as they are rooted in framework laws that integrate both existing institutionality (such as environmental ministries) and new institutionality (such as the multidimensional structures), as well as through the executive decrees that complement them.

In Costa Rica's case, even though climate governance has been formalised, because it has no framework law the legal armature is less strong. The system is protected by law in existing institutionality (such as the ministries), but emerging multidimensional structures forming part of the system (such as the Comité Técnico Interministerial de Cambio Climático and the advisory councils known as $4 \mathrm{C}$ and $5 \mathrm{C}$ ) were created through executive decrees that can be modified relatively simply by the executive power.

\subsection{Challenges and opportunities for EbA institutions}

As indicated throughout this chapter, adaptation institutions in Meso America face several types of challenges

\section{Scant funding}

Lack of financing is a major issue in addressing climate change. This deficiency is particularly severe in local multidimensional structures, as well as in the national and state climate change directorates of the three Meso American countries and State of Chiapas, where staff is limited given the challenges of the climate agenda. Meso America is particularly dependent on international cooperation, making it difficult to generate the institutional capacities needed for tackling adaptation to climate change in the near, medium and long term.

\section{Limitations of the ecosystem agenda}

In Meso America, ecosystem-based responses to climate change are still viewed as an approach anchored in environmental institutionality. Ironically, this situation limits the potential of ecosystems for adaptation since many of the institutions required for successful $\mathrm{EbA}$ (ministries of finance, infrastructure, industry or tourism, among others) continue considering it a strategy for the adaptation of ecosystems. This view holds back the quantitative leap needed for EbA to enter into comprehensive adaptation strategies of multiple economic sectors.

\section{Limited negotiating capacity}

As discussed, the emerging institutionality has limited negotiation capacity when put into practice in multidimensional spaces. On one hand, historically the many government ministries have worked with independent agendas and in some cases take positions perceived as being in opposition to one another (extractive mining vs environmental protection, for example). On the other hand, the articulation of multiple government levels (national and municipal) has generally lagged behind, as seen in the lack of clarity about competencies or in the limited municipal budget, hampering adequate linkage and implementation of climate change adaptation policies.

\section{Scant institutional flexibility}

As stated, formal institutions require a series of rules for effective decision making (Gupta et al., 2010). Incorporating greater flexibility in structures that traditionally strive to increase certainty therefore entails a change of paradigm in recognition of the rising uncertainty climate change imposes on the context. In this scenario, one of the greatest challenges is how to achieve institutional flexibility 
without ignoring the certainty political, legal and institutional processes need. This balance is attained by better incorporating the best information available in public policy decision making (Vij et. al. 2017). This is undoubtedly one of the greatest challenges in a region like Meso America with limited institutional capacity to generate information permitting the adoption of solid public policy.

\section{Limited effective participation}

Current processes aimed at increasing participation through novel governance structures are a step forward, even though their scope is still restricted. Based on the ladder of participation proposed by Arnstein (1969) ${ }^{4}$, the advisory structures recently created in Meso America could be classified in the intermediate category called 'Tokenism' since the scope of members' involvement is limited to "informing," "consulting" or "placating." While providing a sense of 'participation' in decisions, these levels of collaboration do not provide members of the structures substantive decision-making power in public policy formulation on climate change.

\section{Ecosystem integrity}

Lastly, the paradox confronting the current development model is that it is the primary cause of ecosystem degradation (Buscher, Dressler \& Fletcher 2014). This, and climate change, are externalities that must be internalised in the dominant development model of Meso America and the world. This reckoning faces countless challenges since promises about the 'decoupling' State institutions have been working on have not led to the level of effectiveness that was thought. The transfer of emissions from Europe to China testifies to this (Pan et. al., 2017); it has allowed inhabitants of the European continent to 'reduce' their emissions artificially. Hence, institutions (understood in their broadest contention as the rule of organisation in societies) must be subjected to deep transformation if climate change solutions are intended to be successful.

$4 \quad$ Arnstein (1969) classifies citizen participation in three categories and eight steps on the ladder: category 1: Non-participation (includes the Manipulation and Therapy steps); category 2. Tokenism (includes Informing, Consultation and Placation) and category 3. Citizen Control (includes Partnership, Delegation and Citizen Control). 



\section{Negotiation}

\section{Pascal Girot}

\subsection{Introduction}

Climate change continues its relentless advance as unquestionably one of the most important challenges confronting nations, those of Meso America among them. The availability of natural resources such as water will be affected, with impacts on the primary productivity of terrestrial, freshwater and marine ecosystems (IPCC, 2014). But the magnitude, frequency and extent of these impacts is still stamped with uncertainty, as are the consequences these impacts will have on the human systems that depend on those ecosystems. Meso America has already experienced the negative impacts of climate variability in the form of economic losses from extreme hydrometeorological events, including episodes of El Ñiño and La Niña (ENOS).

In response to this uncertainty, preference should be given to nature-based solutions in decision making about adaptation. This premise is based on the principle of In Dubio Pro Natura, or the precautionary principle, which states that given uncertainty around possible impacts on the environment, nature takes preference. In terms of decisions about $\mathrm{EbA}$, creating conditions for longterm ecosystem governance is critical for the provisioning of environmental goods and services.

EbA poses multiple challenges for societies everywhere, including those of Meso America. Countries there have made important efforts to conserve biodiversity in situ. In Meso America, protected areas now cover approximately $25 \%$ of land ecosystems and $14 \%$ of marine ecosystems (Proyecto Estado de la Nación, 2016). Many are established through legal means, with fixed boundaries and delimitations. Because of adverse climate change effects, ecosystems and human production systems will require adjustments and modifications of their coverage and management categories. In this sense, EbA requires flexibility and the creation of spaces and options for future adjustments of in situ conservation and sustainable use of biodiversity.

All climate action must provide opportunity for human communities and productive systems to adapt to climate change within the limits imposed by the provisioning of environmental services and protection of water sources. EbA challenges include, on one hand, the permanence of in situ conservation schemes and national parks with legally established boundaries and management categories, and on the other, the flexibility needed to ensure that these conservation values and the environmental goods and services they provide can continue being provided in the face of climate change.

Such flexibility ranges from making use of a wide range of already existing schemes of conservation, sustainable use of biodiversity and comprehensive water resource management such as biological corridors, watersheds, marine and coastal areas (shoreline and inter-tidal zones), ecological easements, community forest and recharge management regimes, responsible fishing zones and others. 


\subsection{Vertical and horizontal integration}

\subsubsection{Decentralisation and deconcentration}

EbA is determined territorially and therefore requires a multilevel, multisectoral and interministerial approach.

Administrative territorial division of territory in Meso American countries has been based on demographic and electoral criteria and does not correspond to the spatial configuration of a particular country's ecosystems and climate regions. In several countries decision-making power is highly concentrated in national governments, with local governments having little effective participation in matters of climate change policy. However, the UNFCCC Paris Agreement and Sendai Framework for Disaster Risk Reduction point to the essentially local nature of risk management and adaptation to climate change. Furthermore, in most of the isthmus local government authority over land use and urban planning is clearly defined. Implementing international instruments such as the Paris Agreement requires appropriate State deconcentration and decentralisation. There must also be horizontal integration between ministries and vertical integration among government levels (federal, state, provincial, regional, municipal and local).

One of the greatest challenges to deconcentrated and decentralised territorial management may be weak transfer of resources from the national government and limited tax collection by local governments. This in turn restricts the public investment capacity of local officials to guarantee risk prevention tasks, management and administration of national parks, integrated water resource management and planning for watersheds, forest landscape and agricultural production. Vertical integration is still a challenge since coordination between national and municipal governments is limited and inefficient in many of the region's countries. This weakens collective action and legal enforcement of land use stipulations and in situ biodiversity conservation. Given the absence of formal coordination mechanisms, there are many examples of national and sub-national work panels aimed at vertical and horizontal integration of climate governance in the region.

Horizontal integration can improve coordination among institutions with differing mandates and competencies. It requires a governing entity to ensure coordination, or a secretariat to convene the parties, link actions and scale up community-based adaptation practices to cover more extensive territories (Rossing, T. et al., 2014). In pragmatic terms, adaptation must be based on efforts already made in territorial planning, in situ biodiversity conservation, forest and basin management and coastal and marine resource management. Adaptation can promote these bio-regional planning instruments and allow actors to understand current and future risks and respond proactively to prevent those threats.

Prospective risk management is part of adaptation and calls for strengthened linkage among national, regional and local levels of government. Decentralised management structures are an ideal space to channel local territorial planning efforts for climate change adaptation, since they are aimed at strengthening the participation of civil society, private sector and local governments alongside national institutions responsible for implementing not just policy, but also environmental law and policy instruments for economic development and territorial planning. 


\subsubsection{Linkage between nation, region and municipality}

Adaptation must involve different levels of state administration (provinces, regions, departments, municipalities and communities), each with its own complex relations among local and national authorities and public and private actors often having different legal mandates and divergent interests.

Hence the need to negotiate. The following typology of negotiation is proposed here to analyse existing coordination and negotiation entities and define governance improvement:

- between states and international bodies,

- between states with shared ecosystems (transboundary basins, etc.),

- between sectors (for example, agriculture, transportation, energy, environment, economy and trade),

- between the State and private sector,

- between the national State and regional and municipal governments,

- between the national State, municipal governments and communities, and

- between the State and organised civil society.

Obviously, this typology is not exhaustive. The type of negotiation varies from one country to another and one particular situation to another. Examples exist of intertwining negotiations, such as those based on an agreement between bordering States to manage protected areas under an international regime such as biosphere reserves and world heritage sites (both management categories administered by UNESCO and supported by IUCN). The Yorkín River experience on the border between Costa Rica and Panama is a local adaptation action inscribed within a broader, binational framework of cooperation. Similar examples can be found in the Gulf of Fonseca between Honduras and El Salvador, the Trifinio area between Guatemala, Honduras and El Salvador, or the Maya Biosphere Reserve shared by Guatemala, Belize and Mexico.

To a great extent, the nature of negotiation is dictated by the type of resource to be managed for adaptation, its geographical scale and the number of institutions and actors involved. For example, direct negotiation between the State and civil society has taken place around community forest concessions, as in the case of Asociación de Comunidades Forestales del Petén (ACOFOP). Also in Guatemala, payment for forest incentives programmes (Programa Nacional de Incentivos Forestales -PINFOR; Programa de Incentivos Forestales para Poseedores de Pequeñas Extensiones de Tierra de Vocación Forestal o Agroforestal-PINPEP), tasked to the Instituto Nacional de Bosques (INAB), recognises a differentiated financing regime aimed at small producers without property titles but having use rights (usufruct), and effective management of forest lands. Important lessons have been drawn from these community experiences with respect to State recognition of local actors as valid interlocutors in local governance processes (in this case focussed on forest resources). Finally, there are already institutionalised spaces for negotiation between economic sectors and the State, whether through chambers or other trade organisations, unions of business chambers or upper councils that can serve as bridge to negotiate arrangements concerning legislation on water resources or coastal zoning issues.

These examples of negotiation are not abstract, but rather take place often through formal consultation, citizen participation and multisector local or national processes to define relevant public policies for adaptation. Such negotiation must be anchored in territorial terms and refer to specific ecosystems 
and basins. There are many important actions that cannot be labelled as adaptation per se but are no less relevant (such as managing recharge zones for drinking water supply, recognition of environmental services provided through private biodiversity conservation schemes and delimitation of responsible fishing areas).

Territorialising adaptation-related negotiations makes it possible to take advantage of existing local and bioregional spaces of public participation. Inter-institutional coordination entities exist in several of the Meso American countries. For example, Costa Rica has Consejos Regionales de Áreas de Conservación (CORAC), the territories established by Instituto de Desarrollo Rural (INDER), and at municipal level, Comités de Coordinación Cantonales Inter-institucionales (CCCl). These forums of participation directly influence decision making about local administration, public investment and resource allocation for EbA.

\subsubsection{Intersectoral coordination}

In some countries with public policies and legal frameworks on biodiversity, forest management, watershed management and marine-coastal management, multiple opportunities are available to make use of these instruments and mainstream EbA. To be implemented correctly, many legal biodiversity and water resource instruments need input from other sectors and actors. Several of these instruments (legislation on forest, water and biodiversity conservation) lack governance entities such as interministerial or intersectoral councils, and clear spaces of coordination and civil society participation. It would be necessary to make use of existing institutional arrangements, strengthening the institutional nexus at the service of climate change adaptation and risk management. This needs to be achieved without duplicating functions or creating specialised institutions that could contribute to dispersed efforts and expenditure of scarce public funds in not very effective ways.

There are instances of intersectoral coordination in several Meso American countries, such as the Consejo Consultivo de Sociedad Civil of the Sistema Centroamericana de Integración. Climate change acts in Honduras and Guatemala both created a Consejo Nacional de Cambio Climático headed by the President of the Republic and attended by the heads of ministries and pertinent institutions (see Chapter 5). For example, Costa Rica has its Ley de Biodiversidad (1998), Política Nacional de Biodiversidad and Estrategia Nacional de Biodiversidad (2015), Ley Forestal (1997), Estrategia de Adaptación para el sector Biodiversidad (2015) and Política Nacional de Adaptación (2018). The creation in 2010 of the Consejo Técnico Inter-ministerial de Cambio Climático (CTICC) brings together 15 institutions, permitting greater coordination of climate action and the implementation of public climate change policies.

\subsection{Territorial planning and EbA}

\subsubsection{Climate forecasting and territorial planning}

Timely and reliable information are the pillars that support adaptation to climate change. Climate forecasting is based on the generation of future climate scenarios and offers a vision of climate conditions in different parts of a territory. This makes it possible to predict changes in rainfall distribution and average temperature, and thereby provide important scientific elements for decision making and territorial planning. 
It should be emphasised that such forecasting must encompass not only the multiplication of threats attributable to climate change; it also includes a population's conditions of vulnerability and exposure as generators of local risk scenarios.

Territorial planning has advantages for identifying potential exposure and risk zones and preventing future risks. It moreover contributes to risk management through early warning systems and adaptation measures to better cope with climate variability (prolonged drought, hurricanes, etc.) and restrict public investment in zones of potential risk to ensure efficient public expenditure and the continuity of services and businesses.

\subsubsection{Incorporating EbA in territorial planning instruments}

One way to orient territorial planning for climate change adaptation would be by applying bioregional and bioclimate assessment tools. From the 1980s on, these tools guided several Meso American territorial planning efforts concerning protected areas and biological corridors.

The bioregional approach examines how climate changes will transform terrestrial, freshwater and marine ecosystems and in turn affect societies and human groups that depend directly or indirectly on the goods and services they provide. This allows identification of ecosystems critical for society and those requiring special management measures.

Bioregional planning is based on the analysis of ecosystem coverage, structure and function, making it possible to delimit current and future protected areas, design biological corridors and locate productive landscapes contributing to the generation of essential environmental goods and services for EbA. Preventing damages to road infrastructure, for example, often involves microbasin management, embankments and adapted hydraulic designs. EbA requires mechanisms that ensure the provisioning of environmental goods and services and promote local risk reduction.

Sound territorial planning based on bioregional criteria helps create the necessary conditions for resilience to future impacts of climate change. Territorial planning is particularly complex when dealing with border areas where ecosystems or watersheds extend across two or more national jurisdictions. Experience gathered and assessed in this book shows that EbA coordination and dialogue spaces can be established in border zones. A significant part of Meso America's biodiversity and water resources is located in the border areas between two or more countries. The range of goods and services these areas provide (or could provide) could be vital for adapting to climate change, as long as they are properly managed.

This requires agreed governance structures facilitating such local, national and binational management. There are examples of multilevel meetings concerning the Coatán and Suchiate rivers between Mexico and Guatemala ("Soluciones Naturales \& Gobernanza Local para la Adaptación al Cambio Climático"). There are also communal structures like ejidos offering basic arrangements for governance of public goods such as water and forest resources. In the microbasin of the Esquichá River in Guatemala, shared management occurs at different levels: a) community, through signature of writs wherein communities state their interest in joining a forest incentives programme; b) municipal, through the accompaniment of the municipal council presided by the mayor and of the municipal forest office in arrangements for these incentives; and c) institutional, through accompaniment and opening of the entry process for forest incentives by the Instituto Nacional de Bosques. These nested governance levels, along with local capacity building and financial resources through forest incentives, can strengthen local climate action. 


\subsection{Negotiation: warp or weft?}

Inasmuch as negotiation about different EbA options does not take place in a vacuum but rather arises from the existence of opposing forces seeking to marry their interests and settle their differences, certain questions can be posed:

- Who decides the negotiation agenda?

- What capacities are needed for negotiation?

- Who is the arbitrator of negotiation?

- How do we know when there is agreement?

- How do we follow up on agreements?

- How are the effects of climate change and their ramifications for EbA monitored?

- Are there safeguards protecting against maladaptation?

- How are EbA agreements adjusted or updated given the above?

These are not rhetorical questions; they comprise a preliminary guide to orient negotiation processes. It is not the intent here to answer all these questions. Nonetheless, it would be worth taking the risk of formulating such questions; having clear answers could preclude the typical bottlenecks that arise in environmental management initiatives or projects on the ground with real players.

EbA calls for adjustments between environmental supply at a particular site and the local population's demand for environmental goods and services. It is also necessary to understand the complex interweaving of roadway and fluvial networks, geomorphological dynamics and processes that are inherently biological (connectivity, biological corridors, coastal zone). As for local actors, there are many who are relevant but frequently do not participate in planning, decisions and negotiations leading to decisions about adaptation. In these contexts, questions about who controls the negotiation agenda, who is the arbitrator and how concrete agreements materialise from EbA negotiation are crucial. Each situation will dictate who participates in negotiation and how national or local authorities help create the right conditions for it. A first step would be recognising interlocutors as valid social actors in forging agreements that can then be implemented, thus strengthening governance.

Clearly, the rule of law is a prior condition for effective governance and access to legal procedures and due administration of justice. These conditions underlie many of the agreements arising from negotiation.

With these conditions met, lessons drawn from the necessary EbA negotiations can be organised in accordance with general principles and types of instruments.

\subsubsection{Aspects of governance ex ante}

\section{Negotiation as starting point for EbA}

\section{1) Free, prior and informed consent (FPIC)}

The principle of free, prior and informed consent reflects the development of environmental and indigenous law enshrined in ILO Convention 169. Under this principle, the State or company developing large infrastructure works, mega hydroelectric or mining projects is required to conduct prior consultations of communities directly affected by those works. In the Meso American 
countries there is a wide range of indigenous governance structures, from the territorial autonomy of the comarcas of Panama to the community ejidos in Chiapas. Costa Rica recently published official regulations on consultation of indigenous peoples, thus making it possible to define a single procedure across all government institutions. FPIC can level the playing field in negotiations so that structurally disadvantaged peoples have vote and voice about decisions directly affecting access to natural resources and land.

\section{2) Ad hoc structures}

To conduct programmes and strategies, temporary governance structures must be set up bringing together different actors (government and nongovernment, national or local) to take decisions, follow up on plans and projects and facilitate spaces for social auditing of conservation, development or adaptation projects. These structures, which may be composed of community representatives and municipal officials, can lend coherence to public policies while also providing local actors a space for participation in nature-based solutions to climate change. In Mexico, the Consejo Consultivo de Cambio Climático del Estado de Chiapas has an adaptation work group. In the Yorkín River area of Costa Rica, local committees attached to indigenous development associations have given continuity to local adaptation actions driven by specific projects, thus transcending their use life.

\section{3) Formal structures}

Many Meso American countries have a wide range of institutional entities created by law. In Mexico, for example, the Ley de Cambio Climático created the Consejo Consultivo de Cambio Climático offering the possibility of federal and state spaces for public policy consultation and convergence. It is a national regulatory framework that governs climate action and the establishment of formal structures such as state advisory councils facilitating the coordination necessary among actors so that EbA actions can be implemented. In Costa Rica, the Consejo Consultivo Ciudadano de Cambio Climático, comprising 21 representatives from different sectors of civil society, is an emerging deliberative space to accompany public policy on climate action. While not an official government body, this citizen advisory council was created through Executive Decree 40615-MINAE and offers a unique opportunity to strengthen climate governance in the country.

\section{4) Other mechanisms of coordination/linkage/participation}

Experience has also shown the importance of ad hoc coordination/linkage/participation mechanisms making it possible to sensitise local actors and motivate them to take EbA action. As illustration, in the Goascorán river basin between Honduras and El Salvador meetings on nature-based solutions to climate change raised local actors' awareness about EbA benefits and legal and policy frameworks in both countries, facilitating multidimensional (multilevel and multisector) participation and articulation to address climate change.

Another participatory and multidimensional space of transboundary coordination was established thanks to convergence between the Consejo de Cuenco del Río Goascorán (Honduras) and the newly restored Mesas Técnicas Ambientales (El Salvador).

In the Sixaola River (Costa Rica-Panama), greater multidimensional coordination was achieved by strengthening the Comisión Binacional de la Cuenca del Río Sixaola (CBCRS) as multilevel coordination platform, through actions such as the updating of internal regulations and their dissemination among commission members, and formulation of the Plan Estratégico de Desarrollo Territorial Transfronterizo 2017-2021. 


\subsubsection{Aspects of governance ex post}

\section{Negotiation as EbA point of arrival}

\section{1) The dynamics of local governance and the role of negotiation}

There is abundant literature detailing negotiations that led to natural resource governance arrangements (IISD-IUCN, 2002; McNeely, 1995; Borrini-Feyerabend, G. et al., 2007).

Such arrangements often make it possible to settle long-standing disputes between local actors and other institutional or external players regarding land tenure, rights of access to natural resources, and mining or logging. As with in situ biodiversity conservation, adaptation seeks to manage resources from a precautionary standpoint so that future generations can enjoy the same resources as the present population. In this sense, they essentially share inter-generational concern and commitment to leave the world in a better state for coming generations.

One of the most common outcomes of socio-environmental disputes is the creation of ad hoc commissions or work groups. Coordinated by national or local governments, these commissions often involve representatives of main actors in the dispute, presenting options for solutions and ways out of conflict that can frequently lead to new governance arrangements at the local level. In this sense, the outcome of negotiation is the new or complementary arrangement, whose success will depend in good measure on the legitimacy of the decisions made, based on participatory processes.

2) The legitimacy of adaptation decisions based on participatory processes

a) Access to timely and free information

A characteristic of climate change adaptation is that it requires free and timely access to sound information about future climate conditions. This point is illustrated in the following cases.

In the previously mentioned case of the Sixaola River, thanks to farmers' improved knowledge about EbA measures for pilot integrated farms, spaces were established for exchange and multisectoral and multilevel coordination to organise events such as a biodiversity fair and binational reforestation day.

In Guatemala, communities in the Esquichá River microbasin incorporated adaptation actions and currently support their implementation, an outcome of social participation in vulnerability assessment processes and the design and implementation of EbA measures.

In the case of Chiapas, in May 2018 tools to improve EbA knowledge and evidence were presented to the adaptation work group of the Consejo Consultivo de Cambio Climático del Estado de Chiapas so that the council could use these tools to carry out their functions.

As these cases reveal, it is not about creating new structures but rather promoting existing governance arrangements in a given territory by providing the necessary capacities and resources to carry out their functions.

b) The pursuit of consensus and concertation

Arrangements for climate governance mainly result from consensus building and convergence among the parties involved. In many cases, settling disputes over water, land or forest resources reflects the need for shared visions and consensual solutions. Quite often it also requires strategic alliances among actors or initiatives as a vehicle for collaboration that would not have existed otherwise. In the case of the Goascorán River, for example, the joint efforts of projects like AVE, BRIDGE, ICWL or Nuestra Cuenca Goascorán permitted collaboration among many different actors, 
including agricultural producers, microbasin committees, water boards, municipalities, associated municipalities, government institutions, community leaders, women and youth in both countries (Honduras and El Salvador). In Guatemala, the Tacaná municipality now supports adaptation measures and is updating its municipal development plan, which includes EbA and assigns a budget line specifically for climate change adaptation. This resulted from technical support work since 2003 by IUCN and the Tacaná Municipal Forest Office on reforestation campaigns in recharge zones and the approval of forest incentives.

\section{c) Institutional arrangements as outcome}

The most durable governance arrangements are often those demonstrating that they survive crises around the management of natural resources that are a common good (Ostrom, E. 2000). This book includes some examples of governance arrangements whose solidity will be measured years or decades from now when the impact of climate change is felt with greater intensity. Setting processes in motion and on track is one of the most relevant aspects of the examples mentioned.

For example, in Chiapas support to local governance structures led to the development of a sustainable development strategy in the context of climate change in the El Azteca ejido. In the Sixaola river basin, extensive multisectoral participation led to a strategic transboundary territorial development plan for the 2017-2021 period. It now includes basin protection and conservation actions through proposed transboundary ecological connectivity as climate change adaptation measure.

\section{3) Recognition of local institutions/entities}

Recognition of emerging local structures or entities is frequently a key stage in the negotiation process. Once local and national authorities recognise their validity as interlocutors, these entities can help legitimise decisions based on broad citizen participation. To illustrate, in the much-cited Sixaola River local processes were recognised, leading to the formulation of a binational project implemented by the binational commission (CBCRS) on integrated farms for climate change adaptation. This project is a CBCRS initiative and is driven by the Estrategia Centroamericana de Desarrollo Rural Territorial (ECADERT) of the Sistema de la Integración Centroamericana (SICA). The project's ten farms have joined the network of integrated farms promoted with government institutions together with IUCN. In Honduras, efforts by local partners of project AVE contributed technical input for the formulation of the Plan Nacional de Adaptación, which in turn incorporates the EbA approach as one of its strategic core components, and adaptive governance as crosscutting theme.

\section{4) Constituent elements of solid local institutions for EbA}

As can be noted throughout this chapter, negotiations are at once the starting and end point of governance systems or arrangements. Comparing the different experiences in Project AVE's intervention sites, they appear to have several elements in common. As documented by Ostrom (2000), the constituent elements of robust local institutions to manage resources of common good are largely the same as for climate change adaptation. For example, by delimiting territories for EbA intervention and identifying critical water sources given adverse effects of climate change, local actors can define shared priorities about protection, thus reducing incidence of local disputes due to water scarcity. National and regional recognition of local entities and structures legitimises decisions reached collectively.

EbA governance arrangements are still nascent, and it remains to be seen whether they will pass the trial by fire of climate change's adverse impacts. Nevertheless, good governance has direct co- 
benefits, especially in a context prevalent in many places of Meso America where insecurity and violence are a constant threat to the region's countries and their inhabitants.

A community organised to tackle these problems can also fight climate change-imposed challenges related to water security and food security, for example. EbA requires agreements and long-term, nature-based solutions. Indubitably, the agreements that can be forged and the solutions deriving from them will result from complex and continuous negotiation whose ultimate outcome is sound climate governance.

\subsection{Gaps in governance}

The next section examines some of the main factors conditioning effective EbA governance in Meso America, and which could apply as well to developing countries in other parts of the world. If not properly evaluated, they can compromise the viability and effectiveness of any strategy or measure designed to promote EbA.

\subsubsection{Limitations on citizen participation}

Meso American countries have forged democratic institutions for the last 50 years. In many, however, a culture of citizen participation continues to be limited and the transparency and accountability of public institutions are still imperfect.

EbA decisions will require complex negotiation to create the local conditions suitable for long-term, sustainable ecosystem management addressing climate change.

The systems of representative democracy in Meso America put the executive power in charge of executing public policies and ensuring they are implemented within an established and legitimate regulatory frame. Even though public institutions have this responsibility, governance requires the broad participation of civil society actors. Spaces of multisectoral participation and coordination vary from one country to another and doubtlessly present different degrees of legitimacy and representativeness. However, as illustrated in previous chapters, there are important lessons about governance that facilitates EbA. The big question would then be how to establish favourable conditions for effective governance given these conditions.

\subsubsection{Erroneous communication}

Access to timely, free and reliable information is a vital aspect of governance. To be implemented, EbA must be communicated in a simple and accessible way. For example, how does protected area and/or microbasin management help ensure water supply for human consumption or agriculture in a community? How can the adaptation measures taken today guarantee that environmental goods and services will be provided in the long term? What is the best way to communicate future scenarios so that options can be presented in a way that is appealing and easy to understand?

\subsubsection{Legitimacy, recognition and leadership}

Behind every successful experience in community management of biodiversity and EbA there are local leaders who have made it possible to legitimise management whose outcomes and tangible benefits give it credibility. 
Meso America offers multiple examples of local leadership, several based on the organisation and empowerment of local governance structures. Many such experiences reinforce the importance of understanding and strengthening civic life and civil society participation in national and local decision-making processes. They are the vital signs of a participatory democracy. Several of the local management experiences (forest, conservation, water resource management, responsible fishing) are based on mutual recognition and reinforcement among State institutions, local authorities and community organisations. Recognition encourages commitment, citizen participation and the strengthening of transparency, and permits accountability in a society.

The legitimacy of local governance processes rests on recognition of community leadership. The importance of this leadership cannot be underestimated in a context often marred by, inter alia, lack of government transparency, influence peddling, polemical policies and crime. Durable local governance arrangements, the sine qua non for EbA, cannot exist without solid, local, community leadership that is legitimate and recognised by local and national institutionality.

\subsubsection{Land and tenure}

Many of Meso America's terrestrial ecosystems form part of and have co-existed with productive landscapes. The immense majority of protected areas were created from privately held land or vacant public terrain. Meso American history is replete with agrarian conflicts and tension between communal lands, smallholdings, ranches and large estates. Despite agrarian reform efforts in the 1920 s and '30s in Mexico and in the '60s and '70s in Central America, there are still many conflictive situations with respect to land and recognition of communal titles to resources such as water and forests.

In the last 20 years there has been an upsurge in the presence of organisations connected with criminal activities in Meso American coastal zones and border areas. This constitutes a growing threat for local authorities in Mexico and Central America, since these activities erode local organisations' capacity to defend their interests and undermine the foundations of governance.

\subsubsection{National and local organisational weakness}

Many countries have public policies and legal frameworks that contemplate, reinforce and enable $\mathrm{EbA}$. This is no guarantee, however, that EbA will be at adequate levels or scaled up. In many of the region's countries the implementation of regional or territorial land-use planning instruments has always come up against the constraints of public institutionality and difficulties regulating natural resource use, ordering urban land use and assessing the environmental impact of development projects. Like risk management, adaptation requires a prospective management that presupposes the good will of the actors in play with respect to climate scenarios or risk assessments justifying the adjustments necessary for adaptation, and unhampered access to robust, reliable and easily accessed climate data and scenarios.

\subsubsection{Lack of funding}

Not all hydrometeorological events can be attributed entirely to the negative effects of climate change, but the trend described in recent IPCC reports is toward a gradual increase in their magnitude and frequency. 
The host of damages and losses resulting from these events in Meso America does not reflect the indirect costs of disturbances and interruptions in a population's daily life (for example, suspended classes in public schools). Moreover, there is no systematic measurement of ecosystem damages and subsequent upheavals for wildlife and cattle herds and the losses associated (direct and indirect), suggesting that impact is under-recorded. When added to the conditions of exposure and vulnerability already endured by broad sectors of society, these events generate social conflict and the permanent erosion of development assets.

With the impact of climate change, losses could increase in the future, with severe repercussions on countries' economic and social development due to repeated erosion of their own resources. Such losses would have differentiated impacts on vulnerable sectors, territories, communities and groups, but what is certain is that most countries do not have the fiscal resources necessary to cope with these periodic expenditures on emergency response and post-disaster reconstruction.

Climate change adaptation aims to lighten this financial burden by helping reduce losses and damages from hydrometeorological events. Evidence shows that human systems are subject not only to natural resource limitations, but also State resources. Where will the resources be obtained to finance adaptation? There are several international instruments (Green Climate Fund, Global Environmental Facility, Adaptation Fund) and bilateral instruments (Internationale Klimaschutzinitiative (IKI), Spanish Agency for International Development (AECID), European Union) that support adaptation actions. Important national resources also exist to finance biodiversity conservation in situ or community drinking water supply, and which can constitute a significant co-financing source for EbA.

IUCN published an inventory demonstrating that in 2017, USD 716,718,262 was being invested in 173 climate change adaptation projects in Meso America. States must invest in adaptation early to protect their assets and operations. Otherwise, the cost of losses and damages will rise.

\subsection{Challenges and opportunities for negotiation}

Throughout this chapter, elements of analysis have been proposed about the necessary conditions for negotiating EbA governance arrangements, and main relevant gaps were identified. In addition, some steps were indicated for improving vertical and horizontal integration between national and local institutions, local actors, agents and community leaderships to permit better territorial planning and management with an eye to climate change adaptation.

The major challenges identified include the gradual erosion of principles of democratic co-existence, owed in part to public institutions' loss of credibility regarding their capacity to solve the problems citizens face in terms of physical security, water security and food security. These will be accentuated by the adverse effects of climate change. Institutions' weakened legitimacy reflects the lack of local and national leadership and incapacity to propose, through existing mechanisms, viable and lasting solutions to pressing development challenges.

Another significant challenge relates to the incongruence between addressing urgent human development needs (quality employment, access to education, health services, food security) pitted against the need to predict future conditions in light of climate change and take decisions whose remit is neither immediate nor short term but guarantee a minimum quality of life for future generations. How, then, is one to reconcile what is urgent with what is important? This is a challenge for any organisation, entity, actor or community dedicated to environmental management in general, and adaptation to climate change in particular. 
One of the lessons deriving from the analysis set out in this book is that negotiation can be based on a given institutional order or lead to new institutional arrangements that promote more robust and legitimate governance. Clearly, this represents an opportunity as it facilitates local decision making and most especially, allows distinguishing between the need for change and the need for continuity. It thus remains to be determined when to make use of existing governance institutions and arrangements, and when to propose new figures responding better to the needs of all stakeholders.

Opportunity also exists in negotiation concerned with the identification and recognition of co-benefits between public policies, since climate change adaptation can be fostered or constrained by other, non-climate policy instruments. For example, a decision by the agriculture sector to take advantage of wastewater to reduce pollution of water bodies can also be an adaptation opportunity, since such action reduces water consumption and promotes recycling and re-use of a fragile and finite resource subject to changes in availability. This reinforces the idea of improving inter-institutional communication and coordination to identify such opportunities and promote synergies between development actions and $\mathrm{EbA}$.

Finally, another advantage of negotiation lies in how these processes make it possible to build more solid and transparent institutions. Many of the region's countries have a broad and complex legal framework whose interpretation and implementation are at times random and not very effective. An opportunity arising from lessons learnt as described in this book is how co-existence with the adverse impacts of climate change can be strengthened by improving conditions for effective governance. New arrangements resulting from the negotiation processes mentioned here will most certainly offer hope to those who have lost faith in public institutions. They are a direct response to the aspirations and needs of local populations, and thereby contribute to the transparency and legitimacy of institutional order in Meso American countries. 



\section{Conclusions and recommendations: calibrating}

\section{On adjustment}

To be effective, EbA governance must make it possible to link maintenance of ecosystem services with economic development and social equity, while also ensuring that people can peacefully coexist. It must also be tailored to specific contexts and geographical zones with different degrees of vulnerability, becoming a vehicle to ensure that $\mathrm{EbA}$ measures are sustainable regardless of climate uncertainties.

EbA-related policies, laws and regulations should not be viewed as instruments that are impossible to transform, adjust and reform. To the contrary, they must be monitored, appropriated and internalised by civil society as a whole and by the most vulnerable groups in particular. While the reform of EbA legal and institutional frameworks is a complex task demanding time and effort, it will be possible insofar as actors are committed to influencing their formulation and implementation. It is imperative that these actors' capacities be consolidated and strengthened for EbA governance that is efficient, effective, just and equitable.

Also indispensable is coherent, continuous and innovative knowledge management that takes traditional knowledge into account and is science-based (evidence) to show that EbA works effectively. Without concrete evidence and numbers to persuade decision makers and economically influential sectors, EbA will not survive over time.

Effective climate change governance is paramount on the local, national and international agenda of themes to be resolved at this time, given the trial by fire to come within the next 30 years when impacts will be felt more intensely. This calls for solid institutions capable of coping with scarcity and of governing in a context of emergency and crisis. Inescapably, spaces of transparent public administration and citizen participation, while still imperfect, will have to be reinforced as governance structures will otherwise lack the muscle and resilience necessary to address those impacts.

Ecosystems can be society's life insurance against the impacts of climate change. Many of their goods and services support a wide range of productive activities, from farming, ranching and fishing to much of urban life. But their conservation and sustainable use calls for clear policies, effective laws and solid institutions that facilitate the participation of all actors and stakeholders.

EbA requires horizontal integration across ministries, and vertical integration between levels of government (federal, state, provincial, regional, municipal and local). In pragmatic terms, it must be based on concrete efforts of land use planning, management of basins and coastal and marine resources and linkage between national, regional, provincial, departmental and local governments in territorial, environmental and economic development planning.

\section{On capacity}

In relation to climate change adaptation, capacity is a pluri-conceptual notion that covers adaptation capacity, governance capacity and EbA governance capacity.

Given that the countries most vulnerable to climate change are also those with the least adaptation capacity, it is imperative to prioritise capacity-building programmes not only to address climate 
change impacts but also to influence the establishment of effective governance structures in this sphere.

EbA governance capacity touches on a range of aspects, from the sensitisation of different stakeholder groups to the formulation of policy, legal and institutional frameworks for its effective, long-term management. These capacities should be assessed at the most local up to the national level and in States' cooperation with neighbours.

Limitations on EbA governance capacities should be considered a matter of priority and examined holistically and comprehensively to ensure that actors' and ecosystems' different interests and needs are taken into account in the context of the uncertainty inherent to climate change.

Capacities are vital to achieve the objective of EbA governance that is multidimensional, flexible, participatory and ecosystemic.

Bearing in mind that vulnerability is comprised of three distinctive elements, namely exposure, sensitivity and adaptation capacity, it is the last of these that must ultimately be strengthened to reduce vulnerability and enhance the resilience of populations and ecosystems to climate change. EbA governance capacities are therefore essential to improve, in the long term, sustainable livelihoods for human populations and the ecosystems on which they depend.

\section{On evidence}

Given the complexity of the ecosystem and social processes involved, it is necessary to have evidence that can be evaluated periodically and used to modify EbA actions. More intensive research will be needed on the cost-benefit and cost-effectiveness of implementing EbA measures and the corresponding governance arrangements. Existing experiences and lessons drawn from them could be useful. Similarly, global financing mechanisms for adaptation could be instrumental in the formulation and evaluation of EbA-related projects, policies, institutions, laws and processes, and to continue improving them over time.

EbA governance depends on a database of solid, rigorous and comprehensive evidence. Implementation of EbA should include 1) information gathering about ecosystem services and the co-benefits they generate and can generate, and about environmental and social vulnerability; 2) a knowledge management system so that information can be compiled and analysed; 3) a monitoring and evaluation system with realistic indicators; 4) EbA training plans; and 5) clear and timely communication and transfer of knowledge. All of this must incorporate the participation of all stakeholder groups.

Capacity building to generate, analyse and interpret evidence in the face of climate uncertainties, the establishment of information dissemination networks and finally, clearly conveying evidence to decision makers are all essential for feedback on EbA governance and to ensure that the results of projects and measures are positive and sustainable over time.

Evidence about the effectiveness of EbA to improve its governance and in turn, about the effectiveness of EbA governance are both necessary to ensure the sustainability of adaptation actions.

EbA governance frameworks must also be capable of influencing projects and initiatives in this area. Moreover, to the extent that those responsible for implementing policies and laws do so effectively, trust in those frameworks will be generated. Transparency, accountability, enforcement of the law and institutional capacity are important to build participatory and inclusive governance arrangements. 


\section{On policies}

Integrating $\mathrm{EbA}$ in climate change policies makes it possible to guide its gradual integration in sectoral policies and different administrative levels of the State. This could assure EbA's permeation in development policies so that ecosystem conservation, restoration and use is no longer restricted to environmental policy.

Policies integrating EbA must be precise enough to direct the necessary legal reforms. Such reforms should be based on a holistic assessment of gaps and possible synergies among sector regulatory frameworks for EbA.

Legislative reforms must be comprehensive in that they reduce possible ecosystem stressors from sources other than climate change (such as over-exploitation of natural resources or pollution). The reforms should fuel actions for the conservation, restoration and sustainable use of ecosystems, and eliminate perverse incentives contributing to the depletion of natural resources and biodiversity.

Inasmuch as governance inherently contemplates policy and law, the second is necessary to ensure the continuity of the first so that advances in EbA are not set back due to possible changes of government and administrations. In addition, law is relevant for guaranteeing policy coherence and promoting institutional coordination among multiple levels and sectors. Climate change imposes the need to make law more flexible when necessary. This is particularly important, for example, to accommodate changes in the behavioural patterns of species, modifications of the spatial limits of protected areas, etc.

Since effective EbA implementation depends on adequate financial resources, among others, it is recommended that policy and law specify financing sources for EbA and consequently direct the resources necessary to implement these actions, as well as for research and capacity building.

Effective implementation of climate change adaptation and ecosystem conservation, meaning EbA, requires the involvement of society as a whole, which indicates the need to strengthen its capacity and the role of citizens as change agent. Training and empowerment are recommended so that citizens can act as overseers of ecosystem health and thus contribute to the effectiveness and sustainability of EbA.

EbA policy and law must include measures ensuring the participation of indigenous groups, local communities, youth, women and other vulnerable and marginalised groups, helping them improve their influencing abilities in this area and recognising their crucial function in the stewardship, restoration and sustainable management of ecosystems.

Given the threats posed by climate change, it is imperative to improve regulatory frameworks concerning conservation of ecosystems and their services to reduce their vulnerability, enhance their resilience and therefore ensure that EbA can effectively accomplish its mission.

While policy and law are appropriate instruments to assure effective EbA governance at the national, sub-national and local level, at global and transboundary level States must enter into and implement agreements conducive to ensuring the conservation and sustainable use of shared ecosystems, but which also promote collaboration among States on related issues such as sharing information and experiences, capacity building and research. 


\section{On institutions}

The main challenge climate change poses for institutionality, and certainly for EbA, is reconciling uncertainty around this phenomenon and its effects with the rigidity inherent to all institutions, structures or organisations responsible for management of territory and natural resources.

Emerging institutionality to deal with climate change and its consequences contributes to the rise of multidimensional, multi-stakeholder (public and private) and advisory structures that operate parallel and complementarily to traditional entities in the management of environment, biodiversity and natural resources.

Emerging structures present a series of weaknesses (such as insufficient financing, the need to strengthen internal leaderships promoting dialogue and negotiation and the non-binding character of their decisions) that must be addressed to avoid compromising their efficacy. Nevertheless, they have also brought a series of benefits in terms of social participation, awareness and internalisation of the climate agenda for actors not traditionally included in discussions on climate change and EbA.

The multidimensionality of the emerging structures should be understood as being both horizontal (between different sectors) and vertical (between local, sub-national and national entities). The former requires reconciling the work of State ministries, agencies and entities with different agendas, while the latter must promote interaction that encourages dialogue between different levels and establishes a favourable environment for defining actions and formulating and adopting $\mathrm{EbA}$ and EbA-related policies.

Multi-stakeholder institutions involving a broad group from the public sector, civil society and the private sector serve as spaces to facilitate dialogue and negotiation on options of climate change adaptation.

Many key ecosystems for adaptation are shared by two or more States, while a large portion of the communities and populations most vulnerable to climate change, especially in developing countries, depend on those ecosystems and live in border areas. It is therefore necessary to promote the internalisation of $\mathrm{EbA}$ in policy dialogue between States so that it is incorporated in multinational projects and initiatives and in transboundary or transnational governance structures. In this sense, $\mathrm{EbA}$ could be seen as a vehicle fuelling cooperation between States.

The uncertainty and complexity of climate systems and variability and its effects call for the gradual evolution of traditional institutions to incorporate the flexibility needed for integrating the best information available and elements of uncertainty inherent to this phenomenon. Adaptive management thus arises as a new paradigm or trend imposing a change of paradigm in natural resource management.

A significant weakness in the institutional framework for EbA is the limited capacity of institutions themselves to understand that EbA is not just a tool for ecosystem adaptation. This keeps EbA from being seen as part of comprehensive adaptation strategies promoting benefits for the entire society, including all relevant economic sectors (not just environmental).

In the last analysis, the efficacy of the institutional framework for climate change depends on the capacity of institutions, entities, agencies and officials and decision makers themselves, with respect to matters inherent to climate change adaptation. It is therefore necessary to work towards the strengthening of governance capacities at multiple levels and for a multiplicity of actors as means of contributing to effective EbA implementation and management. 


\section{On negotiation}

Negotiation about EbA is multifaceted. Related decision-making requires a complex series of interactions to establish the favourable national and local environment leading to sustainable management of ecosystems in a context of change and uncertainty.

The type of negotiation varies from one country to another, one region to another and one particular situation to another. It ranges from an agreement between neighbouring States on management of protected areas such as biosphere reserves or world heritage sites, to local-level dialogue and consultation processes among authorities, guilds, chambers and community associations to define the reach and scope of a reforestation project or restoration of riverbanks or mangroves.

The nature of negotiation about EbA is dictated by the type of resource to be managed for adaptation purposes, the geographic and territorial scale and the number of institutions and actors involved. In concrete terms, it takes place through formal consultation processes or citizen or multisector participation in defining relevant public policies for adaptation, or in ad hoc form for a particular initiative or project.

EbA negotiation must be anchored in territorial terms and refer to specific spaces, ecosystems or watersheds. The 'territorialisation' of negotiation requires making use of existing spaces at local or bioregional level that directly influence decision making about local administration, public investment and resource allocation related to EbA.

EbA entails discerning and adjusting a complex web of supply and demand for goods and services, biological and geomorphous dynamics, and interrelations between national and local players of all kinds who participate (or not) in decision making and planning. Hence, defining an agenda, its terms, facilitation and decision making in a negotiation are crucial for the adoption of effective agreements that can be implemented and ultimately, serve to strengthen EbA governance.

Climate change requires long-term commitments to adaptation, which can only be achieved through institutions that can evolve and reinvent themselves. This process of institutional transformation is, in the last analysis, the greatest challenge to adaptation. There are no adaptation options based on continuity (business as usual). Coping with the impacts of climate change requires permanent capacity to create and reinvent governance arrangements. 


\section{Bibliography}

\section{Adjustment}

Abell, R., Asquith, N., Boccaletti, G., Bremer,L., Chapin, E., Erickson-Quiroz, A., Higgins, J., Johnson, J., Kang, S., Karres,N., Lehner, B., McDonald,R., Raepple, J., Shemie, D., Simmons, E., Sridhar, A., Vigerstøl, K., Vogl, A. and Wood, S. (2017). Beyond the Source: The Environmental, Economic and Community Benefits of Source Water Protection. Arlington, VA, EE.UU.: The Nature Conservancy.

Aguilar, G. and Iza, A.O. (2011). Governance of Shared Waters. Legal and Institutional Issues. Gland, Switzerland: IUCN. https://portals.iucn.org/library/node/9995

Adger, W.N., Brown I. and Surminski, S. (2018). 'Advances in risk assessment for climate change adaptation policy'. Philosophical Transactions of the Royal Society 376: 20180106. http://dx.doi. org/10.1098/rsta.2018.0106

Andrade, A., Córdoba, R., Dave, R., Girot, P., Herrera-F, B., Munroe, R., Oglethorpe, J., Paaby, P., Pramova, E., Watson, J., Vergara, W. and Suarez, I. (2012). Principles and Guidelines for Integrating Ecosystem-based Approaches to Adaptation in Project and Policy Design. Turrialba, Costa Rica: IUCN-CEM, CATIE.

Bai, X. (2018). 'Advance the ecosystem approach in cities'. Nature 559: 7. Available at: https://doi. org/10.1038/d41586-018-05607-x

Burhenne-Guilmin, F. and Scanlon, J. (eds.) (2004). International Environmental Governance. An International Regime for Protected Areas. IUCN Environmental Policy and Law Paper No. 49. Gland, Switzerland and Cambridge, G.B.: IUCN.

Convention on Biological Diversity (CBD) (2010). Convention on Biological Diversity 2010: Decision adopted by the Conference of the Parties to the Convention on Biological Diversity at its 10th Meeting. X/33. Biodiversity and climate change. UNEP/CBD/COP/DEC/X/33.

Convention on Biological Diversity (CBD) (1992). Convenio de Diversidad Biológica. Available at: https://www.cbd.int/doc/legal/cbd-en.pdf

CBD (2000). Ecoystem Approach. (Decision V/6. UNEP/CBD/COP/5/23). Available at: https://www. cbd.int/decisions/cop/5/6 CBD (2011). Nagoya Protocol on Access to Genetic Resources and the Fair and Equitable Sharing of Benefits Arising from their Utilisation to the Convention on Biodiversity.

CBD (2009 a). COP 10, Decision X/33. Available at: $\underline{\text { https://www.cbd.int/decision/cop/?id=12299 }}$

CBD (2009 b). Connecting biodiversity and climate change mitigation and adaptation. Montreal, Canada. Available at: https://www.cbd.int/doc/publications/ahteg-brochure-en.pdf

CBD (2018). Voluntary Guidelines for the design and effective implementation of ecosystem-based approaches to climate change adaptation and disaster risk reduction. CBD/SBSTTA/22/INF/1. Twenty-second meeting. Montreal, Canada. 2-7 July 2018. Available at: https://www.cbd.int/ doc/c/3f7a/4589/5cc1b7058bf52427fa9bae84/sbstta-22-inf-01-en.pdf 
CBD (2018a). COP 14. Comprehensive and participatory process for the preparation of the post2020 global biodiversity framework. Decision: CBD/ COP/DEC/14/34. Available at: https://www. cbd.int/doc/decisions/cop-14/cop-14-dec-34-en.pdf

CBD (2019). Post-2020 Global Biodiversity Framework: Discussion Paper. CBD/POST2020/PREP/1/. Available at: https://www.cbd.int/doc/c/d0f3/aca0/d42fa469029f5a4d69f4da8e/post2020prep-01-01-en.pdf

Colloff, M.J., Martín-López, B., Lavorel, S., Locatelli, B., Gorddard, R., Longaretti, P.Y., Walters, G., van Kerkhoff, L., Wyborn, C., Coreau, A., Wise, R.M., Dunlop, M., Degeorges, P., Grantham, H., Overton, I.C., Williams, R.D., Doherty, M.D., Capon, T., Sanderson, T. and Murphy, H.T. (2017). 'An integrative research framework for enabling transformative adaptation'. Environmental Science and Policy 68: 87-96. Available at: https://www.sciencedirect.com/science/article/pii/ S1462901116301289

Costanza, R., de Groot, R., Braat, L., Kubiszewski, I., Fioramonti, L., Sutton, P., Farber, S. and Grasso, M. (2017). 'Twenty years of ecosystem services: How far have we come and how far do we still need to go?' Ecosystem Services 28: 1-16. Available at: https://doi.org/10.1016/j.ecoser.2017.09.008

Chong, J. (2014). 'Ecosystem-based approaches to climate change adaptation: progress and challenges'. International Environment Agreements 14: 391-405. Available at: https://doi.org/10.1007/ s10784-014-9242-9

Cohen-Shacham, E., Walters, G., Janzen, C. and Maginnis, S. (eds.) (2016). Nature-based Solutions to address global societal challenges. Gland, Switzerland: IUCN. Available at: https://portals. iucn.org/library/sites/library/files/documents/2016-036.pdf

Cosens, B.A., Craig, R.K., Hirsch, S., Arnold, C.A.(T.), Benson, M.H, DeCaro, D.A, Garmestani, A.S., Gosnell, H, Ruhl, J. and Schlager, E. (2017). 'The role of law in adaptive governance'. Ecology and Society 22(1): 30. Available at: https://doi.org/10.5751/ES-08731-220130

Creed I.F. and van Noordwijk, M. (eds.) (2018). Forest and Water on a Changing Planet: Vulnerability, Adaptation and Governance Opportunities. A Global Assessment Report. Volume 38. Vienna, Austria: IUFRO World Series. Department for International Development (DFID) (1999). Sustainable livelihoods guidance sheets. London, G.B.: DFID. Available at: https://www.ennonline.net/ dfidsustainableliving.

Department for International Development (DFID) (1999). Sustainable livelihoods guidance sheets. Londres, G.B.: DFID. Available at: https://www.ennonline.net/dfidsustainableliving

Evaluación de los Ecosistemas del Milenio. (2005). Ecosistemas y Bienestar Humano. Informe de Síntesis. Available at: https://www.millenniumassessment.org/documents/document.439.aspx.pdf

Friends of Ecosystem-based Adaptation (FEBA) (2017). Making Ecosystem-based Adaptation Effective: A Framework for Defining Qualification Criteria and Quality Standards (FEBA technical paper developed for UNFCCC-SBSTA 46). Bertram, M., Barrow, E., Blackwood, K., Rizvi, A.R., Reid, H., and von Scheliha-Dawid, S.5 (authors). Bonn, Germany: GIZ, IIED; London, G.B.: IIED and Gland, Switzerland. IUCN. 
Gobierno de Costa Rica (2015). Contribución Prevista y Determinada a Nivel Nacional. Gobierno de El Salvador (2015). Contribución Prevista y Determinada a Nivel Nacional. Gobierno de Guatemala (2015). Contribución Prevista y Determinada a Nivel Nacional. Gobierno de México (2015). Intended Nationally Determined Contribution.

Gobierno de Nicaragua (2018). Contribución Nacionalmente Determinada a la Mitigación del Cambio Climático (NDC) de la República Nicaragua ante la Convención Marco de Naciones Unidas sobre Cambio Climático (CMNUCC).

Gobierno de la República de Honduras (2015). Contribución Prevista y Determinada a Nivel Nacional.

Gobierno de la República de Panamá (2016). Contribución Nacionalmente Determinada a la Mitigación del Cambio Climático (NDC) de la Republica Panamá ante la Convención Marco de Naciones Unidas sobre Cambio Climático (CMNUCC).

Government of Belize (2015). Intended Nationally Determined Contribution.

Guerrero, E., de Keizer, O. and Córdoba, R. (2006). La Aplicación del Enfoque Ecosistémico en la Gestión de los Recursos Hídricos. Quito, Ecuador: IUCN. https://portals.iucn.org/library/ $\underline{\text { node/8806 }}$

Instituto Internacional para el Medio Ambiente y el Desarrollo (IIED) and Unión Internacional para la Conservación de la Naturaleza (UICN) (2016). Adaptación basada en ecosistemas ¿una fórmula beneficiosa para la sostenibilidad frente al cambio climático? Producto del conocimiento. Available at: http://pubs.iied.org/17364SIIED

Grupo Intergubernamental de Expertos sobre el Cambio Climático (IPCC) (2007). Cambio climático 2007: Informe de síntesis. Contribución de los Grupos de trabajo I, II y III al Cuarto Informe de evaluación del Grupo Intergubernamental de Expertos sobre el Cambio Climático Equipo de redacción principal: Pachauri, R.K. and Reisinger, A. (directores de la publicación). Geneva, Switzerland IPCC.

IPCC (2014). Glosario. Planton, S. (ed.). Cambio Climático 2013. Bases físicas. Contribución del Grupo de trabajo I al Quinto Informe de Evaluación del Grupo Intergubernamental de Expertos sobre el Cambio Climático. Stocker, T.F., Qin, D., Plattner, G.K., Tignor, M., Allen, S.K., Boschung, J., Nauels, A., Xia, Y., Bex, V. and Midgley, P.M. (eds.). Cambridge, UK and New York, NY, USA: Cambridge University Press.

IUCN (2016). Programme 2017-2020. Available at: https://portals.iucn.org/library/sites/library/files/ documents/WCC-6th-001.pdf

Iza, A. and Stein, R.(eds.) (2009). RULE: Reforming water governance. Gland, Switzerland: IUCN. https://portals.iucn.org/library/node/9322

Lausche, B. (2011). Guidelines for Protected Areas Legislation. Bonn, Germany: IUCN. Available at: https://portals.iucn.org/library/sites/library/files/documents/EPLP-081.pdf

Layke, C. (2009). Measuring Nature's Benefits: A Preliminary Roadmap for Improving Ecosystem Service Indicators. WRI Working Paper. Washington D.C., USA: World Resources Institute. Available at: https://www.wri.org/publication/measuring-natures-benefits. 
MacKinnon, K., Dudley, N.and Sandwith, T. (2011). Natural solutions: protected areas helping people to cope with climate change. Fauna \& Flora International, Oryx, 45(4): 461-462. Available at: https:// www.cambridge.org/core/services/aop-cambridge-core/content/view/D3A6B78674EB20BCC67A3E8F66161471/S0030605311001608a.pdf/div-class-title-natural-solutions-protected-areas-helping-people-to-cope-with-climate-change-div.pdf

Mann, M., Rahmstorf, S. Kornhuber, K., Steinman, B.A., Miller S.K. and Coumou, D. (2017). 'Influence of Anthropogenic Climate Change on Planetary Wave Resonance and Extreme Weather Events'. Scientific Reports 7, 45242. Available at: https://www.nature.com/articles/srep45242. https:// doi.org/10.1038/srep46822

Martínez, L. and Luna, M. (2019). 'Gobernanza para la Adaptación basada en Ecosistemas'. Catálogo de Adaptación basada en Ecosistemas. Serie Gobernanza. San José, Costa Rica: IUCN.

Mumby, P.J., Flower, J., Chollett, I., Box, S.J., Bozec, YM., Fitzsimmons, C., Forster, J., Gill, D., Griffith-Mumby, R., Oxenford, H.A., Peterson, A.M., Stead, S.M., Turner, R.A., Townsley, P., van Beukering, P.J.H., Booker, F., Brocke, H.J., Cabañillas-Terán, N., Canty, S.W.J., Carricart-Ganivet, J.P., Charlery, J., Dryden, C., van Duyl, F.C., Enríquez, S., den Haan, J., Iglesias-Prieto, R., Kennedy, E.V., Mahon, R., Mueller, B., Newman, S.P., Nugues, M.M., Cortés Núñez, J., Nurse, L., Osinga, R., Paris, C.B., Petersen, D., Polunin, N.V.C., Sánchez, C., Schep, S., Stevens, J.R., Vallès, H., Vermeij, M.J.A., Visser, P.M., Whittingham, E., and Williams, S.M. (2014). Towards Reef Resilience and Sustainable Livelihoods: A handbook for Caribbean coral reef managers. Exeter: University of Exeter.

Organisation for Economic Co-operation and Development (OECD) (2015). Principles on Water Governance. OECD. Paris. France. Available at: https://www.oecd.org/cfe/regionaldevelopment/ OECD-Principles-on-Water-Governance-en.pdf

OECD (2018). Implementing the OECD Principles on Water Governance: Indicator Framework and Evolving Practices. OECD Studies on Water. Paris, France: OECD Publishing. http://dx.doi. org/10.1787/9789264292659-en.

Organización de las Naciones Unidas (ONU) (2016). Agenda 2030 y los Objetivos de Desarrollo Sostenible. Una oportunidad para América Latina y el Caribe. Comisión Económica para América Latina y el Caribe (CEPAL). Santiago, Chile.

Programa de las Naciones Unidas para el Medio Ambiente (PNUMA) (2011). Hacia una economía verde: Guía para el desarrollo sostenible y la erradicación de la pobreza - Síntesis para los encargados de la formulación de políticas. Available at: https://www.unenvironment.org/explore-topics/green-economy

Programa Mundial de las Naciones Unidas de Evaluación de los Recursos Hídricos/ONU-Agua (WWAP) (2018). Informe Mundial de las Naciones Unidas sobre el Desarrollo de los Recursos Hídricos 2018: soluciones basadas en la naturaleza para la gestión del agua. Paris, France: UNESCO.

Potschin, M., Jax, K., Görg, C and Haines-Young, R. (2014). OpenNESS Project Deliverable 1.1.: preliminary conceptual frameworks for the analysis of ES and NC in relation to the 4 challenges, and how these issues can be communicated and resolved in difference place based-contexts. European Commission FP7. 
Reid, H., Seddon, N., Barrow, E., Hicks, C., Hou-Jones, X., Kapos, V., Rizvi, A. R., Roe, D. and Wicander,S. (2017). Adaptación basada en Ecosistemas: Guía de preguntas para evaluar la efectividad. London, G.B.: IIED..

Rubio Scarano, F. (2017). 'Ecosystem-based adaptation to climate change: concept, scalability and a role for conservation science'. Perspectives in Ecology and Conservation 15: 65-73. Available at: https://doi.org/10.1016/i.pecon.2017.05.003

Sanchez, J.C. and Roberts, J. (eds.) (2014). Transboundary Water Governance. Adaptation to Climate Change. Gland, Switzerland: IUCN. https://portals.iucn.org/library/node/44675

Sieber, I.M., Biesbroek, R. and de Block, D. (2018). 'Mechanism-based explanations of impasses in the governance of ecosystem-based adaptation'. Regional Environmental Change 18(8): 23792390. Available at: https://doi.org/10.1007/s10113-018-1347-1

Sistema Nacional de Áreas de Conservación (SINAC) (2013). Análisis de vulnerabilidad al cambio climático de las áreas silvestres protegidas terrestres. San José, Costa Rica.

Strategic Plan for Biodiversity 2011-2020 and the Aichi Targets. Available at: https://www.cbd.int/ doc/strategic-plan/2011-2020/Aichi-Targets-En.pdf

Tickner, D., Parker, H., Moncrieff, C.R., Oates, N.E.M., Ludi, E. and Acreman, M. (2017). 'Managing Rivers for Multiple Benefits - A Coherent Approach to Research, Policy and Planning'. Frontiers in Environmental Science 5:4, 1-8. Available at: https://doi.org/10.3389/fenvs.2017.00004

Unión Internacional para la Conservación de la Naturaleza (UICN) (2006). Plan Estratégico de Incidencia Centroamérica 2006-2010. Costa Rica: IUCN. Available at: https://portals.iucn.org/library/sites/library/files/documents/2006-095.pdf

United Nations Development Programme (UNDP) (2015). Sustainable Development Goals. Available at: https://www.undp.org/content/undp/en/home/sustainable-development-goals.html

UNEP-DHI Partnership/IUCN/TNC (2014). Green Infrastructure Guide for Water Management: Ecosystem-Based Management Approaches for Water-Related Infrastructure Projects. UNEP. Available at: https://portals.iucn.org/library/node/44769

UNFCCC (1992). United Nations Framework Convention on Climate Change.

UNFCCC (2015). United Nations Framework Convention on Climate Change. Paris Agreement.

Oficina de las Naciones Unidas para Reducción de Riesgo de Desastres (UNISDR) (2015). Marco de Sendai para la Reducción del Riesgo de Desastres 2015-2030.

United Nations System Task Team on the Post-2015 UN Development Agenda (UNSTT) (2012). Governance and development: thematic think piece. New York, USA: United Nations. Available at: http://www.un.org/millenniumgoals/pdf/Think\%20Pieces/7 governance.pdf

Williams, G.D., Andrews, K., Tolimieri, N., Samhouri, J.F. and Levin, P.S. (2012). Ecological Integrity. CCIEA. Reporte de la Fase II.

Wood, S.L.R., Jones, S.K., Johnson, J.A., Brauman, K.A., Chaplin-Kramer, R., Fremier, A. and DeClerck, F.A. (2018). 'Distilling the role of ecosystem services in the Sustainable Development Goals'. Ecosystem Services 29, 70-82. Available at: https://doi.org/10.1016/j.ecoser.2017.10.010 


\section{Capacities}

Arrevillaga, F. and López, D. (2019). 'Protección de ecosistemas, seguridad alimentaria e hídrica en ejidos: Cuenca del río Cahoacán, Chiapas, México'. Catálogo de Adaptación basada en Ecosistemas. Serie Comunidades con Inteligencia Natural. San José, Costa Rica: IUCN.

Cumming, G.S., Cumming, D.H.M. and Redman, C.L. (2006). 'Scale mismatches in social-ecological systems: causes, consequences, and solutions'. Ecology and Society 11(1): 14. Available at: http://www.ecologyandsociety.org/vol11/iss1/art14/

Gupta, J., Termeer, C., Klostermann, J., Meijerink, S., van den Brink, M., Jong, P., Nooteboom, S. and Bergsma, E. (2010). 'The Adaptive Capacity Wheel: a method to assess the inherent characteristics of institutions to enable the adaptive capacity of society'. Environmental Science \& Policy 13: 459-471. Available at: https://doi.org/10.1016/j.envsci.2010.05.006

Intergovernmental Panel on Climate Change (IPCC)(2014). 'Summary for policymakers'. In: Field, C.B., V.R. Barros, D.J. Dokken, K.J. Mach, M.D. Mastrandrea,T.E. Bilir, M. Chatterjee, K.L. Ebi, Y.O. Estrada, R.C. Genova, B. Girma, E.S. Kissel, A.N. Levy, S. MacCracken, P.R. Mastrandrea, and L.L. White (eds.) Climate Change 2014: Impacts, Adaptation, and Vulnerability. Part A: Global and Sectoral Aspects. Contribution of Working Group II to the Fifth Assessment Report of the Intergovernmental Panel on Climate Change, pp. 1-32. Cambridge, G.B. and New York, NY, USA: Cambridge University Press.

Ministerio de Ambiente y Recursos Naturales (MARN) (2016). Acuerdo Ministerial 335-2016. Guatemala: Ministerio de Ambiente y Recursos Naturales.

Martínez, L. and Luna, M. (2019). 'Gobernanza para la Adaptación basada en Ecosistemas'. Catálogo de Adaptación basada en Ecosistemas. Serie Gobernanza. San José, Costa Rica: IUCN.

Narvaez-Marulanda, B.L. (2018). 'Communities perception of their adaptive capacities related to water availability in El Aguacate microwatershed - Paz River, El Salvador'. Thesis. Bonn, Germany: United Nations University, Institute for Environment and Human Security (UNU - EHS).

Newborne, P. and Dalton, J. (2016). Water Management and Stewardship: Taking stock of corporate water behaviour. Gland, Switzerland: IUCN and London, G.B.: DOI. Available at: https://doi. org/10.2305/IUCN.CH.2016.16.en

Pérez de Madrid, M. (2019). Fortalecimiento de la gobernanza comunitaria para la restauración de manglares y la seguridad alimentaria del río Paz, El Salvador. Available at: https://panorama. solutions/es/node/3502.

Pérez de Madrid, M. and Navarro, M. (2019). Seguridad alimentaria e hídrica de las comunidades indí genas en Guatemala. Available at: https://panorama.solutions/es/node/3502.

Reid, H., Seddon, N., Barrow, E., Hicks, C., Hou-Jones, X., Kapos, V., Rizvi, A. R., Roe, D. and Wicander S. (2017). Adaptación basada en Ecosistemas: Guía de preguntas para evaluar la efectividad. London, G.B: IIED.

Smit, B. and Pilifosova, O. (2001). 'Adaptation to climate change in the context of sustainable development and equity'. In: McCarthy, J.J., Canzianni, O.F., Leary, N.A., Dokken, D.J.and White, K.S. (eds.), Climate Change 2001: Impacts, Adaptation, and Vulnerability, pp. 876-912. Contribution of Working Group II to the Third Assessment Report of the Intergovernmental Panel on Climate Change. Cambridge, G.B.: Cambridge University Press 
World Economic Forum (WEF) (2016). The Future of Jobs. Employment, Skills and Workforce Strategy for the Fourth Industrial Revolution. Global Challenge Insight Report. World Economic Forum.

\section{Evidence}

Albert, C., Schröter, B., Haase, D., Brillinger, M., Henze, J., Herrmann, S., Gottwald, S., Guerrero, P., Nicolas, C., and Matzdorf, B. (2019). 'Addressing societal challenges through nature-based solutions: How can landscape planning and governance research contribute?'. Landscape and Urban Planning 182: 12-21. Available at: https://doi.org/10.1016/j.landurbplan.2018.10.003

Bennett, N.J. and Satterfield, T. (2018). 'Environmental governance: A practical framework to guide design, evaluation, and analysis'. Conservation Letters. Available at: https://doi.org/10.1111/ conl. 12600

Calliari, E., Staccione, A. and Mysiak, J. (2019). 'An assessment framework for climate-proof nature-based solutions'. Science of the Total Environment 656: 691-700. Available at: https://doi. org/10.1016/j.scitotenv.2018.11.341

CBD (2010) Convention on Biologial Diversity: ABS Theme Taditional Knowledge. Available at: https:// www.cbd.int/abs/infokit/factsheet-tk-en.pdf

Convention on Biological Diversity (CBD) (2018). Voluntary Guidelines for the design and effective implementation of ecosystem-based approaches to climate change adaptation and disaster risk reduction. CBD/SBSTTA/22/INF/1. Twenty-second Meeting. Montreal, Canada, 2-7 July 2018. Available at: https://www.cbd.int/doc/publications/cbd-ts-93-en.pdf

Chong, J. (2014). 'Ecosystem-based approaches to climate change adaptation: progress and challenges'. International Environment Agreements 14:391-405. Available at: https://doi.org/10.1007/ $\underline{\text { s10784-014-9242-9 }}$

Collins, A., Coughlin, D., Miller, J., and Kirk, S. (2015). The Production of Quick Scoping Reviews and Rapid Evidence Assessments: A How To Guide. Department for Environment, Food and Rural Affairs. Natural Environment Research Council and Environment Agency. G.B.

Comas, D. (2015). ‘¿Qué es la evidencia científica y cómo utilizarla? EMPIRIA'. Revista de Metodología de Ciencias Sociales 31: 211-214. Available at: https://doi.org/10.5944/empiria.31.2015.14560

Cvitanovic, C., McDonald, J. and Hobday, A.J. (2016). 'From science to action: Principles for undertaking environmental research that enables knowledge exchange and evidence-based decision-making'. Journal of Environmental Management 183: 864-874. Available at: https://doi. org/10.1016/j.jenvman.2016.09.038

Davenport, T.H. and Prusak, L. (1998). Working knowledge: how organizations manage what they know. Available at: https://books.google.co.cr/books?hl=en\&lr=\&id=-4-7vmCVG5cC\&oi=fnd\&pg=PR7\&dq=Thomas + H. + Davenport+\&ots=mzkaX 9IL6\&sig=dOu8VAOjfnsIcUThRGqSdi4MidE\&redir esc=y\#v=onepage\& $\mathrm{q}=$ Thomas $\% 20 \mathrm{H} . \% 20$ Davenport\&f=false

Dendoncker, N., Turkelboom, F., Boeraeve, F., Boerema, A., Broekx, S., Fontaine, C., Demeyer, R., De Vreese, R., Devillet, G., Keune, H., Janssens, L., Liekens, I., Lord-Tarte, E., Popa, F., Simoens, I., Smeets, N., Ulenaers, P., Van Herzele, A., Van Tichelen, K. and Jacobs, S. (2018). 'Integrating Ecosystem Services values for sustainability? Evidence from the Belgium Ecosystem Services community of practice'. Ecosystem Services 31: 68-76. Available at: https://doi. org/10.1016/j.ecoser.2018.03.006 
Departamento Administrativo Nacional de Estadística (DANE) (2013). Guía para diseño, construcción e interpretación de indicadores: Estrategia para el Fortalecimiento Estadístico Territorial. Herramientas estadísticas para una gestión territorial más efectiva. Número 2. Colombia.

Doswald, N., Munroe, R., Roe, D., Giuliani, A., Castelli, I., Stephens, J., Möller, I., Spencer, T., Vira, B. and Reid, H. (2014). 'Effectiveness of ecosystem-based approaches for adaptation: review of the evidence-base'. Climate and Development. Available at: http://dx.doi.org/10.1080/17565 $\underline{529.2013 .867247}$

Encalada, M. A. (2005). Comunicación sobre el cambio climático. Manual para su planificación y práctica en América Latina. Ecuador: OIKOS and Kenia: PNUMA. Available at: https://www.oei. es/historico/decada/manual.htm

Hills, T. (2015). The State of Ecosystem-based Adaptation (EbA) to Climate Change in 2015 -EbA. Policy Analysis-. Informe técnico. Conservación Internacional. Available at: https://www.conservation.org/publications/Documents/EbA-Synthesis-28-July-2015.pdf

Iza, A. y Stein, R. (eds.) (2009). RULE: Reforming water governance. Gland, Switzerland: IUCN. Available at: https://portals.iucn.org/library/node/9322

Marín, M. and Navarro, M. (2019). Adaptación basada en Ecosistemas y seguridad alimentaria en la subcuenca del río Esquichá, Guatemala. Catálogo de Adaptación basada en Ecosistemas. Serie Comunidades con Inteligencia Natural. San José, Costa Rica: IUCN.

Marín, M., Pérez de Madrid, M. and Cruz, E. (2019). Tendencias, enfoques y oportunidades de los proyectos sobre cambio climático y adaptación en Mesoamérica. Catálogo de Adaptación basada en Ecosistemas. Serie Evidencia. San José, Costa Rica: IUCN. Available at: http://iucn.cr/ arcgis/apps/webappviewer/index.html?id=202a718c741e498aad091b39ee93508f

McKinnon, M.C., Cheng, S.H., Dupre, S., Edmond, J., Garside, R., Glew, L., Holland, M.B., Levine, E., Masuda, Y.J., Miller, D.C., Oliveira, I., Revenaz, J., Roe, D., Shamer, S., Wilkie,D. Wongbusarakum, S. y Woodhouse, E. (2016). 'What are the effects of nature conservation on human well-being? A systematic map of empirical evidence from developing countries'. Environmental Evidence 5:8. Available at: https://doi.10.1186/s13750-016-0058-7

Mehvar, S., Filatova, T., Sarker, M.H. and Ranasinghe, R. (2019). 'Climate change-driven losses in ecosystem services of coastal wetlands: A case study in the West coast of Bangladesh'. Ocean and Coastal Management 169: 273-283. Available at: https://doi.org/10.1016/j.ocecoaman.2018.12.009

Montaña, T. (2015). Gobernanza para el Cambio Climático Estudio del caso gobierno local de Mendoza-Argentina. Banco Interamericano de Desarrollo. Available at: http://www.mendoza.gov.ar/ wp-content/uploads/sites/14/2016/05/Gobernanza-para-el-CC-en-gobiernos-locales-VF.pdf

Munroe, R., Roe, D., Doswald, N., Spencer, T., Möller, I., Vira, B., Reid, H., Kontoleon, A., Giuliani, A., Castelli, I. and Stephens, J. (2012). 'Review of the evidence base for ecosystem-based approaches for adaptation to climate change'. Environmental Evidence 1:13. Available at: http:// www.environmentalevidencejournal.org/content/1/1/13. https://doi.org/10.1186/2047-2382-1-13

Nalau, J. and Becken, S. (2018). Ecosystem-based Adaptation to Climate Change: Review of Concepts. Griffith Institute for Tourism. Research Report No 15. Queensland, Australia. 
Organization for Economic Co-operation and Development (OECD) (2018). Implementing the OECD Principles on Water Governance: Indicator Framework and Evolving Practices. OECD Studies on Water. París, Francia: OECD Publishing. Available at: http://dx.doi.org/10.1787/9789264292659en

Pérez de Madrid, M. and Guillén, R. (2019). Seguridad alimentaria e hídrica en la cuenca del río Goascorán (Honduras, El Salvador). Catálogo de Adaptación basada en Ecosistemas. Serie Comunidades con Inteligencia Natural. San José, Costa Rica: IUCN.

PNUD-INECC (2017). Experiencias internacionales en el desarrollo de sistemas de indicadores para el seguimiento de políticas de cambio climático. Proyecto 00085488: "México: Sexta Comunicación Nacional ante la Convención Marco de Naciones Unidas sobre Cambio Climático". Ciudad de México. Available at: https://www.gob.mx/inecc/documentos/experiencias-internacionales-desarrollo-de-un-sistema-de-indicadores-que-oriente-la-evaluacion-de-la-politica-nacional-de-cambio-climatico

Programa Mundial de las Naciones Unidas de Evaluación de los Recursos Hídricos)/ONU-Agua (WWAP) (2018). Informe Mundial de las Naciones Unidas sobre el Desarrollo de los Recursos Hídricos 2018: Soluciones basadas en la naturaleza para la gestión del agua. París, Francia: UNESCO.

Raum, S. (2018). 'A framework for integrating systematic stakeholder analysis in ecosystem services research: Stakeholder mapping for forest ecosystem services in the UK'. Ecosystem Services 29: 170-184. Available at: https://doi.org/10.1016/j.ecoser.2018.01.001

Raymond, C.M., Frantzeskaki, N., Kabisch,N., Berry, P., Breil, M., Razvan Nita, M., Geneletti, D. and Calfapietra, C. (2017). 'A framework for assessing and implementing the co-benefits of nature-based solutions in urban areas'. Environmental Science \& Policy 77:15-24. Available at: https://doi.org/10.1016/j.envsci.2017.07.008

Real Academia Española (RAE) (2018). Diccionario de la lengua española. Available at: https://dle. rae.es/?w=diccionario.

Reid, H., Bourne, A., Mulle, H., Podvin, K., Scorgie, S., and Orindi, V. (2018). 'A Framework for Assessing the Effectiveness of Ecosystem-Based Approaches to Adaptation'. in: Zommers, Z. and Alverson, K. (eds.) Resilience: The Science of Adaptation to Climate Change, pp. 207-216. Amsterdam, Países Bajos. Available at: https://doi.10.1016/B978-0-12-811891-7.00016-5

Reid, H., Pérez de Madrid, M. and Ramírez, O. (2018). Ecosystem-based approaches to adaptation: strengthening the evidence and informing policy. Research results from the Adaptation, Vulnerability and Ecosystems (AVE) project, Costa Rica and Panama. IIED-NUAmbiente-IUCN-WCMC. Available at: http://pubs.iied.org/17627IIED.

Reid, H., Pérez de Madrid, M., Ramírez, O. and Hicks, C. (2019a). Ecosystem-based approaches to adaptation: strengthening the evidence and informing policy. Research results from the Adaptation,Vulnerability and Ecosystems (AVE) project, Costa Rica and Panama. Available at: http://pubs.iied.org/17627IIED/

Reid, H., Pérez de Madrid, M., Ramírez, O. and Hicks, C. (2019b). Ecosystem-based climate adaptation: building on the positives in EI Salvador. Available at: http://pubs.iied.org/17496IIED/ 
Reid, H., Seddon, N., Barrow, E., Hicks, C., Hou-Jones, X., Kapos, V., Rizvi, A.R., Roe, D. and Wicander. S. (2017). Adaptación basada en Ecosistemas: Guía de preguntas para evaluar la efectividad. Londres, G.B.: IIED.

Seddon, N., Reid, H., Barrow, E., Hicks, Ch., Hou-Jones, X., Kapos, V., Rizvi, A.R. and Roe, D. (2016). Ecosystem-based approaches to adaptation: strengthening the evidence and informing policy. Research overview and overarching questions. Londres, G.B.: IIED.

Sieber, I.M., Biesbroek, R. and de Block, D. (2018). 'Mechanism-based explanations of impasses in the governance of ecosystem-based adaptation'. Regional Environmental Change. Available at: https://doi.org/10.1007/s10113-018-1347-1.

SINAC-PNUD-GEF (2018). Proyecto Humedales. Herramientas para mejorar la gestión en Sitios Ramsar de Costa Rica y otros ecosistemas de humedal. Reporte 2014-2018 del Proyecto Humedales. SINAC/PNUD/GEF. San José, Costa Rica.

United Nations System Task Team on the Post-2015 UN Development Agenda (UNSTT) (2012). Governance and development: thematic think piece. Nueva York, EE.UU.: Naciones Unidas Available at: http://www.un.org/millenniumgoals/pdf/Think\%20Pieces/7 governance.pdf

Vignola, R., Otárola, M., Alpízar, F., Rivera, P. (2019). ‘Gobernanza para la Adaptación basada en Ecosistemas (AbE) para pequeños caficultores de América Central'. Agronomía Mesoamericana 30 (1): 19-32. Available at: https://doi.org/10.15517/am.v30i1.32615

\section{Policy}

Aguilar, G. and Iza, A.O. (2011). Governance of Shared Waters. Legal and Institutional Issues. IUCN Environmental Policy and Law Paper No. 58 rev. Gland, Switzerland: IUCN. https://portals.iucn. org/library/node/9995

Amaya, O. (2002). La Constitución ecológica de Colombia. Análisis comparativo con el sistema constitucional latinoamericano. Bogotá: Universidad Externado de Colombia

Andrade A., Arguedas S. and Vides R. (2011). Guía para la aplicación y monitoreo del Enfoque Ecosistémico. CEM-UICN, CI-Colombia, ELAP-UCI, FCBC, UNESCO-Programa MAB.

Andrade, A., Córdoba, R., Dave, R., Girot, P., Herrera-F, B., Munroe, R., Oglethorpe, J., Paaby, P., Pramova, E., Watson, J., Vergara, W. and Suarez, I. (2012). Principles and Guidelines for Integrating Ecosystem-based Approaches to Adaptation in Project and Policy Design. Turrialba, Costa Rica: IUCN-CEM, CATIE

Austin, E., Ford, J.D., Berrag-Ford, L., Biesbroek, R. and Ross, N.A. (2019). 'Enabling local public health adaptation to climate change'. Social Science \& Medicine vol. 220, pp. 236-244. Available at: https://doi.org/10.1016/j.socscimed.2018.11.002

Boer, B. and Clarke, P. (2012). Legal frameworks for ecosystem-based adaptation to climate change in the Pacific Islands. Apia, Samoa: SPREP.

Burhenne-Guilmin, F. and Scanlon, J. (eds.) (2004). International Environmental Governance. IUCN Environmental Policy and Law Paper No. 49. Gland, Switzerland: IUCN. https://portals.iucn.org/ library/node/8377

Convention on Biological Diversity (CBD) (2006). Decision VIII/30. Biodiversity and climate change: guidance to promote synergy among activities for biodiversity conservation, mitigating or 
adapting to climate change and combating land degradation, Curitiba, Brazil, 20-31 March, UN Doc. UNEP/CBD/COP/DEC/VIII/30

CBD (2009). Connecting Biodiversity and Climate Change Mitigation and Adaptation: Informe del Segundo Grupo Ad Hoc de Expertos Técnicos sobre Biodiversidad y Cambio Climático. Montreal, Serie Técnica No. 41.

CBD (2014). Decision XII/20. Biodiversity and climate change and disaster risk reduction, 6-17 October, UN Doc. UNEP/CBD/COP/DEC/XII/20.

CBD (2018). Decision 14/5. Biodiversity and Climate Change. COP14. Sharm El-Sheikh, Egypt. CBD/ COP/DEC/14/5

Comisión Económica Para América Latina (CEPAL) (2009). Guía de evaluación ambiental estratégica. $\mathrm{NU}$.

Decisions 12/72 to 12/74. Climate Change and Migratory Species. 23-28 October. UN Doc. UNEP/ CMS/COP12/Decisions. Available at: https://www.cms.int/en/cop12

Convention on the Conservation of Migratory Species of Wild Animals (CMS) (2017a). Decisions $12 / 72$ to $12 / 74$. Climate Change and Migratory Species. 23-28 October. UN Doc. UNEP/CMS/ COP12/Decisions. Available at: https://www.cms.int/en/cop12

CMS (2017b). Resolution 12/21. Climate Change and Migratory Species. 23-28 October. UN Doc. UNEP/CMS/Resolution 12.21. Available at: https://www.cms.int/sites/default/files/document/ cms cop12 res.12.21 climate-change e.pdf

Constitución Política de Colombia (1991).

Convention on Wetlands of International Importance especially as Waterfowl Habitat (Convention of Wetlands) (2015a). Resolution XII.2. The Ramsar Strategic Plan 2016 - 2024. 1 - 9 June.

Convention on Wetlands (2015b). Resolution XII.13. Wetlands and disaster risk reduction. 1 - 9 June.

Cosens, B., Craig, R., Hirsch, S.L., Craig, A. A., Benson, M., De Caro, A., Garmestani, A. S., Gosnell, H., Ruhl, J.B. and Schlager, E. (2017). 'The Role of Law in Adaptive Governance'. Ecology and Society 22(1):30. Available at: https://doi.org/10.5751/ES-08731-220130

Craig, R. K. (2010). "'Stationary is dead"- Long live transformation: Five Principles for Climate Change Adaptation Law'. Harvard Environmental Law Review 34:10-73.

Flatt, V. (2012). 'Adapting Laws for a Changing World: A Systemic Approach to Climate Change Adaptation'. FLA L. Rev. 269 (2012) Available at: https://scholarship.law.ufl.edu/flr/vol64/iss1/6/

Gesellschaft für Internationale Zusammenarbeit (GIZ) (2018). Finance options and instruments for Ecosystem-based Adaptation. Overview and compilation of ten examples. Authors: Kiran Hunzai, Thiago Chagas, Lieke 't Gilde, Tobias Hunzai, Nicole Krämer. Bonn, Germany: Deutsche Gesellschaft für Internationale Zusammenarbeit (GIZ) GmbH.

Greiber, T. (ed.) (2010). Pagos por servicios ambientales. Marcos jurídicos e institucionales. Gland, Switzerland: IUCN. https://portals.iucn.org/library/node/9609

Greiber, T. and Schiele, S. (2011). Governance of Ecosystem Services. Lessons learned from Cameroon, China, Costa Rica and Ecuador. Gland, Switzerland: IUCN. https://portals.iucn.org/library/ $\underline{\text { node/10078 }}$ 
Intergovernmental Panel on Climate Change (IPCC) (2014). Cambio climático 2014: Impactos, adaptación y vulnerabilidad. Resúmenes, preguntas frecuentes y recuadros multicapítulos. Contribución del Grupo de trabajo II al Quinto Informe de Evaluación del Grupo Intergubernamental de Expertos sobre el Cambio Climático. Field, C.B., Barros, V.R., Dokken, D.J., Mach, K.J., Mastrandrea, M.D., Bilir, T.E., Chatterjee, M., Ebi, K.L.,Estrada, Y.O.,Genova, R.C., Girma, B., Kissel, E.S., Levy, A.N., MacCracken, A.N., Mastrandrea, P.R. and White, L.L. (eds.). Geneva, Switzerland: Organización Meteorológica Mundial. Available at: https://www.ipcc.ch/site/assets/uploads/2018/03/WGIIAR5-IntegrationBrochure es-1.pdf

Iza, A. and Stein, R. (eds.) (2009). RULE: Reforming water governance. Gland, Switzerland: IUCN. https://portals.iucn.org/library/node/9322

Lausche, B. (2011). Guidelines for Protected Areas Legislation. Bonn, Germany: IUCN. https://portals.iucn.org/library/node/9869

Lausche, B., Farrier, D., Verschuuren, J., La Viña, A. G. M., Trouwborst, A., Born, C.H. and Aug, L. (2013). The Legal Aspects of Connectivity Conservation. A Concept Paper. Bonn, Germany: IUCN. https://portals.iucn.org/library/node/30283

Lausche, B. (2018). Integrated Planning. Policy and law tools for biodiversity conservation and climate change. Gland, Switzerland: IUCN. Available at: https://doi.org/10.2305/IUCN.CH.2019. EPLP.88.en

Ley de Cambio Climático de Honduras.

Ley de Cambio Climático del Estado de Chiapas.

Ley General de Cambio Climático de México.

Ley Marco para regular la reducción de la vulnerabilidad, la adaptación obligatoria ante los efectos del cambio climático y la mitigación de gases de efecto invernadero de Guatemala.

Lobos, V. (2015). 'La Evaluación Ambiental Estratégica (EAE) como instrumento de gestión ambiental: conceptos, evolución y práctica'. En: Carmona-Lara, M.C. and Acuña-Hernández, A.L. (coord.) La Constitución y los derechos ambientales. Instituto de Investigaciones Jurídicas de la Universidad Nacional Autónoma de México. Available at: https://archivos.juridicas.unam.mx/ www/bjv/libros/9/4089/12.pdf

Martin, P., Boer, B. and Slobodian, L. (eds.) (2016) Framework for Assessing and Improving Law for Sustainability. Gland, Switzerland and Bonn, Germany: IUCN. Available at: https://doi. org/10.2305/IUCN.CH.2016.EPLP.87.en

Millenium Ecosystem Assessment. (2005). Ecosystem and Human Wellbeing: Synthesis. Washington: Island Press.

Organization for Economic Co-operation and Development (OECD) (2015). National Climate Change Adaptation Framework: emerging practices in monitoring and evaluation. París. Francia: OECD Publishing

Paris Agreement, signed 12 December 2015 and entered into force 4 November 2016.

Plan Nacional de Adaptación al Cambio Climático (2006). Marco para la coordinación entre administraciones públicas para las actividades de evaluación de impactos, vulnerabilidad y adaptación al cambio climático. Oficina Española de Cambio Climático. S.G. para la prevención de la contaminación y del cambio climático. Ministerio de Medio Ambiente. 
Proyecto "Adaptation and Blue Carbon in Mexico". (SF) Available at: https://www.youtube.com/ watch? $v=$ AyovXQIVKQM\&t=11s

Proyecto Ecovalor. (SF) Soluciones Económico-Ambientales. Incorporando soluciones ambientales múltiples y sus implicaciones económicas, en el manejo de los paisajes, bosques y sectores productivos en Cuba. Consultar con Oficina de Implementación Nacional. Centro Nacional de Áreas Protegidas.

Ramsar Convention on Wetlands (2002). Resolution VIII.3 Climate change and wetlands: impacts, adaptation, and mitigation. 18-26 November.

Ramsar Convention on Wetlands (2008). Resolution X.24 Climate change and wetlands. 28 October-4 November.

Rozas-Vásquez, D., Fürst, C., Geneletti, D. and Almendra, O. (2018). 'Integration of ecosystem services in strategic environmental assessment across spatial planning scales'. Land Use Policy 71: 303-310. Available at: https://doi.org/10.1016/j.landusepol.2017.12.015

Ruhl, J.B. (2010). 'Climate Change Adaptation and the Structural Transformation of Environmental Law'. Environmental Law 40.

Sanchez, J.C. and Roberts, J. (eds.) (2014). Transboundary Water Governance: Adaptation to Climate Change. Bonn, Germany: IUCN. https://portals.iucn.org/library/node/44675

Sands, F. (1995). Principles of International Environmental Law. Frameworks, standards and implementation. Manchester, G.B.: Manchester University Press.

Tanner-McAllister, S., Rhodes, J. and Hockings, M. (2017). 'Managing for climate change on protected areas: An adaptive management decision making framework'. Journal of Environmental Management 204. https://doi.org/10.1016/j.jenvman.2017.09.038

The Economics of Ecosystems and Biodiversity (TEEB)-Russia (2018). Ecosystem Services of Russia. Prototype National Report. Vol. 1. Terrestrial Ecosystem Services. Moscow. Available at: http:// www.biodiversity.ru/programs/ecoservices/first-steps/Ecosystem-Services-Russia V1 eng web.pdf

Unión Internacional para la Conservación de la Naturaleza (IUCN) (2017). ‘El Desafío de Bonn: Catalizando liderazgo en América Latina'. Forest Brief 14.

United Nations Convention to Combat Desertification in those Countries Experiencing Drough and/ or Desertification, Particularly in Africa (UNCCD) (2017a). Decision 21/COP.13: Work programme of the Science-Policy Interface for the biennium 2018-2019, (12 October 2017), (UN Doc. ICCD/ $\operatorname{COP}(13) / 21)$

UNCCD (2017b). Decision 4/COP.13: Report on progress in the implementation of the comprehensive communication strategy and on the United Nations Decade for Deserts and the Fight against Desertification (2010-2020), (6-16 September 2017), (UN Doc. ICCD/COP(13)/4)

United Nations Economic Commission for Europe (UNECE) (2018). DRAFT Words into Action. Implementation Guide for Addressing Water-Related Disasters and Transboundary Cooperation: Integrating disaster risk management with water management and climate change adaptation. 28-30 May. UN Doc. ECE/MP.WAT/WG.2/2018/INF.8

UNECE. Task Force on Water and Climate Change. https://www.unece.org/env/water/water and climate.html. Consultada: el 20 de julio de 2018. 
United Nations Environment Programme (UNEP) (2014). Integrating Ecosystem Services in Strategic Environmental Assessment: A guide for practitioners. A report of Proecoserv. Geneletti, D.

UNEP (2019). Environmental Rule of Law. First Global Report. Nairobi,Kenia: United Nations Environment Programme.

United Nations Framework Convention on Climate Change (UNFCCC) (2013). Report on the technical workshop on ecosystem-based approaches for adaptation to climate change, 28th SABSTA session, Bonn, 3-14 June. UN Doc FCCC/SBSTA/2013/2.

Vallejo, L. (2017). Insights from national adaptation monitoring and evaluation systems. Climate Change Expert Group. Paper No. 2017(3), OECD. Available at: https://www.oecd.org/environment/cc/Insights\%20from\%20national\%20adaptation\%20monitoring\%20and\%20evaluation\%20systems.pdf

Vasseur, L., Horning, D., Thornbush, M., Cohen-Schacham, E., Andrade, A., Barrow, E., Edwards, S.R., Wit, P., and Jones, M. (2017). Complex problems and unchallenged solutions: Bringing ecosystem governance to the forefront of the UN. Available at: https://doi.org/10.1007/s13280$\underline{017-0918-6}$

Verschuuren, J. (2013). 'Legal Aspects of Climate Change Adaptation'. En: Hollo, E., Kulovesi, K., Mehling, M. (eds.) Climate Change and the Law. Amsterdam, Países Bajos: Springer Netherlands. Available at: https://doi.org/10.1007/978-94-007-5440-9 11

Verschuuren, J. (ed.) (2013a) Research Handbook on Climate Change Adaptation. Cheltenham, G.B. and Northampton, EE.UU. : Edward Elgar Publishing Limited.

Yazykova, S., Bruch, C. (2018). 'Incorporating Climate Change Adaptation into Framework Environmental Laws'. Environmental Law Reporter 48.

\section{Institutions}

Asamblea Legislativa de Costa Rica. (1995). Ley Orgánica del Ambiente No. 7554.

Buscher, B., Dressler, W., and Fletcher, R. (eds.) (2014). Nature Inc.: Environmental Conservation in the Neoliberal Age, p.304. Tucson, EE.UU.: University of Arizona Press. Available at: https://doi. org/10.2307/j.ctt183pdh2

Bolman, L.G. and Deal, T.E. (2013). Reframing Organizations: Artistry, Choice and Leadership. Jossey-Bass.

Chaudhury, A., Ventresca, M., Thornton, T., Helfgott, A., Sova, C., Baral, P., Rasheed, T., and Ligthart, J. (2016). 'Emerging meta-organisations and adaptation to global climate change: Evidence from implementing adaptation in Nepal, Pakistan and Ghana'. Global Environmental Change 38: 243-257. Available at: https://doi.org/10.1016/j.gloenvcha.2016.03.011

Comisión Nacional de Prevención de Riesgos y Atención de Emergencias (CNE) (2009). Reglamento de Organización y Funcionamiento de los Comités Regionales, Municipales y Comunales de Emergencia. Acuerdo No. 123-2009

Congreso Nacional de Honduras (2014). Ley de Cambio Climático. Decreto 297-2013.

Congreso de la República de Guatemala (2013). Ley Marco para regular la reducción de la vulnerabilidad, la adaptación obligatoria ante los efectos del climático y la mitigación de gases de efecto invernadero. Decreto 7-2013. 
Congreso de la Unión de los Estados Unidos Mexicanos (2012). Ley General de Cambio Climático. Nueva Ley DOF 06-06-2012.

Congreso del Estado de Chiapas. (2014). Ley para la Adaptación y Mitigación ante el Cambio Climático en el Estado de Chiapas. Decreto 228.

Cuevas S.C. (2018). 'Institutional dimensions of climate change adaptation: insights from the Philippines'. Climate Policy 18(4): 499-511. Available at: https://doi.org/10.1080/14693062.2017.131 $\underline{4245}$

Dirección de Cambio Climático de Costa Rica (DCC) (2018). ¿Quiénes somos?. Página web de la DCC. Available at: http://www.cambioclimaticocr.com/2012-05-22-19-42-06/quienes-somos. (Consultada: 02 de agosto de 2018)

Delamaza Escobar, G. and Flores, L. (2017). 'El Estado en América Latina: un análisis desde las políticas públicas'. Polis (Santiago), 16(48): 5-10. Available at: https://dx.doi.org/10.4067/S071865682017000300005 (Consultado: 10 de agosto de 2018).

Fröhlich J. and Knieling J. (2013). 'Conceptualising Climate Change Governance'. En: Jörg Knieling and Walter Leal Filho. Climate Change Governance. Berlín and Heidelberg, Germany: Springer-Verlag. Available at: https://doi.org/10.1007/978-3-642-29831-8

Girard C., Pulido-Velazquez, M., Rinaudo, J., Pagé, C. and Caballero, Y. (2015). 'Integrating top-down and bottom-up approaches to design global change adaptation at the river basin scale'. Global Environmental Change 34: 132-146. Available at: https://doi.org/10.1016/i.gloenvcha.2015.07.002

Gobierno de la República de Costa Rica. (2007). Decreto Ejecutivo 34361-MP.

Gobierno de la República de Costa Rica. (2011). Decreto Ejecutivo 35669-MINAET.

Gobierno de la República de Costa Rica. (2011). Decreto Ejecutivo 36823-MINAET.

Gobierno de la República de Costa Rica. (2014). Decreto Ejecutivo 38536-PLAN.

Gobierno de la República de Costa Rica. (2017). Decreto Ejecutivo 40615- MINAE.

Gobierno de la República de Costa Rica. (2017). Decreto Ejecutivo 40616-MINAE.

Gobierno de la República de Honduras. (2017). Plan Maestro Agua, Bosque y Suelo. Tegucigalpa, Honduras.

González Jacobo, J.A. (2008). El Desafío de la descentralización en Centroamérica. Ciudad de Guatemala, Guatemala: Estado de la Región.

Gupta, J., Termeer, C., Klostermann, J., Meijerink, S., van den Brink, M., Jong, P, Nooteboom, S., and Bergsma, E. (2010). 'The Adaptive Capacity Wheel: a method to assess the inherent characteristics of institutions to enable the adaptive capacity of society'. Environmental Science and Policy 13: 459-471. Available at: https://doi.org/10.1016/j.envsci.2010.05.006

Iza, A. and Stein, R. (eds.) (2009). RULE: Reforming water governance. Gland, Switzerland: IUCN. Available at: https://portals.iucn.org/library/node/9322

Lozano Moheno, I. (2012). Ejidos y comunidades: ¿cuarto nivel de gobierno?: exploración sobre las facultades legales de ejidos y comunidades en materia ambiental. México DF, México: Centro de Investigación y Docencia Económicas, División de Administración Pública. 
Luna, M. and Cruz, E. (2019). Gobernanza para la Adaptación basada en Ecosistemas: Cuenca del Río Sixaola. San José, Costa Rica: IUCN.

Martínez, L. and Navarro, M. (2019). Gobernanza para la Adaptación basada en Ecosistemas: Cuenca del Río Caotán, Guatemala. San José, Costa Rica: IUCN.

Millennium Ecosystem Assessment (2005). Ecosystems and Human Well Being: Synthesis. Washington D.C., EE. UU.: Island Press

Ministerio de Ambiente y Energía (MINAE) (2018). Política Nacional de Adaptación. San José, Costa Rica: MINAE.

Ministerio de Ambiente y Recursos Naturales de Guatemala (MARN) (2018). Dirección de Cambio Climático. Available at: http://www.marn.gob.gt/paginas/Direccin de Cambio Climtico. (Consultada: 10 de agosto de 2018)

Mubaya, C.P. and Mafongoya, P. (2017). 'The role of institutions in managing local level climate change adaptation in semi-arid Zimbabwe'. Climate Risk Management 16: 93-105. Available at: https://doi.org/10.1016/j.crm.2017.03.003

North, C.N. (1991). 'Institutions'. Journal of Economic Perspectives 5: 97-112. Available at: https://doi. org/10.1257/jep.5.1.97

Observatorio Nacional de Cambio Climático para el Desarrollo Sostenible (ONCCDS) (s.a.). Secretaría de Energía, Recursos Naturales, Ambiente y Minas (SERNA). Tegucigalpa, Honduras.

O'Riordan, T. and Jordan, A. (1999). 'Institutions, climate change and cultural theory: towards a common analytical framework'. Global Environmental Change 9: 81-93. Available at: https://doi. org/10.1016/S0959-3780(98)00030-2

Pan, C., Peters, G., Andrew, R., Korsbakken, J., Li, S., Zhou, D. and Zhou, P. (2017). 'Emissions embodied in global trade have plateaued due to structural changes in China'. Earth's Future 5:9; 934-46. Available at: https://doi.org/10.1002/2017EF000625

Sanchez, J.C. and Roberts, J. (eds.) (2014). Transboundary Water Governance. Adaptation to Climate Change. Gland, Switzerland: IUCN. https://portals.iucn.org/library/node/44675

Secretaría de Medio Ambiente y Recursos Naturales (SEMARNAT) (2018). Sistema Nacional de Cambio Climático (SINACC) 2018. Available at: https://www.gob.mx/inecc/acciones-y-programas/ sistema-nacional-de-cambio-climatico-sinacc. (Consultada: 02 de agosto de 2018).

Secretaría de Recursos Naturales y Ambiente (SERNA) (2018a). Plan Nacional de Adaptación al Cambio Climático. Tegucigalpa, Honduras: SERNA.

SERNA (2018b). ¿Quiénes Somos?. Available at: http://www.miambiente.gob.hn/dncc/quiensomos/. (Consultada: 10 de agosto de 2018).

Steffen, W., Biggs, R., Richardson, K., de Wit, C., Gerten, D., Mace, G., Publist, C., Fetzer, I., Rockstrom, J., Rockstrom, J., Cornell, S., Fetzer, I., Biggs, R., Folke, C., Reyers, B., Richardson, K., Bennett, E., Carpenter, S., de Vries, W., de Wit, C., Gerten, D., Heinke, J., Mace, G., Persson, L., Ramanathan, V., and Sorlin, S. (2015). 'Planetary boundaries: Guiding human development on a changing planet'. Science 347: 6223. Available at: https://doi.org/10.1126/science.1259855

Unión Internacional para la Conservación de la Naturaleza (UICN) (2017). Reglamento de la Comisión Binacional de la Cuenca del Río Sixaola (CBCRS). San José, Costa Rica. 
Vignola, R., Locatelli B., Martínez C., and Imbach P. (2009). 'Ecosystem-based adaptation to climate change: what role for policy-makers, society and scientists?'. Mitigation and Adaptation Strategies for Global Change 14: 691-696. Available at: https://doi.org/10.1007/s11027-009-9193-6

Vij, S., Moors, E., Ahmad, B., Arfanuzzaman, M., Bhadwal, S., Biesbroek, R., Gioli, G., Groot, A. Mallick, D., Regmi, B., Saeed, B.A., Ishaq, S., Thapa, B., Werners, S.E. and Wester, P. (2017). 'Climate adaptation approaches and key policy characteristics: Cases from South Asia'. Environmental Science and Policy 78: 58-65. Available at: https://doi.org/10.1016/j.envsci.2017.09.007

Wang , J., Brown, D.G. and Agrawal, A. (2013). 'Climate adaptation, local institutions, and rural livelihoods: A comparative study of herder communities in Mongolia and Inner Mongolia, China'. /* 23: 1673-1683.Available at: Available at: https://doi.org/10.1016/j.gloenvcha.2013.08.014

\section{Negotiation}

Borrini-Feyerabend, G., Farvar, M. T., Nguinguiri, J. C. and Ndangang, V. A. (2007). Comanagement of Natural Resources: Organising, Negotiating and Learning-by-Doing. Reimpresión 2007. Kasparek Verlag, Heidelberg, Germany: GTZ and IUCN.

IISD-IUCN (2002). Conserving the Peace: Resources, Livelihoods and Security. Geneva, Switzerland: IISD.

Intergovernmental Panel on Climate Change (IPCC) (2014). Climate Change 2014: Synthesis Report. Contribution of Working Groups I, II and III to the Fifth Assessment Report of the Intergovernmental Panel on Climate Change [Core Writing Team, Pachauri, R.K. and Meyer, L.A. (eds.)]. Geneva. Switzerland: IPCC

McNeely, J. (1995). Expanding Partnerships in Conservation. Segunda edición. New York: Island Press.

Ostrom, E. (2000). El gobierno de los bienes comunes. La evolución de las instituciones de acción colectiva. México: UNAM-CRIM-FCE.

Proyecto Estado de la Nación (2016). Quinto Informe Estado de la Región en Desarrollo Humano Sostenible. San José, Costa Rica.

Rossing, T., Otzelberger, A. and Girot, P. (2014). Scaling-up the use of tools for community-based adaptation: Issues and challenges. In: Community Based Adaptation to Climate Change: Scaling it up, J. Ayers et al (eds.), London. G.B.: Earthscan. 


\section{IUCN}

IUCN Environmental Law Programme Environmental Law Centre

Godesberger Allee 108-112

53175 Bonn, Alemania

Tel: +492282692231

Fax: +492282692246

elcsecretariat@iucn.org

www.iucn.org/law
Oficina Regional para México, América Central y el Caribe (ORMACC)

San José, Costa Rica

Tel: +50622838449

Fax: +506 22838472

ormacc@iucn.org

www.iucn.org/ormacc 